\title{
UBERIZATION OF ROOFTOPS FOR VEGETATION
}

\author{
By \\ Mahsa Hatefi Shirvan \\ Bachelor of Architecture \\ Khayyam University, 2011
An MRP presented to Ryerson University
in partial fulfillment of the
requirements for the degree of
Master of Building Science in the
Program of Building Science

Toronto, Ontario, Canada, 2017

(C) Mahsa Hatefi Shirvan, 2017 


\section{AUTHOR'S DECLARATION}

I hereby declare that I am the sole author of this MRP. This is a true copy of the MRP, including any required final revisions.

I authorize Ryerson University to lend this MRP to other institutions or individuals for the purpose of scholarly research

I further authorize Ryerson University to reproduce this MRP by photocopying or by other means, in total or in part, at the request of other institutions or individuals for the purpose of scholarly research.

I understand that my MRP may be made electronically available to the public. 


\section{ABSTRACT \\ Uberization of Rooftops for Vegetation, M.B.Sc. 2017, Mahsa Hatefi Shirvan, Master of Building Science, Ryerson University.}

Agricultural rooftop systems can be productive during the growing season which starts from mid-spring and lasts until mid-fall. The absence of snow load in summer time presents an opportunity to receive and accommodate the extra load from agricultural assemblies in order to turn the underutilized summer rooftops into productive organic food resource for the community.

For this purpose, roof morphology of 31 supermarkets in Mississauga has been reviewed through case study method along with exploration of urban-condition growing methods and requirements from recent literature and case studies. The results indicate the possibility of seasonal growing through extensive, intensive planter-based and hydroponic systems as well as hanging planters with trellises structure. 


\section{TABLE OF CONTENTS}

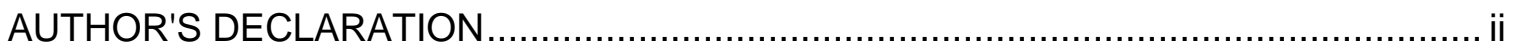

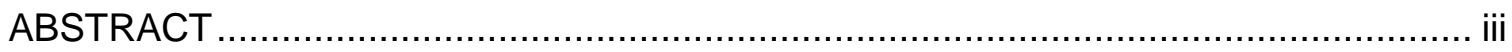

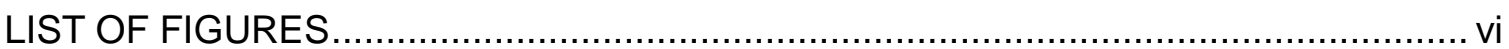

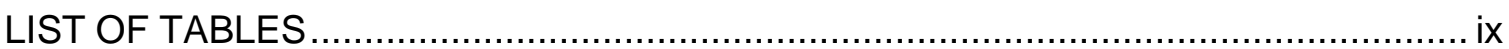

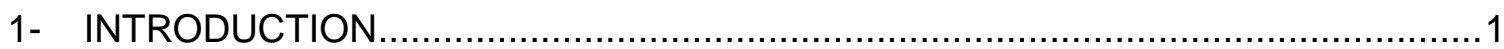

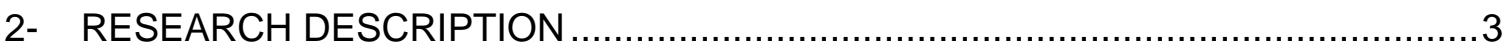

2-1 Scope

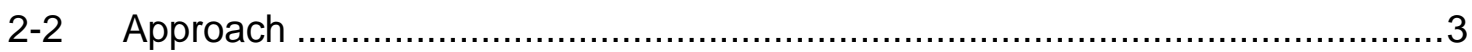

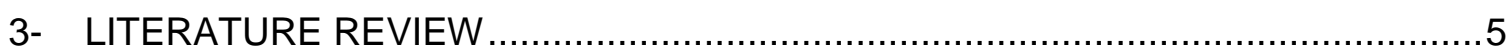

Barriers in Adaptation of Existing Rooftops for Food Production ................................5

Possible solutions for food production imposed by limited structural capacity of

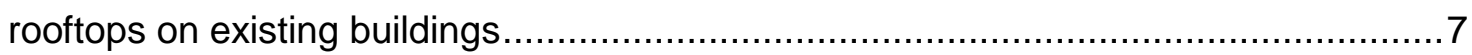

Driving Forces behind Agricultural Systems on Supermarket Rooftops.....................11

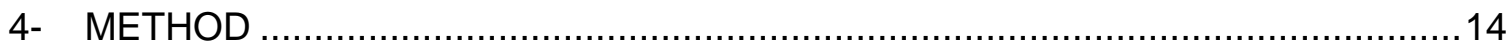

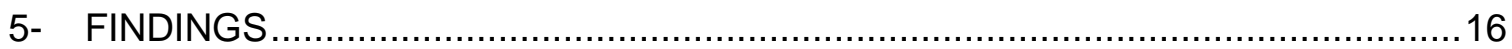

5-1 Characteristics of Existing Single-Storey Supermarkets .............................16

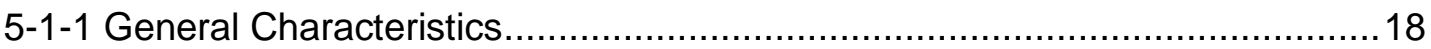

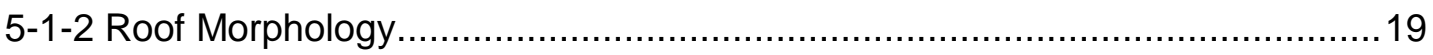

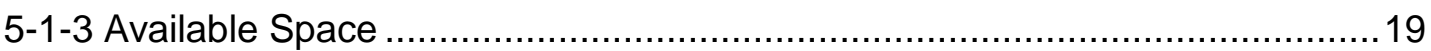

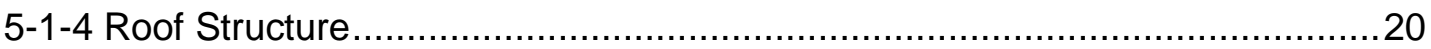

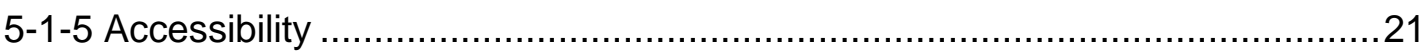

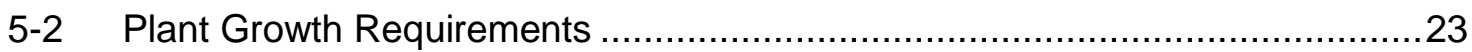

5-3 Case Studies with Agricultural Rooftops................................................26

5-4 Methods for Growing Vegetables on Rooftops ……….............................29

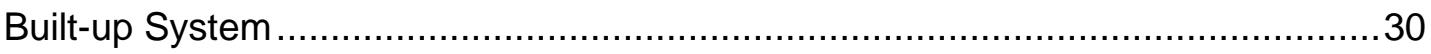




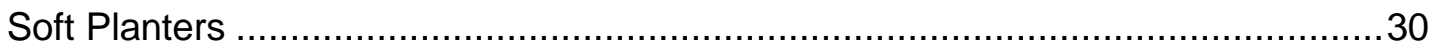

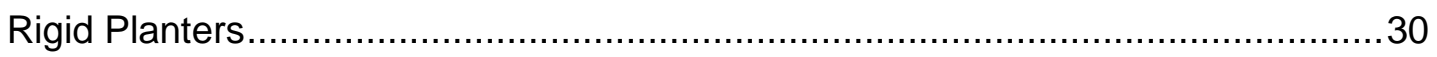

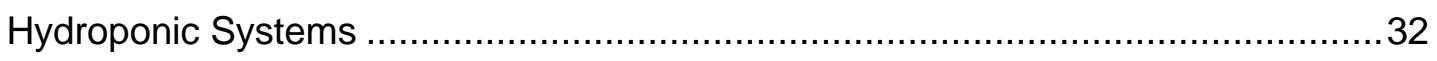

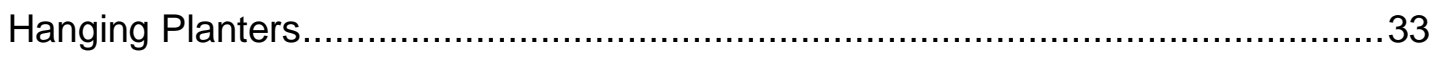

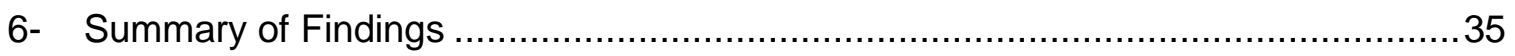

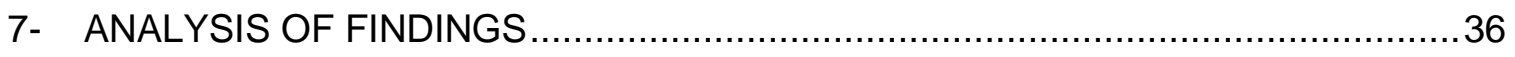

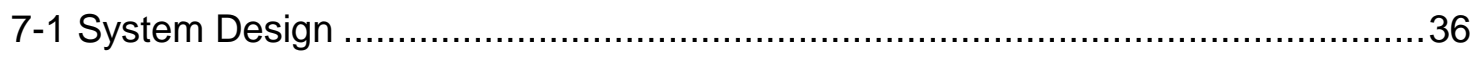

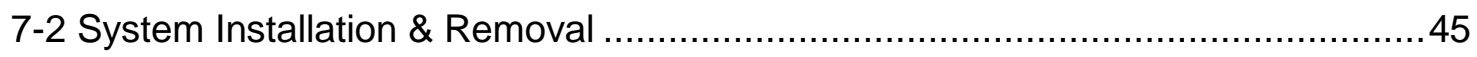

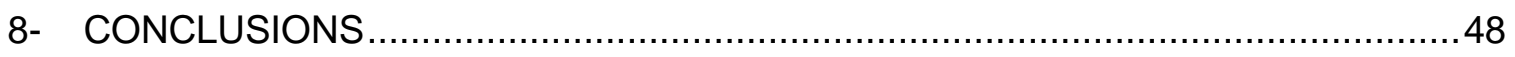

APPENDIX A: Characteristics of Supermarkets ……….........................................50

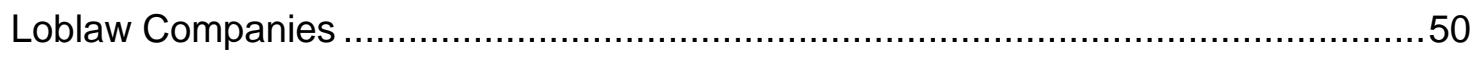

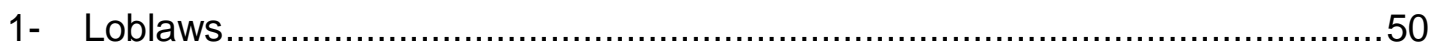

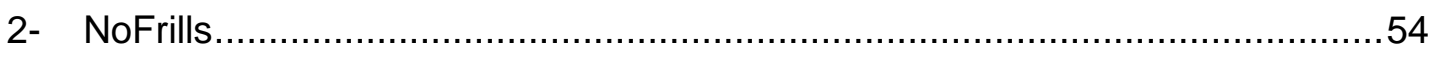

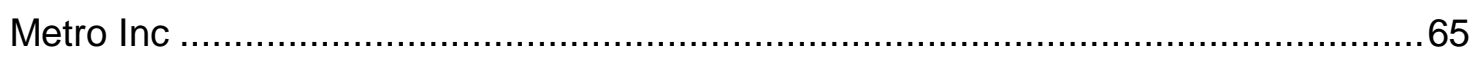

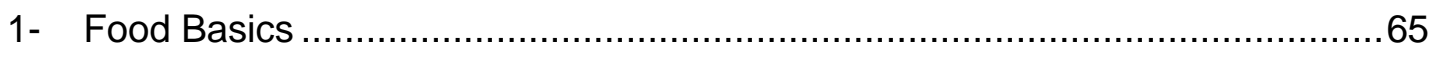

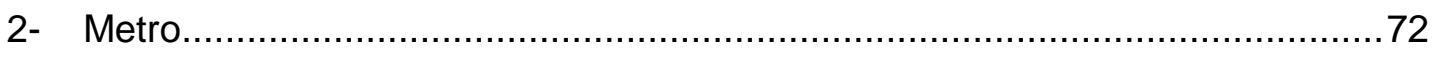

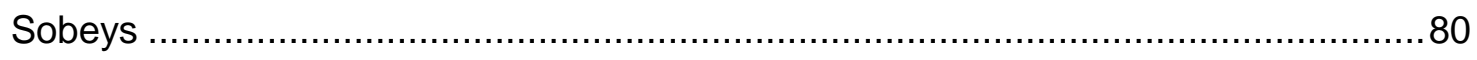

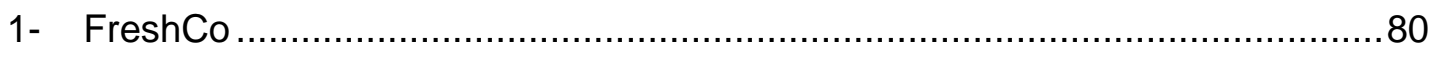

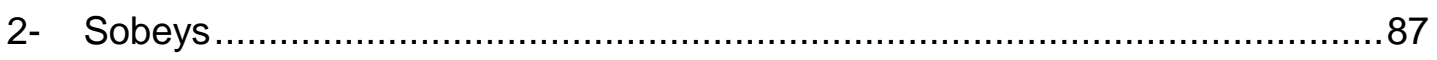

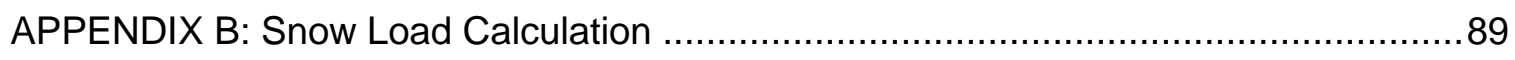

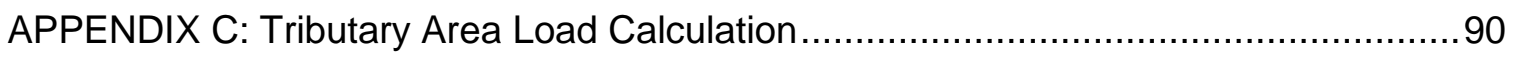

APPENDIX D: Potential Rooftop Agriculture of Studied Supermarkets.........................91

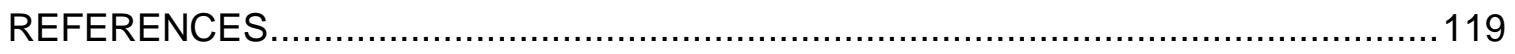




\section{LIST OF FIGURES}

Figure 1 - Top Critical Barriers in Adaptation of Existing Rooftops for Food Production...6 Figure 2 - Ballast Replacing with Extensive System in Inverted Roofing System, Illustrated by Author Based on Castleton et al., (2010)

Figure 3 - Bronxcape Rooftop, Locating heavy Planters on Structural Elements Illustrated by Author Based on Peck \& Kuhn, (2003) and Liu, (2012)

Figure 4 - P.S. 64 Roof Conceptual Section Illustrated by Author based on Gorgolewski et al., (2011)

Figure 5 - Eli Zabar's Vinegar Factory Greenhouse - Retrieved July 31, 2016 from learninglivingroofs.ca

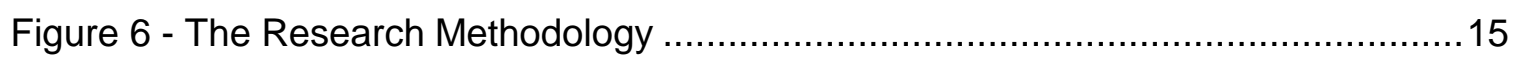

Figure 7 - Single Storey Chain Supermarkets in Mississauga …………………......17

Figure 8 - Typical Position of Supermarket Building within the Site...........................18

Figure 9 - Rectilinear vegetable beds at Eagle Street Rooftop Farm, Retrieved July 21,

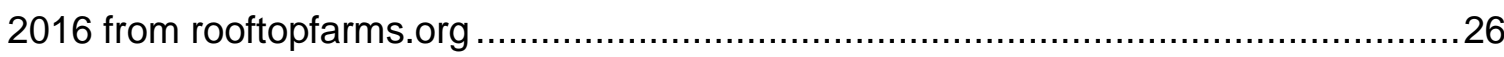

Figure 10 - Brooklyn Grange Rooftop Layout, Retrieved July 21, 2016 from manhattanwomensclub.com.

Figure 11 - Brooklyn Navy Yard Rooftop Layout, Retrieved July 28, 2016 from

greenroofs.com

Figure 12 - An Overview of Greenpoint Greenhouse - Retrieved Oct 6, 2016 from

gothamgreens.com

Figure 13 - An overview of Gowanus - Retrieved Oct 6, 2016 from gothamgreens.com 28

Figure 14 - Network of Columns \& Trellis at 21 Carlton St

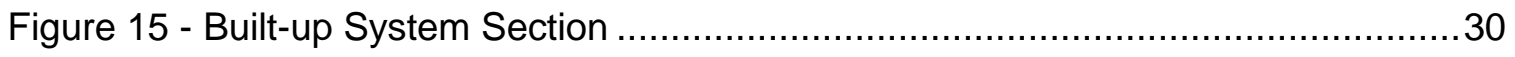

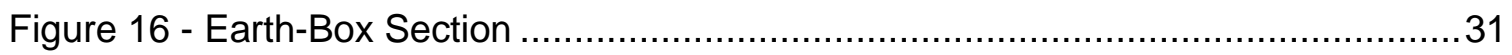

Figure 17 - Hydroponic System Configuration .......................................................32

Figure 18 - Hydroponic System Retrieved Nov 19, 2016 from growthrivingveggies.com33

Figure 19 - Mobile Edible Wall Units Retrieved January, 2017 from agreenroof.com.....34 
Figure 20 - Loads Can be Transferred to the Main Structure through Trellis Structure Retrieved January, 2017 from Pinterest.com.

Figure 21 - Potential Agricultural Area for Extensive Seasonal Growing (5010 Glen Erin Drive Mississauga, ON). 39

Figure 22 - Potential Agricultural Area for Extensive Seasonal Growing (250 Lakeshore Rd, Mississauga, ON) 39

Figure 23 - Columns Tributary Area 41

Figure 24 - Potential Agricultural Area for Intensive $20 \mathrm{~cm}$ Seasonal Growing (5970

Mclaughlin, Rd, and Mississauga, ON). 43

Figure 25 - Potential Agricultural Area for Intensive $40 \mathrm{~cm}$ Seasonal Growing (5970

Mclaughlin, Rd, and Mississauga, ON). 43

Figure 26 - Schematic Idea of Utilizing Supermarket Rooftops for Food Production ......45

Figure 27 - Loblaws Branches in Mississauga .........................................................

Figure 28 - Loblaws at 5010 Glen Erin Drive Mississauga, ON ………......................51

Figure 29 - Loblaws at 250 Lakeshore Rd W, Port Credit, ON....................................52

Figure 30 - Loblaws at 5970 Mclaughlin, Road, Mississazauga, ON ...........................53

Figure 31 - Loblaws at 3045 Mavis Rd, Mississauga, ON..........................................54

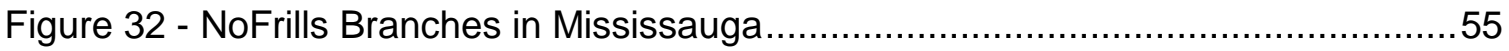

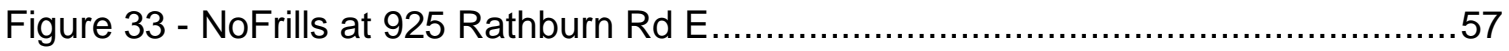

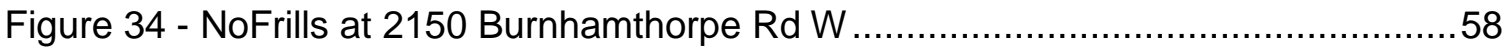

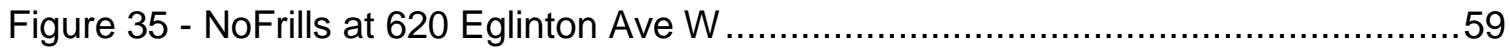

Figure 36 - NoFrills at 6465 Erin Mills Parkway ………..............................................60

Figure 37 - NoFrills at 4040 Creditview Rd .............................................................61

Figure 38 - NoFrills at 7070 McLaughlin Rd ..........................................................62

Figure 39 - NoFrills at 6085 Creditview Road ……….............................................63

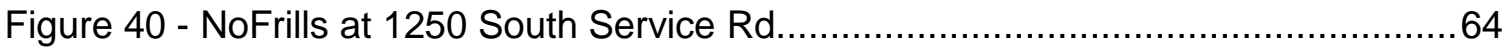

Figure 41 - Food Basics branches in Mississauga.......................................................65 


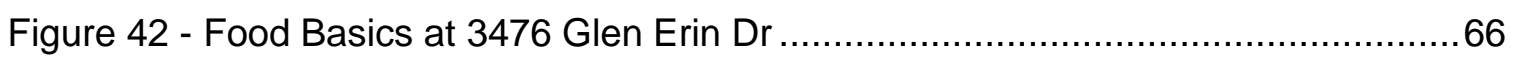

Figure 43 - Food Basics at 377 Burnhamthorpe Rd E ……...................................67

Figure 44 - Food Basics at 2550 Hurontario St......................................................6

Figure 45 - Food Basics at 2425 Truscott Dr.........................................................

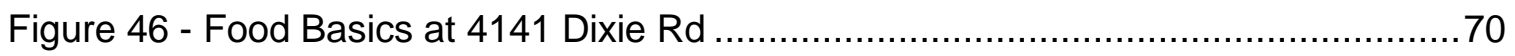

Figure 47 - Food Basics at 7070 Saint Barbara Blvd ............................................... 71

Figure 48 - Metro Branches in Mississauga ............................................................

Figure 49 - Metro at 910 Southdown Rd............................................................

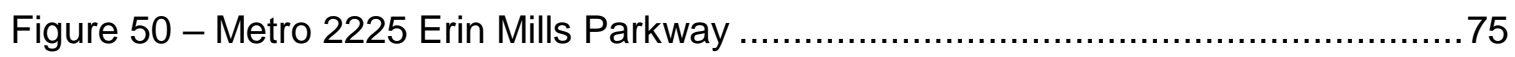

Figure 51 - Metro at 1585 Mississauga Valley Blvd …………….............................76

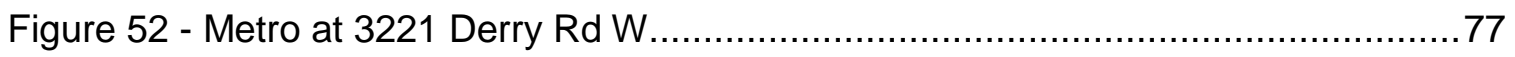

Figure 53 - Metro at 6677 Meadowvale Town Centre Circle .......................................78

Figure 54 - Metro at 406 Lakeshore Rd E.........................................................

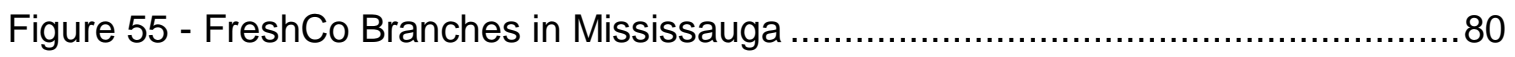

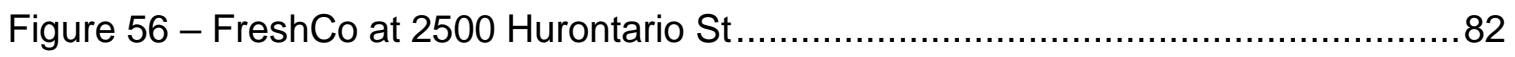

Figure 57 - FreshCo at 6040 Glen Erin Dr ........................................................ 83

Figure 58 - FreshCo at 1151 Dundas St W............................................................ 84

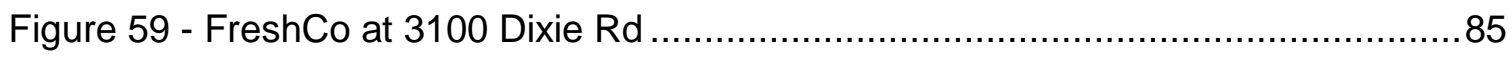

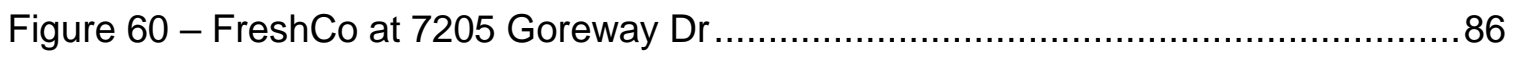

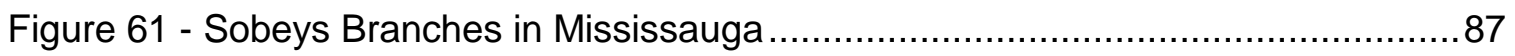

Figure 62 - Sobeys located at 5602 Tenth Line West ..............................................8

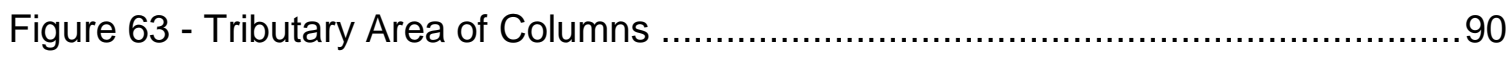




\section{LIST OF TABLES}

Table 1-Single Storey Supermarkets in Mississauga.............................................16

Table 2 -Total Gross Area of Studied Supermarkets ................................................20

Table 3 - Summary of Available Space for Food Production based on Studied

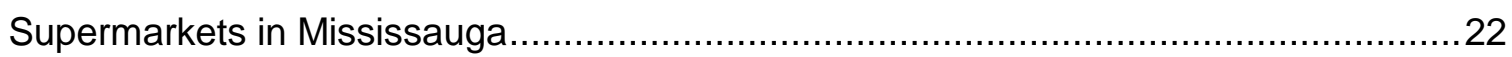

Table 4 - Bulk Density of Lightweight Growing Media, ("Growing Medium Specification," n.d.)

Table 5 - Soil depth requirements of different crops, ("Raised Beds Soil Depth

Requirement," 2014) 24

Table 6 - Approximate Height of Plants, ("Raised Beds Soil Depth Requirement," 2014)

Table 7 - Quantity and Type of Vegetation per Earth Box - ("Super Efficient All-In-One Garden," n.d.).

Table 8 - Potential Unoccupied Surface on Studied Rooftops for Extensive Lightweight

System.

Table 9 - Potential Unoccupied Surface on Studied Rooftops for Extensive Lightweight

System

Table 10 - Pressure of lightweight agricultural medium in different depth .....................38

Table 11 - Maximum growing medium load based on plant requirements......................38

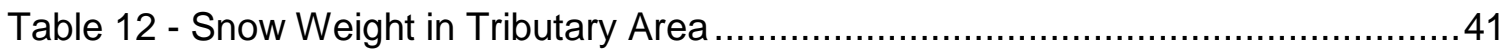

Table 13 - Potential available Area on Studied Rooftops for Intensive System ..............42

Table 14 - Loblaw's Branches in Mississauga ……………..................................50

Table 15 - Data Summary of Loblaws Branches in Mississauga .....................................54

Table 16 - NoFrills Branches in Mississauga ...............................................................5

Table 17 - Data Summary of NoFrills Branches in Mississauga …….............................56

Table 18 - Data Summary of Food Basics Branches in Mississauga ……....................72

Table 19 - Metro Branches in Mississauga ............................................................ 
Table 20 - Data Summary of Metro Branches in Mississauga

Table 21 - FreshCo Branches in Mississauga ........................................................ 80

Table 22 - Data Summary of FreshCo Branches in Mississauga .................................. 81

Table 23 - Data Summary of Sobeys Branches in Mississauga...................................87 


\section{1- INTRODUCTION}

Single storey supermarkets in urban areas have the potential to be stewards of locally grown food. The rooftops of these stores offer the potential for food production with all the benefits of locally grown food.

While considering all other benefits that productive/vegetated roofs offer, design and installation seems to be a challenging process. Load bearing capacity of the roofs requires attentive evaluation and assessment at the initial design steps, especially for existing buildings (supermarkets).

The load bearing capacity of existing supermarkets is usually restricted to the weight of the roof system and any permanent materials/units attached to it, in addition to any temporary live load on the roof such as snow.

Productive/vegetative assemblies exert load to the roof structure which conventionally would not have been considered in the structural design of existing buildings (supermarkets). Therefore, installing permanent vegetative assemblies on existing buildings without structural reinforcement has been either impossible or limited to systems of shallow soil depth with non-edible succulent planting. Consequently, benefitting from agricultural systems, which require deeper growing media seems infeasible on existing supermarket rooftops.

Reviewing the current literature, it appears that there is limited information regarding productive/agricultural roof adaptation to existing buildings which have structural capacity limitation. Most of the reviewed cases already had the required structural capacity or undertook expensive structural upgrading. One of the main purposes of this paper is to explore the potential design strategies that can be considered for food production on roofs and that would overcome existing roof structures limitation on additional permanent loading by using their available snow load capacity during the summer months. Most roofs in Southern Ontario are required to be designed for snow load which only occurs during the winter months. Agriculture can be carried out during the non-winter months. In other words, given the existing structural load bearing capacity limitation what can be 
done to grow vegetables on a seasonal basis to utilize the capacity available from snow load design considerations?

A literature review has been conducted to understand the nature of research that has been carried out to address the existing buildings load bearing limitations. Then, case studies where roofs have been used for vegetation growth have been analyzed to understand the practical treatments.

The main focus of this work is to use a case study method to study existing supermarket rooftops and the structural support systems to identify the potential for food production. A case study approach is also used to determine the variety of ways in which rooftops have been used for food production.

Overall, this research has collected data on the structural organization of existing supermarkets in the Greater Toronto Area, has determined the different ways in which urban agriculture can work on roofs and has analyzed this information to determine the approaches to overcome the limited load bearing capacity of supermarkets to assist promoting productive adaptation on existing buildings. 


\section{2- RESEARCH DESCRIPTION}

\section{2-1 Scope}

Since limited actions are taken in utilizing the available space of rooftops with lightweight structural configuration, this research aims to discuss the possibility of growing vegetables on existing supermarkets without structural intervention that disrupts the use of the facility.

For this objective, this project targets single-storey supermarkets since most of these buildings have a reasonably sized low-sloped roof-surface available for potential use. Additionally, these buildings are usually built with a similar layout plan which means that a solution for one may be the answer for many, with small modifications.

The supermarkets studied have been limited to those in the Greater Toronto Area. This was predominantly done to ensure access to these facilities to study their structural arrangements within the scope of work that can be accomplished in the MRP research. It is believed that the configurations of these supermarkets in other parts of the Southern Ontario region would be similar and therefore the results of the study would apply.

It is recognized that cost is an important consideration for anyone adopting a solution. In this work the focus was on feasibility with spatial, functional and structural issues and cost feasibility was not included in this study.

\section{2-2 Approach}

The overall approach for this work is based on data on roof morphologies and building characteristics of the existing supermarkets and the data on the nature of food production on rooftops. The roof morphology and building characteristics data was collected as part of this study and constitutes primary data. The nature of food production was done primarily based on information reported in the literature. 
An initial literature review has been carried out for the purpose of better understanding the present knowledge on the following:

1- Barriers in adaptation of existing rooftops for food production

2- Possible solutions for food production imposed by limited structural capacity of rooftops on existing buildings

3- Driving forces behind the use of supermarkets for rooftop food production

The literature review helped formulate the following questions which were further explored as part of this work:

1. What are the roof morphologies of existing single storey supermarkets?

2. Are one storey existing supermarket rooftops suitable for food production?

3. What are the existing restrictions and barriers to food production on supermarket rooftops?

4. Is the existing structure sufficient to carry the loads for food production?

5. What types of structural loads can be anticipated on rooftops used for food production?

6. What are the potential solutions to overcome limitations on existing supermarkets?

Thus, research on current literature and existing projects has been carried out to identify the level to which above questions have been addressed and the gaps in current knowledge. Then, via case study approach, characteristics of supermarkets in Mississauga, $\mathrm{ON}$ and as well as growing methods on rooftops have been explored.

Considering the lightweight rooftop limitations, the spare unused snow load capacity which would be available in summer time has been utilized, to study possible seasonal growing methods on supermarket rooftops. 


\section{3- LITERATURE REVIEW}

A literature review has been completed to better understand the nature of rooftop food production. During this review, the obstacles and key factors essential to the evaluation of the existing rooftops for food production were identified. Besides, in order to find practical approaches to meet the limits of structural capacity as the major barrier, the research was narrowed down to those articles and case studies targeting this issue. Furthermore, through case study method, I have reviewed existing supermarkets with food production to analyze the potential for furthering food production on supermarket rooftops.

\section{Barriers in Adaptation of Existing Rooftops for Food Production}

The concept behind the rooftop food production has been created by replacing the ornamental vegetation layer with edible vegetables, in the green roof systems. Although other characteristics of these two systems such as soil depth and its properties, level of maintenance, irrigation and etc. are different, the technical challenges to deal with when implementing the rooftop agricultural (RA) systems are almost the same as the challenges when implementing a green roof system.

When evaluating a building for green roof adaptation, roof surveys are necessary to ascertain the amount of available space (S. Wilkinson \& Feitosa, 2016) and the amount of sun exposure for plant selection and productivity determination (Dunnett \& Kingsbury, 2008).

Roof system and deck structure are known as design factors that must be considered when evaluating a rooftop for green roof retrofit (Dunnett \& Kingsbury, 2008) \& (S. Wilkinson \& Feitosa, 2016). Slippage of sloped surfaces was known as a problem causing growing media to shift. S. Wilkinson \& Feitosa (2016) discussed that only low-sloped roofs are suitable for intensive green roofs although pitches up to $32^{\circ}$ can accommodate the extensive systems. Since the characteristics of edible vegetated systems are very similar to intensive systems and considering accessibility is an important element, these systems should be 
adopted on low-sloped roofs. This issue, known as design barrier, exists in both new and existing buildings.

Review of the recent literature revealed that age of existing buildings is another factor to be considered when evaluating existing buildings for green roof retrofit (Townshend, 2007), (Zhang, Shen, Tam, Wing, \& Lee, 2012) \& (S. Wilkinson \& Feitosa, 2016). Stovin et al., (2007) discussed that due to the modern structural efficiency of new buildings, older buildings are likely to have more reserved structural capacity. However, the critical factor in many literatures was found to be the weak structural capacity of existing buildings.

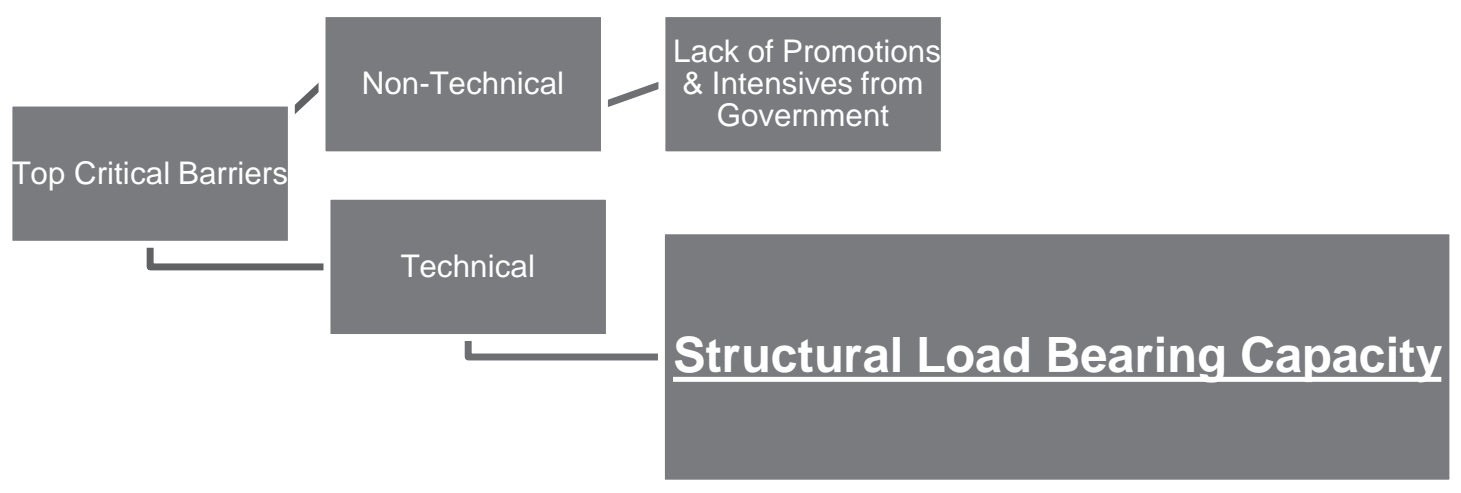

Figure 1 - Top Critical Barriers in Adaptation of Existing Rooftops for Food Production Investigation about structural capacity should be done beforehand since it directly affects the type of vegetation and growing medium depth (Peck \& Kuhn, 2003) \& (Dunnett \& Kingsbury, 2008). A low-sloped roof structure is supported by building's structural frame and roof deck. Depending on the roof deck material and spacing of the supporting columns and beams, a certain amount of load can be carried. Based on Standards that Hallsal (2007) provided for City of Toronto, the dead load associated with a vegetated assembly is the weight of that assembly under drained condition and the live load is the saturated weight during an active rainfall. Therefore the capacity of an existing structure must meet the saturated weight expectations. 
Based on gathered surveys and questioners by Zhang et al., (2012), lack of promotion and incentives from government are the top non-technical barriers in adaptation of green roofs for existing buildings while age and load bearing capacity are the top technical barriers and predominant issues for existing buildings (Stovin, Dunnett, \& Hallam, 2007), (Castleton, Stovin, Beck, \& Davison, 2010) \& (Zhang et al., 2012).

Employing vegetation on existing rooftops without structural examination may cause failures. On the other hand, structural reinforcement is very expensive (Peck \& Kuhn, 2003) and in most cases would not be feasible due to the level of intervention required to the interior of the building. Therefore, the lack of adequate structural capacity of the buildings was found to be one of the top three critical barriers to green/productive roof adaptation.

\section{Possible solutions for food production imposed by limited structural capacity of rooftops on existing buildings}

Structural capacity of rooftops on existing building appears to be a significant barrier for further consideration of rooftops for food production. Yet the literature review showed many successful examples of the manner in which the limitations imposed by structural capacity have been addressed.

Liu (2012) mentioned that extensive and semi-intensive systems can be adopted on existing buildings. In other words, structural upgrading is not required due to the light weight of these systems which is in the range of $0.5-1.9 \mathrm{kPa}(10-40$ psf). S. Wilkinson \& Dixon (2016) discussed that, regardless of the green roof system type, the structural capacity of existing buildings should be always determined beforehand to prevent any deflection damages that may cause due to overloading the structure. Therefore, the first step is to understand if the existing structure has any reserved loading capacity. The ballpark minimum reserved capacity required for a 5 centimeter deep system is $0.56 \mathrm{kPa}$.

To determine the potential spare capacity of the building, the original drawings of existing buildings should be used. When these drawings are not available, 
information such as age of the building, thickness of structural slab and the span between the columns can reveal the load bearing capacity of the building ( $\mathrm{S}$. Wilkinson \& Dixon, 2016). Another solution proposed by Peck \& Kuhn (2003) \& Dunnett \& Kingsbury (2008) is comparing codes and bylaws with their previous comparable versions to determine if any spare load capacity exists. For example, Peck \& Kuhn, (2003) referred to changes in snow load requirement based on comparison between Ontario Building Code 2003 version and the older version. Based on this comparison, $0.86 \mathrm{kPa}$ (18 psf) is reserved on buildings built before 2003 which can accommodate the load from a permanent extensive green roof system on existing rooftops. Liu (2012) also suggested another strategy. Replacing the old heavy roofing system of existing buildings with lightweight systems, provides extra capacity. Although this strategy provides enough capacity to implement the extensive system, it is still an intervening approach and also may not be applicable for existing rooftops with lightweight roofing systems. In inverted warm roofs where ballast, is used to hold the insulation, the roof has the capability in range of $0.5-1.2 \mathrm{kPa}$ to support an extensive green roof system in place of ballast (Castleton et al., 2010).
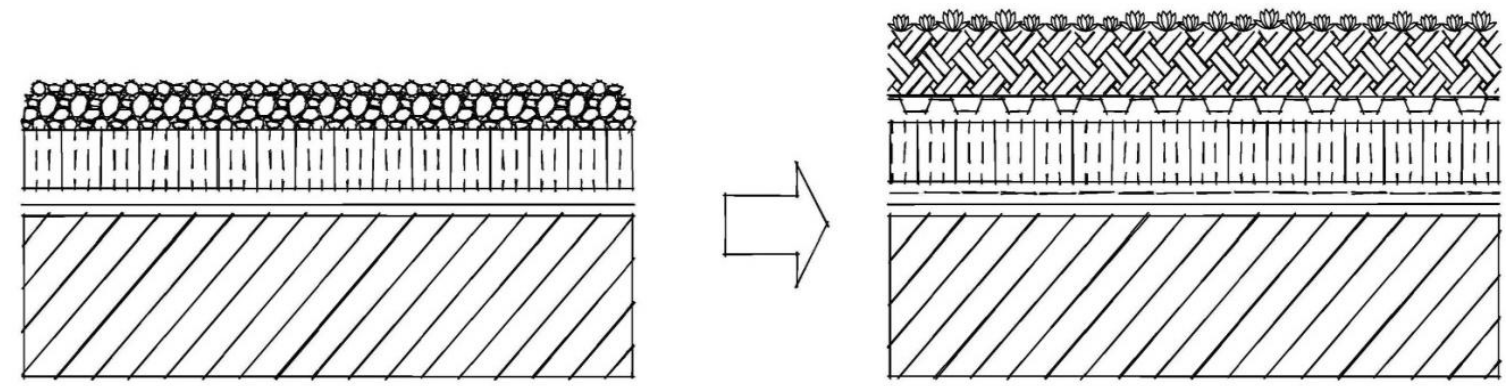

Figure 2 - Ballast Replacing with Extensive System in Inverted Roofing System, Illustrated by Author Based on Castleton et al., (2010)

Locating heavy materials such as deep planters on top of structural components such as load bearing walls or columns (Figure 3 ) is another approach Peck \& Kuhn, (2003) and Liu (2012) recommended. Although it seems an interesting strategy, it is very general and structural evaluation of the building is still a requirement. 


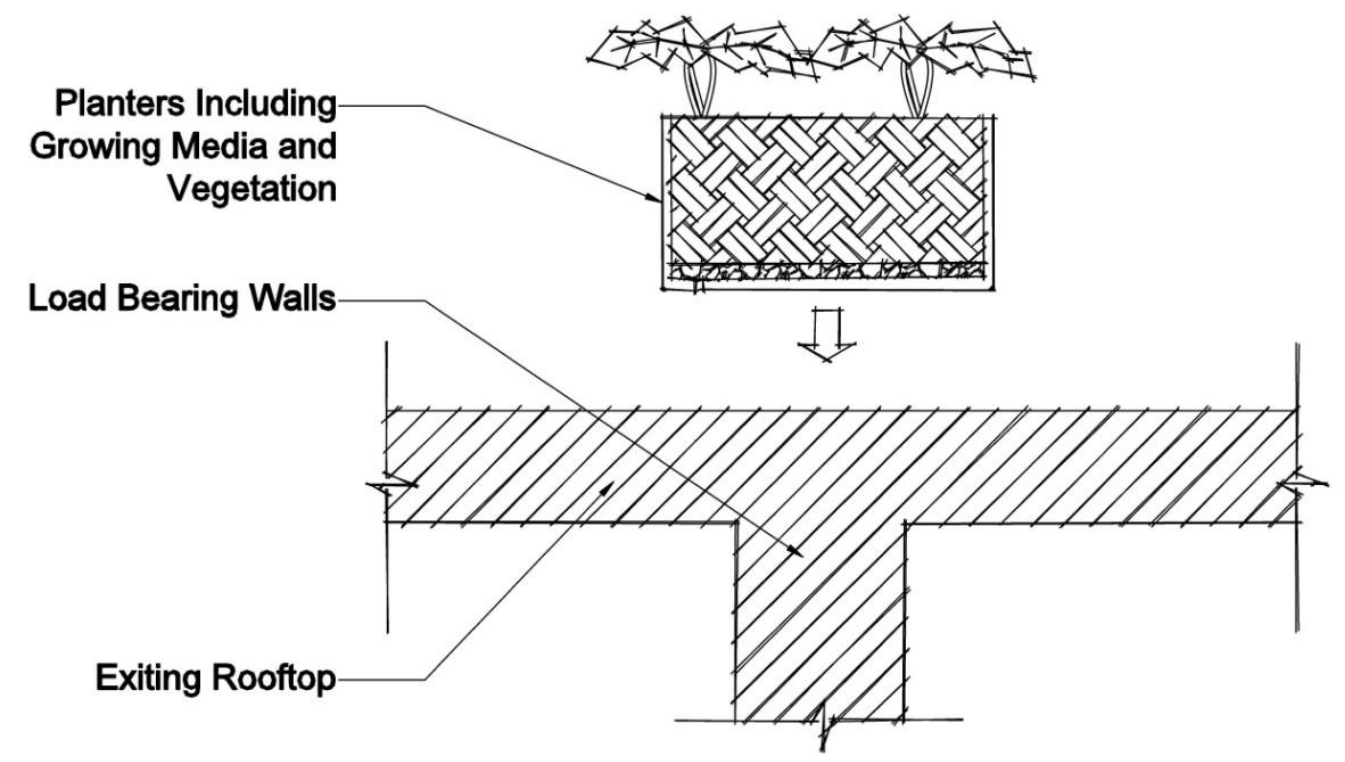

Figure 3 - Bronxcape Rooftop, Locating heavy Planters on Structural Elements Illustrated by Author Based on Peck \& Kuhn, (2003) and Liu, (2012)

Further study on recent projects has been done in order to find the practical solutions which dealt with structural load bearing limitation of existing buildings.

The Capital Regional District in Victoria (Peck \& Kuhn, 2003) is one of the projects being reviewed, which faced several challenges, including structural load bearing limitation for green roof construction on its multi-level roofs. They implemented a low profile system comprising of $5.5 \mathrm{~cm}$ of growing media with hardy species instead of their original design with intensive system. This system weight $0.48 \mathrm{kPa}$ (10 psf) at the saturated situation, therefore, met the limited load capacity expectation. The Mountain Equipment Co-op headquarters building in downtown Toronto followed the same approach. Since the initial load capacity was limited to $1.91 \mathrm{kPa}$ (40 psf), the accessible rooftop with intensive system were omitted and therefore, only extensive system with $10 \mathrm{~cm}$ perennial pots was installed (Peck \& Kuhn, 2003). It appears that ultra-lightweight and extensive systems are one approach when the existing structure cannot support the loads from intensive systems.

In another case, Bronxscape, followed a different method as their solution. They installed the deeper vegetable boxes on the load bearing walls (Gorgolewski, Nasr, \& Komisar, 2011). Directing the heavy loads to the main structure was not 
only limited to this project. Public School 64 in New York followed almost the same approach to accommodate intensive system on its old rooftop. The solution was cutting through the roof slab and stubbing up columns to install two steel beams transferring the new 6 -meter-wide deck load to the main structure (Gorgolewski et al., 2011). Figure 4 demonstrates the conceptual design. Although this is an interesting solution without structural upgrading, the cost to build the new supporting structure is still significant.

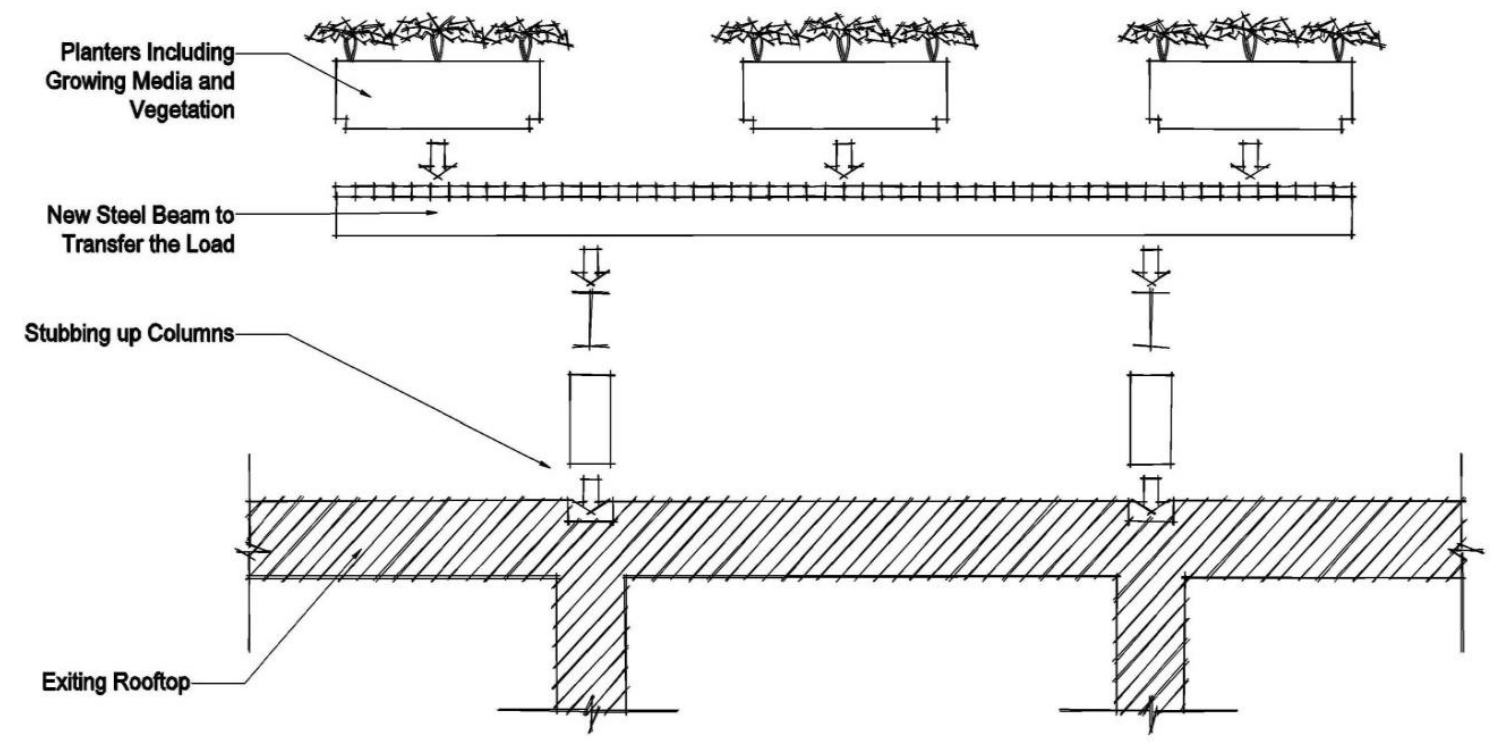

Figure 4 - P.S. 64 Roof Conceptual Section Illustrated by Author based on Gorgolewski et al., (2011) Another existing case study that has been reviewed is American Associate of Landscape Architects (ASLA) headquarters building located in Washington DC. The total load capacity of the roof was evaluated by the engineering team and they concluded that structural reinforcement for green roof installation is not required. The roof joists were spaced $75 \mathrm{~cm}(2.5 \mathrm{ft})$ instead of $120 \mathrm{~cm}(4 \mathrm{ft})$ according to the as-built drawings. Thus, the existing roof structure could support more than the actual required load, and designers could count on extra $2.4-3.6$ kPa (50 to 75 psf) capacity (Werthman, 2007). Lufa Farms in Montreal adopted a commercial scale greenhouse on its rooftop. Further investigation revealed that the building initially was designed for a 3-storey office building. However, the third floor was never built and therefore the roof enjoyed the reserved capacity towards this adaptation (Pons, Nadal, Sanyé-mengual, Llorach-massana, \& 
Rosa, 2015). These projects again emphasized on the importance of structural assessment beforehand and did not provide any solution to overcome the structural barriers of existing buildings.

Gumal Student Housing, Science Roof in Sydney (S. Wilkinson \& Dixon, 2016) and Brooklyn Grange ("About Brooklyn Grange," n.d.), GreenPoint, Brooklyn Navy Yard ("Brooklyn Navy Yard, Building No. 3," n.d.) in New York are another five cases that have been reviewed which adopted intensive agricultural systems. However, since the structure of all of these buildings was built with concrete, no structural reinforcement was required and again did not provide any solution to overcome the structural limitations of existing buildings.

Generally reviews indicated that most of the literature and case studies are either on new buildings designed with consideration of extra load bearing capacity or do not address how to overcome the load bearing limitation of existing buildings to reduce the initial cost. There were a few cases which discussed to transfer the heavy loads to the main structure; however, this approach is still very expensive and is above the budgets of most projects. Furthermore, seasonal growing option and getting advantage of the spare snow load in summer time was not offered in any of the reviewed cases.

Overall, it was found that most of the literature only emphasize and explore the potential benefits of green roof adaptation rather than proposing strategies to overcome the barriers of existing buildings. There is scarce information regarding the possible strategies to overcome the load limitations of existing buildings and no one explored the possibility of rooftop uberization for vegetation using spare snow load capacity during the summer time.

\section{Driving Forces behind Agricultural Systems on Supermarket}

\section{Rooftops}

As the cities continue to grow, food production process is required to become closer to the main centers of food consumption (Orsini et al., 2014). Despite the ancient cities in which agriculture was integrated into the metropolitan area, 
modern urban planning has lost this connection (Pons et al., 2015). Researchers concluded that from cradle to customer point of view, locally produced vegetable and herbs have lower price and environmental impact. Locally produced vegetables, not only it helps to decrease the fuel consumption for food transportation but also it improves the urban climate quality. However, land availability and accessibility is one of the major challenges of urban agriculture viability in dense cities (Specht et al., 2014). As discussed in Gorgolewski et al. (2011), since ground level food production is limited to available spaces in cities where it also attracts vandalism, wasted spaces on rooftops seem a secure solution for this purpose.

Supermarkets set environmental targets aiming at reducing waste, improving energy efficiency and packaging. Also customers nowadays tend to purchase fresh local produce. Turing the unoccupied supermarket rooftops to productive roofs not only provide this opportunity but also lessen the packaging and fuel consumption for transportation which help achieving the sustainable targets.

Eli Zabar's Vinegar Factory Greenhouse is a supermarket which turned its rooftop to a greenhouse. Since 1995, Eli Zabar's Vinegar Factory is selling fresh, local produce of its rooftop while using the waste heat from the bakery below to heat the green house. Also, organic discards from this market like are used as compost in the green house.

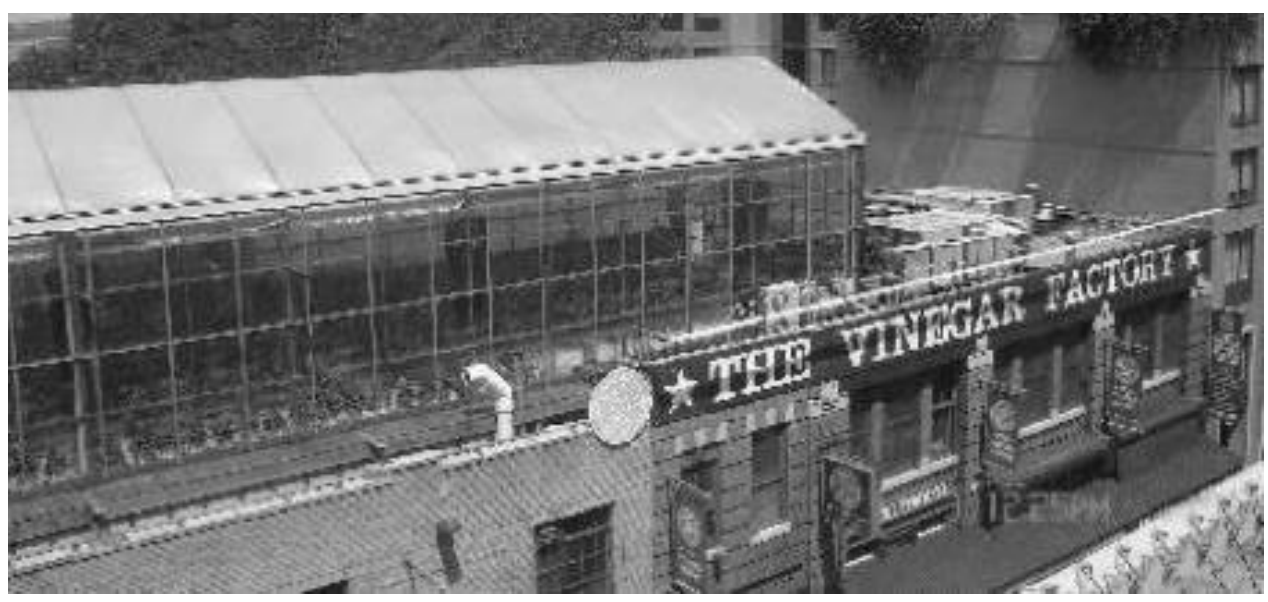

Figure 5 - Eli Zabar's Vinegar Factory Greenhouse - Retrieved July 31, 2016 from learninglivingroofs.ca 
Gotham Greens and Lufa Farms are other examples of commercial scale, hydroponic rooftop farm. Gotham Greens greenhouse is installed over a 1,850 $\mathrm{m}^{2}$ single storey supermarket, producing over $90,700 \mathrm{~kg}$ of tomatoes, herbs and leafy greens annually (“Gotham Greens," n.d.).

Overall, unless structural capacity has already been considered, existing buildings require intensive structural improvements which cost dramatically. Existing supermarket rooftops are not exceptional of this fact. Additionally, structural improvement intervenes in the interior activities. Thus, proposing any strategies that do not interfere with interior activities and sales of supermarkets, can encourage the stakeholders to undertake the rooftop transformation. As discussed earlier, none of the reviewed literature or case studies offered the possibility of seasonal growing and getting advantage of the winter time snow load capacity for growing purposes. Therefore, this research aiming to explore the possibility of utilizing snow loads capacity to assist promoting productive adaptation on existing supermarket rooftops. 


\section{4- METHOD}

As discussed, the structural load bearing capacity of existing buildings restricts the thickness of growing medium and depth of vegetated assemblies. Having said that, the structures of existing buildings are designed to carry the snow load which occurs in winter time starting from late October and lasting until March or April. This paper tries to identify the possibility of utilizing this capacity to grow vegetables in the warmer season on supermarket rooftops. Combination of different methodologies has been used to conduct this project.

Supermarkets are usually built with similar layout plan meaning that a solution for one may be applicable to many. The case study method was adopted to understand the similarities that might exist in roof morphology of single storey supermarkets. Therefore, this paper targeted the single storey giant supermarkets in Mississauga, Ontario. Mississauga, with the area of $292 \mathrm{~km}^{2}$ and population of 713,455 people (2011), is known to be the $6^{\text {th }}$ largest city in Canada which is located in west of Toronto next to Lake Ontario and represents a suburban area in Canada especially Ontario (City of Mississauga, n.d.).

The websites of supermarkets have been checked to understand the numbers and locations of existing branches in Mississauga. The initial data in order to identify the characteristics of single-storey supermarkets within Mississauga area have been collected through Google Maps and Bings Map. Site plan drawings have been generated using scaled images from Google Maps in Auto-Cad. Using Google Maps and Bings Map satellite mod and perspective view, unoccupied rooftops have been observed. Moreover, existing obstacle on the rooftops have been identified and transferred to the drawings.

The total gross area of each store as well as the potential available area for food production has been calculated based on the generated drawings. The potential available area for RA (Rooftop Agriculture) is calculated as the total area which is not sloped or used for mechanical units and/or maintenance. Other information such as height of building, span between columns and joists have been identified through site visits and measurements. The information then transferred to the 
drawings which is available in Appendix A (Page 48 to 86) and Appendix D (Page 89 to 116).

The requirements for growing vegetables including growing media characteristics, root depth and spacing of common plant species in Ontario are identified through reviewing the literature. This information was required to calculate the loads exerting form various type of crops in different growing media depth. It can also be used as a helpful guide when arranging different species on rooftops.

Since the growing methods in urban area especially on rooftops are different than traditional agricultural systems, current rooftop growing methods have been reviewed through investigation in case studies. The specification of agricultural built-up systems, planter-based systems, hydroponic systems and hanging gardens have been learnt through case studies and further specifications have been discovered through reviewing the literature.

And finally, the possible strategies have been selected through analyzing these data to identify the possible food production strategies on the supermarket roofs.

Identify Roof

Morphology of

Supermarkets

(Case Study)
Requirements for

Growing Vegetables

(Literature Review)
Growing Methods

on Rooftops

(Literature Review

\& Case Study )
Analyzing All

Gathered

Data for

Conclusion

Figure 6 - The Research Methodology 


\section{5- FINDINGS}

\section{5-1 Characteristics of Existing Single-Storey Supermarkets}

Structural behavior, in conjunction with roof morphologies, appears to be among the first challenges on the list, particularly in relation to existing buildings. Roofs need to be reviewed in terms of size, direction, slope and other design criteria and be evaluated suitable for greening and growing operations. Lack of appropriate size, deep slope, etc. poses a problem in set up and installation of a green roof system. Structural behavior, if unable to support the weight of green roof system, is a barrier.

As discussed, roof morphologies of the single storey supermarkets in Mississauga have been studied in order to find a similar pattern. Totally 31 cases have been studied. Results from these studies are available in the Appendix A, which is summarized in .

Table 1. These chain stores generally belong to 3 major corporations listed in the same table.

The initial observations using Google Maps indicated that, except one rooftop which is occupied by photovoltaic panels, the rest of the rooftops are left unoccupied. It was also identified during site visits that one of the stores has a traditional masonry load bearing structure. The last two mentioned outlets are not viable and therefore not included in the scope of this research.

Table 1-Single Storey Supermarkets in Mississauga

\begin{tabular}{|c|c|c|c|c|}
\hline & Operations & $\begin{array}{c}\text { Existing Branches } \\
\text { in Mississauga }\end{array}$ & $\begin{array}{c}\text { Number of } \\
\text { Branches with } \\
\text { Unoccupied } \\
\text { Rooftops }\end{array}$ & $\begin{array}{c}\text { Number of } \\
\text { Branches } \\
\text { Studied }\end{array}$ \\
\hline \multirow{2}{*}{ Lomplaw } & Loblaws & 4 & 3 & 3 \\
\cline { 2 - 5 } Metro Inc & No Frills & 9 & 9 & 8 \\
\cline { 2 - 5 } & Metro / Metro Plus & 6 & 6 & 6 \\
\hline \multirow{2}{*}{ Sobeys } & FreshCo & 5 & 6 & 6 \\
\cline { 2 - 5 } & Sobeys & 1 & 5 & 1 \\
\hline
\end{tabular}




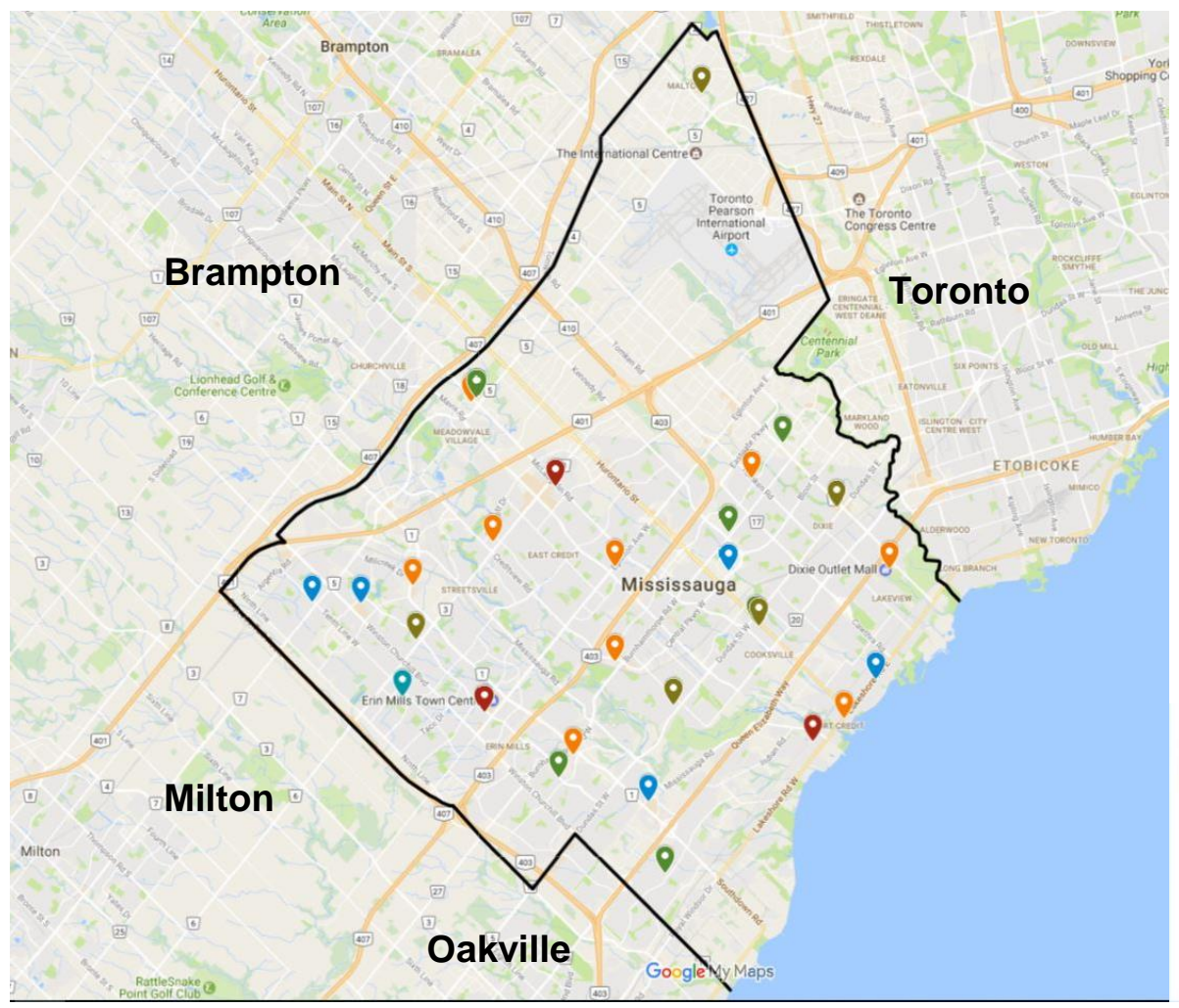

$\begin{array}{ll}9 & \text { No Frills } \\ 9 & \text { Loblaws } \\ 9 & \text { Food Basics } \\ 9 & \text { Metro } \\ 9 & \text { FreshCo } \\ 9 & \text { Sobeys }\end{array}$

Figure 7 - Single Storey Chain Supermarkets in Mississauga

Figure 7, illustrates the distribution of major grocery stores in Mississauga region. Transformation of these rooftops can create a network of organic food production and resource accessible to residents across Mississauga. Each store can provide to a range of neighborhoods in its vicinity.

Table 1The results of overall observations then are classified and summarized into the 5 following categories:

1- General Characteristics

2- Roof Morphology

3- Available Space

4- Roof Structure

5- Accessibility 


\section{5-1-1 General Characteristics}

The first preliminary field study pointed out that more than $60 \%$ of supermarkets are located in the $1 / 3$ back of the property, dedicating the rest of the property to parking lot. This setback provides enough distance from taller adjacent buildings. Therefore, the rooftops are not overshadowed by taller buildings. Figure 8 illustrates the typical position of a supermarket building within the site boundaries.

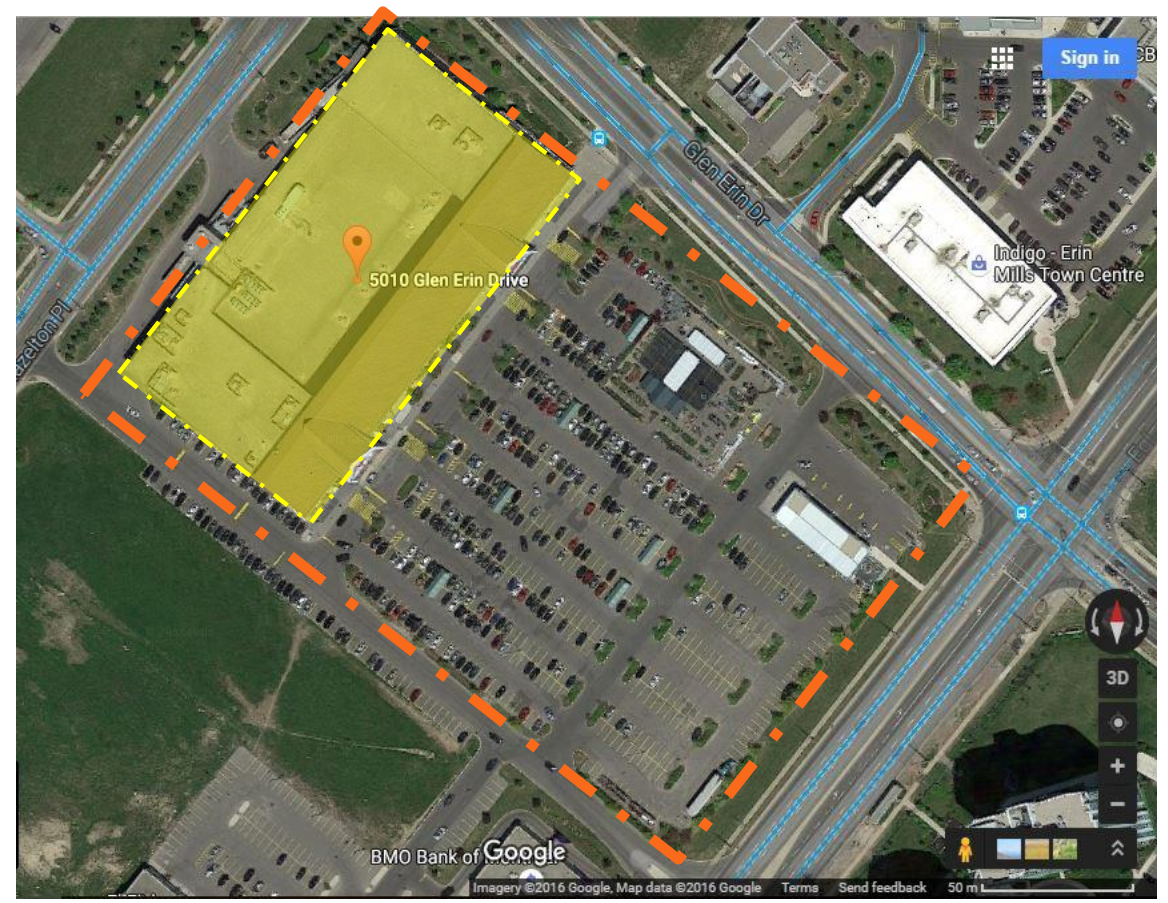

Figure 8 - Typical Position of Supermarket Building within the Site

Site visits revealed that most supermarkets typically have double-height ceiling. The approximate external height of these one-storey buildings is in the range of $8.2-11.8$ meters excluding the height of parapet. About $35 \%$ of supermarkets were identified with multiple rooftop levels.

The orientation of the buildings was another factor that has been reviewed. About $65 \%$ of the studied buildings have NW-SE orientation and $35 \%$ have NE$\mathrm{SW}$ orientation. This orientation is following the site orientation and the street grid, and is not intentional. As long as the building is not overshadowed, the orientation can only influence the arrangement of the plants on the rooftop. Taller 
plants and those plants which require a supporting structure to grow on must be arranged on the northern portion of the roof.

\section{5-1-2 Roof Morphology}

The average size of reviewed supermarket rooftop is around 5,300 square meters. The observations show that supermarket rooftops are not identical. However, generally $94 \%$ of the supermarkets have low-sloped roofs and the rest $6 \%$ have a combination of both low-sloped roofs and sloped sections.

\section{5-1-3 Available Space}

Studied supermarkets are grouped based on their size in three categories of small, medium and large scale (Table 2). The reason behind this categorization is that to understand any correlation that might exist between the size of stores and available areas for growing in an urban context for future studies. Overall, the total gross area of all medium and small scale supermarkets is more than the total gross area of all large scale supermarket buildings in Mississauga.

Mechanical units and gas pipes appear to be the main obstacles for growing vegetables. Although mechanical units and air handlers occupy less than 13 percent of each roof, the layout and location of mechanical units and pipes affect the suitability of available low-sloped spaces.

At least one meter clearance should be considered around the mechanical units and around the perimeter of the roof for the maintenance and wind uplift mitigation. The potential RA area can increase substantially if relocation of the mechanical units and pipes happen within the roof's retrofitting budget of each store. 
Table 2 -Total Gross Area of Studied Supermarkets

\begin{tabular}{|c|c|c|c|c|}
\hline Category & Location & Company & Total Groos Area $\left(\mathrm{M}^{2}\right)$ & Total \\
\hline \multirow{3}{*}{ Large $8,000<X$} & 5010 Glen Erin Dr & \multirow{2}{*}{ Loblaws } & 10,800 & \multirow{3}{*}{32,200} \\
\hline & 5970 Mclaughlin, Rd & & 8,000 & \\
\hline & 1250 South Service Rd & NO Frills & 13,400 & \\
\hline \multirow{12}{*}{$\begin{array}{c}\text { Medium } \\
4,000<X<8,000\end{array}$} & 250 Lakeshore Rd W & Loblaws & 4,100 & \multirow{12}{*}{45,400} \\
\hline & 925 Rathburn Rd E & \multirow{5}{*}{ NO Frills } & 4,400 & \\
\hline & 4040 Creditview Rd & & 2,900 & \\
\hline & 2150 Burnhamthorpe Rd W & & 4,600 & \\
\hline & 620 Eglinton Ave W & & 5,300 & \\
\hline & 6085 Creditview Rd & & 4,400 & \\
\hline & 4141 Dixie $\mathrm{Rd}$ & Food Basics & 5,300 & \\
\hline & 910 Southdown Rd & \multirow{4}{*}{$\begin{array}{c}\text { Metro / Metro } \\
\text { Plus }\end{array}$} & 5,300 & \\
\hline & 2225 Erin Mills Parkway & & 5,100 & \\
\hline & 3221 Derry Rd W & & 4,600 & \\
\hline & 6677 Meadowvale & & 4,600 & \\
\hline & 5602 Tenth Line W & Sobeys & 4,500 & \\
\hline \multirow{14}{*}{$\underset{x<4000}{\text { Small }}$} & 6465 Erin Mills Parkway & \multirow{2}{*}{ NO Frills } & 3,100 & \multirow{14}{*}{42,1000} \\
\hline & 7070 McLaughlin Road & & 3,200 & \\
\hline & 3476 Glen Erin Drive & \multirow{5}{*}{ Food Basics } & 3,100 & \\
\hline & 377 Burnhamthorpe Road East & & 3,200 & \\
\hline & 2550 Hurontario Street & & 3,000 & \\
\hline & 2425 Truscott Drive & & 2,900 & \\
\hline & 7070 Saint Barbara Blvd & & 3,700 & \\
\hline & 1585 Mississauga Valley Blvd & \multirow{2}{*}{$\begin{array}{c}\text { Metro / Metro } \\
\text { Plus }\end{array}$} & 3,400 & \\
\hline & 406 Lakeshore Road East & & 1,900 & \\
\hline & 2500 Hurontario Street & \multirow{5}{*}{ Freshco } & 2,600 & \\
\hline & 6040 Glen Erin Drive & & 3,100 & \\
\hline & 1151 Dundas Street West & & 3,500 & \\
\hline & 3100 Dixie Road & & 2,700 & \\
\hline & 7205 Goreway Drive & & 2,700 & \\
\hline
\end{tabular}

\section{5-1-4 Roof Structure}

Supermarkets are found to be long-span type of buildings in order to allow cooler cabinets and aisles in between. The span between columns was found to be in the range of 9-13 meters (30-43 feet) apart. 
The roof is typically built from pre-engineered steel joists and girders. The structure comprises of columns and beams with bracing at the sidewalls.

\section{5-1-5 Accessibility}

The accessibility to the roof was found to be through the roof hatch. Although the roof hatches provide convenient access to the roof for maintenance, might not be a good passage for initial installation purposes.

Table 3, shows the initial information gathered for each store from generated drawings. Total gross area compromise both low-sloped portion and sloped portion of the rooftop which helped to categorize the stores based on their size rather than the brand name. Potential available area is the offered area for food production which does not account for any walkway, maintenance vegetation free zone; indicating how slopes, mechanical units and spatial dividers affect the available area for food production. The orientation of the building indicates compass direction the building faces. 
Table 3 - Summary of Available Space for Food Production based on Studied Supermarkets in Mississauga

\begin{tabular}{|c|c|c|c|c|c|c|c|c|}
\hline Name & Location & $\begin{array}{l}\text { Total Gross } \\
\text { Area }\left(\mathrm{m}^{2}\right)\end{array}$ & $\begin{array}{l}\text { Unusable } \\
\text { Sloped } \\
\text { Portion \% }\end{array}$ & $\begin{array}{c}\text { Mechanical } \\
\text { Area \% }\end{array}$ & \multicolumn{2}{|c|}{$\begin{array}{c}\text { Potential } \\
\text { Available Area } \\
\left(\mathrm{m}^{2}\right)\end{array}$} & Orientation & Roof Levels \\
\hline \multirow{4}{*}{ Loblaws Branches } & 5010 Glen Erin Dr. & 10,800 & $30 \%$ & $1.8 \%$ & 10,600 & $98 \%$ & NE-SW & 3 \\
\hline & 5970 Mclughlin Rd & 8,000 & $36 \%$ & $1.3 \%$ & 5,000 & $63 \%$ & NW-SE & 1 \\
\hline & 250 Lakeshore Rd & 4,100 & $0 \%$ & $2 \%$ & 4,000 & $97 \%$ & NE-SW & 1 \\
\hline & 3045 Mavis Rd & 7,800 & $38 \%$ & $4 \%$ & \multicolumn{2}{|c|}{$\begin{array}{c}\mathrm{N} / \mathrm{A} \\
\text { (PV Panels) }\end{array}$} & NE-SW & 2 \\
\hline \multirow{8}{*}{ NoFrills Branches } & 925 Rathburn Rd E & 4,400 & $0 \%$ & $11 \%$ & 3,900 & $88 \%$ & NE-SW & 1 \\
\hline & $\begin{array}{c}2150 \\
\text { Burnhamthorpe Rd } \\
W\end{array}$ & 4,600 & $0 \%$ & $2 \%$ & 4,400 & $95 \%$ & NW-SE & 1 \\
\hline & 620 Eglinton Ave W & 5,400 & $0 \%$ & $14 \%$ & 5,300 & $98 \%$ & NW-SE & 1 \\
\hline & 6465 Erin Mills & 3,100 & $0 \%$ & $4 \%$ & 3,000 & $96 \%$ & NW-SE & 1 \\
\hline & 4040 Creditview Rd & 3000 & $0 \%$ & $4 \%$ & 2,900 & $96 \%$ & NW-SE & 1 \\
\hline & $\begin{array}{c}7070 \text { McLaughlin } \\
\text { Rd }\end{array}$ & 3,200 & $0 \%$ & $1.3 \%$ & 3,100 & $97 \%$ & NW-SE & 1 \\
\hline & 6085 Creditview Rd & 4,400 & $0 \%$ & $5 \%$ & 4,100 & $95 \%$ & NW-SE & 1 \\
\hline & $\begin{array}{c}1250 \text { South Service } \\
\text { Rd }\end{array}$ & 13,400 & $0 \%$ & $1 \%$ & 13,300 & $98 \%$ & NW-SE & 2 \\
\hline \multirow{6}{*}{$\begin{array}{l}\text { Food Basics } \\
\text { Branches }\end{array}$} & 3476 Glen Erin Dr & 3,100 & $0 \%$ & $2 \%$ & 3,000 & $97 \%$ & NE-SW & 1 \\
\hline & $\begin{array}{c}377 \text { Burnhamthorpe } \\
\text { Rd E } \\
\end{array}$ & 3,200 & $0 \%$ & $4 \%$ & 3,000 & $95 \%$ & NW-SE & 1 \\
\hline & 2550 Hurontario St & 3,000 & $0 \%$ & $2 \%$ & 2,800 & $97 \%$ & NE-SW & 1 \\
\hline & 2425 Truscott Dr & 3,000 & $0 \%$ & $2 \%$ & 2,800 & $97 \%$ & NA & 2 \\
\hline & 4141 Dixie Rd & 5,300 & $0 \%$ & $2 \%$ & 5,200 & $98 \%$ & NE-SW & 2 \\
\hline & $\begin{array}{c}7070 \text { Saint Barbara } \\
\text { Blvd }\end{array}$ & 3,700 & $0 \%$ & $2 \%$ & 3,600 & $98 \%$ & NE-SW & 1 \\
\hline \multirow{6}{*}{ Metro Branches } & 910 Southdown Rd & 5,300 & $0 \%$ & $6 \%$ & 4,900 & $92 \%$ & NA & 1 \\
\hline & $\begin{array}{c}2225 \text { Erin Mills } \\
\text { Parkway }\end{array}$ & 5,100 & $3 \%$ & $2 \%$ & 4,800 & $94 \%$ & NE-SW & 1 \\
\hline & $\begin{array}{c}1585 \text { Mississauga } \\
\text { Valley Blvd }\end{array}$ & 3,400 & $0 \%$ & $2 \%$ & 3,300 & $97 \%$ & NW-SE & 2 \\
\hline & 3221 Derry Rd W & 4,600 & $0 \%$ & $2 \%$ & 4,500 & $97 \%$ & NW-SE & 1 \\
\hline & $\begin{array}{c}6677 \text { Meadowvale } \\
\text { Circle }\end{array}$ & 4,600 & $0 \%$ & $2 \%$ & 4,500 & $97 \%$ & NE-SW & 1 \\
\hline & 406 Lakeshore Rd E & 1,900 & $0 \%$ & $5.3 \%$ & 1,800 & $94 \%$ & NW-SE & 1 \\
\hline \multirow{5}{*}{ FreshCo Branches } & 2500 Hurontario St & 2,600 & $0 \%$ & $4 \%$ & 2,500 & $96 \%$ & NE-SW & 1 \\
\hline & 6040 Glen Erin Dr & 3,100 & $0 \%$ & $2 \%$ & 3,000 & $96 \%$ & NW-SE & 1 \\
\hline & 1151 Dundas St W & 3,500 & $0 \%$ & $3 \%$ & 3,300 & $96 \%$ & NW-SE & 2 \\
\hline & 3100 Dixie Rd & 2,700 & $0 \%$ & $4 \%$ & 2,600 & $96 \%$ & NE-SW & 2 \\
\hline & 7205 Goreway Dr & 2,800 & $0 \%$ & $3 \%$ & 2,700 & $96 \%$ & NE-SW & 2 \\
\hline Sobeys Branches & 5602 Tenth Line W & 4,500 & $0 \%$ & $11 \%$ & 3,400 & $75 \%$ & NW-SE & 1 \\
\hline
\end{tabular}




\section{5-2 Plant Growth Requirements}

Growing media is the heaviest load in the assembly used for food production.

Therefore, the first critical factor to review is the depth of growing media.

There is a reciprocal relationship between soil and vegetation. Rich soil provides the nutrient and holds required water for growth ("Urban agriculture: cultivating soils in the city," 2015). Not all types of soil are suitable for growing vegetables specially having structural loadbearing restrictions on rooftops; lightweight growing medium with rich nutrients should be used. Bulk density of lightweight growing media suitable for different systems on rooftops is classified on Table 4 .

Table 4 - Bulk Density of Lightweight Growing Media, (“Growing Medium Specification,” n.d.)

\begin{tabular}{|l|c|c|c|c|}
\hline \multirow{2}{*}{ Type of Growing Medium } & \multicolumn{2}{|c|}{$\begin{array}{c}\text { Bulk Density } \\
\text { (Dry) }\end{array}$} & \multicolumn{2}{c|}{$\begin{array}{c}\text { Bulk Density } \\
\text { (Maximum Saturation) }\end{array}$} \\
\cline { 2 - 5 } & $\mathrm{kg} / \mathrm{m}^{3}$ & $\mathrm{lbs} / \mathrm{ft}^{3}$ & $\mathrm{~kg} / \mathrm{m}^{3}$ & $\mathrm{lbs} / \mathrm{ft}^{3}$ \\
\hline Lightweight Extensive & $320-480$ & $20-30$ & $800-960$ & $50-60$ \\
\hline Lightweight Semi- Intensive & $640-880$ & $40-55$ & $1,020-1,280$ & $70-80$ \\
\hline Lightweight Intensive & $800-1,040$ & $50-65$ & $1,280-1,440$ & $80-90$ \\
\hline Lightweight Agricultural & $400-720$ & $25-45$ & $960-1,120$ & $60-70$ \\
\hline
\end{tabular}

The bulk density of lightweight agricultural growing medium is around $400-721$ $\mathrm{kg} / \mathrm{m}^{3}$ (25-45 lbs. $\left./ \mathrm{ft}^{3}\right)$ when is dry. However, it is critical to consider the saturation weight when determining the load capacity calculation. The density of saturated lightweight agricultural growing medium is around $960-1,120 \mathrm{~kg} / \mathrm{m} 3$ based on Table 4. In other word, every 10 centimeter of lightweight agricultural growing medium exert $1.11 \mathrm{kPa}$.

Since the requirements for rooting are different for variable crops, therefore planters with limited depths and volumes are only suitable for limited species. A research has been conducted to better understand the minimum space requirement of food production on rooftops. Table 5 , categorizes some of the common species in Ontario based on the soil depth requirement. 
Table 5 - Soil depth requirements of different crops, ("Raised Beds Soil Depth Requirement," 2014)

\begin{tabular}{|c|c|c|c|c|c|}
\hline \multicolumn{2}{|c|}{ Shallow Rooting } & \multicolumn{2}{|c|}{ Medium Rooting } & \multicolumn{2}{|c|}{ Deep Rooting } \\
\hline $10-12 \mathrm{~cm}$ & $15-18 \mathrm{~cm}$ & $20-25 \mathrm{~cm}$ & $25-30 \mathrm{~cm}$ & $45-60 \mathrm{~cm}$ & $60-90 \mathrm{~cm}$ \\
\hline Basil & Asian Greens & Carrots & Arugula & Beans, dry & Artichokes \\
\hline Chives & Bush Beans & Chard & Beets & Cantaloupe & Asparagus \\
\hline Coriander & Garlic & Cucumber & Broccoli & Carrots & Beans, lima \\
\hline Lettuce & Kohlrabi & Eggplant & $\begin{array}{l}\text { Brussels } \\
\text { sprouts }\end{array}$ & Kale & Parsnips \\
\hline Radishes & Onions & Fennel & Cabbage & Rutabagas & Pumpkins \\
\hline $\begin{array}{c}\text { Other Salad } \\
\text { Greens }\end{array}$ & Mint & Leeks & Cauliflower & Turnips & Rhubarb \\
\hline & Peas & Parsley & Celery & & $\begin{array}{c}\text { Sweet } \\
\text { potatoes }\end{array}$ \\
\hline & Thyme & Peppers & $\begin{array}{l}\text { Chinese } \\
\text { cabbage }\end{array}$ & & Tomatoes \\
\hline & & Pole Beans & Corn & & Watermelon \\
\hline & & Rosemary & Endive & & $\begin{array}{l}\text { Winter } \\
\text { Squash }\end{array}$ \\
\hline & & Spinach & Okra & & \\
\hline & & & Potatoes & & \\
\hline & & & Strawberries & & \\
\hline & & & $\begin{array}{l}\text { Summer } \\
\text { Squash }\end{array}$ & & \\
\hline
\end{tabular}

Likewise, crop size at maturity is another factor should be considered. That is important when determining the location and spacing of the seeds or plugs. It is essential to categorize the crops based on their height as well, so, that taller crops do not block the sunlight for shorter ones. The north-south layout minimizes shading so the taller plants are better to be planted on the north side. Generally vine crops such as pole beans and peas, which usually are planted against a trellis can block the sunlight and should be considered in the design process.

Table 6, categorizes the above-mentioned common species based on their space requirement at maturity. 
Table 6 - Approximate Height of Plants, ("Raised Beds Soil Depth Requirement," 2014)

\begin{tabular}{|l|c|l|c|}
\hline Vegetable & Size at Maturity $\mathbf{( c m})$ & Vegetable & Size at Maturity (cm) \\
\hline Artichoke & $122-150$ & Kohlrabi & $23-30$ \\
\hline Arugula & 20 & Leeks & $30-60$ \\
\hline Asparagus & $120-180$ & Lettuce & $15-30$ \\
\hline Beans, bush & $60-90$ & Okra & $60-120$ \\
\hline Beans, lima & $60-90$ & Onions & $20-60$ \\
\hline Beans, pole & $20-30$ & Parsnips & $15-45$ \\
\hline Beets & $10-30$ & Peas & $60-120$ \\
\hline Broccoli & $45-60$ & Peppers, hot & $60-120$ \\
\hline Brussels sprouts & $60-90$ & Peppers, bell & $60-90$ \\
\hline Cabbage & $30-45$ & Potatoes & $30-75$ \\
\hline Carrots & $15-40$ & Pumpkin & $30-60$ \\
\hline Cauliflower & $30-75$ & Radishes & 60 \\
\hline Celery & $45-60$ & Rhubarb & $30-90$ \\
\hline Chard & $30-75$ & Rutabaga & $30-45$ \\
\hline Chinese cabbage & $30-60$ & Spinach & $15-40$ \\
\hline Corn & $10-20$ & Squash, summer & $30-60$ \\
\hline Cucumber & $30-150$ & Squash, winter & $30-60$ \\
\hline Eggplant & $30-90$ & Sweet potato & $30-75$ \\
\hline Endive & $15-25$ & Tomatoes & $60-120$ \\
\hline Garlic & $30-60$ & Turnips & $15-30$ \\
\hline Kale & $30-60$ & Watermelon & 90 \\
\hline
\end{tabular}

The other requirement is irrigating the crops on a regular basis. In both permanent and seasonal applications, a simple irrigation system with a controller can reduce the maintenance. Although automatic irrigation system can stay on roof all year round in seasonal growing application, this MRP explores hand watering for the time being.

As discussed earlier, growing methods on rooftops should be identified through case study method. The combination of data from plant growth requirements and rooftop growing methods form the food production strategies for supermarket rooftops. 


\section{5-3 Case Studies with Agricultural Rooftops}

Since food production in urban areas is different from conventional rural agriculture, the approaches are required to be identified in order to select the best options for existing single storey supermarket rooftops.

The first approach which was followed by most of the cases was a built up system, comprising general layers of a root barrier, drainage course, growing media and vegetation. Eagle Street Rooftop Farms, Brooklyn Grange and Brooklyn Navy Yard are three cases which used the built-up system.

Eagle Street Rooftop Farm is a $560 \mathrm{~m} 2$ rooftop over a three-storey industrial warehouse in Greenpoint, Brooklyn, used $90,718 \mathrm{~kg}$ of lightweight growing media and compost to create a farm with commercial sales purposes ("EAGLE STREET ROOFTOP FARM," n.d.). The farm comprises sixteen north-south planting beds separated with mulched aisles. The built-up planting beds consist of 2 inches of drainage/retention layers and 4 to 7 inches of lightweight growing medium. Hand watering is used for seedlings and transplants using collected onsite rainwater. Hot peppers, cherry tomatoes and sage were the most successful crops in this project. Moreover, the farm keeps two traditional English beehives and a top bar hive (Eagle Street Rooftop Farm Fact Sheet, 2012). Google Maps has been used to study the site neighborhood and it was found that the building is not overshadowed by any taller building.

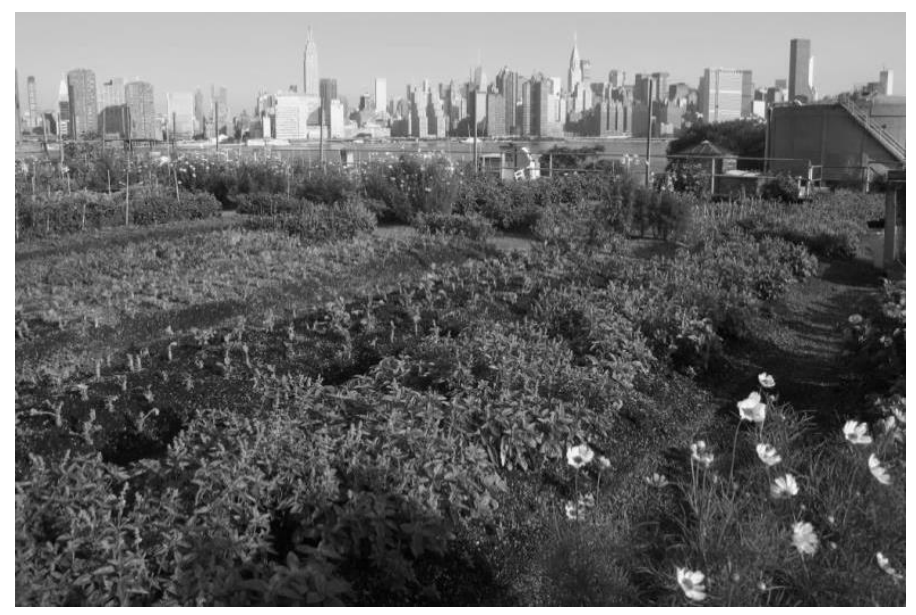

Figure 9 - Rectilinear vegetable beds at Eagle Street Rooftop Farm, Retrieved July 21, 2016 from rooftopfarms.org 
Brooklyn Grange is built over the 3,700 $\mathrm{m}^{2}$ reinforced concrete deck of a sixstorey building in New York. Eight to ten inches of growing medium was used in built-up planting beds which produces over 22 tons of crops every year ("About Brooklyn Grange," n.d.). Using Google Maps, although tall elements on the rooftop seem to overshadow the planting area, they are not dominantly overshadowed during the day.

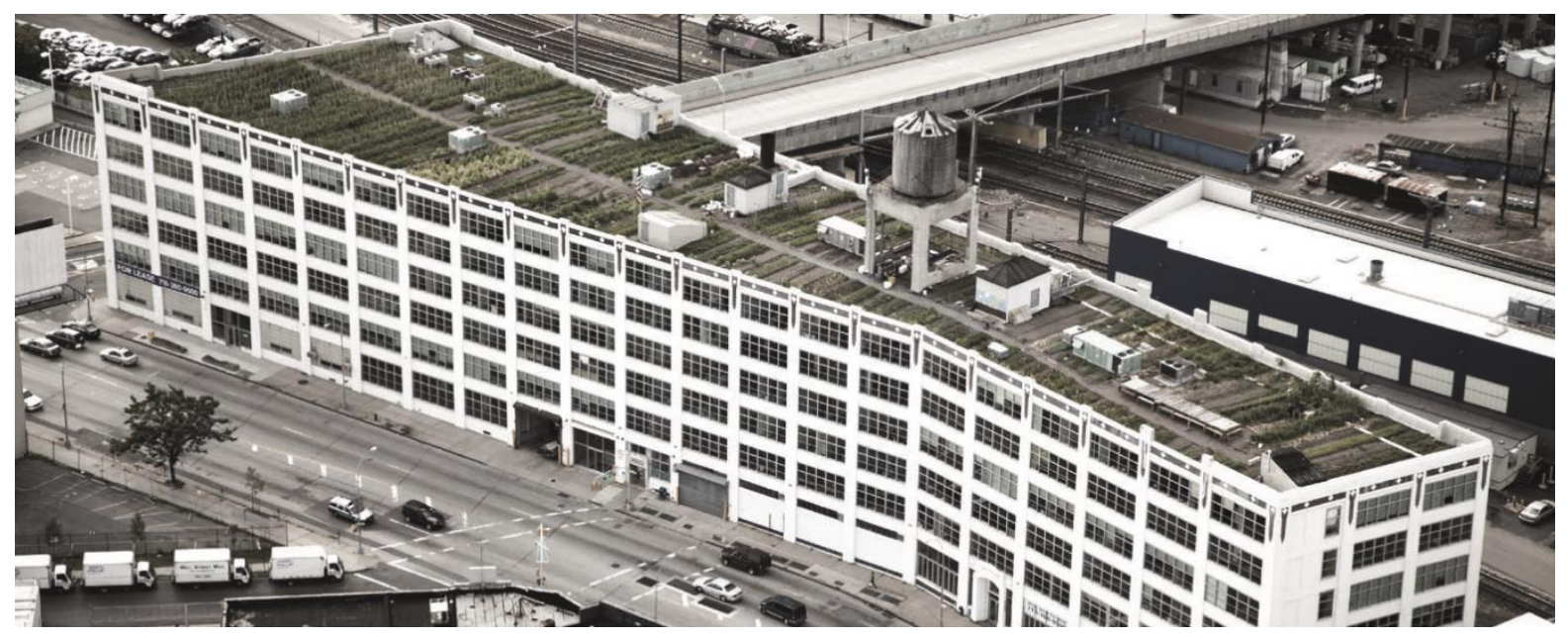

Figure 10 - Brooklyn Grange Rooftop Layout, Retrieved July 21, 2016 from manhattanwomensclub.com A very similar approach is done at the historic Brooklyn Navy Yard. The twelvestorey building has around 1,375 square meters rooftop and 10-12 inches of growing media constructed the east-west built-up beds ("Brooklyn Navy Yard, Building No. 3," n.d.).

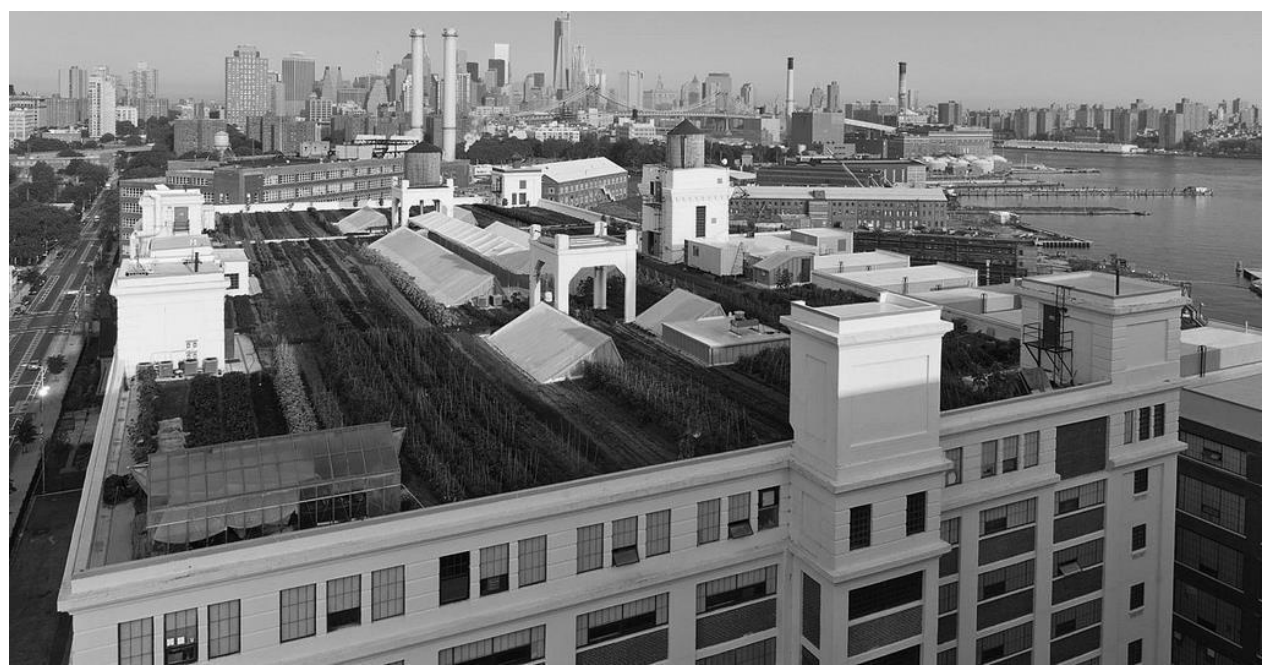

Figure 11 - Brooklyn Navy Yard Rooftop Layout, Retrieved July 28, 2016 from greenroofs.com 
The second approach that was identified on urban rooftops is building a green house facility.

Greenpoint greenhouse in New York City is a commercial greenhouse facility built over an existing 2-storey building in US producing around $45360 \mathrm{~kg}$ of leafy greens annually. The electricity is supplied by $60 \mathrm{~kW}$ onsite high efficient photovoltaic panels. The irrigation system consumes the rainwater captured onsite which is totally free of chemicals and pesticide ("Gotham Greens," n.d.).

The same company built their second greenhouse facility in Brooklyn in 2011. This greenhouse is installed over a $1,850 \mathrm{~m}^{2}$ single storey supermarket producing over $90,700 \mathrm{~kg}$ of tomatoes, herbs and leafy greens annually. Harvested rainwater for irrigation as well as electricity generated by Photovoltaic panels onsite(“Gotham Greens," n.d.).

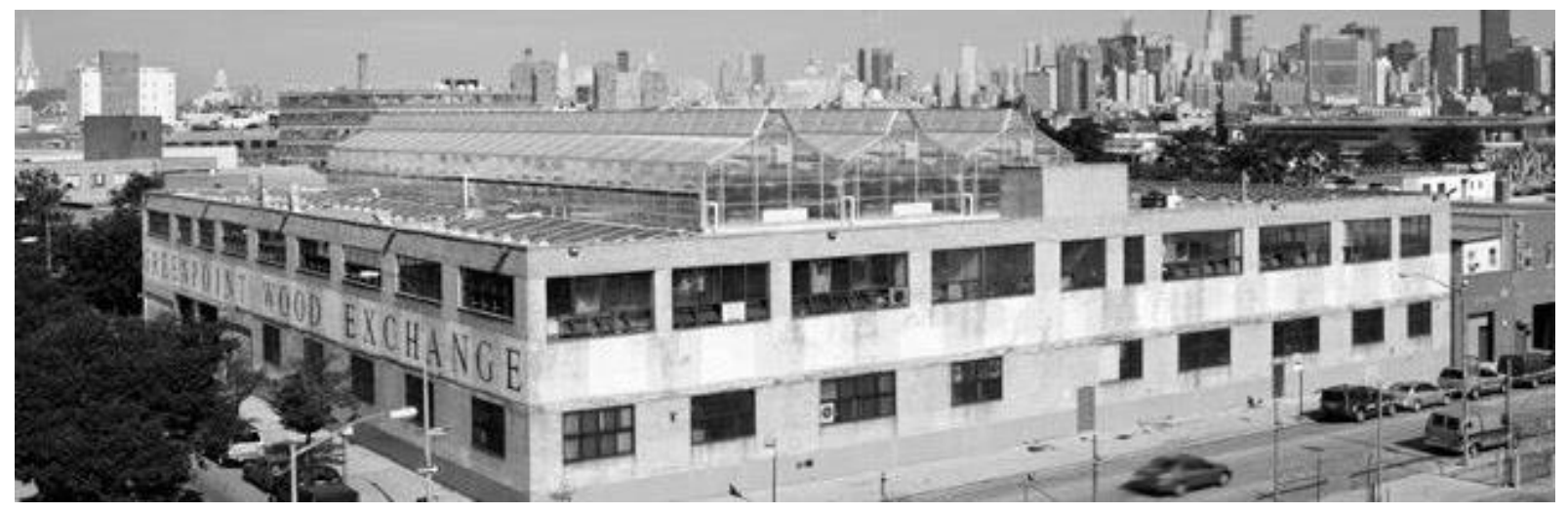

Figure 12 - An Overview of Greenpoint Greenhouse - Retrieved Oct 6, 2016 from gothamgreens.com

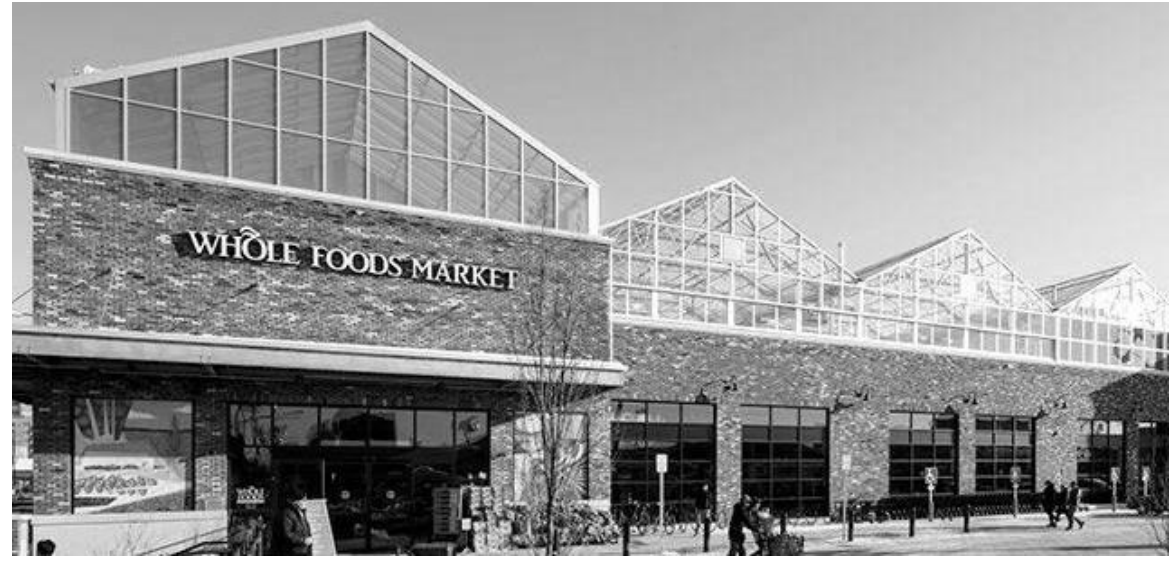

Figure 13 - An overview of Gowanus - Retrieved Oct 6, 2016 from gothamgreens.com 
Two aforementioned cases use soil-less hydroponic system which yields more harvest annually than traditional approach and is suitable for commercial scale projects.

An interesting intensive garden roof exists on the amenity barbeque terrace of a condo located at 21 Carlton Street in Toronto. The interesting feature of this amenity area is the network of columns and trellis acting as a support for vines to grow on and provide shade for gathering space. Although this project is not a rooftop farm, its trellis network idea is the focal point which can be adopted for growing vine purposes.

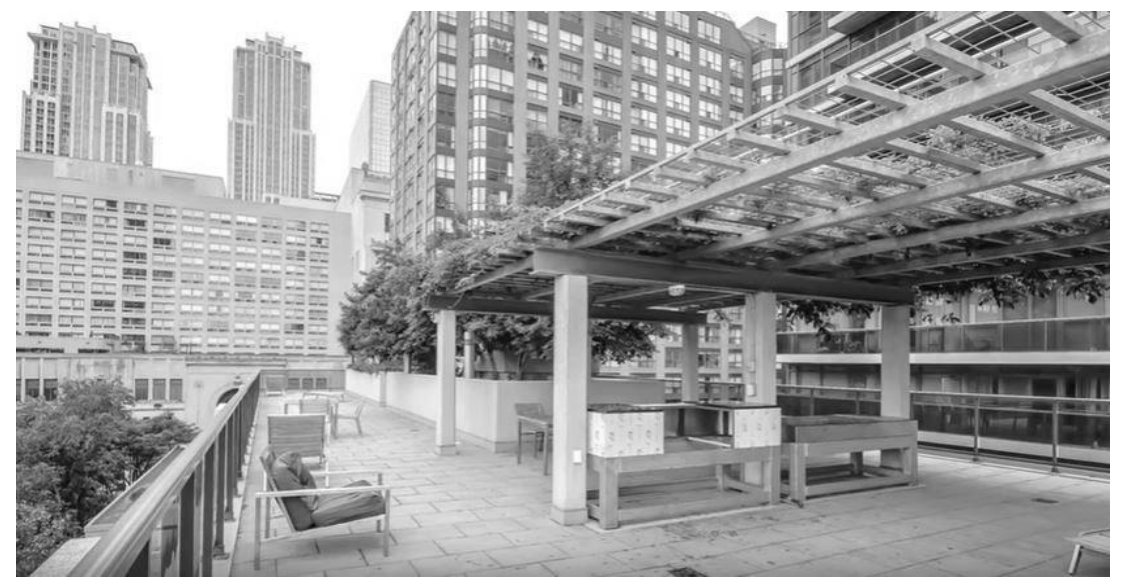

Figure 14 - Network of Columns \& Trellis at 21 Carlton St.

Based on the reviewed case studies, the proper growing methods have been identified which are studied individually in the next section in order to select the practical options for existing rooftops with load bearing limitation.

\section{5-4 Methods for Growing Vegetables on Rooftops}

According to the case studies, different methods have been used for growing vegetables on rooftops. The summary of these methods are listed below:

1- Built-up System

2- Soft Planters

3- Rigid Planters (Earth-Box)

4- Hydroponic Systems

5- Hanging Planters 
These methods have been analyzed further to select the appropriate options for supermarket rooftops.

\section{Built-up System}

The built-up system generally consists of 4 permanent layers of root barrier, drainage course, growing media and vegetation. Since the structural capacity of supermarket rooftops is limited, can't tolerate the weight of these permanent layers and it is not recommended for rooftop application.

Nevertheless, as was discussed in Peck \& Kuhn, (2003) paper, 18 lbs./SF extra capacity reserved in existing buildings which can accommodate the weight of extensive 5 centimeter deep built-up system.

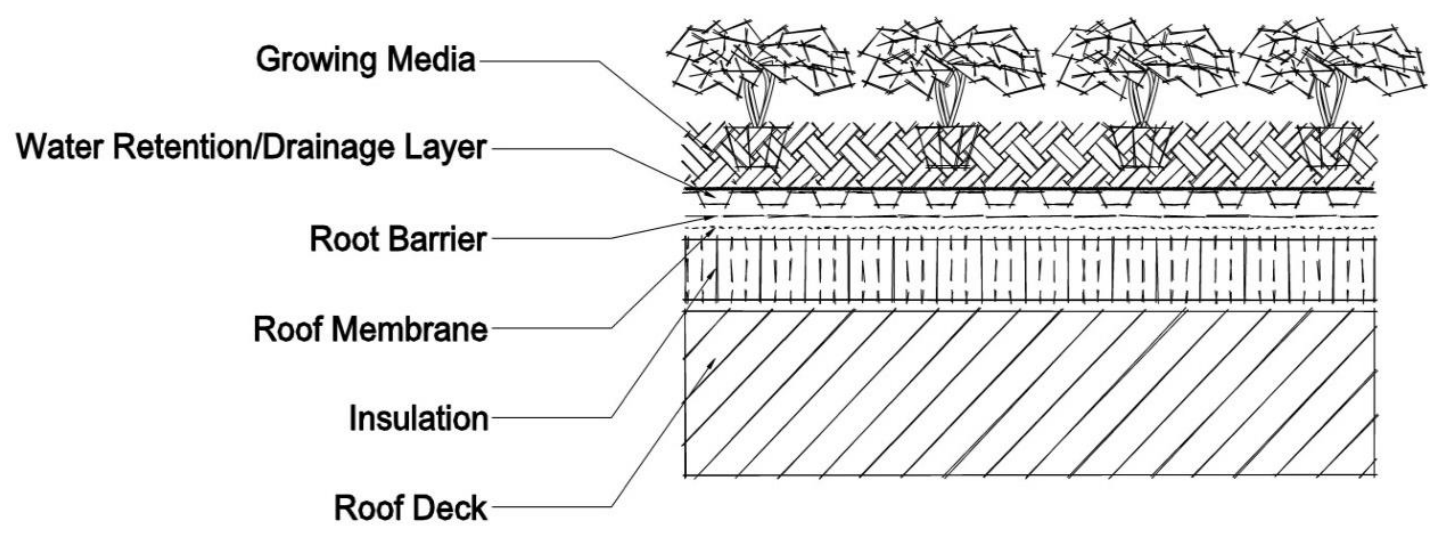

Figure 15 - Built-up System Section

\section{Soft Planters}

Soft planters have been used in projects where temporary landscaping is desirable. Kale, spinach, squash, spring onions can be grown in soft planters. Although flexibility of construction and low cost are some of the advantages of this system, weight of intensive bags might be an issue for rooftop application (Gorgolewski et al., 2011).

\section{Rigid Planters}

Rigid containers are common traditional method for growing plants. Simple containers and reusable materials can be used for this purpose. Other examples 
could be lockable planters to create a bigger network especially on rooftops where a unified network is desirable.

Earth-Box is a sub-irrigated planter-based system used when the soil quality is poor or the space is limited ("Homegrown Vegetables Without A Garden," n.d.).

The dimensions are about $73.6 \mathrm{~cm} \mathrm{~L} \mathrm{x} 34.3 \mathrm{~cm} \mathrm{D} \mathrm{x} 28 \mathrm{~cm} \mathrm{H}$ (29"x 13.5"x11") with capacity of $0.07 \mathrm{~m}^{3}$ (18.6 US Gallons) which can hold 11 liters ( 3 US Gallons) of water and 0.06 cubic meter of growing media. An empty EarthBox weighs about $2 \mathrm{~kg}(2.5 \mathrm{lbs})$ and up to $36 \mathrm{~kg}(80 \mathrm{lbs})$ in saturated situation with heavy plants such as tomatoes ("Homegrown Vegetables Without A Garden," n.d.).

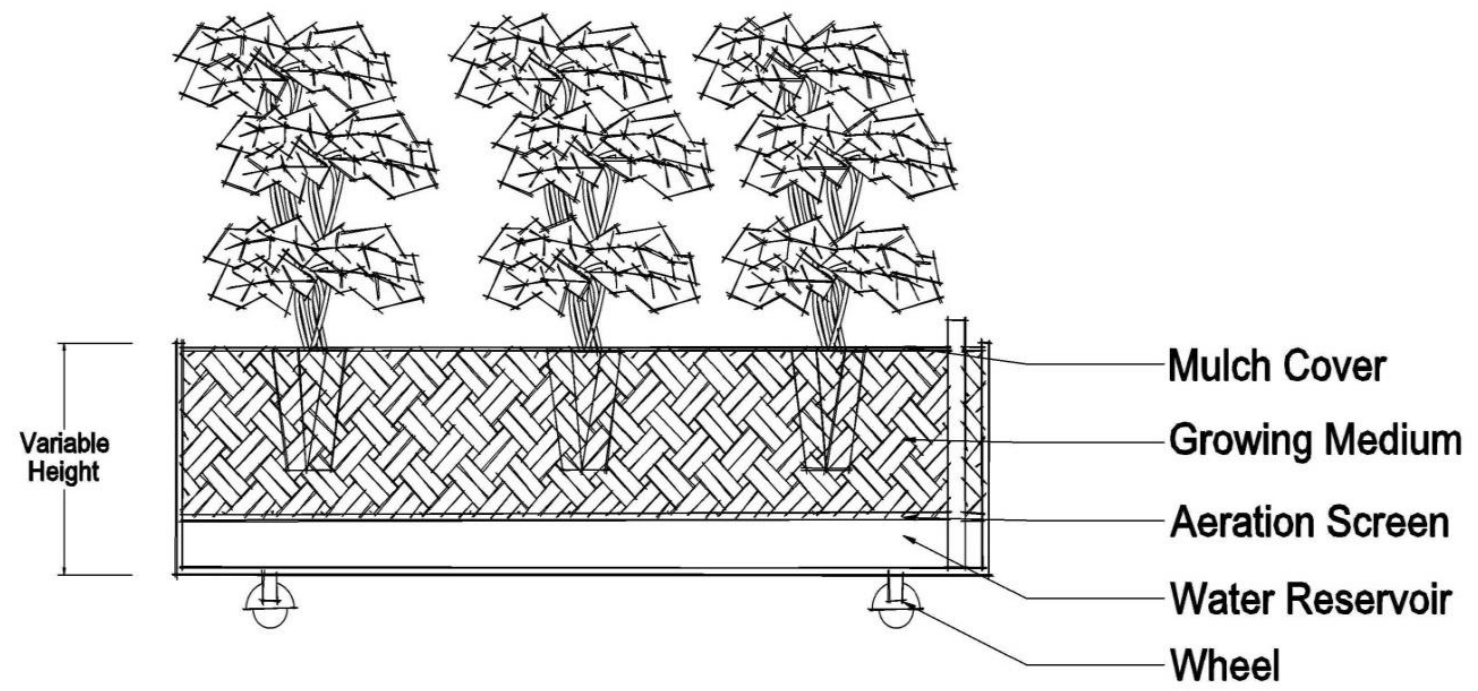

Figure 16 - Earth-Box Section

Since pre-manufactured system can be adapted as movable units on the rooftops, it would be a suitable option for seasonal growing.

The table below summarizes the quantity of the seedlings per Earth-Box based on the type of plants ("Super Efficient All-In-One Garden," n.d.). 
Table 7 - Quantity and Type of Vegetation per Earth Box - ("Super Efficient All-In-One Garden," n.d.)

\begin{tabular}{|c|l|}
\hline $\begin{array}{c}\text { Seedling Quantity } \\
\text { per EarthBox }\end{array}$ & Type of Vegetables \\
\hline $\mathbf{2}$ & Tomato, Eggplant, Artichoke, Melons, Zucchini, Squash, Chickpeas \\
\hline $\mathbf{4}$ & Cucumbers \\
\hline $\mathbf{6}$ & $\begin{array}{l}\text { Broccoli, Brussel Sprouts, Cabbage, Chard, Collards, Herbs, Kale, } \\
\text { Peppers, Strawberries }\end{array}$ \\
\hline $\mathbf{8}$ & Kohlrabi, Okra, Lettuce, Salad greens \\
\hline $\mathbf{1 0}$ & Beets, Onions, Spinach, Turnip, Garlic \\
\hline $\mathbf{1 6}$ & Carrot, Radish \\
\hline Entire Surface & Alfalfa, Cilantro, Green Onions, Watercress \\
\hline
\end{tabular}

\section{Hydroponic Systems}

It was recognized in 1937 that soil itself is not a requirement for growth of the plants. The contained water and other nutrients within the soil are the most important factors for growing plants which can be supplied to plants in other manners (Gorgolewski et al., 2011) and (S. J. Wilkinson et al., 2015). Hydroponic and aeroponics techniques are suitable where static load restriction is critical. These systems use significantly less amount of water than conventional system and also produce various crops at commercial scale.

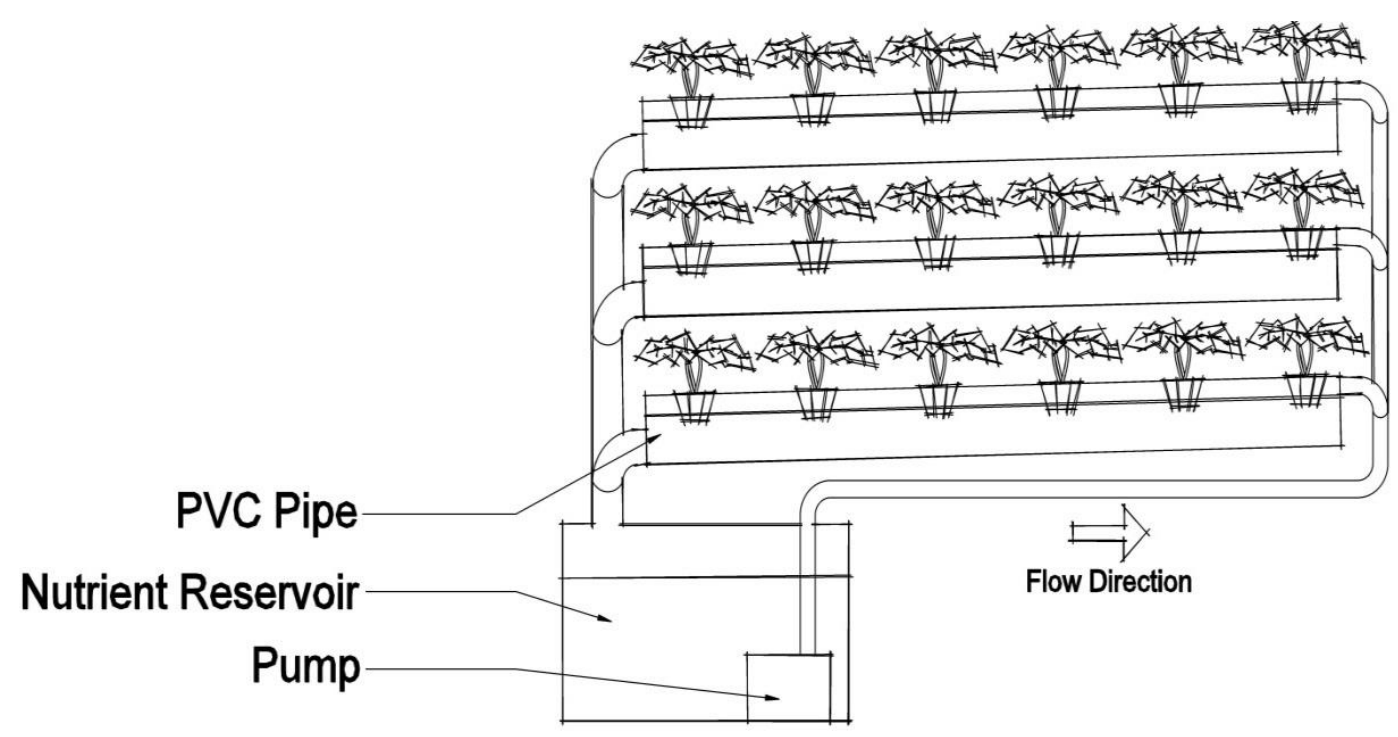

Figure 17 - Hydroponic System Configuration 
The main components of this lightweight technology consist of a container with channel to make the soluble nutrients and oxygen accessible to the roots. Usually pumps are used to control the flow of nutrients from the supply container through the channels. Orsini et al., (2014) conducted a research using Nutrient Film Technique (NFT) on PVC pipes, floating system and solid substrate cultivation techniques to grow lettuce, black cabbage, chicory, tomato, eggplant, chili paper, melon and water melon in different seasons. They reported that floating technique yields better than NFT technique due to the linear design, NFT is preferable where the space is limited.

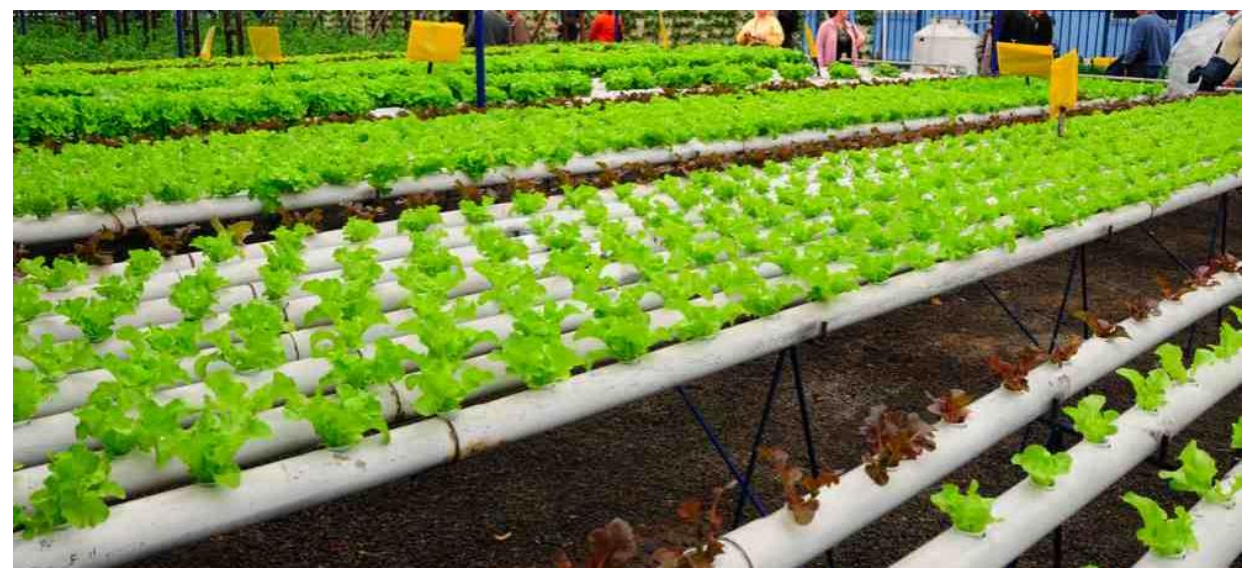

Figure 18 - Hydroponic System Retrieved Nov 19, 2016 from growthrivingveggies.com

As mentioned, hydroponic system is a lightweight assembly since the growing medium is not a critical growing factor. The maximum weight of the assembly is approximately $13.8 \mathrm{~kg} / \mathrm{m}$ (9.3 lbs./ft) which is calculated based on the maximum weight of the maximum number of mature plants and nutrient fluid in a 10 foot PVC pipe (R: $5 \mathrm{~cm})$.

\section{Hanging Planters}

Modular planters and flexible fabric are the main representatives of this system. Mobile Edible Wall Units (Figure 19), as one of the possible options, are modular planters mounted on a wheeled structure and can accommodate the required depth for deeper plants. Rigid modular planters can be replaced with flexible fabric sacks in the same concept as an alternative. Hanging planters can be 
beneficial for rooftop application since the weight of the system can be distributed to the main structure of the building.
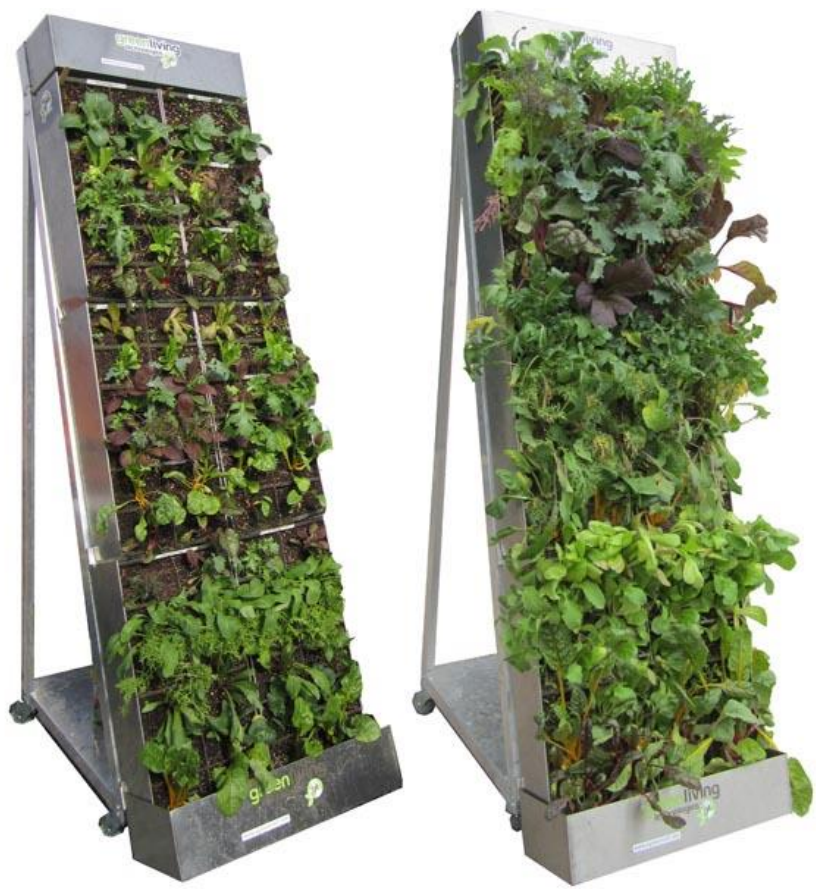

Figure 19 - Mobile Edible Wall Units Retrieved January, 2017 from agreenroof.com

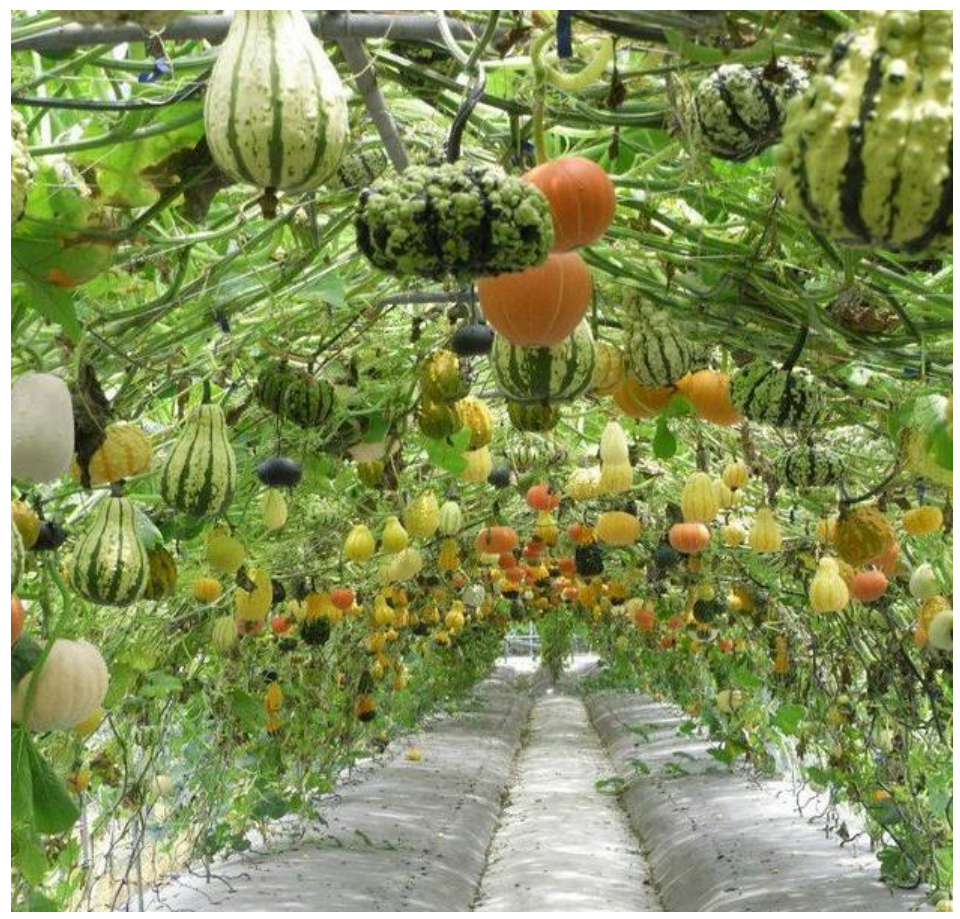

Figure 20 - Loads Can be Transferred to the Main Structure through Trellis Structure Retrieved January, 2017 from Pinterest.com 


\section{6- Summary of Findings}

The results from the finding section are summarized as following:

1- Supermarkets are typically one-story buildings with significant empty lowsloped rooftops.

2- Supermarket rooftops in sub-urban area are found exposed to sunlight.

3- Mechanical units and gas pipes are the main barriers, occupying approximately $3-13 \%$ of the rooftops. If relocation of units is not desired, clearance path for maintenance should be considered.

4- Supermarkets are long-span buildings with lightweight roof structure. Columns are spaced in range of 9 to 13 meters apart.

5- The accessibility to the rooftop is through the roof hatch.

6- The bulk density of light weight agricultural growing medium is in range of $400-721$ and $961-1,121 \mathrm{~kg} / \mathrm{m}^{3}$ for dry and saturated situation respectively.

7- Plants should be planned based on their root size and their mature size preferably on north-south layout to minimize over shading.

8- Built-up system, soft planters, rigid planters, hydroponic system and hanging planters are found growing methods in urban area.

9- Since supermarket rooftops are not suitable for permanent installation, using rigid planters, hydroponic system and hanging planters for seasonal growing are recommended.

10- $5 \mathrm{~cm}$ deep built-up system can be installed on existing buildings in Ontario since the Ontario Building code edition.

11- Hydroponic systems have low weight which known as commercial scale techniques.

12- Use of trellises for growing vines or using them as a structure to transfer the loads from hanging planters to the main structure. 


\section{7- ANALYSIS OF FINDINGS}

\section{7-1 System Design}

Based on comparison between OBC 2012 and 2003, $0.86 \mathrm{kPa}\left(18 \mathrm{lbf} / \mathrm{ft}^{2}\right)$ snow load capacity is available for buildings built before 2003 . This capacity would be sufficient for permanent installation of $6 \mathrm{~cm}$ (2.5 inch) deep lightweight extensive green roof systems consisting of vegetative mat and a water retention/drainage layer. Provided one meter clearance around the perimeter and mechanical units, the potential area that can be utilized for lightweight built-up system has been calculated.

Table 8 - Potential Unoccupied Surface on Studied Rooftops for Extensive Lightweight System

\begin{tabular}{|c|c|c|c|c|}
\hline Brand & Location & Total Groos Area $\left(\mathrm{m}^{2}\right)$ & Extensive $6 \mathrm{~cm}$ System $\left(\mathrm{m}^{2}\right)$ & Percentage \\
\hline \multirow{3}{*}{$\begin{array}{l}\text { Loblaws } \\
\text { Branches }\end{array}$} & 5010 Glen Erin Dr. & 10,800 & 4,900 & $45 \%$ \\
\hline & 5970 Mclughlin Rd & 8,000 & 3,400 & $41 \%$ \\
\hline & 250 Lakeshore Rd & 4,100 & 2,500 & $62 \%$ \\
\hline \multirow{8}{*}{$\begin{array}{l}\text { NoFrills } \\
\text { Branches }\end{array}$} & 925 Rathburn Rd E & 4,400 & 3,500 & $79 \%$ \\
\hline & 2150 Burnhamthorpe Rd W & 4,600 & 2,500 & $55 \%$ \\
\hline & 620 Eglinton Ave W & 5,300 & 2,700 & $50 \%$ \\
\hline & 6465 Erin Mills & 3,100 & 1,800 & $59 \%$ \\
\hline & 4040 Creditview Rd & 2,900 & 2,100 & $71 \%$ \\
\hline & 7070 McLaughlin Rd & 3,200 & 1,900 & $58 \%$ \\
\hline & 6085 Creditview Rd & 4,400 & 2,500 & $56 \%$ \\
\hline & 1250 South Service Rd & 13,400 & 10,100 & $75 \%$ \\
\hline \multirow{6}{*}{$\begin{array}{c}\text { Food Basics } \\
\text { Branches }\end{array}$} & 3476 Glen Erin Dr & 3,100 & 2,300 & $73 \%$ \\
\hline & 377 Burnhamthorpe Rd E & 3,200 & 2,100 & $67 \%$ \\
\hline & 2550 Hurontario St & 3,000 & 2,000 & $67 \%$ \\
\hline & 2425 Truscott Dr & 2,900 & 2,000 & $70 \%$ \\
\hline & 4141 Dixie Rd & 5,300 & 3,700 & $69 \%$ \\
\hline & 7070 Saint Barbara Blvd & 3,700 & 2,500 & $67 \%$ \\
\hline \multirow{6}{*}{$\begin{array}{c}\text { Metro } \\
\text { Branches }\end{array}$} & 910 Southdown Rd & 5,300 & 2,800 & $53 \%$ \\
\hline & 2225 Erin Mills Parkway & 5,100 & 3,100 & $61 \%$ \\
\hline & 1585 Mississauga Valley & 3,400 & 2,300 & $68 \%$ \\
\hline & 3221 Derry Rd W & 4,600 & 3,200 & $69 \%$ \\
\hline & 6677 Meadowvale Town & 4,600 & 3,700 & $81 \%$ \\
\hline & 406 Lakeshore Rd E & 1,800 & 1,300 & $75 \%$ \\
\hline \multirow{5}{*}{$\begin{array}{l}\text { FreshCo } \\
\text { Branches }\end{array}$} & 2500 Hurontario St & 2,600 & 1,800 & $68 \%$ \\
\hline & 6040 Glen Erin Dr & 3,100 & 2,600 & $85 \%$ \\
\hline & 1151 Dundas St W & 3,400 & 1,700 & $52 \%$ \\
\hline & 3100 Dixie Rd & 2,700 & 1,700 & $64 \%$ \\
\hline & 7205 Goreway Dr & 2,800 & 1,500 & $55 \%$ \\
\hline Sobeys & 5602 Tenth Line West & 4,500 & 3,300 & $72 \%$ \\
\hline
\end{tabular}


More than $50 \%$ of medium to small scale supermarkets can utilize their roof space and have extensive green rooftop. Overall, based on Table 9 - more than $60 \%$ of the total gross roof area of all supermarkets in Mississauga can adopt extensive green roof system.

Table 9 - Potential Unoccupied Surface on Studied Rooftops for Extensive Lightweight System

\begin{tabular}{|c|c|c|c|}
\hline & $\begin{array}{c}\text { Total Gross Roof Area } \\
\left(\mathbf{m}^{\mathbf{2}}\right)\end{array}$ & $\begin{array}{c}\text { Available Space for Extensive } \\
\left.\text { Built-up system } \mathbf{( m}^{\mathbf{2}}\right)\end{array}$ & Percentage \\
\hline Large Scale & 32,300 & 18,700 & $58 \%$ \\
\hline Medium Scale & 55,100 & 33,700 & $61 \%$ \\
\hline Small Scale & 41,900 & 29,900 & $71 \%$ \\
\hline All Supermarkets & 129,300 & 82,300 & $63 \%$ \\
\hline
\end{tabular}

As discussed, the lightweight roof structures of existing single-storey supermarkets are not designed to support the extra weight of growing medium exerted from agricultural systems. However, all the building structures in Ontario conform to minimum standards of Ontario .Building .Code. with respect to load capacity and load tolerance. All these structures are designed to support snow loads which is around $1.15 \mathrm{kPa}$ (Calculations are available in Appendix $\mathrm{B}$, Page 89).

The growing season in Ontario starts ten days after the minimum daily temperature stays more than $5^{\circ} \mathrm{C}$ until fall frost when the temperature reaches $0^{\circ} \mathrm{C}$ or October $31^{\text {st }}$ whichever comes first ("Length of Growing Season in Ontario," 2016). So, in the interim, the snow load capacity of structures which is minimum $1.15 \mathrm{kPa}$ can be used to turn rooftops into agricultural fields or urban roof-farms.

Based on Table 4 - Bulk Density of Lightweight Growing Media, ("Growing Medium Specification," n.d.), the bulk density of lightweight agricultural growing medium at maximum saturation is in the range of $960-1,110 \mathrm{~kg} / \mathrm{m}^{3}\left(60-70 \mathrm{lbs} . / \mathrm{ft}^{3}\right)$. Below, the exerted pressure from lightweight agricultural medium in different depths have been calculated and summarized in Table 10. 
Table 10 - Pressure of lightweight agricultural medium in different depth

\begin{tabular}{|c|c|c|c|c|}
\hline \multirow{2}{*}{ Depth } & \multicolumn{2}{|c|}{ Min. Pressure (Dry) } & \multicolumn{2}{c|}{ Max. Pressure (Saturated) } \\
\cline { 2 - 5 } & $\mathbf{~ k P a}$ & $\mathbf{P S F}$ & $\mathbf{~ P P a}$ & $\mathbf{P S F}$ \\
\hline $\mathbf{1 0} \mathbf{~ c m ~ ( 4}$ inch) & 0.4 & 8.3 & 1.11 & 23.3 \\
\hline $\mathbf{1 5} \mathbf{~ c m}$ (6 inch) & 0.6 & 12.5 & 1.67 & 35 \\
\hline $\mathbf{2 0} \mathbf{~ c m}$ (8 inch) & 0.8 & 16.6 & 2.23 & 46.6 \\
\hline $\mathbf{2 5} \mathbf{~ c m ~ ( 1 0 ~ i n c h ) ~}$ & 1 & 20.8 & 2.8 & 58.3 \\
\hline $\mathbf{3 0} \mathbf{~ c m ~ ( 1 2 ~ i n c h ) ~}$ & 1.2 & 25 & 3.35 & 70 \\
\hline $\mathbf{6 1} \mathbf{~ c m ~ ( 2 4}$ inch) & 2.4 & 50 & 6.7 & 140 \\
\hline $\mathbf{9 1} \mathbf{~ c m ~ ( 3 6 ~ i n c h ) ~}$ & 3.6 & 75 & 10.05 & 210 \\
\hline
\end{tabular}

Table 11 - Maximum growing medium load based on plant requirements categorizes the types of vegetation according to their root requirements. Considering the reserved snow load capacity during summer time and Table 10, it is clear that the maximum depth of growing media comes to be around $10 \mathrm{~cm}$ (4 inches). Consequently, diversity of vegetation will be limited to shallow rooting plants listed in the first two columns of Table 11.

Table 11 - Maximum growing medium load based on plant requirements

\begin{tabular}{|c|c|c|c|c|c|}
\hline \multicolumn{4}{|c|}{ Shallow Rooting } & \multirow{2}{*}{$\begin{array}{c}\begin{array}{c}\text { Medium } \\
\text { Rooting }\end{array} \\
61 \mathrm{~cm}\end{array}$} & \multirow{2}{*}{$\begin{array}{c}\text { Deep Rooting } \\
91 \mathrm{~cm}\end{array}$} \\
\hline $10 \mathrm{~cm}$ & $15 \mathrm{~cm}$ & $20 \mathrm{~cm}$ & $25-30 \mathrm{~cm}$ & & \\
\hline $1.11 \mathrm{kPa}$ & $1.67 \mathrm{kPa}$ & $2.23 \mathrm{kPa}$ & $2.8-3.35 \mathrm{kPa}$ & $6.7 \mathrm{kPa}$ & $10.05 \mathrm{kPa}$ \\
\hline Basil & $\begin{array}{c}\text { Asian } \\
\text { Greens }\end{array}$ & Carrots & Arugula & Beans, dry & Artichokes \\
\hline Chives & $\begin{array}{l}\text { Bush } \\
\text { Beans }\end{array}$ & Chard & Beets & Cantaloupe & Asparagus \\
\hline Coriander & Garlic & Cucumber & Broccoli & Carrots & Beans, lima \\
\hline Lettuce & Kohlrabi & Eggplant & Brussels sprouts & Kale & Parsnips \\
\hline \multirow[t]{10}{*}{ Radishes } & Onions & Fennel & Cabbage & Rutabagas & Pumpkins \\
\hline & Mint & Leeks & Cauliflower & Turnips & Rhubarb \\
\hline & Peas & Parsley & Celery & & Sweet potatoes \\
\hline & Thyme & Peppers & $\begin{array}{l}\text { Chinese } \\
\text { cabbage }\end{array}$ & & Tomatoes \\
\hline & & Pole Beans & Corn & & Watermelon \\
\hline & & Rosemary & Endive & & Winter Squash \\
\hline & & Spinach & Okra & & \\
\hline & & & Potatoes & & \\
\hline & & & Strawberries & & \\
\hline & & & $\begin{array}{l}\text { Summer } \\
\text { Squash }\end{array}$ & & \\
\hline
\end{tabular}


As an example, Figure 21 and Figure 22 illustrate the potential areas that can be used for agricultural purposes on two supermarkets that have been studied in Mississauga. Almost the entire unoccupied roof can be used for extensive $10 \mathrm{~cm}$ agricultural purposes during summer time. (Refer to Appendix D, page 91).

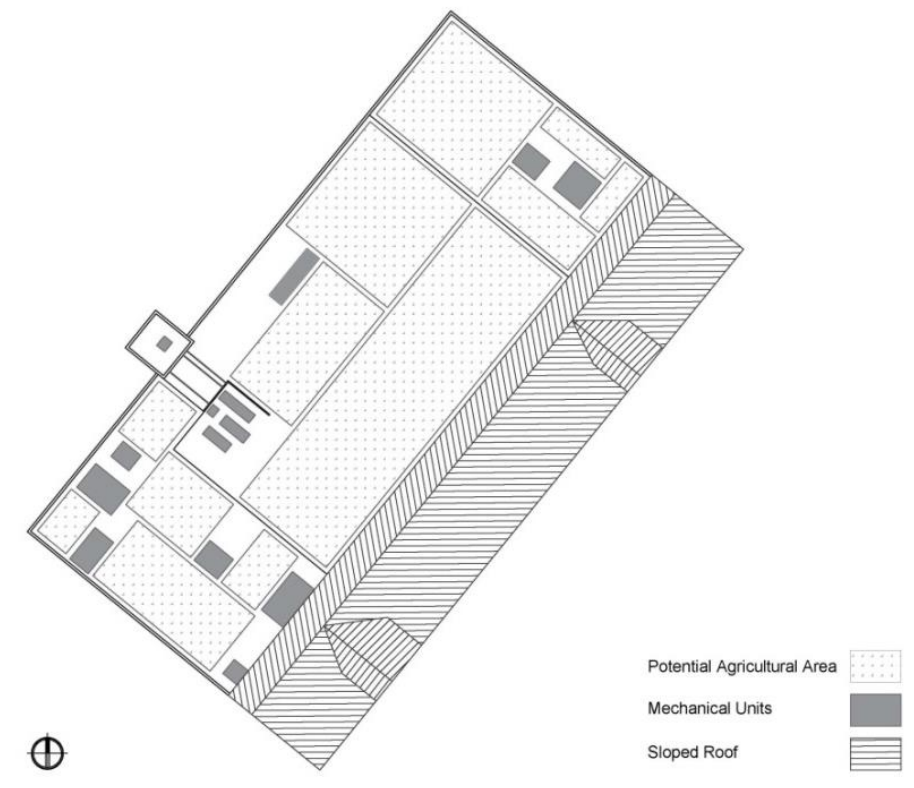

Figure 21 - Potential Agricultural Area for Extensive Seasonal Growing (5010 Glen Erin Drive Mississauga, ON)

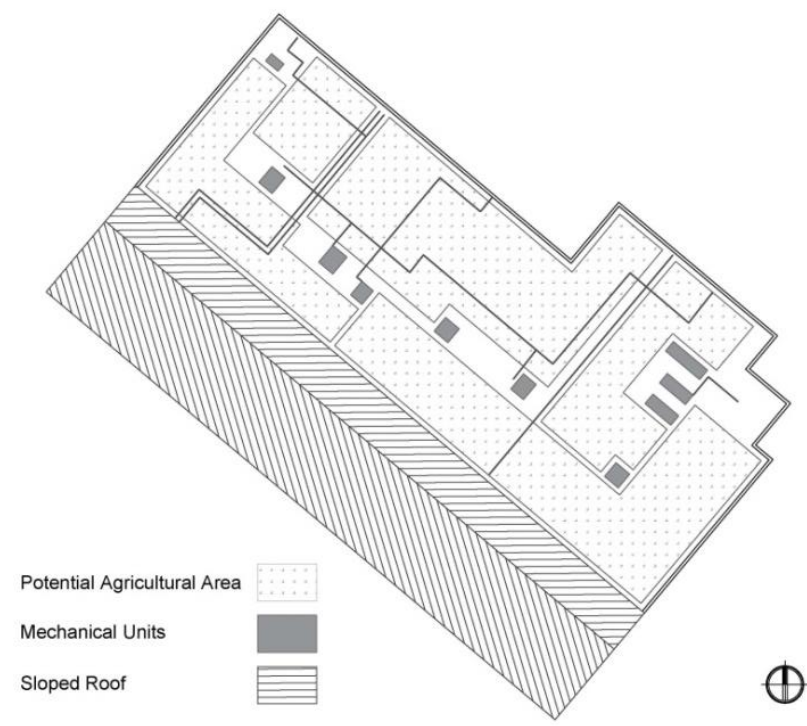

Figure 22 - Potential Agricultural Area for Extensive Seasonal Growing (250 Lakeshore Rd, Mississauga, ON) 
Although about $75 \%$ of the unoccupied rooftop area would be available for agricultural purposes during the summer time, the variety of vegetables are limited mostly due to the depth of the growing media.

In order to enhance and enjoy a variety of crops, combination of intensive and extensive systems should be pursued and be more desirable. In the following, the practicality of positioning intensive systems on structural elements has been analyzed.

Each column is responsible to transfer both dead loads and live loads within its tributary area. Working with that capacity, the idea is to convert the distributed snow load within a tributary area to less distributed and more functional concentrated load within that same tributary area. In other words, the idea will be to calculate the total distributed snow load within the tributary area of each column and use that towards the design of the planting/growing areas layout and depth (Refer to Appendix C, Page 90). The re-distribution of loads will be managed by two functions: vertical load allowance of steel deck with its supporting joists and engineering/composition of the growth media.

Vertical load allowance of steel decks is driven by deck profile and minimum span length. This information should be available from the specification and literature by steel deck-joist manufacturer. Further investigation is required to determine the exact nature of implementation.

Engineering and composition of the growth media is achieved through services of a consultant and/or soil manufacturer. Engineered soil can be made lighter through decrease in mineral components and increase in compost and organic ingredients of the blend in a way to not compromise the efficiency of the mix. This custom design and weight adjustment is essential to remain within the load capacity of the steel deck where higher planter depth is required on the roof. 
For example, the total snow load in tributary area of columns in $10 \mathrm{~m} \times 10 \mathrm{~m}$ grid layout is calculated as below:

- Snow load in Tributary Area of Middle Columns:

$100 \mathrm{~m}^{2} \times 1.15 \mathrm{kPa}=115 \mathrm{kPa}$

- Snow load in Tributary Area of Side Columns:

$50 \mathrm{~m}^{2} \times 1.15 \mathrm{kPa}=58 \mathrm{kPa}$

- Snow load in Tributary Area of Corner Columns:

$25 \mathrm{~m}^{2} \times 1.15 \mathrm{kPa}=27 \mathrm{kPa}$

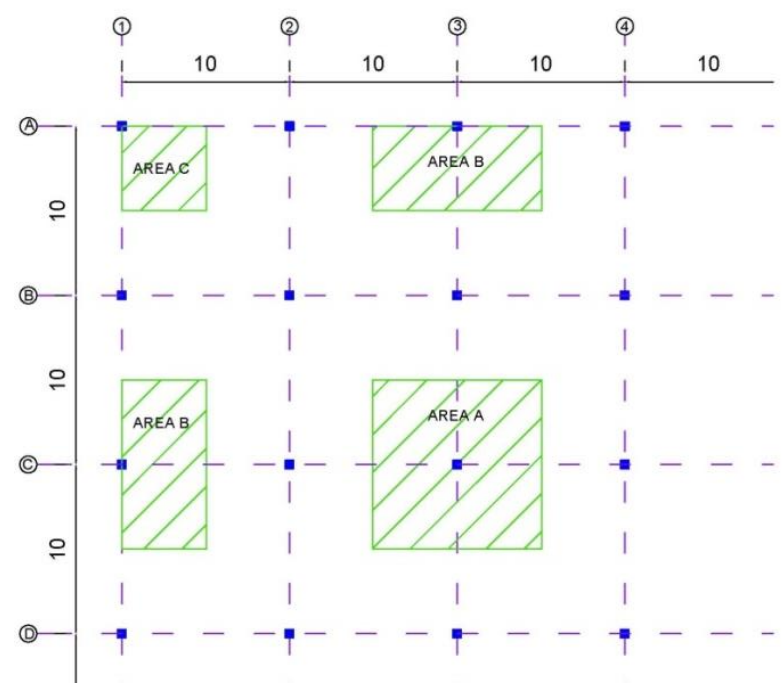

Figure 23 - Columns Tributary Area

The above calculations reveal the maximum snow load capacity during summer time which can be utilized toward the implementation of desired growing methods. Since it was found that supermarket grids layout is in the range of 9 to 13 meters, the limitation of snow weight in different layout plans has also been calculated and summarized in Table 12 - Snow Weight in Tributary Area12.

Table 12 - Snow Weight in Tributary Area

\begin{tabular}{|c|c|c|c|}
\hline \multirow{2}{*}{ Span $\mathrm{m}(\mathrm{ft})$} & \multicolumn{3}{|c|}{ Snow weight in Tributary Area kg (lbs.) } \\
\hline & Middle Columns & Side Columns & Corner Columns \\
\hline $9 * 9(30 \star 30)$ & $10,560(23,280)$ & $5,340(11,775)$ & $2,610(5,750)$ \\
\hline $10 * 10(33 * 33)$ & $13,030(28,730)$ & $6,515(14,365)$ & $3,270(7,210)$ \\
\hline $11 * 11(36 * 36)$ & $15,775(34,775)$ & $7,890(17,390)$ & $3,950(8,705)$ \\
\hline $12 * 12(39 * 39)$ & $18,770(41,385)$ & $9,390(20,700)$ & $4,700(10,360)$ \\
\hline $13^{\star} 13\left(43^{\star} 43\right)$ & $48,570(107,070)$ & $1,1020(24,300)$ & $5,510(12,150)$ \\
\hline
\end{tabular}


Growing Method 1. Table 13 illustrates the gross roof area of each

supermarket, as well as the potential area for $20 \mathrm{~cm}$ (8 inch) intensive and $40 \mathrm{~cm}$

(16 inch) deep systems. This method consists of portable earth-boxes (Figure 16 -

Earth-Box Section) filled with engineered soil and selected plant species (Refer to

Table 11). These earth-boxes can be overlaid by a network of drip lines for

watering in hot months. Not considering the tributary area of side and corner

columns, rooftop area suitable for vegetation and intensive systems still appear

to be less than $32 \%$.

Table 13 - Potential available Area on Studied Rooftops for Intensive System

\begin{tabular}{|c|c|c|c|c|c|}
\hline Location & $\begin{array}{c}\text { Total Gross } \\
\text { Roof Area }\left(\mathbf{m}^{2}\right)\end{array}$ & $\begin{array}{c}20 \mathrm{~cm} \text { Intensive } \\
\text { System }\left(\mathrm{m}^{2}\right)\end{array}$ & Percentage & $\begin{array}{c}40 \mathrm{~cm} \text { Intensive } \\
\text { System }\left(\mathrm{m}^{2}\right)\end{array}$ & Percentage \\
\hline 5010 Glen Erin Dr. & 10,800 & 1,900 & $18 \%$ & 950 & $9 \%$ \\
\hline 5970 Mclughlin Rd & 8,000 & 1,400 & $18 \%$ & 700 & $9 \%$ \\
\hline 250 Lakeshore Rd & 4,100 & 600 & $16 \%$ & 300 & $9 \%$ \\
\hline 925 Rathburn Rd E & 4,400 & 1,400 & $32 \%$ & 700 & $16 \%$ \\
\hline 2150 Burnhamthorpe Rd W & 4,600 & 800 & $18 \%$ & 400 & $10 \%$ \\
\hline 620 Eglinton Ave W & 5,300 & 1,000 & $19 \%$ & 500 & $9 \%$ \\
\hline 6465 Erin Mills & 3,100 & 400 & $16 \%$ & 200 & $8 \%$ \\
\hline 4040 Creditview Rd & 2,900 & 400 & $16 \%$ & 200 & $8 \%$ \\
\hline 7070 McLaughlin Rd & 3,200 & 500 & $15 \%$ & 250 & $8 \%$ \\
\hline 6085 Creditview Rd & 4,400 & 900 & $20 \%$ & 450 & $10 \%$ \\
\hline 1250 South Service Rd & 13,400 & 3,300 & $25 \%$ & 1,700 & $12 \%$ \\
\hline 3476 Glen Erin Dr & 3,100 & 500 & $16 \%$ & 250 & $8 \%$ \\
\hline 377 Burnhamthorpe Rd E & 3,200 & 700 & $20 \%$ & 350 & $10 \%$ \\
\hline 2550 Hurontario St & 3,000 & 600 & $20 \%$ & 300 & $10 \%$ \\
\hline 2425 Truscott Dr & 2,900 & 600 & $20 \%$ & 300 & $10 \%$ \\
\hline 4141 Dixie Rd & 5,300 & 900 & $17 \%$ & 450 & $9 \%$ \\
\hline 7070 Saint Barbara Blvd & 3,700 & 900 & $23 \%$ & 450 & $12 \%$ \\
\hline 910 Southdown Rd & 5,300 & 800 & $15 \%$ & 400 & $8 \%$ \\
\hline 2225 Erin Mills Parkway & 5,100 & 1,300 & $25 \%$ & 650 & $13 \%$ \\
\hline 1585 Mississauga Blvd & 3,400 & 700 & $20 \%$ & 350 & $10 \%$ \\
\hline 3221 Derry Rd W & 4,600 & 1,300 & $28 \%$ & 650 & $14 \%$ \\
\hline 6677 Meadowvale Circle & 4,600 & 1,100 & $23 \%$ & 550 & $12 \%$ \\
\hline 406 Lakeshore Rd E & 1,800 & 450 & $26 \%$ & 200 & $13 \%$ \\
\hline 2500 Hurontario St & 2,600 & 600 & $25 \%$ & 300 & $13 \%$ \\
\hline 6040 Glen Erin Dr & 3,100 & 800 & $25 \%$ & 400 & $13 \%$ \\
\hline 1151 Dundas St W & 3,500 & 800 & $24 \%$ & 400 & $12 \%$ \\
\hline 3100 Dixie Rd & 2,700 & 600 & $24 \%$ & 300 & $12 \%$ \\
\hline 7205 Goreway Dr & 2,800 & 600 & $21 \%$ & 300 & $11 \%$ \\
\hline 5602 Tenth Line West & 4,500 & 1,100 & $23 \%$ & 550 & $12 \%$ \\
\hline
\end{tabular}


Figure 24 and Figure 25 illustrate the layout for $20 \mathrm{~cm}$ and $40 \mathrm{~cm}$ intensive systems as examples. (Refer to Appendix D (page 91), for proposed layouts on reviewed cases.)

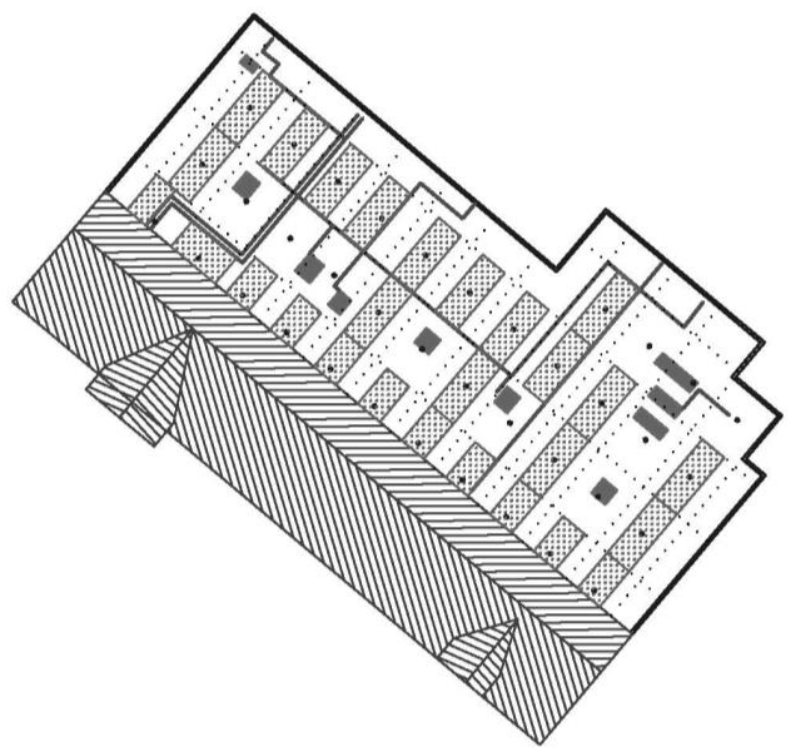

Potential Area for $20 \mathrm{~cm}$ Intensive Assembly

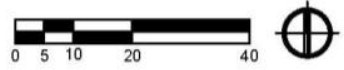

Figure 24 - Potential Agricultural Area for Intensive $20 \mathrm{~cm}$ Seasonal Growing (5970 Mclaughlin, Rd, and Mississauga, ON)

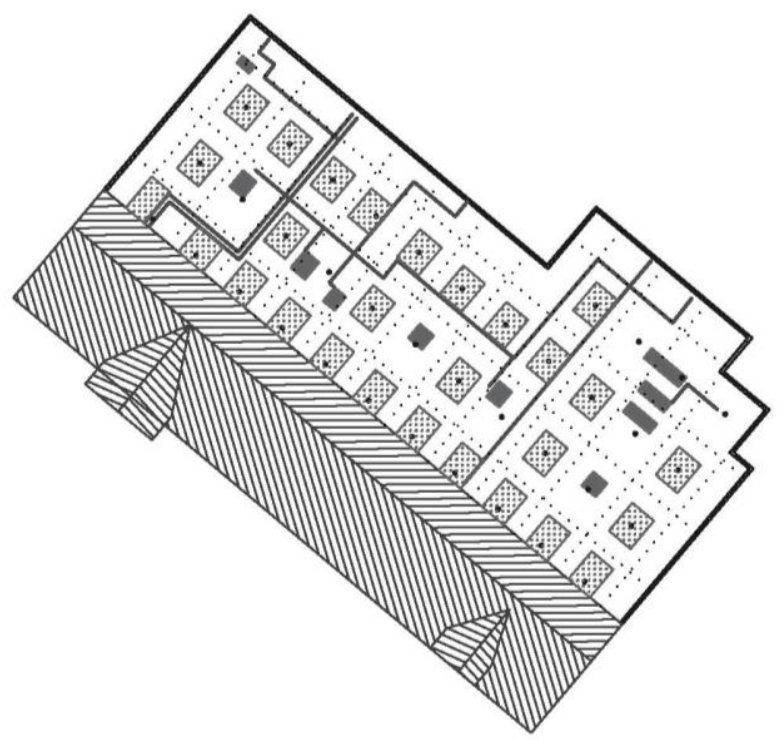

Potential Area for $40 \mathrm{~cm}$ Intensive Assembly

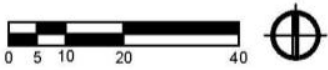

Figure 25 - Potential Agricultural Area for Intensive $40 \mathrm{~cm}$ Seasonal Growing (5970 Mclaughlin, Rd, and Mississauga, ON) 
Growing Method 2. Hydroponic system is another identified growing method. The system is recognized as a commercial scale lightweight system which weighs approximately $13.8 \mathrm{~kg} / \mathrm{m}$. The flexibility of design in hydroponic system provides the opportunity to meet the building's snow load capacity. In other words, the spacing between the PVC pipes can be arranged in a way to meet the available capacity of the structure.

Since the major and heavy components of this system are the nutrient fluid and vegetables, which are absent in winter time, the weight of the rest of assembly is approximately $1-1.3 \mathrm{~kg} / \mathrm{m} \mathrm{(2} \mathrm{-} 3 \mathrm{lbs} / \mathrm{ft})$.

Although clearance around the mechanical units should be considered, existing pipes on rooftops would not interfere with this system. Therefore all the available area for $6 \mathrm{~cm}$ extensive system would serve as a site for hydroponic system set up (Table 8). It is worth mentioning that wind uplift tests should be analyzed for this system.

Growing Method 3. Another growing method that has been explored is to set up a metal structure with hang planters. This supporting structure can be attached/fastened permanently or temporarily to the main structural columns of the building to transfer the loads directly to the ground. This system can be combined with seasonal intensive planters to grow vines. 


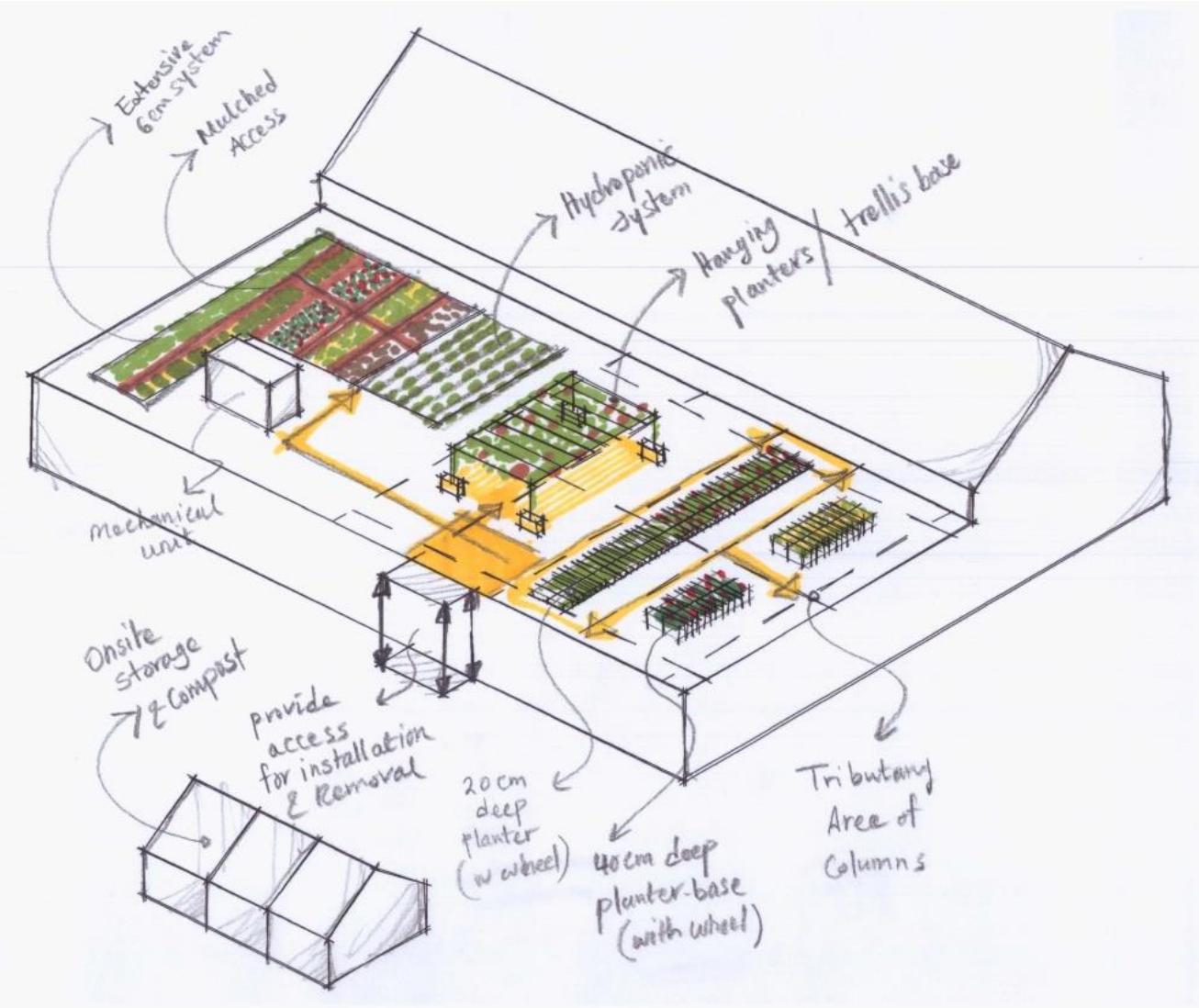

Figure 26 - Schematic Idea of Utilizing Supermarket Rooftops for Food Production

\section{7-2 System Installation \& Removal}

It is very important to consider and plan for the installation, removal and maintenance of the seasonal agricultural rooftops in advance and during the design phase. The following steps explain the general ideas about this process in this research; however, this process is very complicated and demands additional studies and exploration in other research projects especially in the field of project management.

Once the roof structure is analyzed and the tributary of columns, and the extent around columns where roof can receive system loads, is determined then the layout of the planted areas are decided. The shapes of planted areas are usually considered to be square or rectangle for compatibility with the standard shape of components and ease of installation. 
The walkways and circulation between planting zones should develop and connect to the existing walkways or maintenance paths on the roof.

Once planting areas and walkways are demarcated, the underneath of planting areas must be covered with plastic (Polyethylene) root resistance layer. This layer, which sits directly on the membrane, will protect the waterproofing layer against root invasion and consequent leak problems. This layer comes in rolls and gets attached to the membrane through weather-resistant adhesives. Since the weight of this layer is negligible, around $210 \mathrm{~g} / \mathrm{m}^{2}$ (Tremco, 2016), it can stay on the roof during winter time, which can be representative of vegetated area for the following year as well. Since the access to the roofs is through roof hatches, access from outside for installation and removal process is required. This access can be provided temporary, twice a year by hiring a crane or a rental scissor lift; or permanent through purchasing a scissor lift or similar equipment. The permanent option is more desirable since the lift can be used to transfer yields as well.

The next component above the root barrier and essential to system performance and plants' yield is water retention/drainage layer. This 10 centimeter layer collects excess water from rainfall or irrigation prevents plants from wilting. In an extensive system approach, this component is usually a rolled plastic (Polystyrene, Polypropylene, etc.) material with water reservoirs formed during the manufacturing process to retain water. Each section can be identified with a number so that removed rolls can be re-used in their same place in the next season. In a planter system approach, this retention/drainage layer is integrated into the design of the planter. Due to the compact all-in-one design of planters, this system is easier to install and remove whereas in an extensive system layers have to be installed and removed individually.

Lightweight soil is delivered and installed either from super bags or via pump trucks. However, for removal and storage over the winter, it has to be bagged if not contained in planters. The planters will be removed and stored as a whole unit, whereas in an extensive system growing medium will be bagged and 
removed similar to other layers. The recycled bags may be sent to a compost processing center or stored on-site in compost bins to be enriched and ready for the next season.

For maintenance, both hand watering and automatic irrigation can be adopted for these systems. To install the automatic irrigation system, skilled labor is required in the first year, and can be operated with general labor within the following years.

It is clear that each method has its own advantages and disadvantages when it comes to installation, operation and removal. Moreover, production capacity and installation and removal cost depends directly on the growing method as well. Due to the timeline and level of complexity, further future research on this issue is required. 


\section{8- CONCLUSIONS}

The possibility of turning existing supermarket rooftops to productive rooftops without structural improvements has been explored through studying the roof morphology of 31 supermarkets in Mississauga. Case study method has been adapted to study the structure and characteristics of these rooftops. Growing requirements information for Ontario's native vegetable including, root size and their space requirement at mature size has been gathered from the literature. Moreover, the growing methods on urban rooftops have been explored through reviewing the cases with commercial scale productive rooftops.

The findings indicated that all supermarkets have a reasonable size, lowsloped rooftop suitable for growing purposes. The layout of mechanical units and piping, access to the roof, lightweight roof structure and load bearing capacity were found to be the main restrictions. As a solution to the restricted load bearing capacity of supermarkets, seasonal growing was proposed. The absence of snow load in summer time provides an opportunity to accommodate the extra load exerted from agricultural assemblies to turn the underutilized summer rooftops into productive organic food resource for the community. The analysis of findings approves the possibility of seasonal growing through different methods. The available area for different methods have been calculated based on rooftop drawings which are available in Appendix D (page 91).

The results indicated that, more than $60 \%$ of the rooftops are available to adopt $6 \mathrm{~cm}$ lightweight extensive system or hydroponic system for seasonal growing. In order to increase the variety of vegetables, intensive planterbased system was proposed. Based on calculating the tributary area of reviewed supermarkets, it was found that around $20 \%$ of rooftop areas can adopt planter-based system with 20 centimeters of growing media. This percentage reduces to $10 \%$ if the growing medium depth increases to 40 centimeters. 
It should be noted that while an extensive system accommodates smaller varieties vegetables in a shallower depth, it can provide more surface area for planting purposes which means more opportunity in the amount of produce. Planter-based systems, on the other hand, can provide more plant diversity, however, due to load restriction; less surface area is available for this system. Installation and maintenance in the spring and removal for winter time was found to be a complex process out the scope of this project.

Overall, based on the finding analysis of this research, it appears that seasonal growing on existing supermarket rooftops is possible. Different growing methods were proposed and available space for each method has been calculated and analyzed. However, due to the timeline and scope of this project, it was not possible to explore the installation, removal and storage process. The complexity of this process requires a project management approach. In addition to logistical issues, the feasibility of cost and also production capacity are other future researches that could expand upon this study. 


\section{APPENDIX A: Characteristics of Supermarkets}

The chain supermarkets in Mississauga are operating under three main corporations, including Loblaw's Companies, Metro Inc and Sobeys. These three major companies are operating Loblaw's and Nofrills, Merto and Food Basics, and Sobeys and FreshCo respectively.

The data used in "Method" section are the summary of gathered observations for above-listed supermarkets in Mississauga.

\section{Loblaw Companies}

\section{1- Loblaws}

Overall 4 branches are identified in Mississauga which are listed in the following table:

Table 14 - Loblaw's Branches in Mississauga

\begin{tabular}{|c|l|}
\hline Loblaws & Locations \\
\hline $\mathbf{1}$ & 5010 Glen Erin Drive Mississauga, ON L5M 6J3 \\
\hline $\mathbf{2}$ & 250 Lakeshore Rd W, Port Credit, ON L5H 1G6 \\
\hline $\mathbf{3}$ & 5970 Mclaughlin, Road, Mississauga, ON L5R 3X9 \\
\hline $\mathbf{4}$ & 3045 Mavis Rd, Mississauga, ON L5B 4M3 \\
\hline
\end{tabular}

Google Maps satellite mode was used to identify unoccupied rooftops and check if these stores are located in dense urban areas or surrounded by taller buildings.

Figure 27 shows locatin of the buildings within its site.
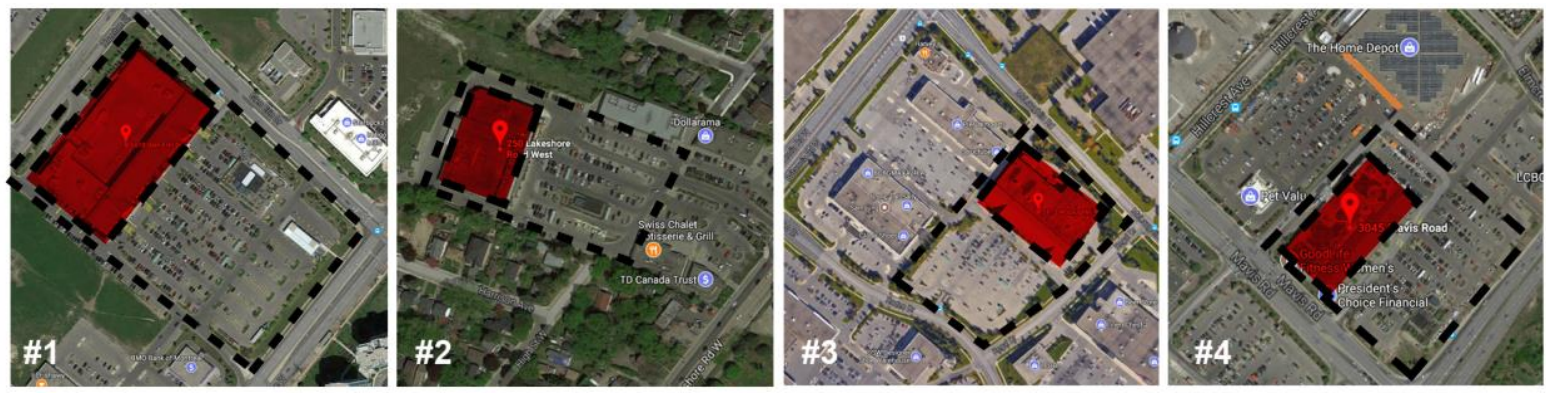

Figure 27 - Loblaws Branches in Mississauga

Generally, 3 stores have similar roof morphology. However except one rooftop which was occupied with photovoltaic panels, the main obstacle on the rest 
rooftops was found to be mechanical units and associated piping. Figure 28 to Figure 31 illustrate the roof morphology of lablaws stores in Mississauga.

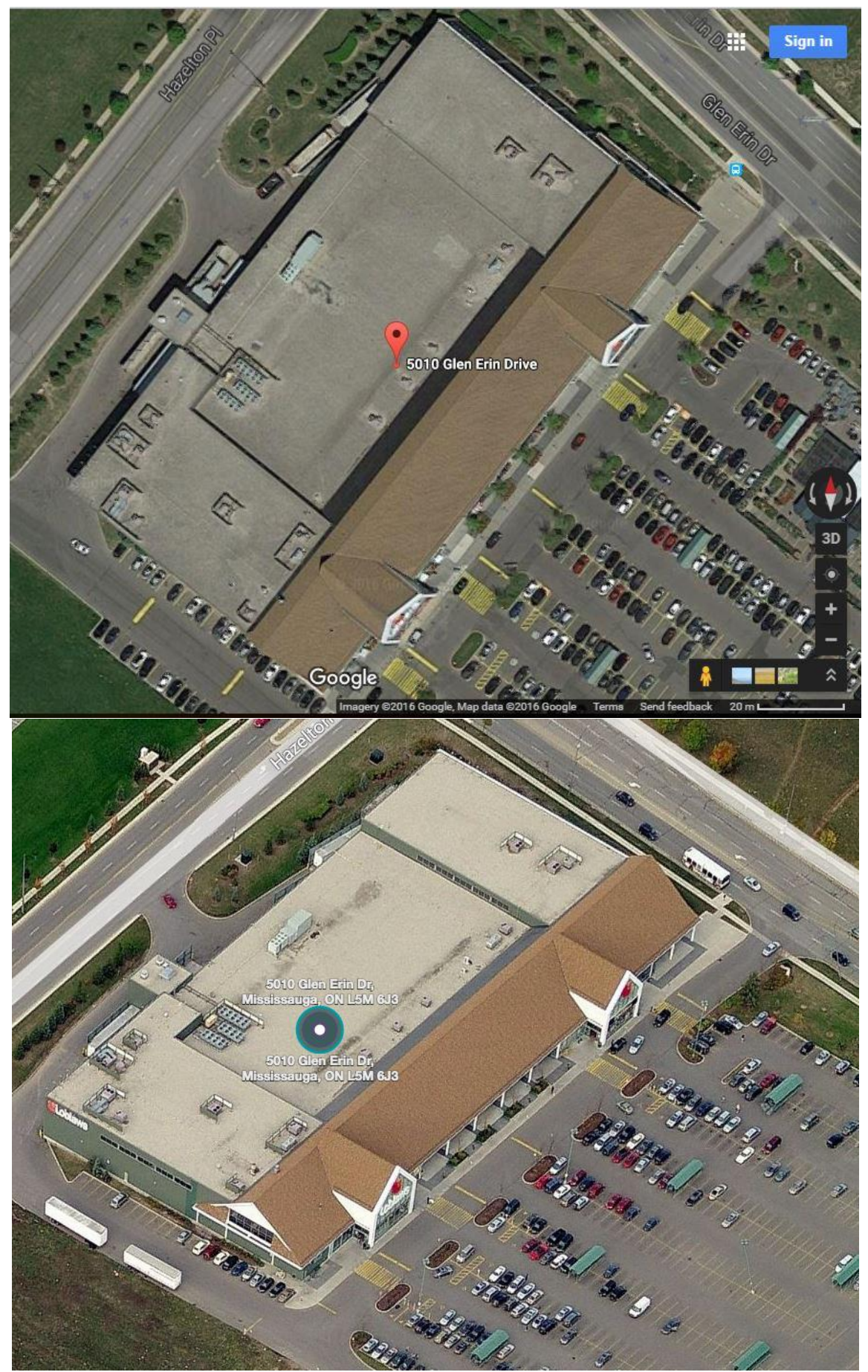

Figure 28 - Loblaws at 5010 Glen Erin Drive Mississauga, ON 


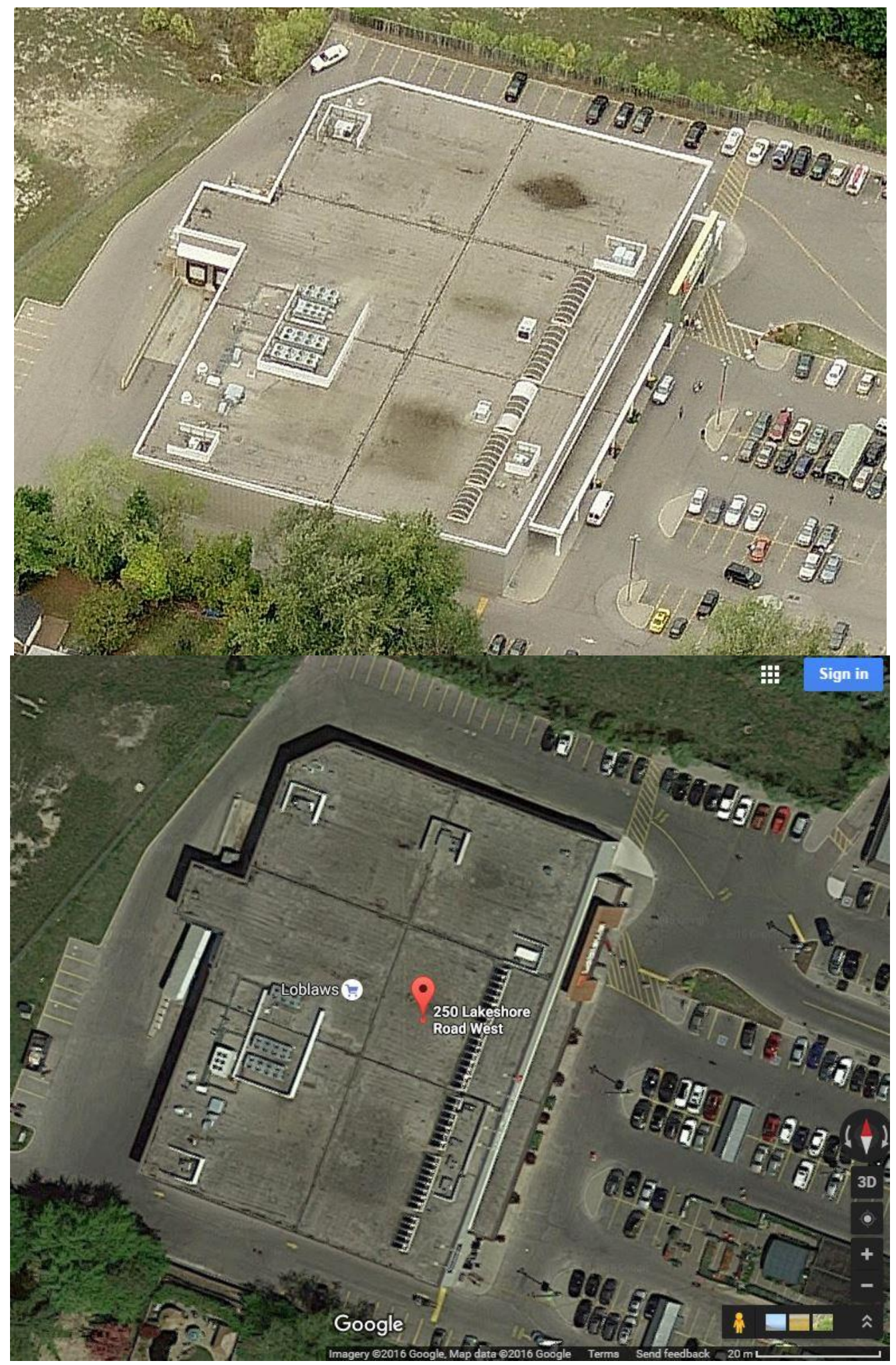

Figure 29 - Loblaws at 250 Lakeshore Rd W, Port Credit, ON 


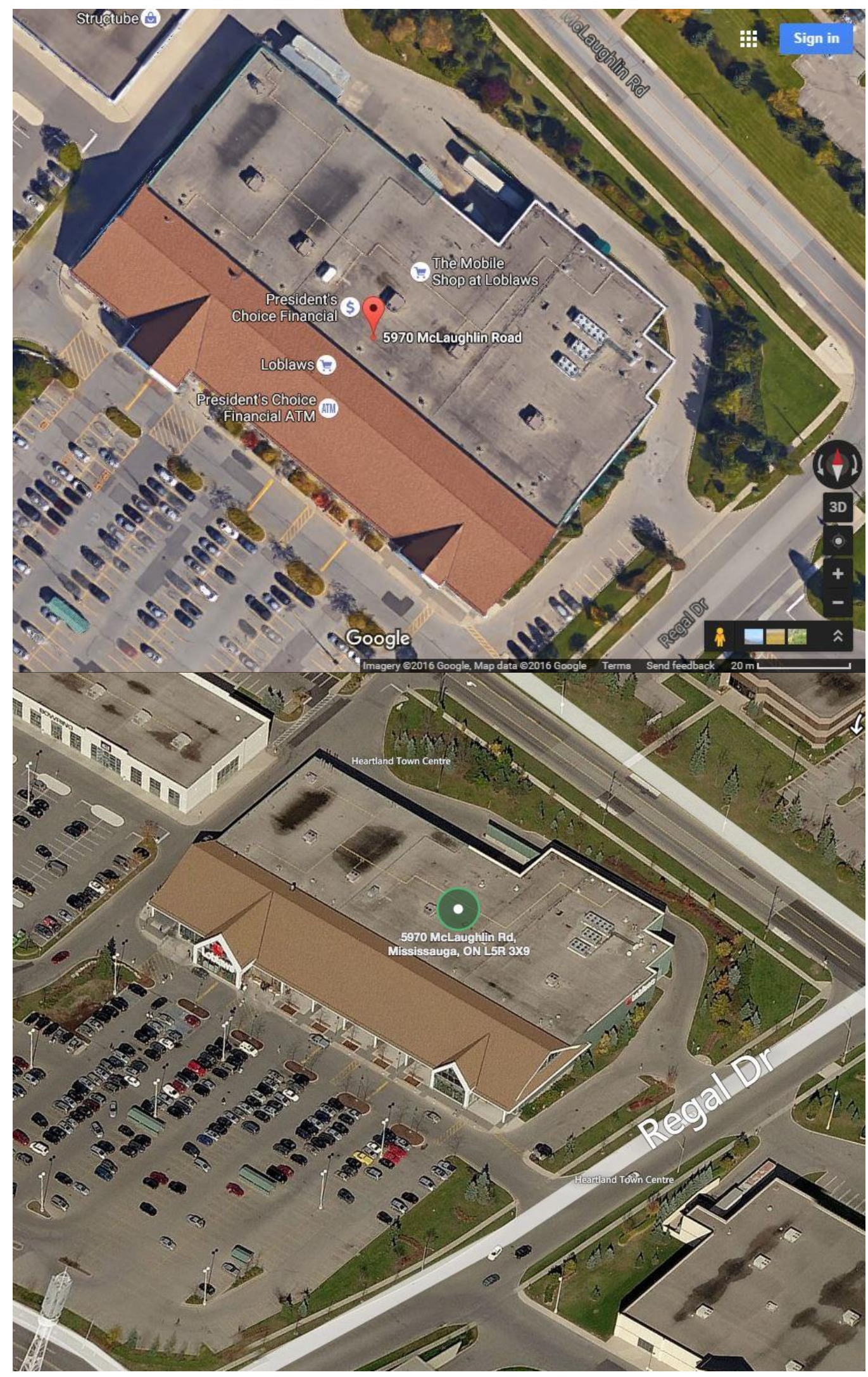

Figure 30 - Loblaws at 5970 Mclaughlin, Road, Mississazauga, ON 


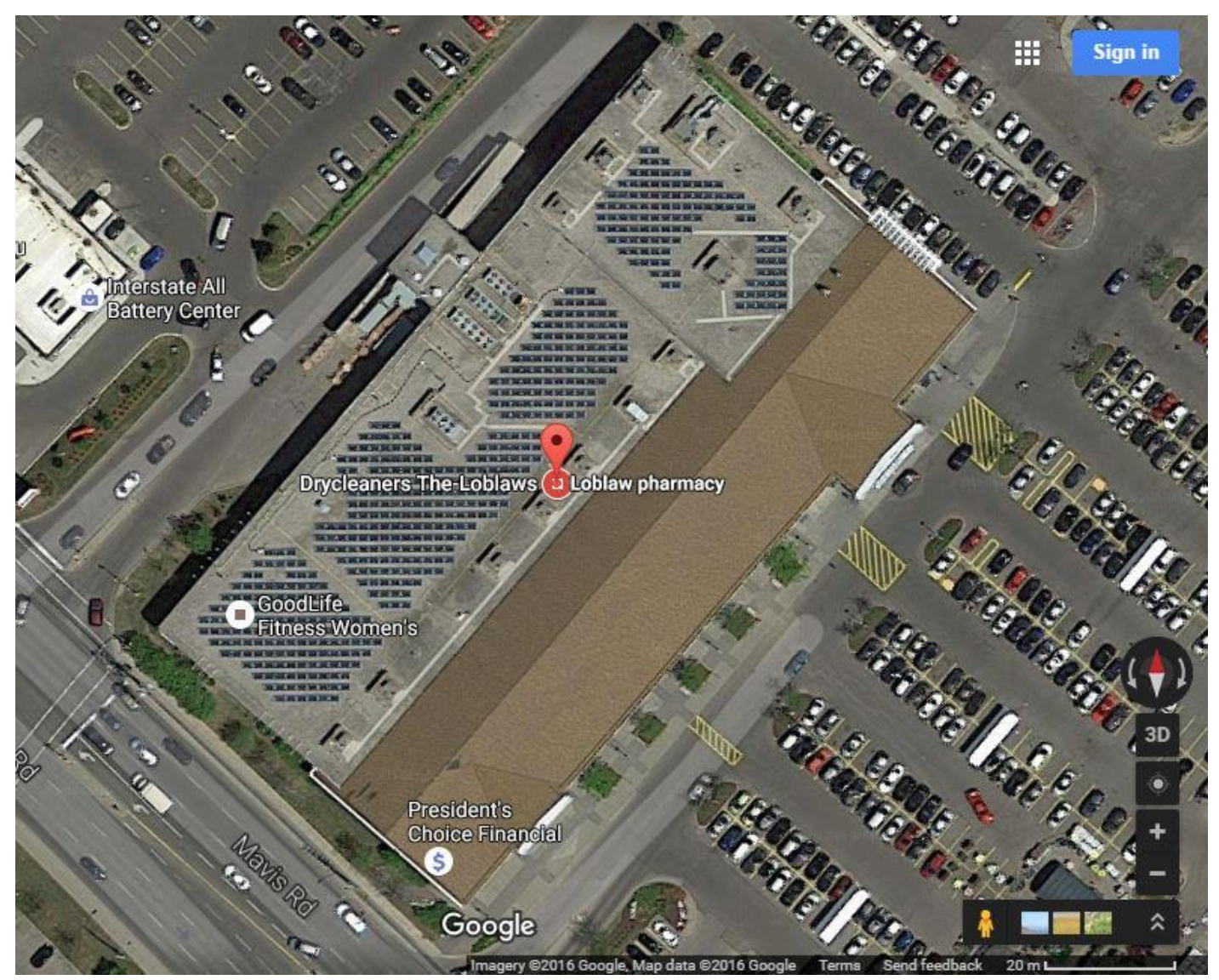

Figure 31 - Loblaws at 3045 Mavis Rd, Mississauga, ON

The other data generated from auto cad are summarized in Table 15.

Table 15 - Data Summary of Loblaws Branches in Mississauga

\begin{tabular}{|c|c|c|c|c|c|c|c|c|}
\hline \multicolumn{2}{|c|}{ Loblaws Branch } & $\begin{array}{c}\text { Total } \\
\text { Groos } \\
\text { Area } \\
\left(\mathbf{m}^{2}\right)\end{array}$ & $\begin{array}{c}\text { Sloped } \\
\text { Portion } \\
\%\end{array}$ & $\begin{array}{c}\text { Mechanical } \\
\text { Area }\left(\mathbf{m}^{2}\right)\end{array}$ & $\begin{array}{c}\text { Unoccupied } \\
\text { Area }\left(\mathbf{m}^{2}\right)\end{array}$ & Orientation & $\begin{array}{c}\text { Roof } \\
\text { Levels }\end{array}$ & $\begin{array}{c}\text { Approximate } \\
\text { Height (m) }\end{array}$ \\
\hline $\mathbf{1}$ & $\begin{array}{c}\mathbf{5 0 1 0} \text { Glen Erin } \\
\text { Dr. }\end{array}$ & 10,840 & $30 \%$ & 195 & 10,645 & NE-SW & 3 & $8.4-9.8$ \\
\hline $\mathbf{2}$ & $\begin{array}{c}\mathbf{2 5 0} \text { Lakeshore } \\
\text { Rd }\end{array}$ & 4,120 & $0 \%$ & 125 & 3,995 & NE-SW & 1 & 8.2 \\
\hline $\mathbf{3}$ & $\begin{array}{c}\mathbf{5 9 7 0} \text { Mclughlin } \\
\text { Rd }\end{array}$ & 8,035 & $36 \%$ & 110 & 5,040 & NW-SE & 1 & 8.4 \\
\hline $\mathbf{4}$ & $\mathbf{3 0 4 5}$ Mavis Rd & 7,820 & $38 \%$ & 325 & $\begin{array}{c}\text { N/A } \\
\text { (PV Panels) }\end{array}$ & NE-SW & 2 & $8.4-9.8$ \\
\hline
\end{tabular}

\section{2- NoFrills}

Overall, 9 NoFrills branches exist in Mississauga which are listed in the table below: 
Table 16 - NoFrills Branches in Mississauga

\begin{tabular}{|c|l|}
\hline NoFrills & Locations \\
\hline $\mathbf{1}$ & 925 Rathburn Rd E, Mississauga, ON L4W 4C3 \\
\hline $\mathbf{2}$ & 2150 Burnhamthorpe Rd W, Mississauga, ON L5L 5Z5 \\
\hline $\mathbf{3}$ & 6620 Eglinton Ave W, Mississauga, ON L5R 3V2 \\
\hline $\mathbf{4}$ & 66465 Erin Mills Pkwy, Mississauga, ON L5N 4H4 \\
\hline $\mathbf{5}$ & 99 Lakeshore Rd E, Mississauga, ON L5G 1E2 \\
\hline $\mathbf{6}$ & 4040 Creditview Rd, Mississauga, ON L5C 3Y8 \\
\hline $\mathbf{7}$ & 7070 McLaughlin Rd, Mississauga, ON L5W 1W7 \\
\hline $\mathbf{8}$ & 6085 Creditview Rd, Mississauga, ON L5V 2A8 \\
\hline $\mathbf{9}$ & 1250 S Service Rd, Mississauga, ON L5E 1V4 \\
\hline
\end{tabular}

The satellite mode revealed all of the branches have low-sloped rooftops and only host mechanical units.
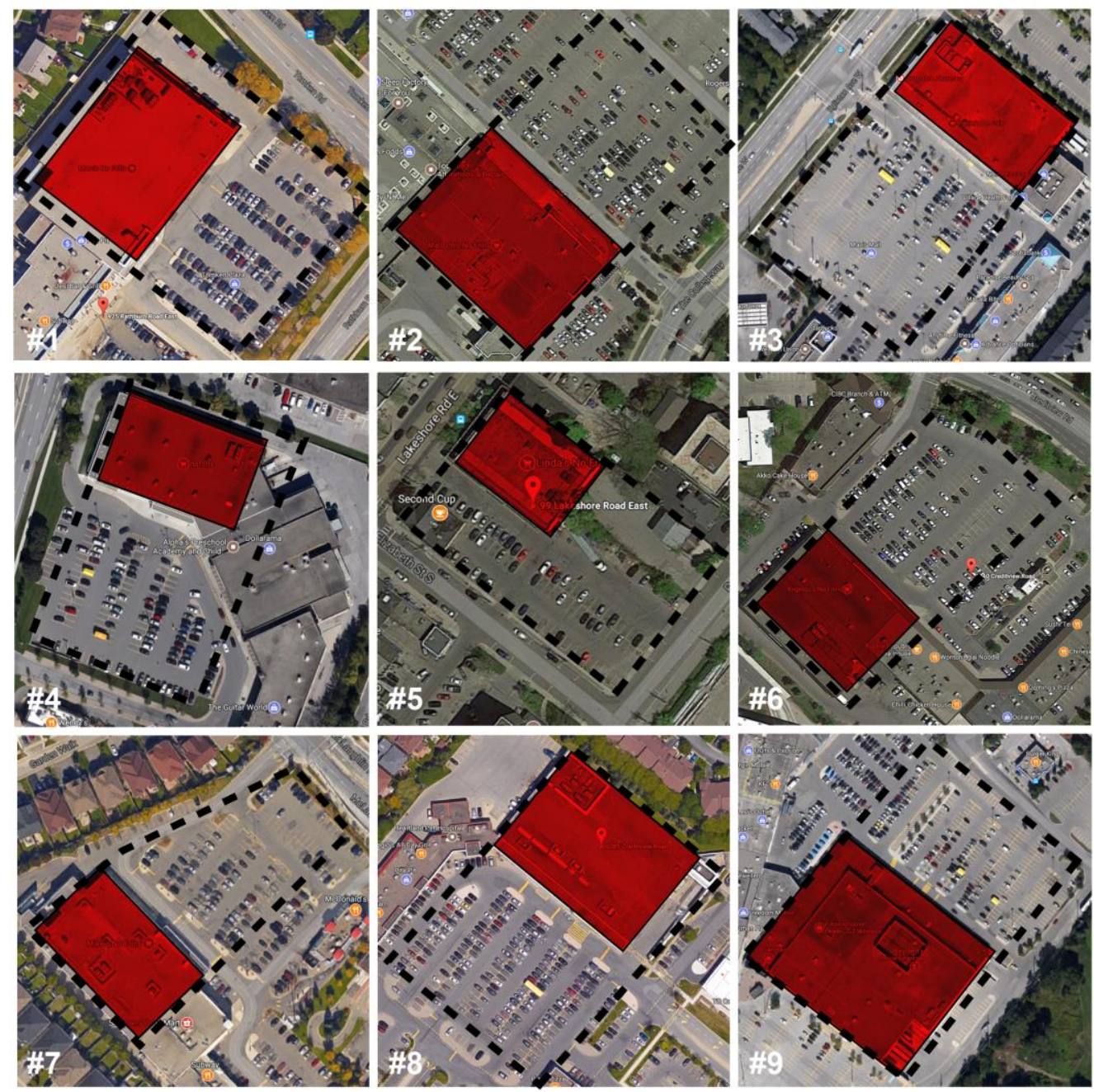

Figure 32 - NoFrills Branches in Mississauga 
It was found during the site visit that the structure of the store located at 99 Lakeshore Rd East is traditional load bearing masonry system therefore is not included in this paper. The data generated from auto cad is summarized in the table below:

Table 17 - Data Summary of NoFrills Branches in Mississauga

\begin{tabular}{|c|c|c|c|c|c|c|c|c|}
\hline \multicolumn{2}{|c|}{ NoFrills Branch } & \multirow{2}{*}{$\begin{array}{c}\text { Total } \\
\text { Groos } \\
\text { Area } \\
\left(\mathbf{m}^{2}\right)\end{array}$} & \multirow{2}{*}{$\begin{array}{c}\text { Sloped } \\
\text { Portion \% } \\
0 \%\end{array}$} & \multirow{2}{*}{$\begin{array}{c}\text { Mechanical } \\
\text { Area }\left(\mathrm{m}^{2}\right) \\
75\end{array}$} & \multirow{2}{*}{$\begin{array}{c}\text { Unoccupied } \\
\text { Area }\left(\mathbf{m}^{2}\right) \\
3,890\end{array}$} & \multirow{2}{*}{$\begin{array}{c}\text { Orientation } \\
\text { NE-SW }\end{array}$} & \multirow{2}{*}{$\begin{array}{c}\begin{array}{c}\text { Roof } \\
\text { Levels }\end{array} \\
1\end{array}$} & \multirow{2}{*}{$\begin{array}{c}\text { Approximate } \\
\text { Height (m) } \\
8.2\end{array}$} \\
\hline 1 & $\begin{array}{c}\text { 925 Rathburn Rd } \\
\text { E }\end{array}$ & & & & & & & \\
\hline 2 & $\begin{array}{c}2150 \\
\text { Burnhamthorpe } \\
\text { Rd W }\end{array}$ & 4,555 & $0 \%$ & 100 & 4,455 & NW-SE & 1 & 8.2 \\
\hline 3 & $\begin{array}{c}620 \text { Eglinton Ave } \\
\text { W }\end{array}$ & 5,330 & $0 \%$ & 110 & 5,220 & NW-SE & 1 & 8.2 \\
\hline 4 & 6465 Erin Mills & 3,070 & $0 \%$ & 102 & 2,970 & NW-SE & 1 & 7 \\
\hline 5 & $\begin{array}{l}4040 \text { Creditview } \\
\text { Rd }\end{array}$ & 2,930 & $0 \%$ & 60 & 2,820 & NW-SE & 1 & 7 \\
\hline 6 & $\begin{array}{c}7070 \text { McLaughlin } \\
\text { Rd }\end{array}$ & 3,180 & $0 \%$ & 80 & 3,100 & NW-SE & 1 & 7 \\
\hline 7 & $\begin{array}{l}6085 \text { Creditview } \\
\text { Rd }\end{array}$ & 4,355 & $0 \%$ & 88 & 4,145 & NW-SE & 1 & 8 \\
\hline 8 & $\begin{array}{l}1250 \text { South } \\
\text { Service Rd }\end{array}$ & 13,405 & $0 \%$ & 140 & 13,265 & NW-SE & 2 & $8-11.8$ \\
\hline
\end{tabular}




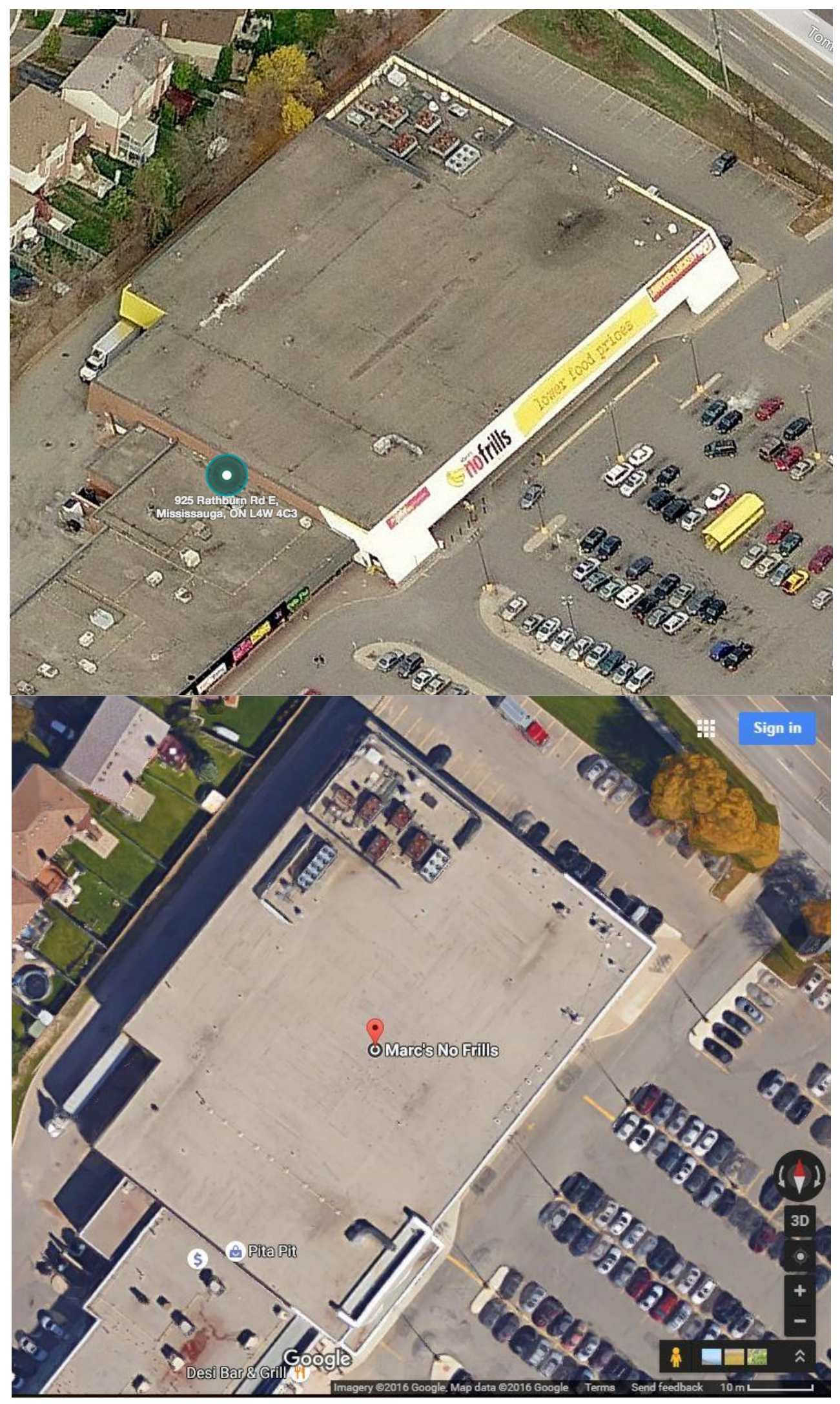

Figure 33 - NoFrills at 925 Rathburn Rd E 


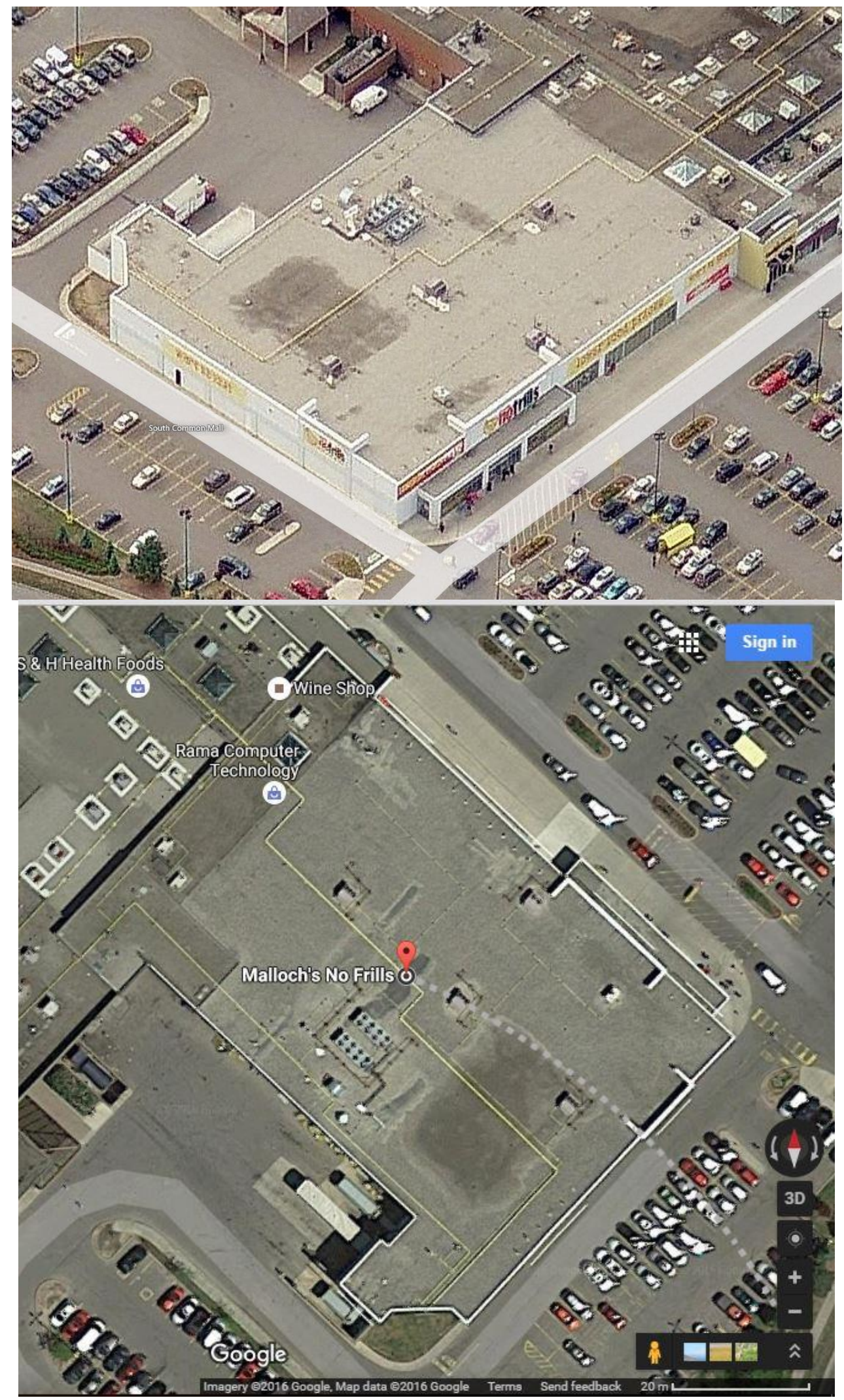

Figure 34 - NoFrills at 2150 Burnhamthorpe Rd W 


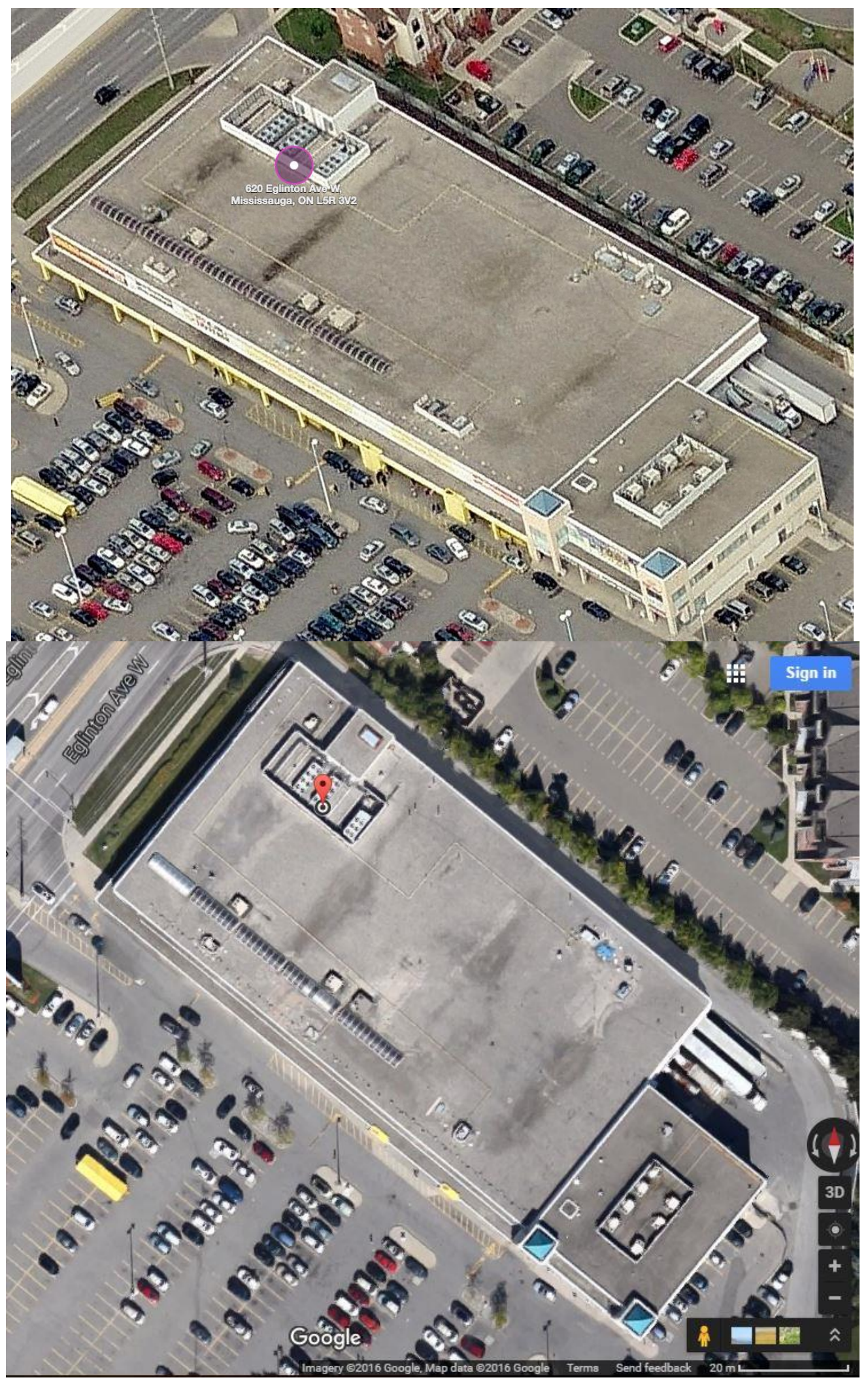

Figure 35 - NoFrills at 620 Eglinton Ave W 


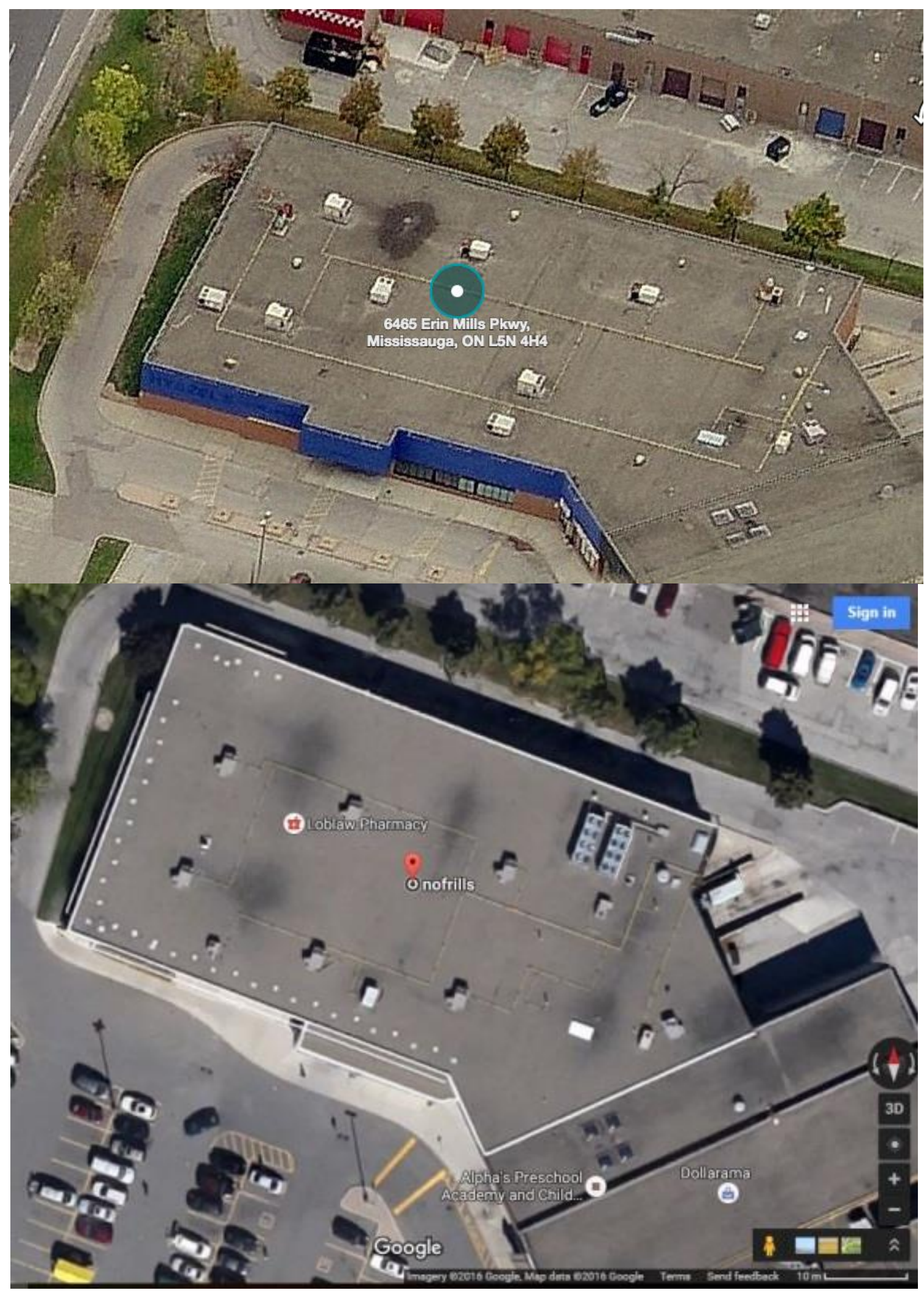

Figure 36 - NoFrills at 6465 Erin Mills Parkway 


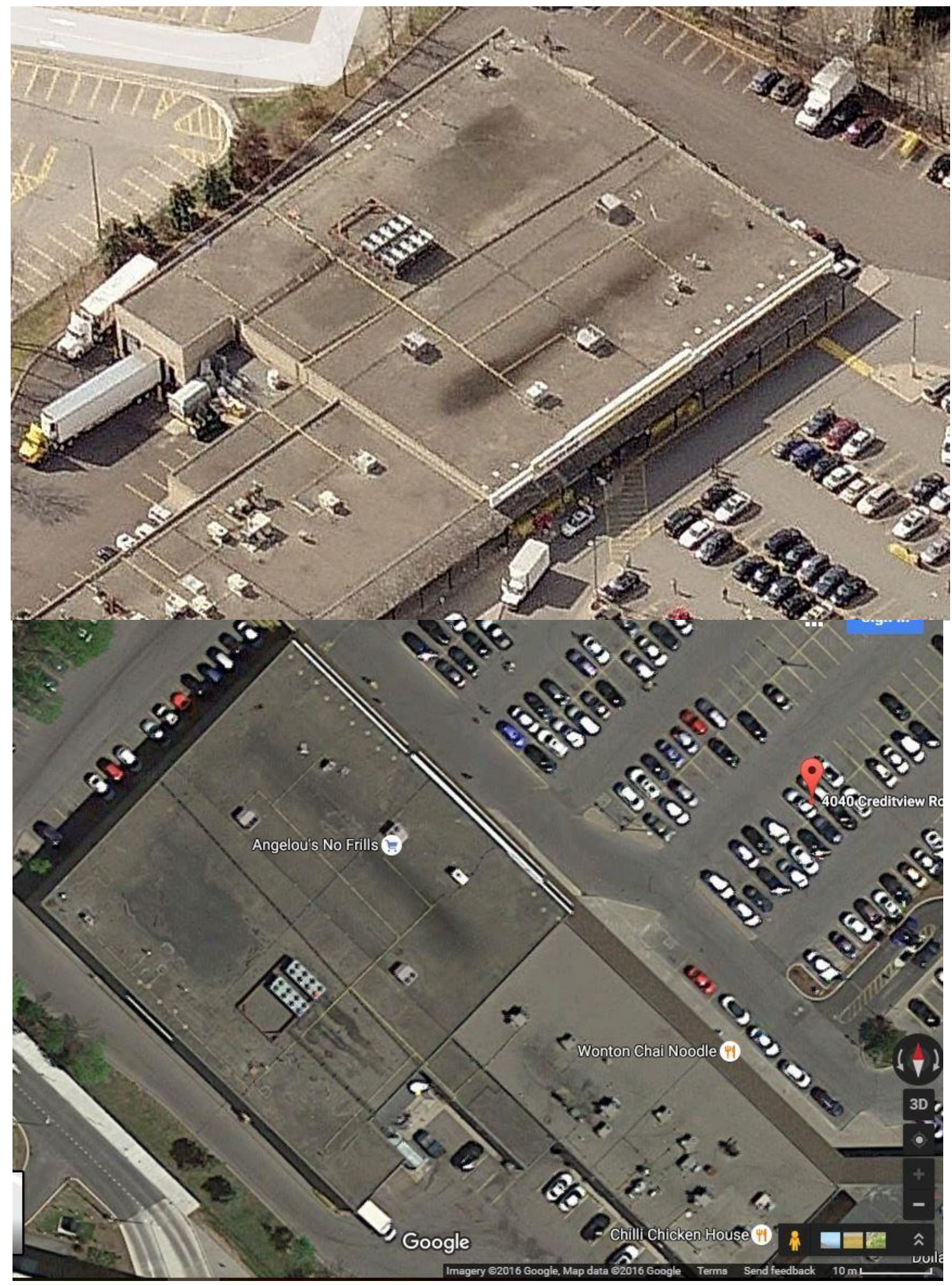

Figure 37 - NoFrills at 4040 Creditview Rd 


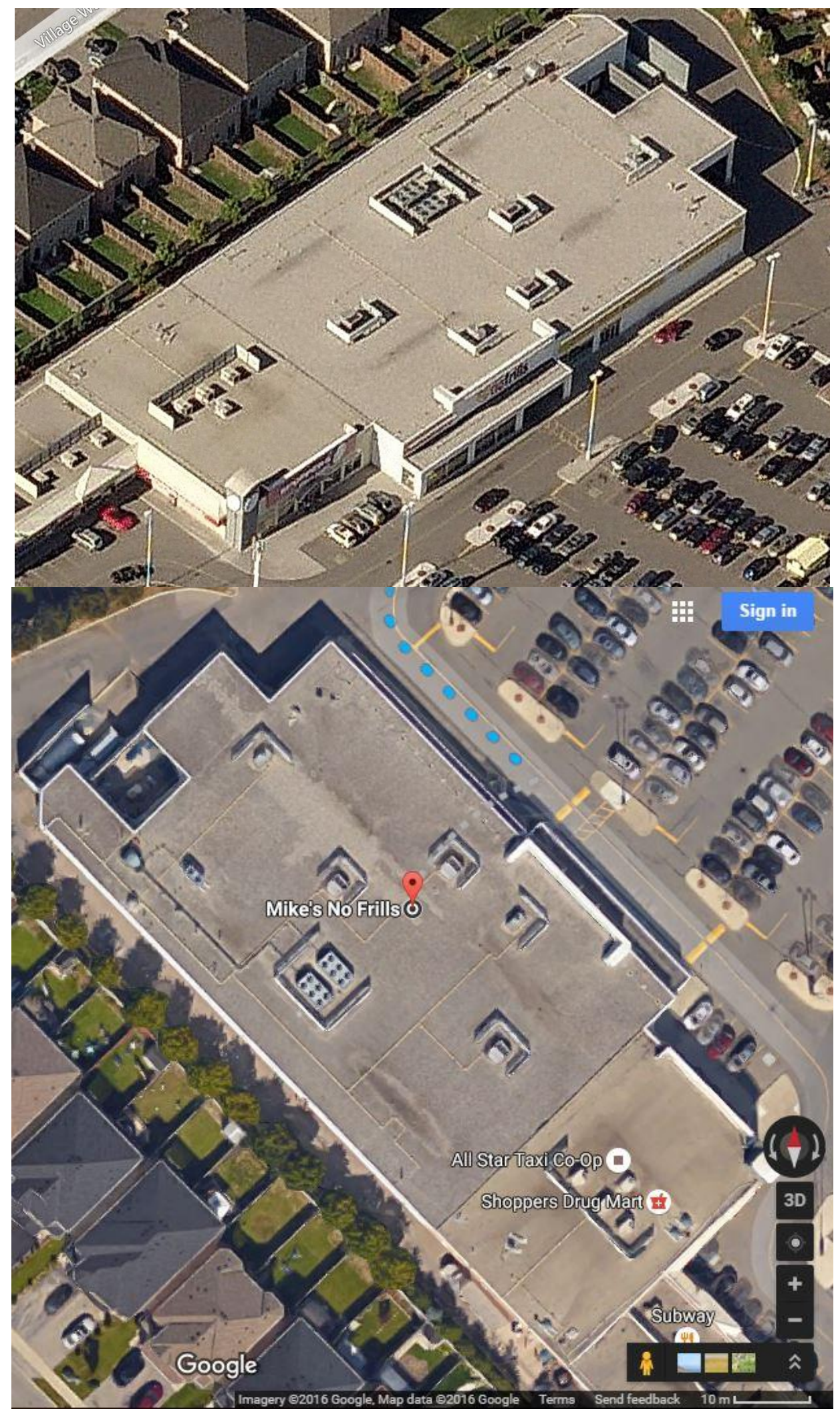

Figure 38 - NoFrills at 7070 McLaughlin Rd 


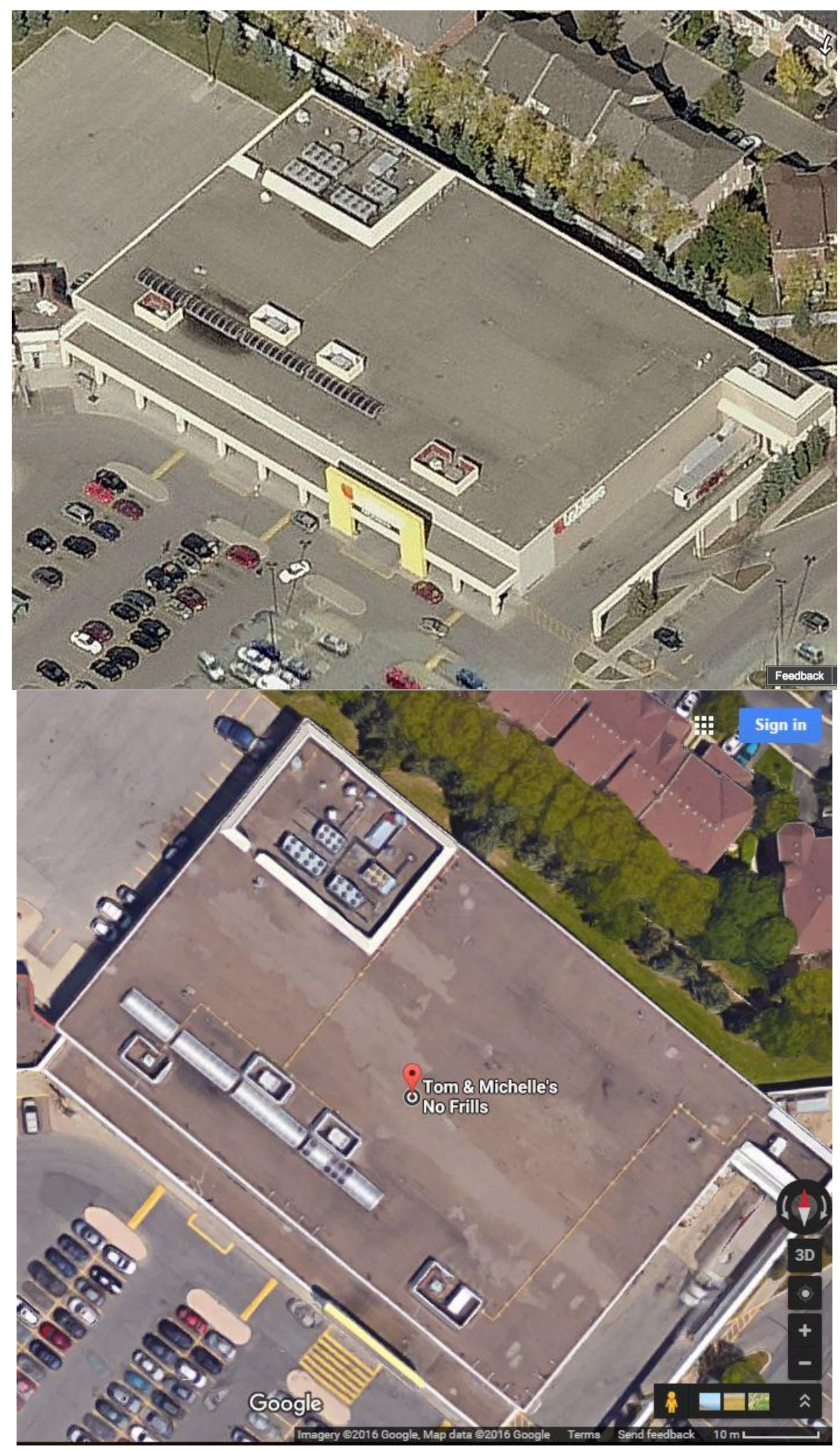

Figure 39 - NoFrills at 6085 Creditview Road 


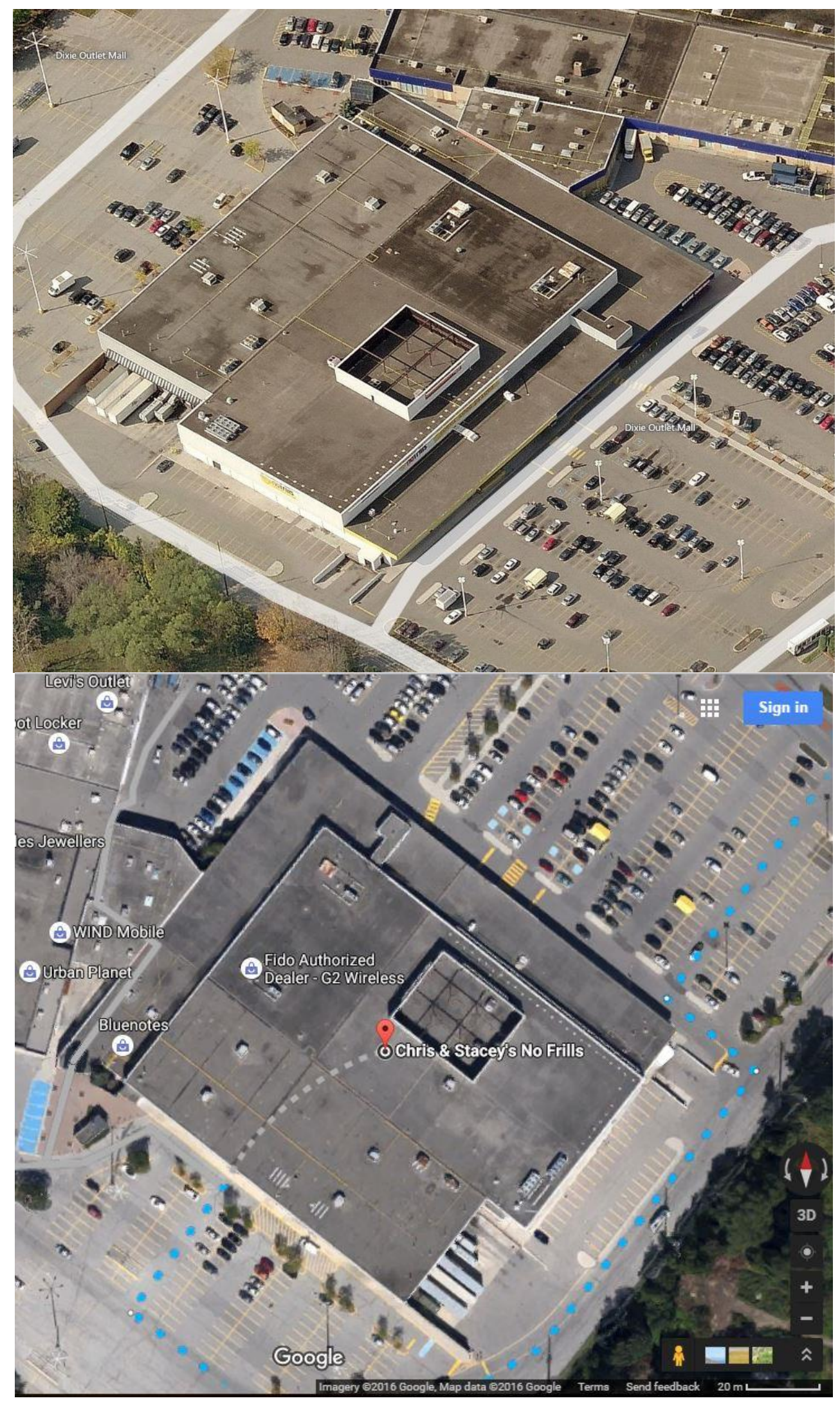

Figure 40 - NoFrills at 1250 South Service Rd 


\section{Metro Inc}

\section{1- Food Basics}

Six Food Basic branches are located in Mississauga which are listed in the table below:

Food Basics Branches in Mississauga

\begin{tabular}{|c|l|}
\hline Food Basics & Locations \\
\hline $\mathbf{1}$ & 3476 Glen Erin Dr, Mississauga, ON L5L 3R4 \\
\hline $\mathbf{2}$ & 377 Burnhamthorpe Rd E, Mississauga, ON L5A 3Y1 \\
\hline $\mathbf{3}$ & 2550 Hurontario St, Mississauga, ON L5B 1N5 \\
\hline $\mathbf{4}$ & 2425 Truscott Dr, Mississauga, ON L5J 2B4 \\
\hline $\mathbf{5}$ & 4141 Dixie Rd, Mississauga, ON L4W 1V5 \\
\hline $\mathbf{6}$ & 7070 St Barbara Blvd, Mississauga, ON L5W 0E6 \\
\hline
\end{tabular}

The stores were studied in satellite mod (Figure $42-47$ ) and revealed that all the rooftops are low-sloped and unoccupied. Furthermore, site studies indicated that adjacent taller buildings overshadowed none of these stores (Figure 41).
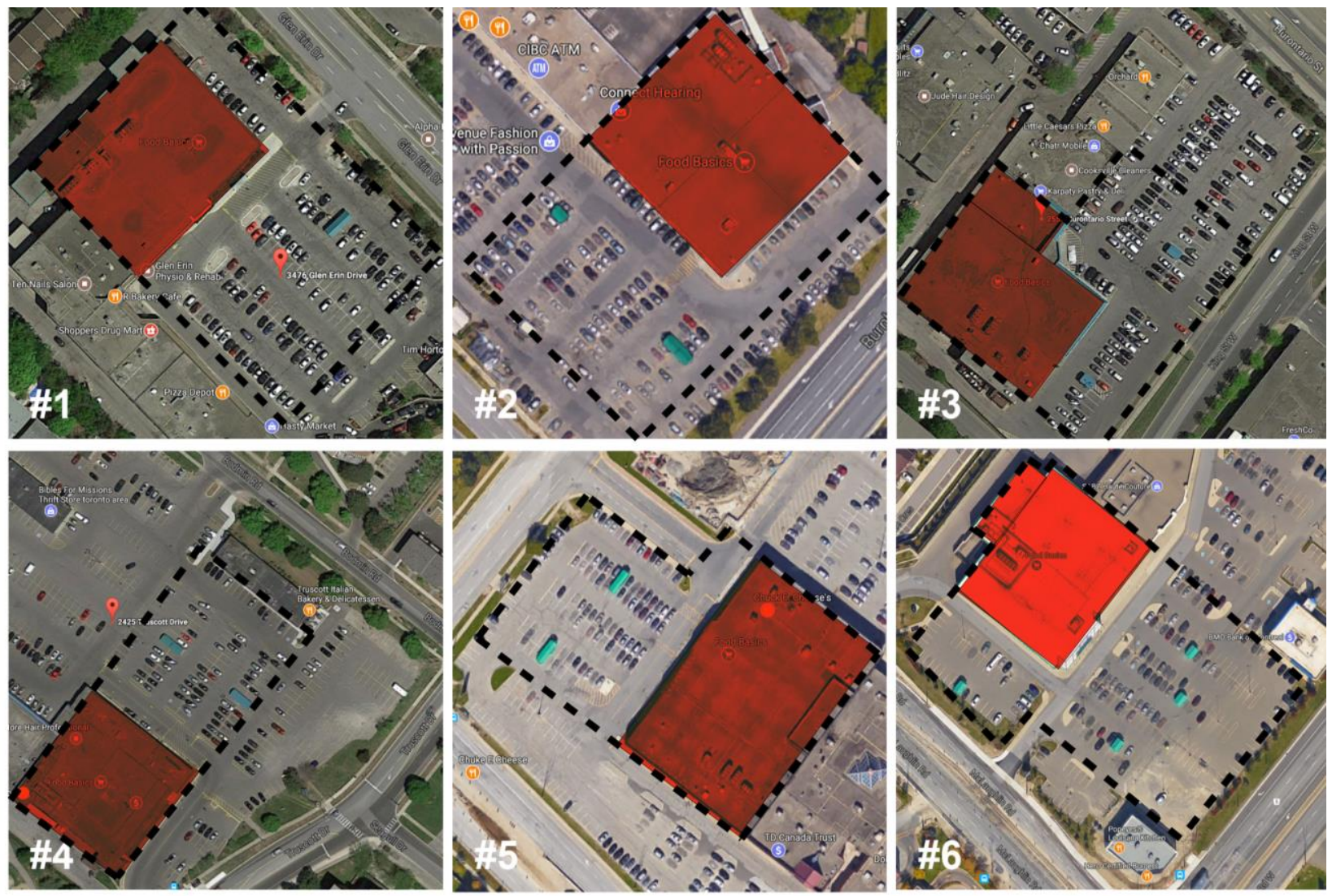

Figure 41 - Food Basics branches in Mississauga 


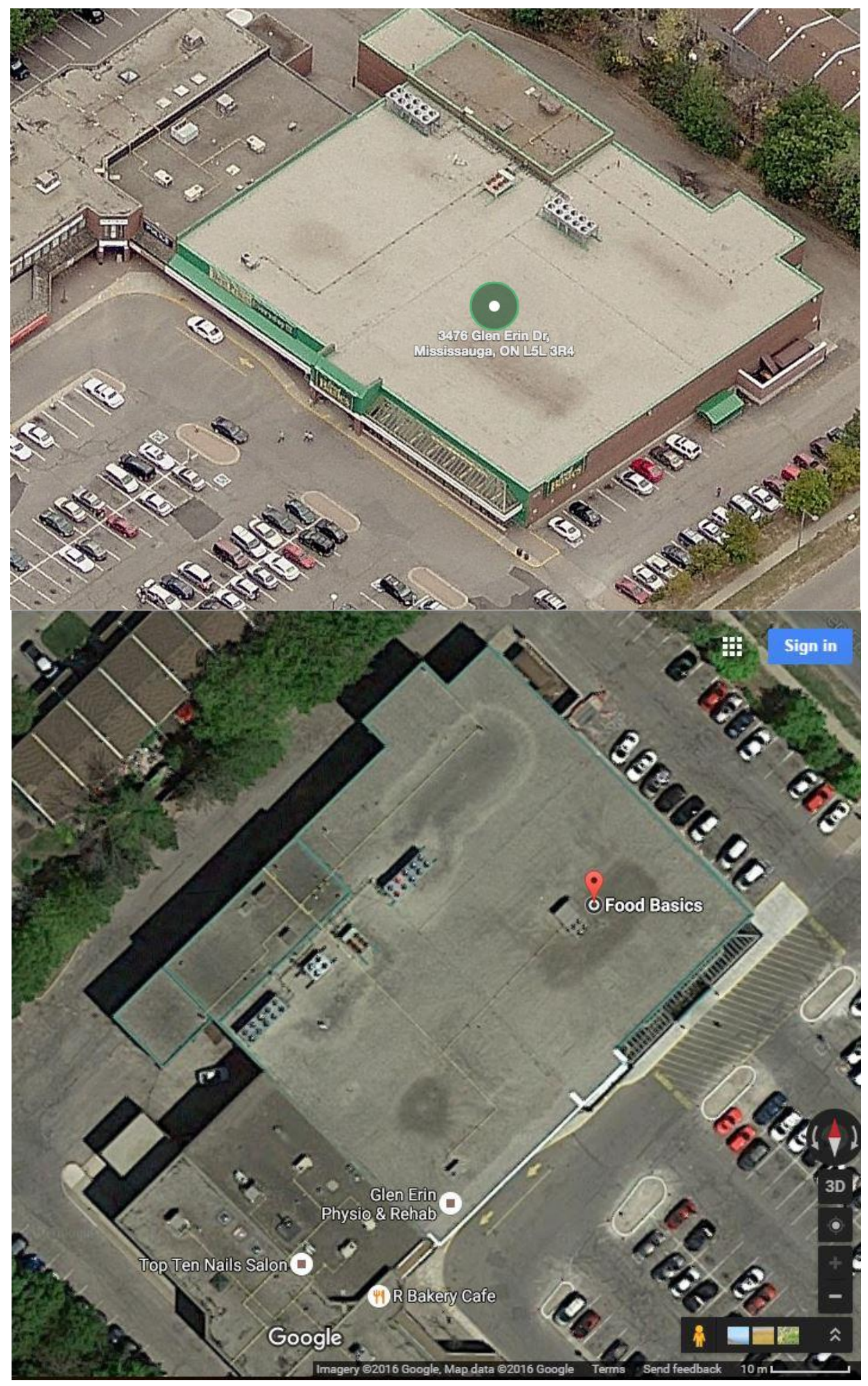

Figure 42 - Food Basics at 3476 Glen Erin Dr 


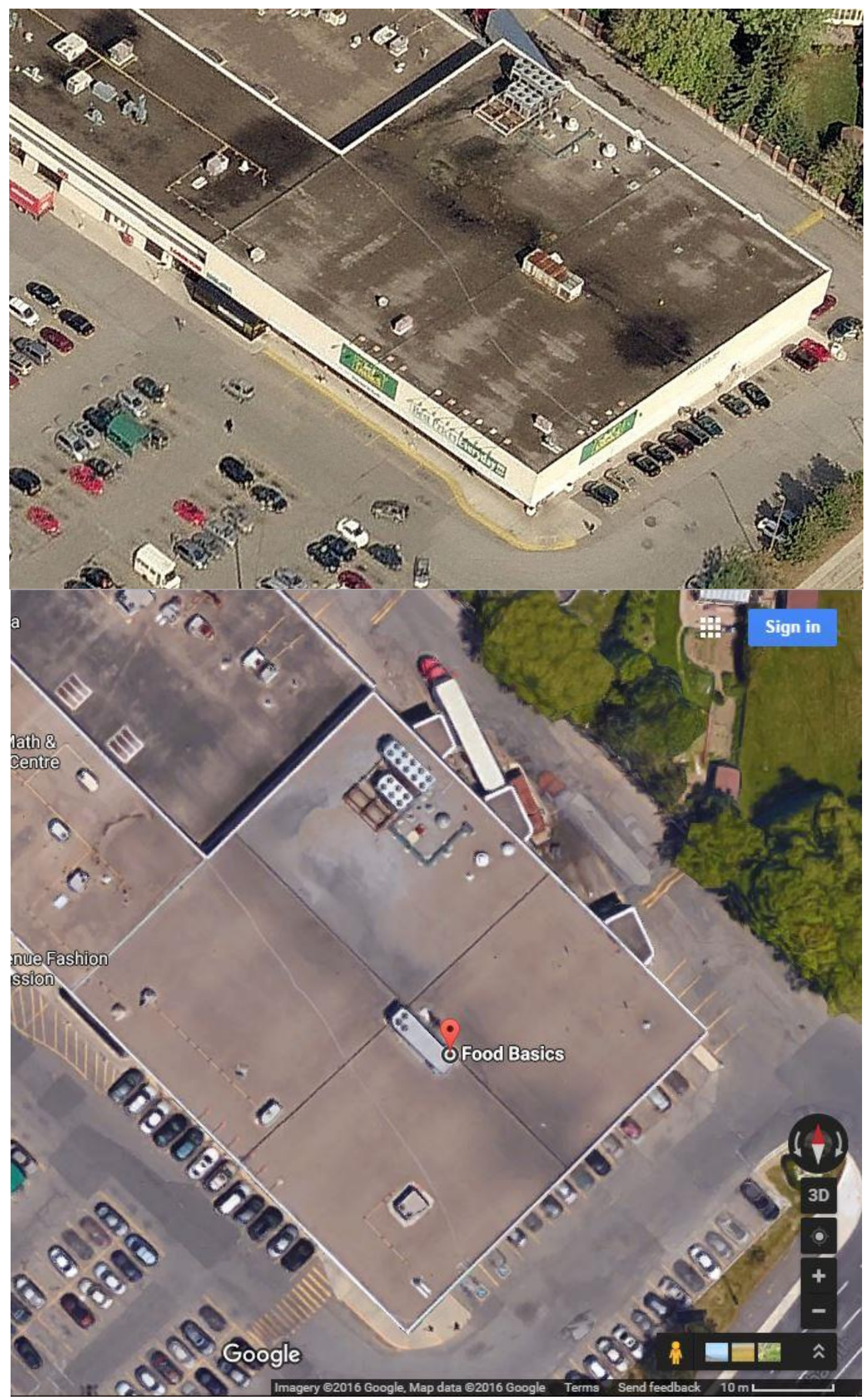

Figure 43 - Food Basics at 377 Burnhamthorpe Rd E 


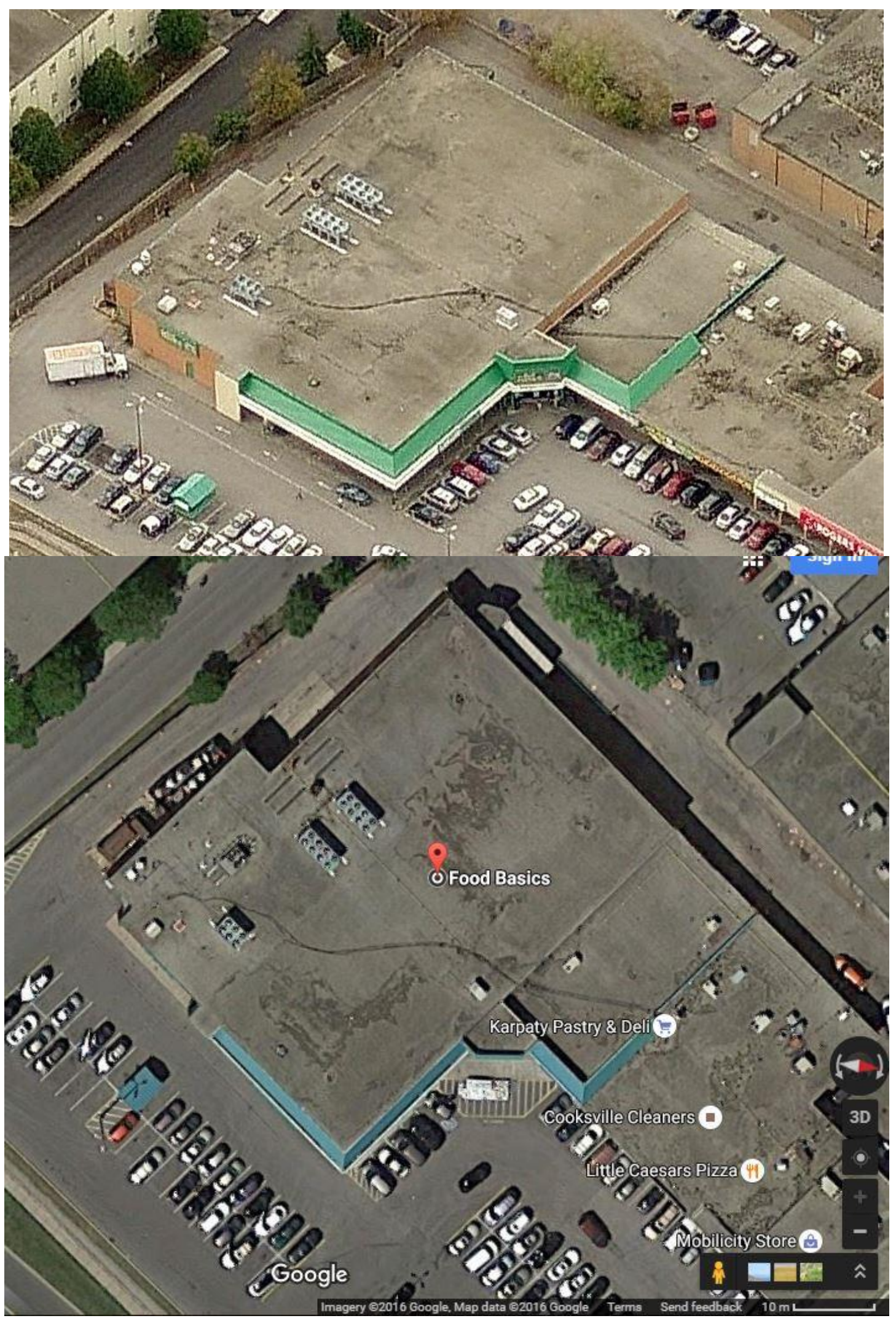

Figure 44 - Food Basics at 2550 Hurontario St 


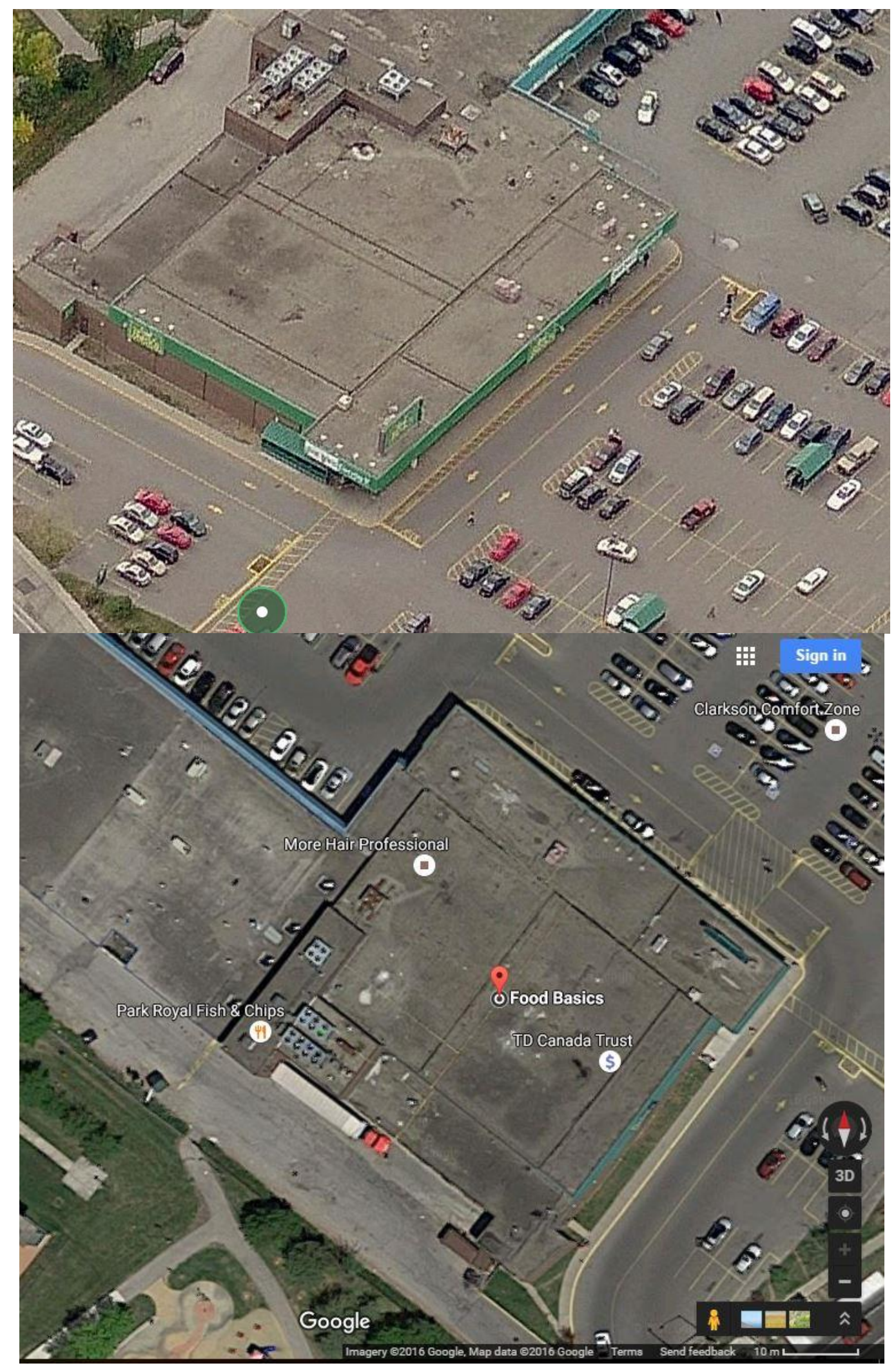

Figure 45 - Food Basics at 2425 Truscott Dr 


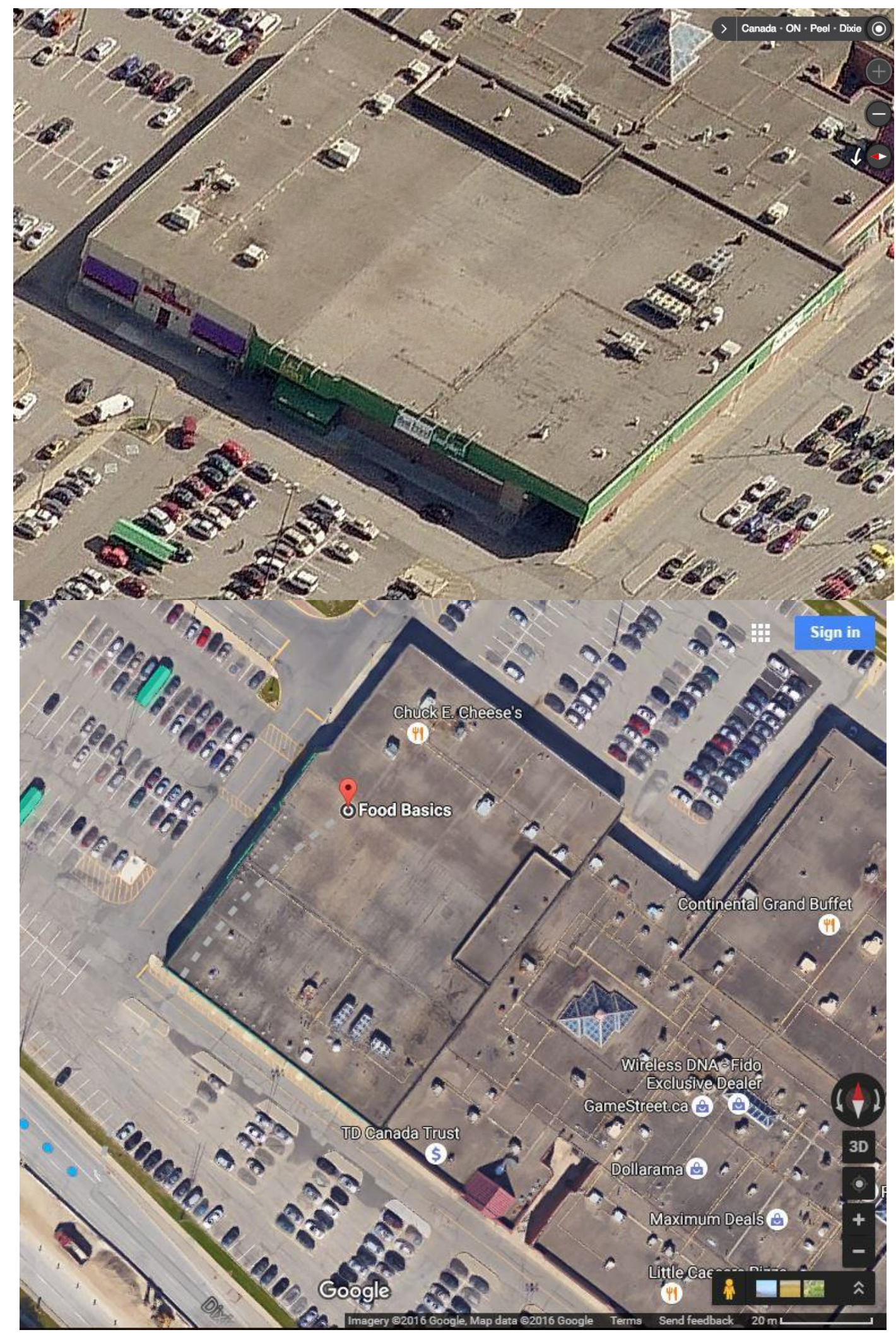

Figure 46 - Food Basics at 4141 Dixie Rd 


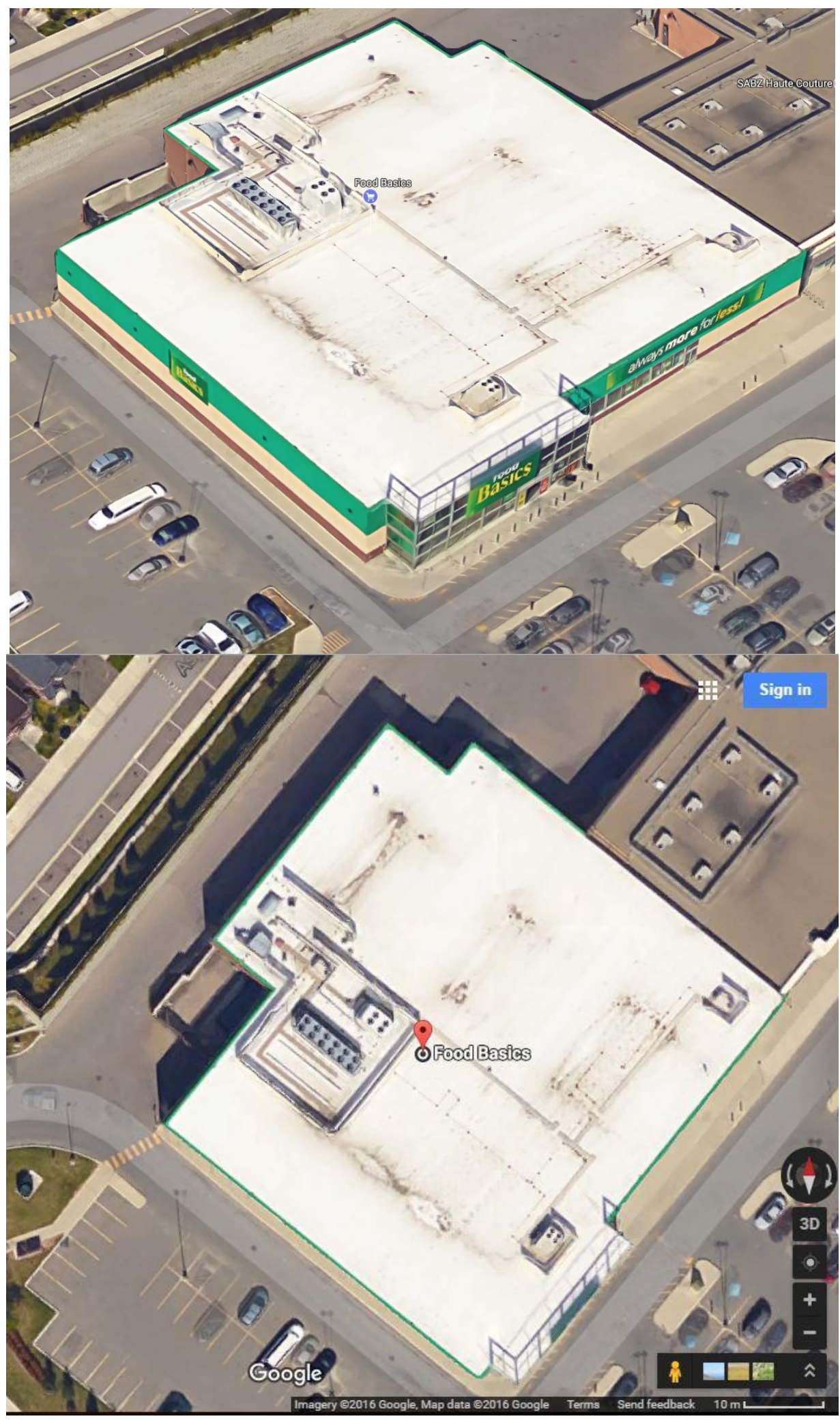

Figure 47 - Food Basics at 7070 Saint Barbara Blvd 
The data generated from auto cad is summarized in the table below:

Table 18 - Data Summary of Food Basics Branches in Mississauga

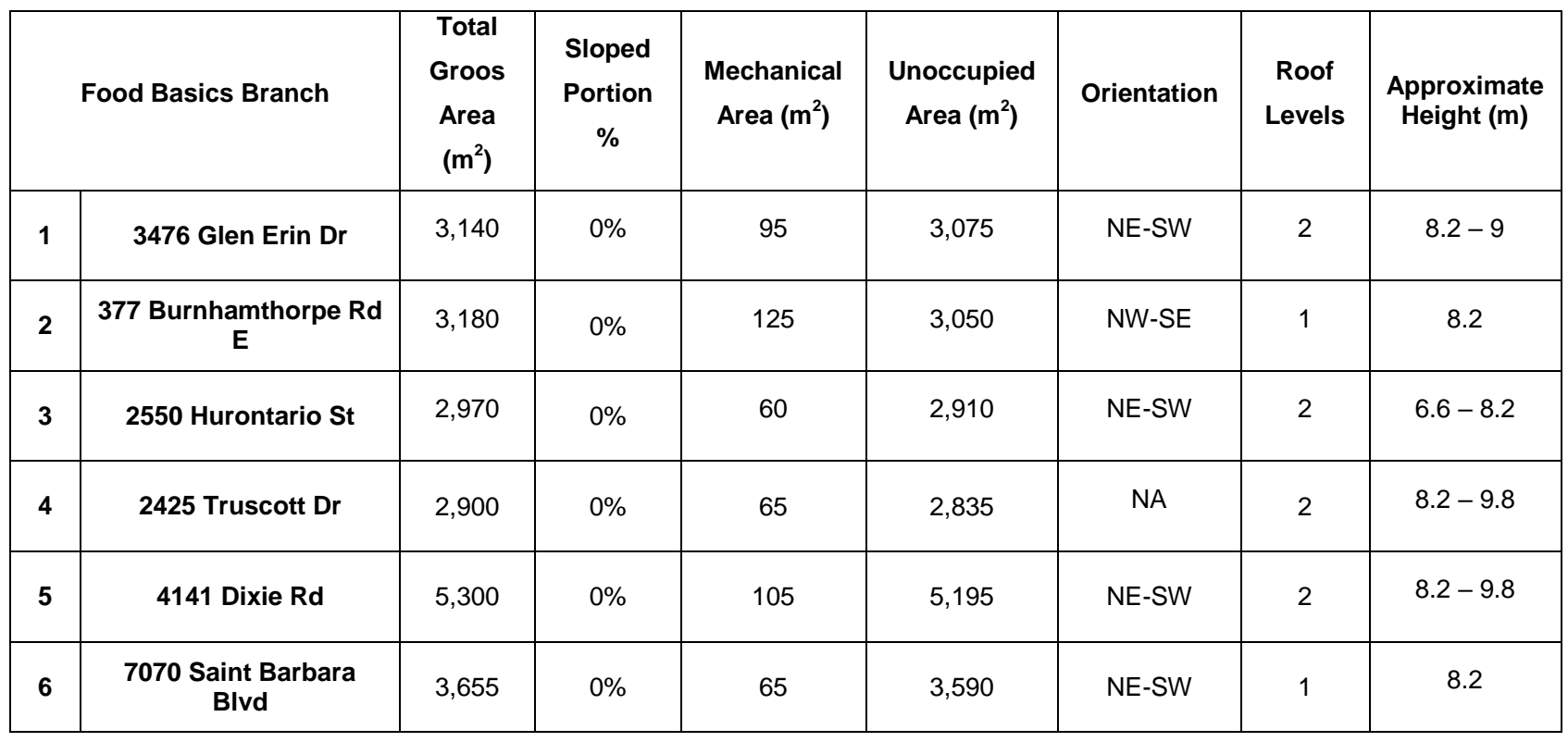

\section{2- Metro}

Overall, Mississauga has six Metro supermarkets which are listed in the following table:

Table 19 - Metro Branches in Mississauga

\begin{tabular}{|c|l|}
\hline Metro & Locations \\
\hline $\mathbf{1}$ & 910 Southdown Rd, Mississauga, ON L5J 2Y \\
\hline $\mathbf{2}$ & 2225 Erin Mills Pkwy, Peel ON L5K \\
\hline $\mathbf{3}$ & 1585 Mississauga Valley Blvd, Mississauga, ON L5A 3W9 \\
\hline $\mathbf{4}$ & 3221 Derry Rd W, Mississauga, ON L5N 7L7 \\
\hline $\mathbf{5}$ & 6677 Meadowvale Town Centre Cir, Mississauga, ON L5N 2R5 \\
\hline $\mathbf{6}$ & 406 Lakeshore Rd E, Mississauga, ON L5G 1H5 \\
\hline
\end{tabular}

The stores were studied in satellite mod (Figure 49 - 54 and revealed that all the rooftops are low-sloped and unoccupied. Furthermore site study (Figure 48) indicated that adjacent taller buildings overshadowed none of these stores. 

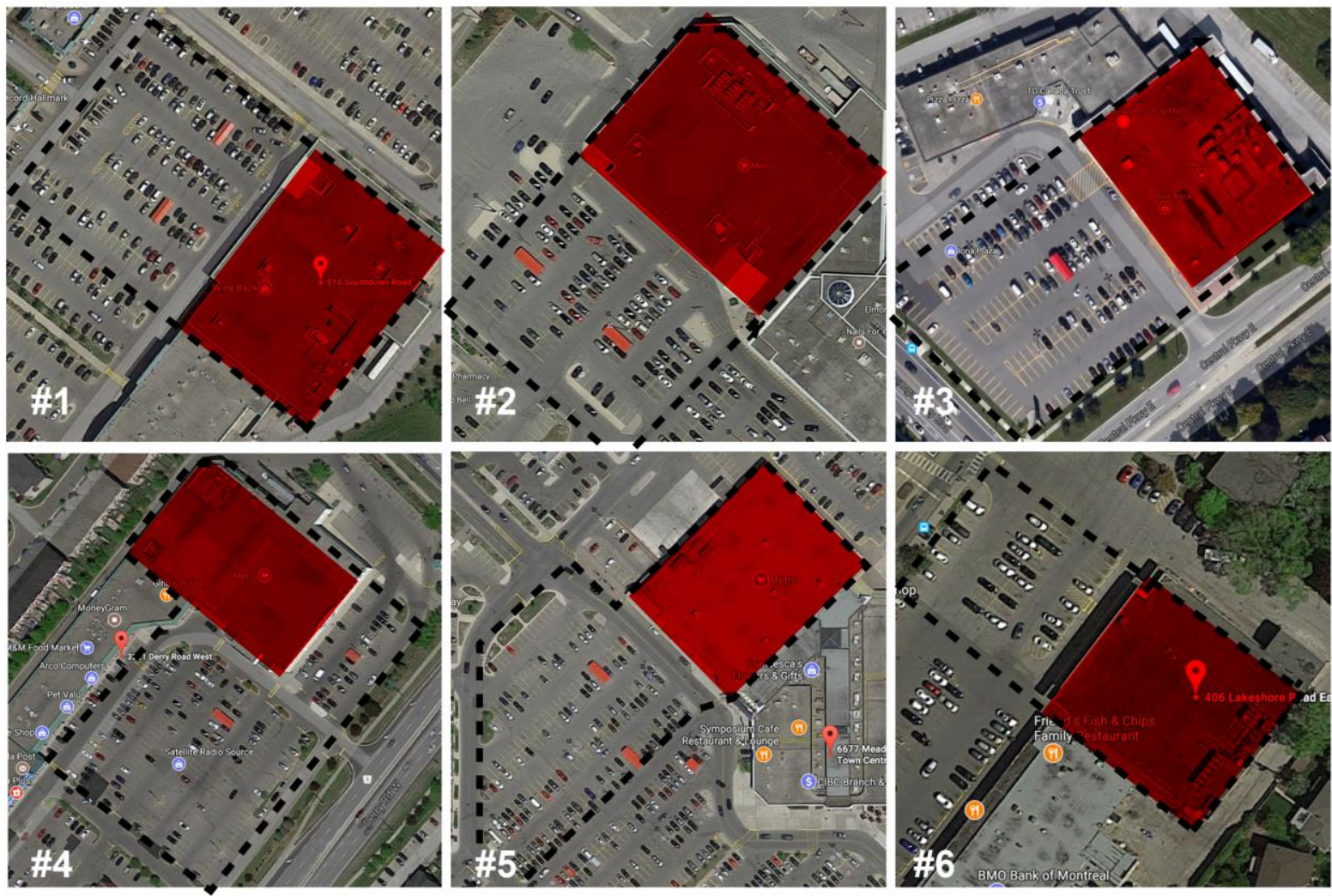

Figure 48 - Metro Branches in Mississauga

The data generated from auto cad is summarized in the table below:

Table 20 - Data Summary of Metro Branches in Mississauga

\begin{tabular}{|c|c|c|c|c|c|c|c|c|}
\hline & Metro Branch & $\begin{array}{c}\text { Total } \\
\text { Groos } \\
\text { Area } \\
\left(\mathrm{m}^{2}\right)\end{array}$ & $\begin{array}{c}\text { Sloped } \\
\text { Portion \% }\end{array}$ & $\begin{array}{c}\text { Mechanical } \\
\text { Area }\left(\mathrm{m}^{2}\right)\end{array}$ & $\begin{array}{c}\text { Unoccupied } \\
\text { Area }\left(\mathrm{m}^{2}\right)\end{array}$ & Orientation & $\begin{array}{l}\text { Roof } \\
\text { Levels }\end{array}$ & Height \\
\hline 1 & 910 Southdown Rd & 5,260 & $2.3 \%$ & 198 & 4,945 & NE-SW & 1 & 8.2 \\
\hline 2 & $\begin{array}{l}2225 \text { Erin Mills } \\
\text { Parkway }\end{array}$ & 5,110 & $3 \%$ & 102 & 4,842 & NE-SW & 1 & 8.2 \\
\hline 3 & $\begin{array}{c}1585 \text { Mississauga } \\
\text { Valley Blvd }\end{array}$ & 3,380 & $0 \%$ & 75 & 3,310 & NW-SE & 2 & 9 \\
\hline 4 & 3221 Derry Rd W & 4,625 & $0 \%$ & 75 & 4,550 & NW-SE & 1 & 8.2 \\
\hline 5 & $\begin{array}{l}6677 \text { Meadowvale } \\
\text { Town Centre Circle }\end{array}$ & 4,620 & $0 \%$ & 92 & 4,525 & NE-SW & 1 & 8.2 \\
\hline 6 & 406 Lakeshore Rd E & 1,865 & $0 \%$ & 100 & 1,765 & NW-SE & 2 & 8.2 \\
\hline
\end{tabular}




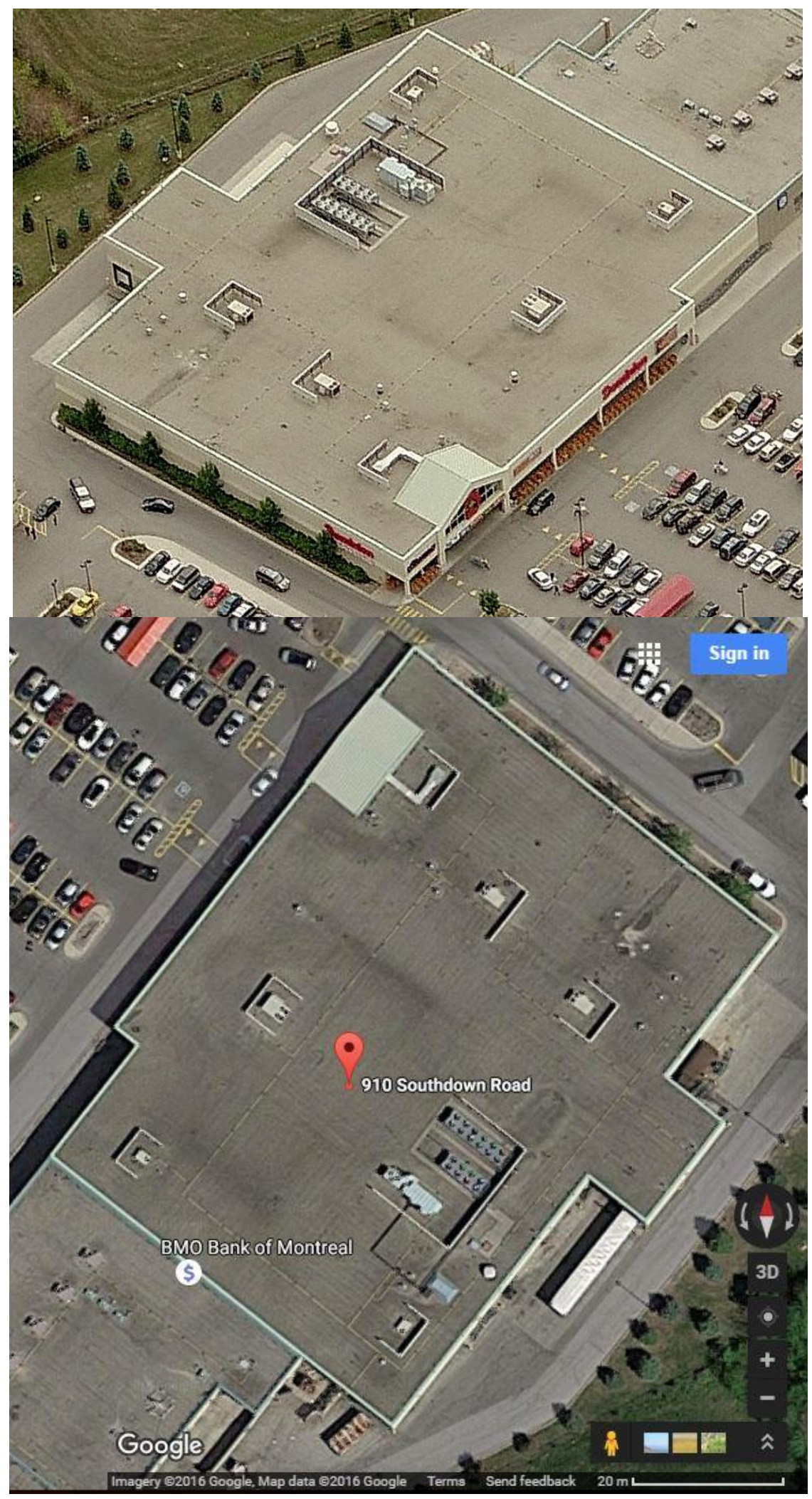

Figure 49 - Metro at 910 Southdown Rd 


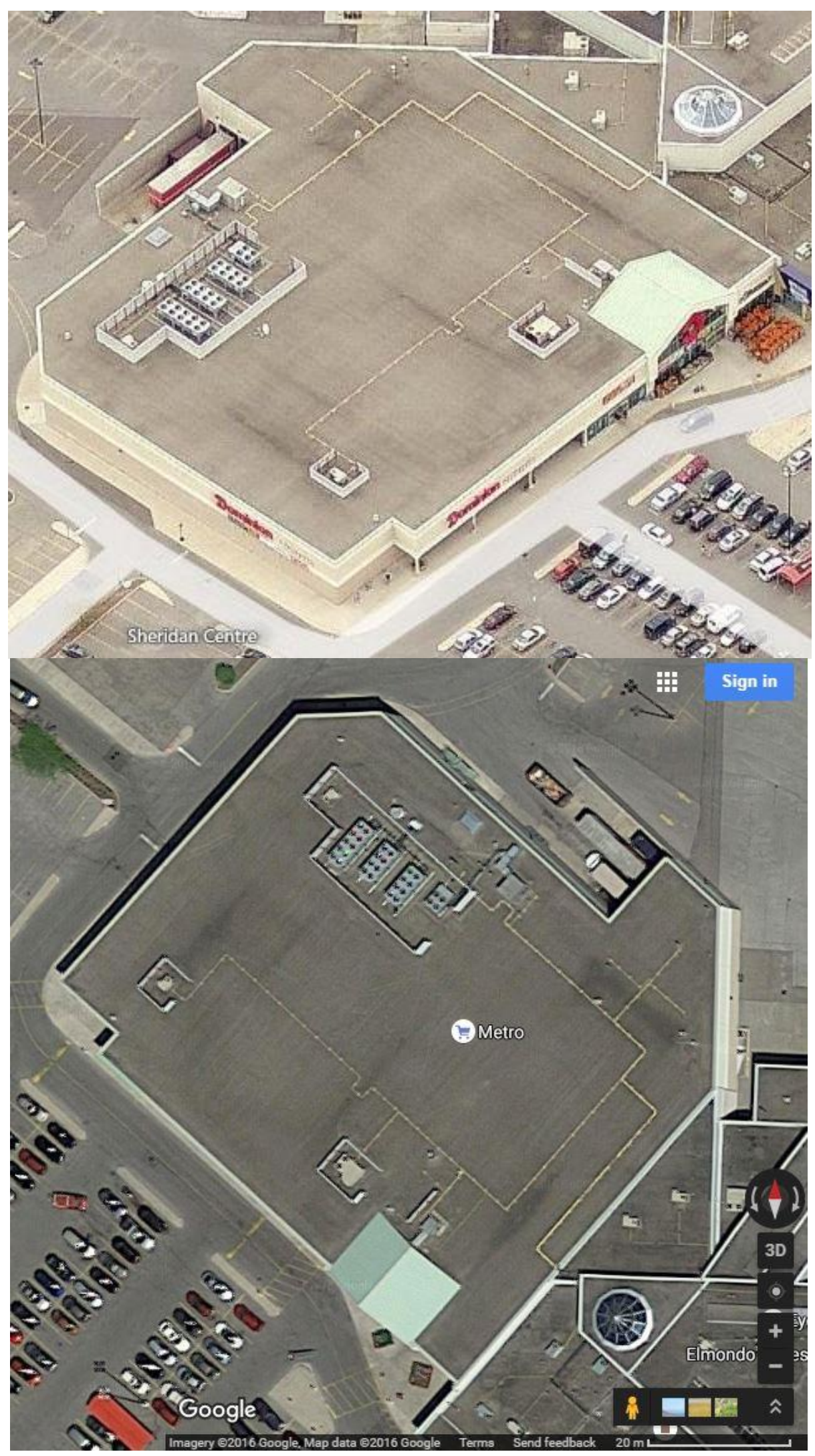

Figure 50 - Metro 2225 Erin Mills Parkway 


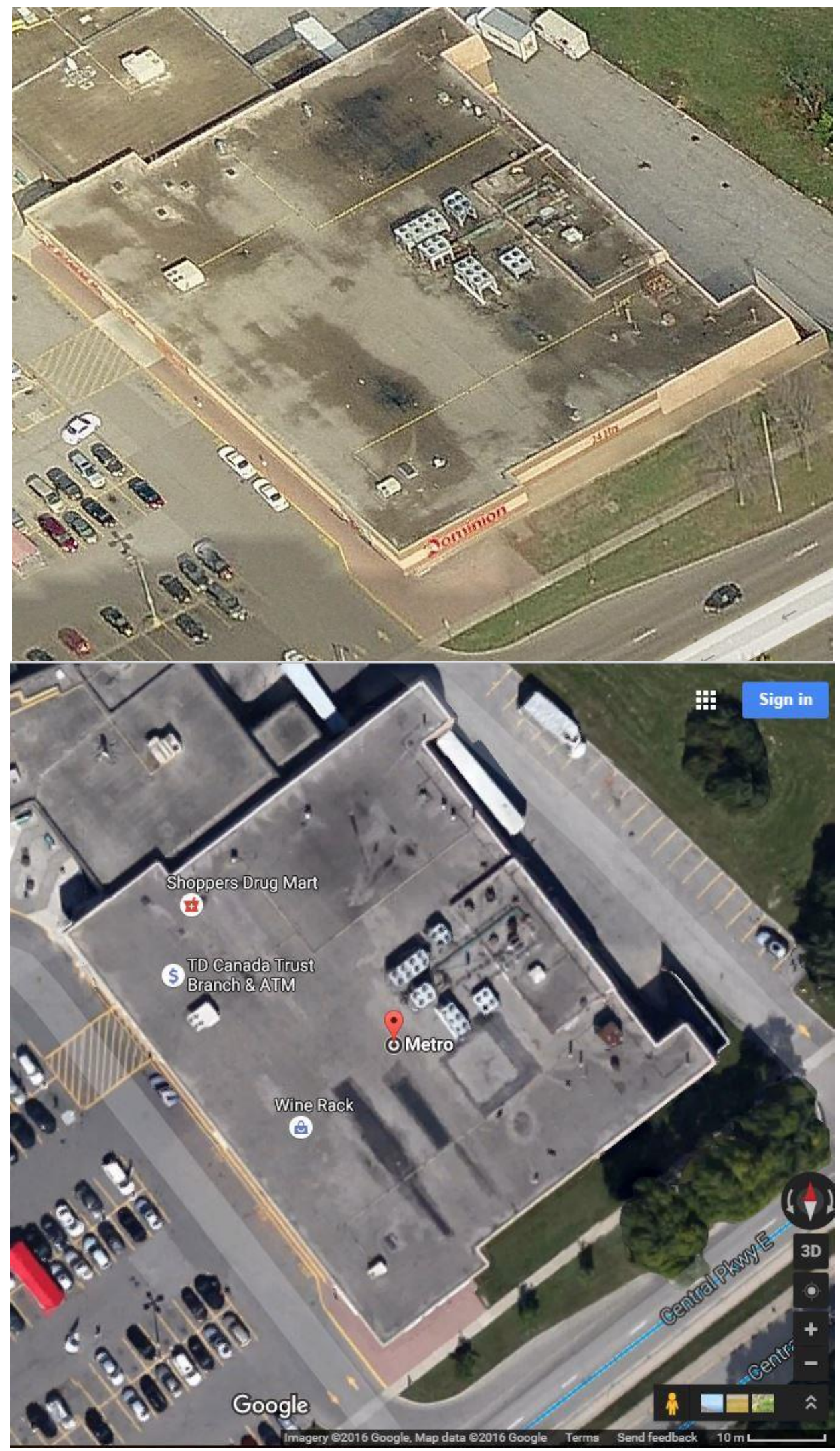

Figure 51 - Metro at 1585 Mississauga Valley Blvd 


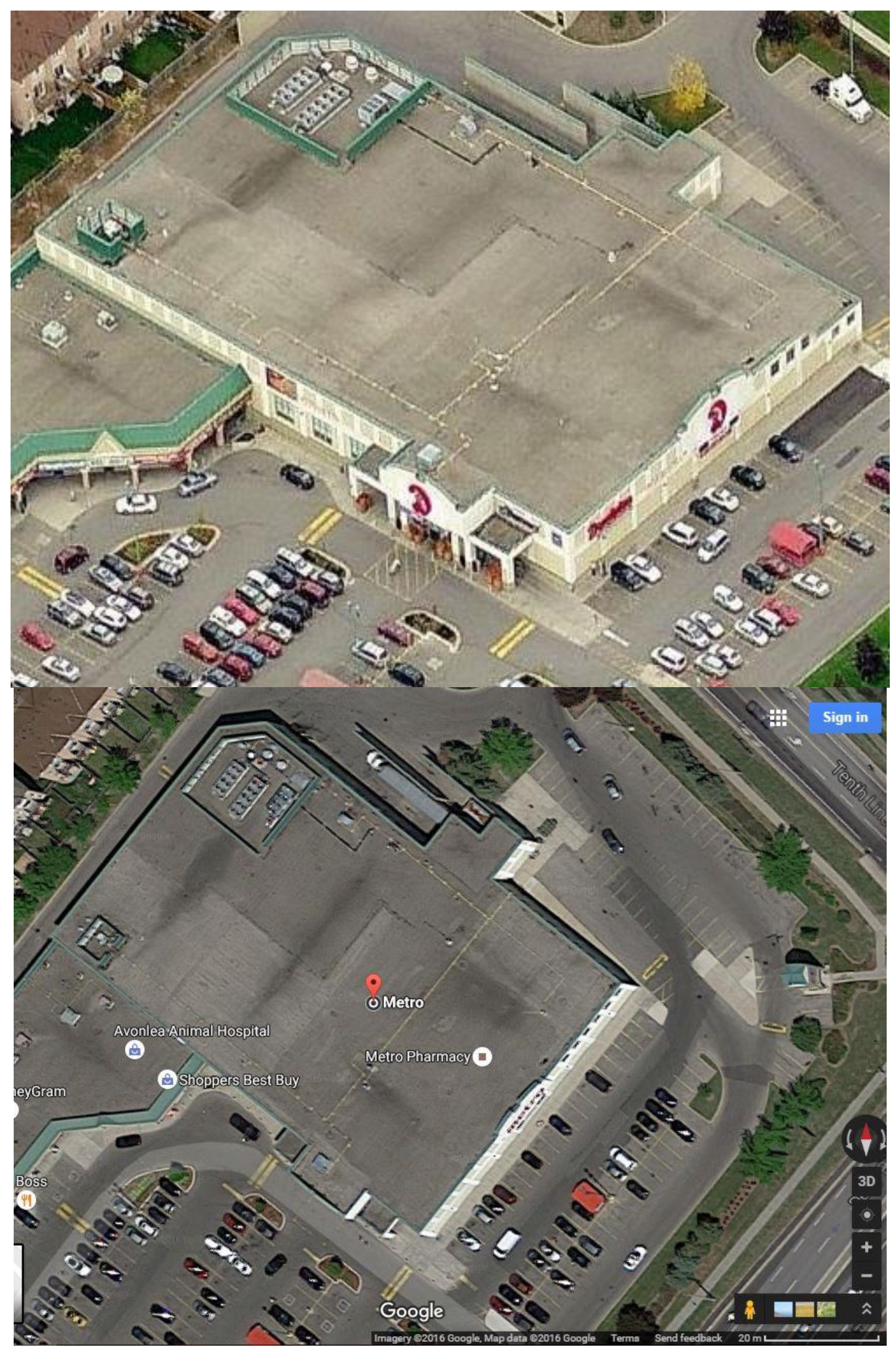

Figure 52 - Metro at 3221 Derry Rd W 


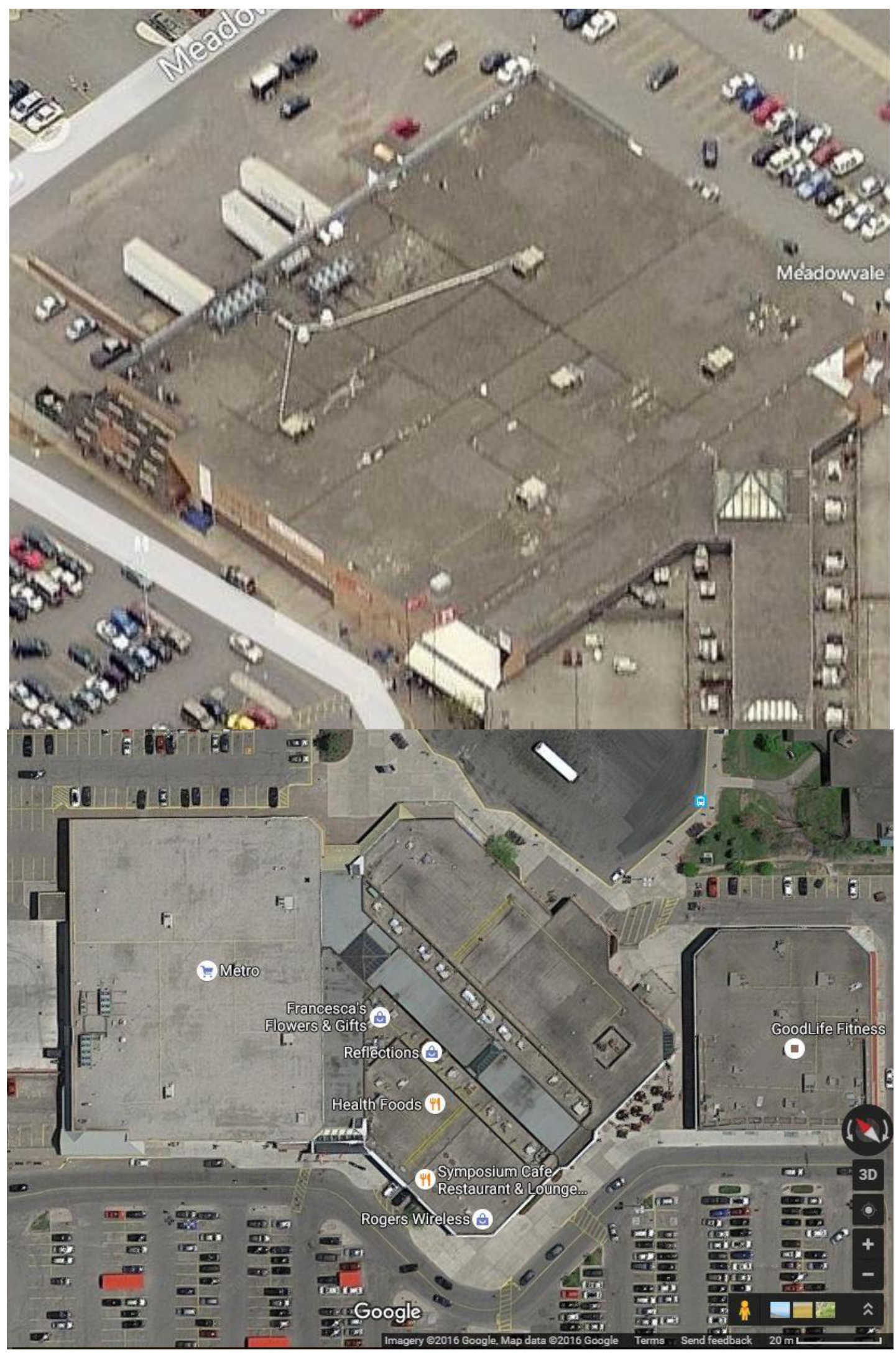

Figure 53 - Metro at 6677 Meadowvale Town Centre Circle 


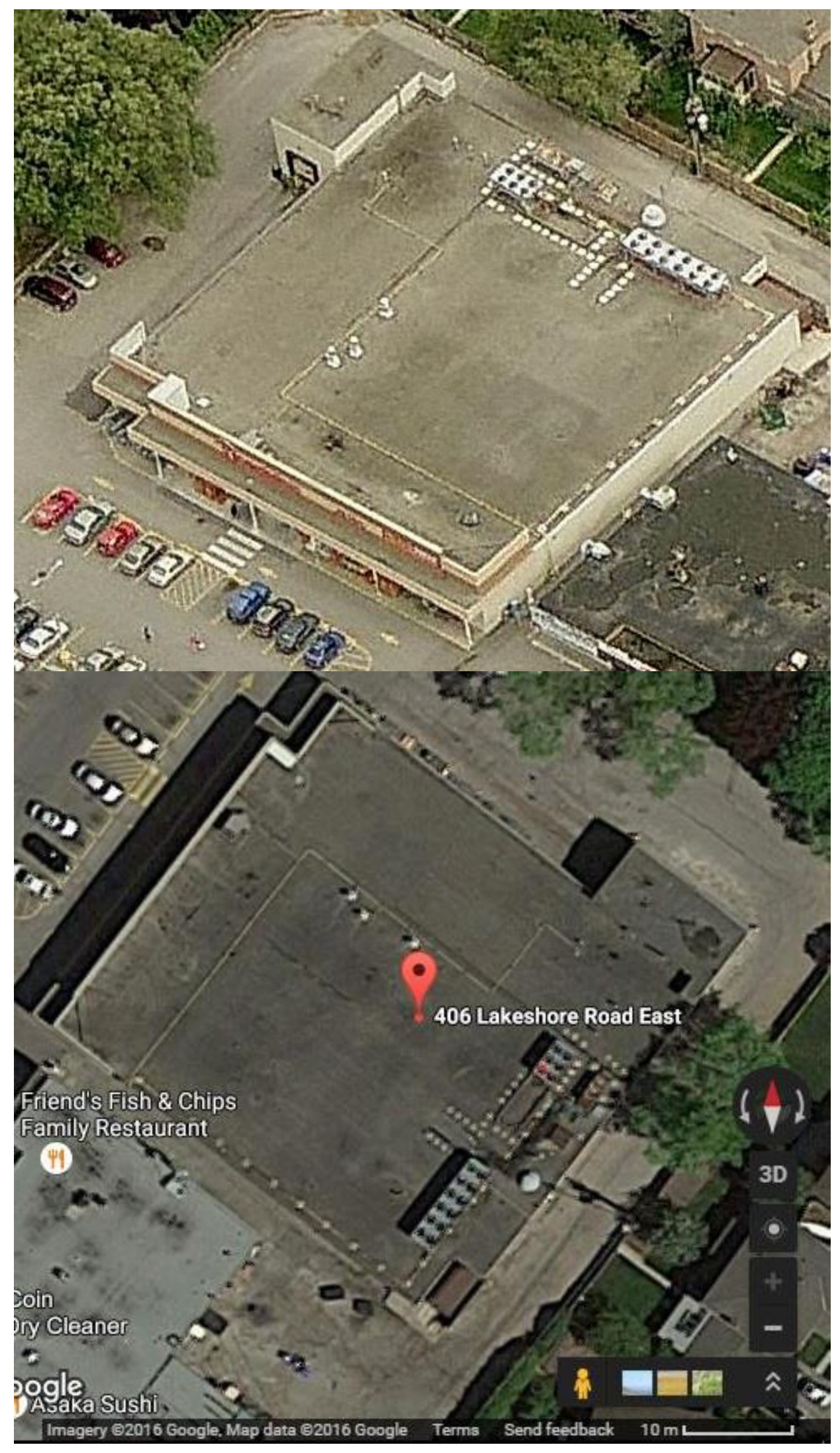

Figure 54 - Metro at 406 Lakeshore Rd E 


\section{Sobeys}

\section{1- FreshCo}

In general, 5 FreshCo branches (Figure 56- Figure 60) are located in Mississauga which are listed in the table below:

Table 21 - FreshCo Branches in Mississauga

\begin{tabular}{|c|l|}
\hline FreshCo & Locations \\
\hline $\mathbf{1}$ & 2500 Hurontario St, Mississauga, ON L5B 1N4 \\
\hline $\mathbf{2}$ & 6040 Glen Erin Dr, Mississauga, ON L5N 3M4 \\
\hline $\mathbf{3}$ & 1151 Dundas St W, Mississauga, ON L5C 1C4 \\
\hline $\mathbf{4}$ & 3100 Dixie Rd, Mississauga, ON L4Y 2A6 \\
\hline $\mathbf{5}$ & 7205 Goreway Dr, Mississauga, ON L4T 2T9 \\
\hline
\end{tabular}

Reviewing the 2D and 3D images from Google Maps and Bing Maps, shown that rooftops are low-sloped and host mechanical units.
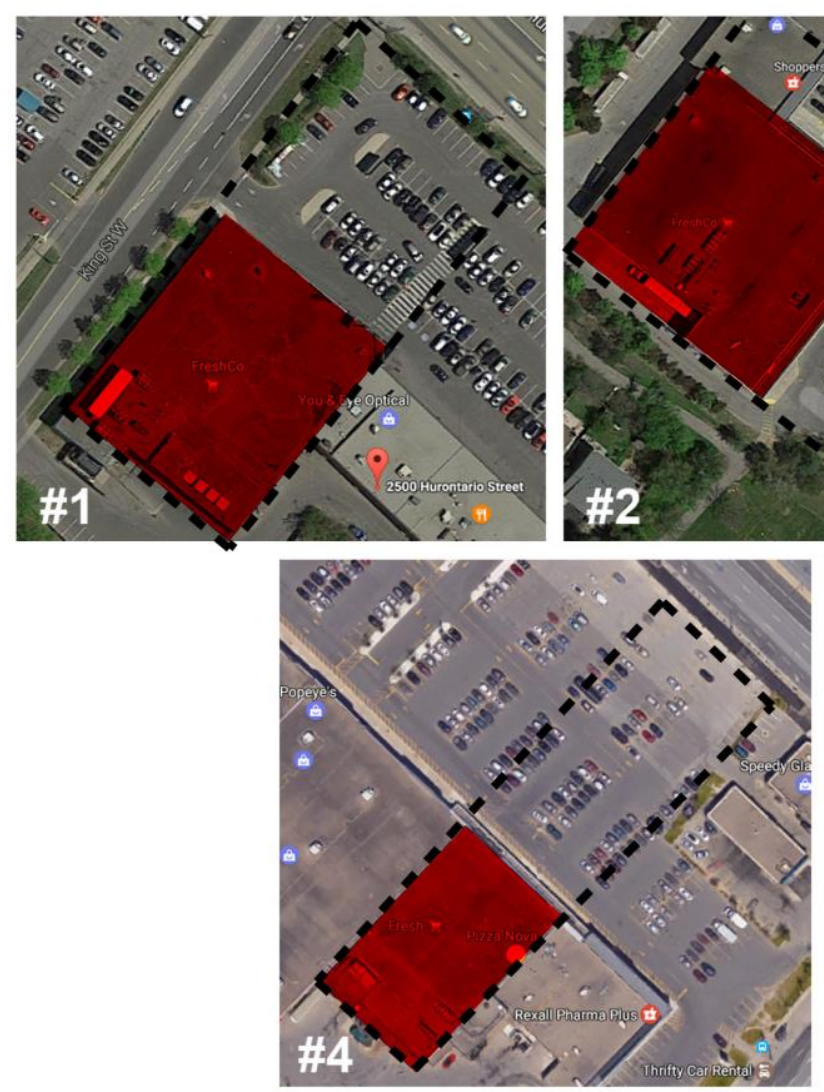
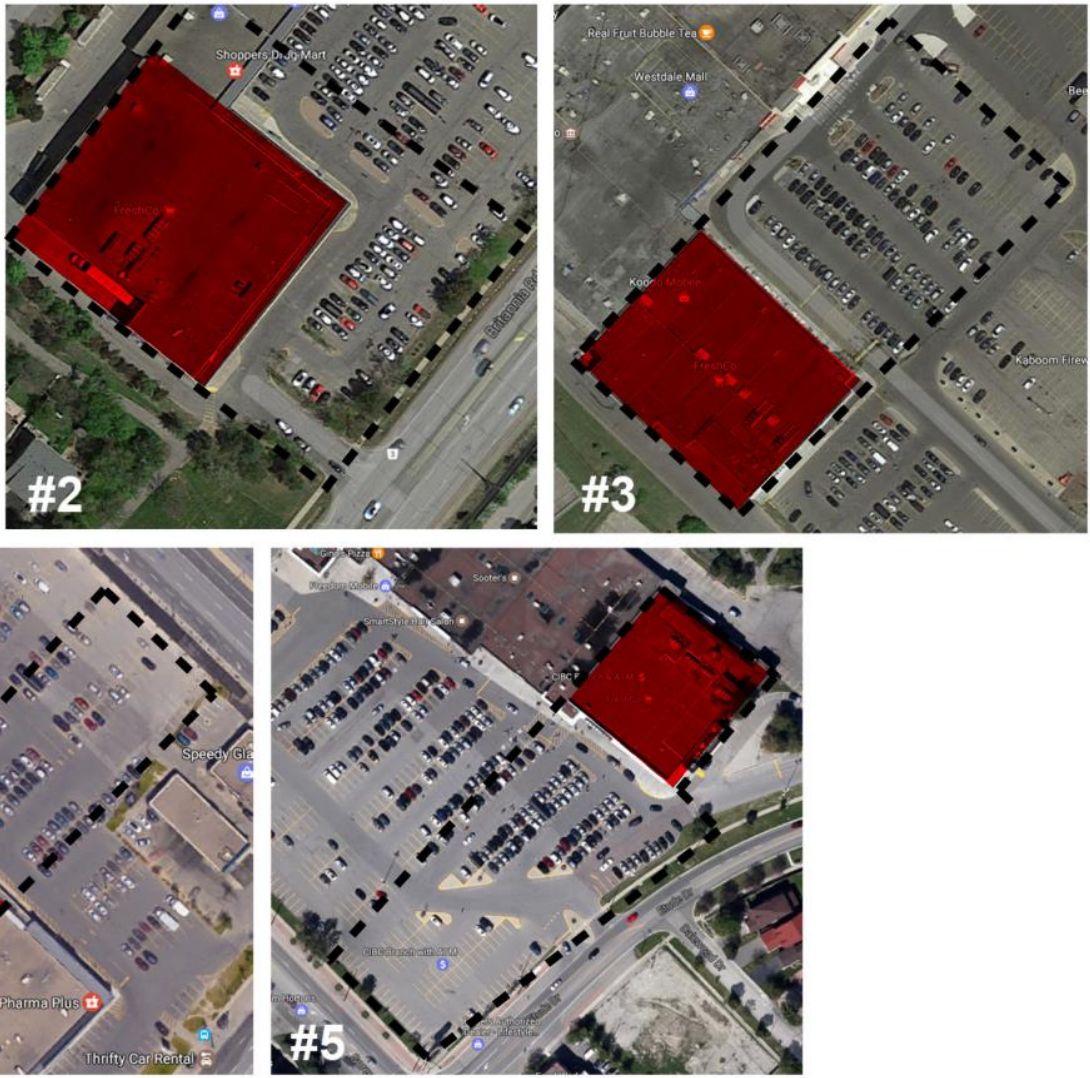

Figure 55 - FreshCo Branches in Mississauga 
Table 22 - Data Summary of FreshCo Branches in Mississauga

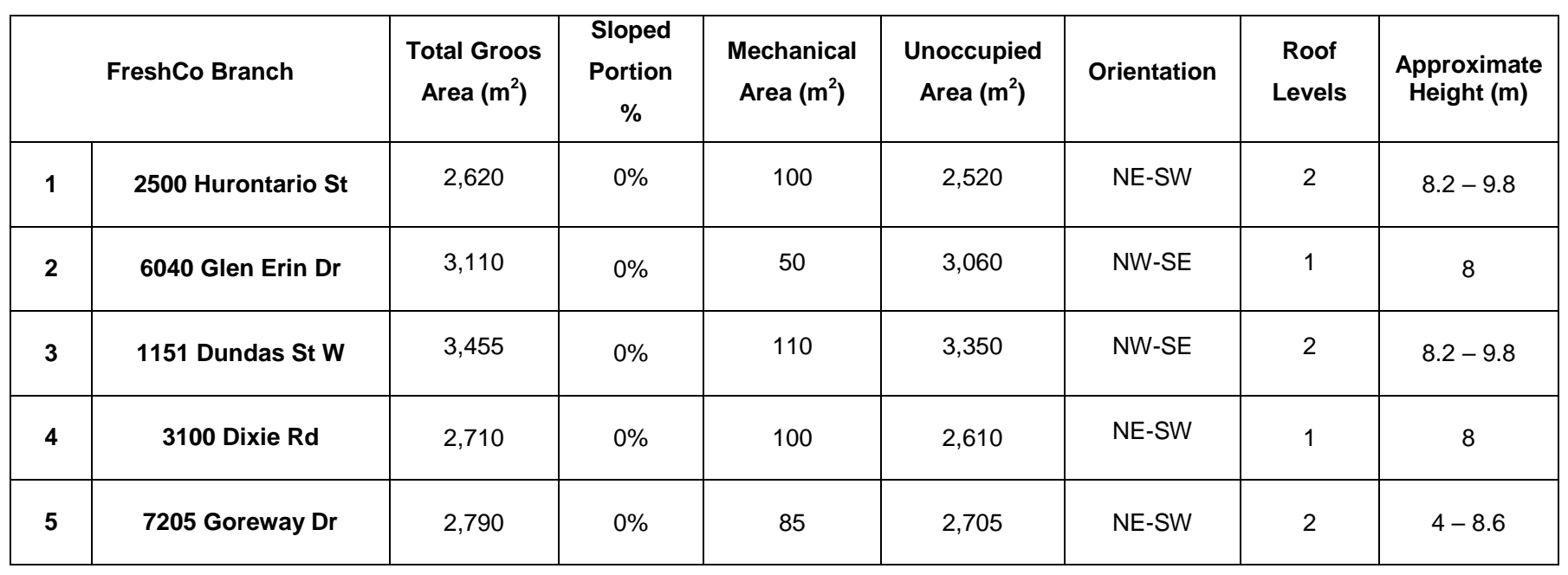




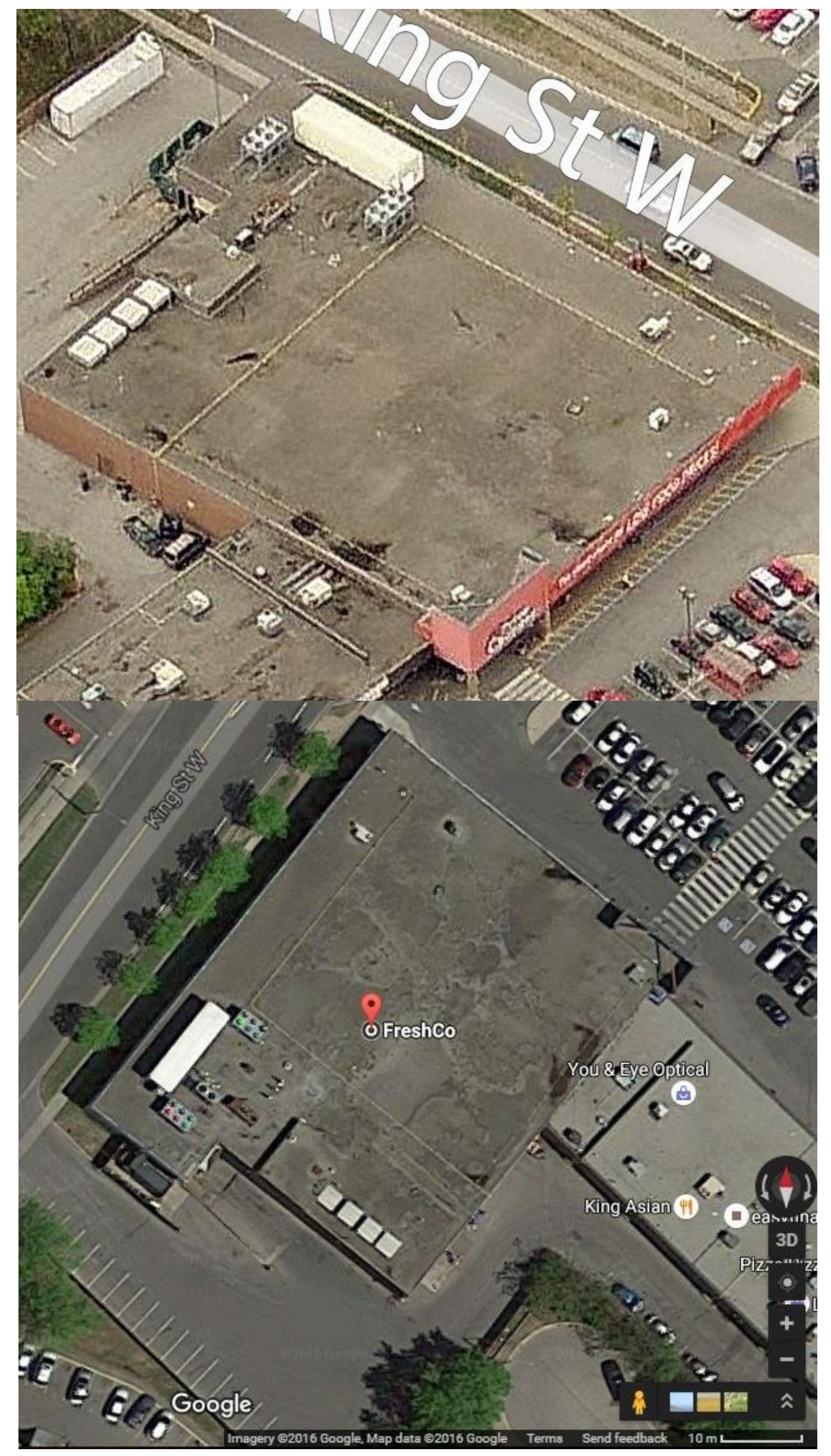

Figure 56 - FreshCo at 2500 Hurontario St 


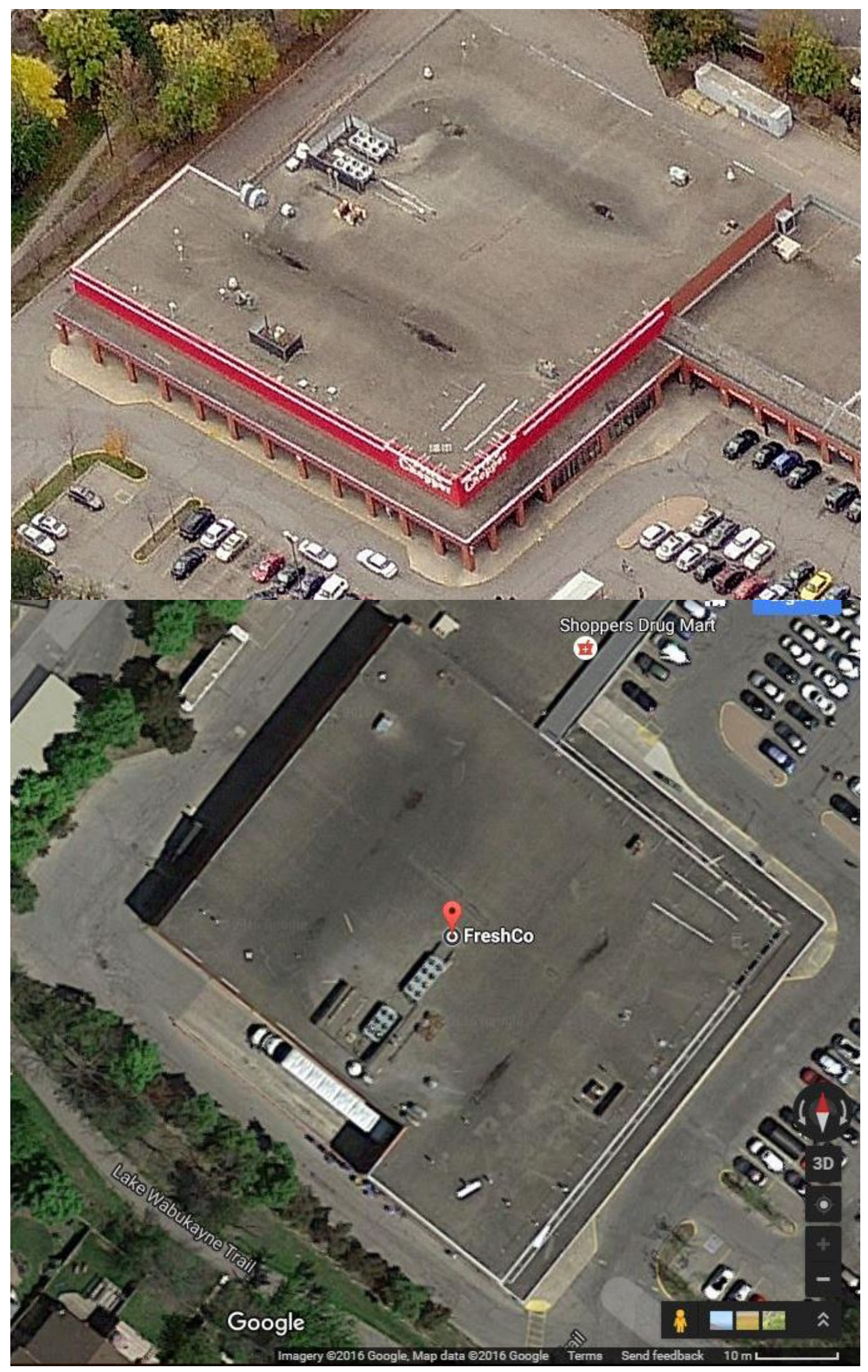

Figure 57 - FreshCo at 6040 Glen Erin Dr 


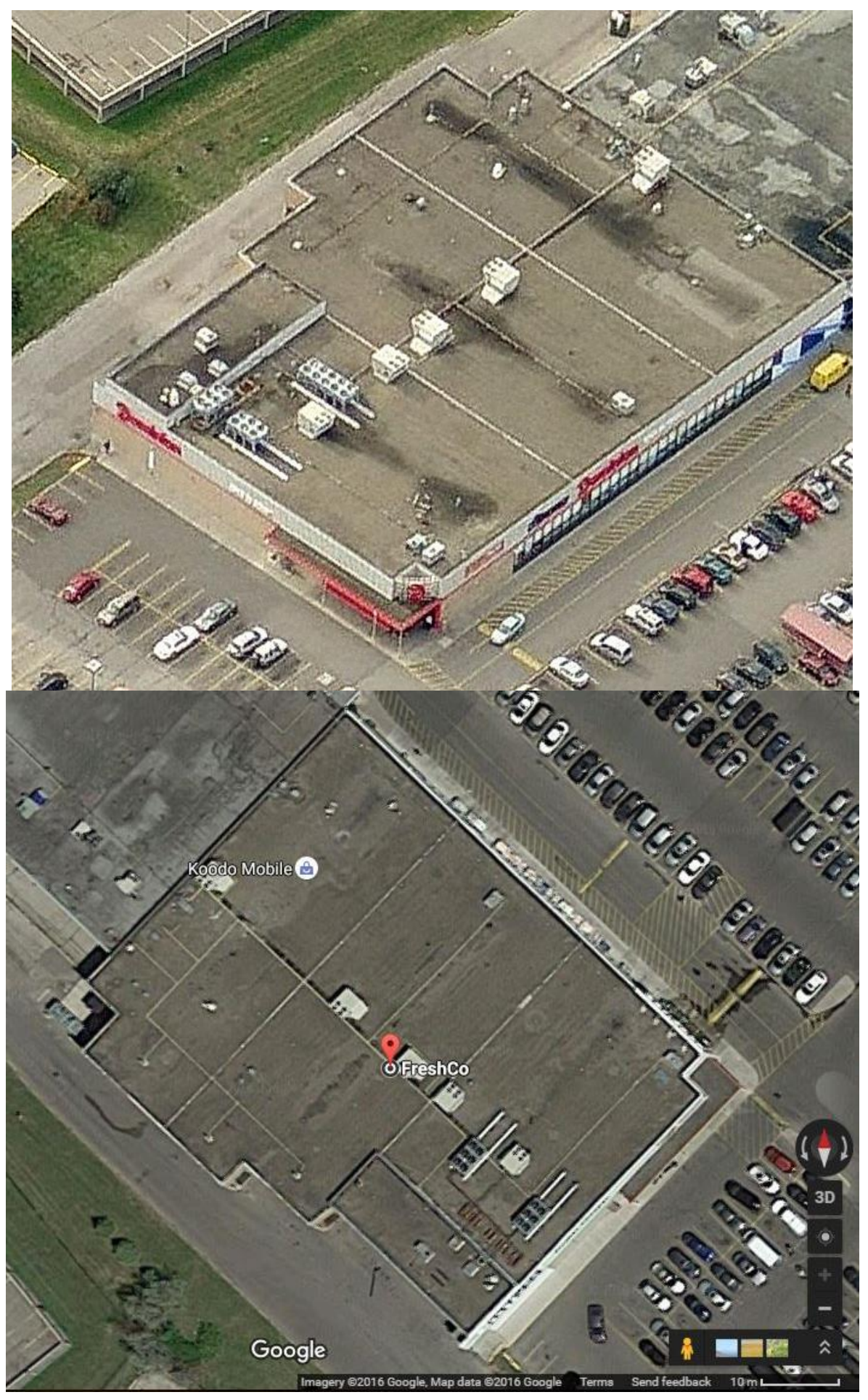

Figure 58 - FreshCo at 1151 Dundas St W 


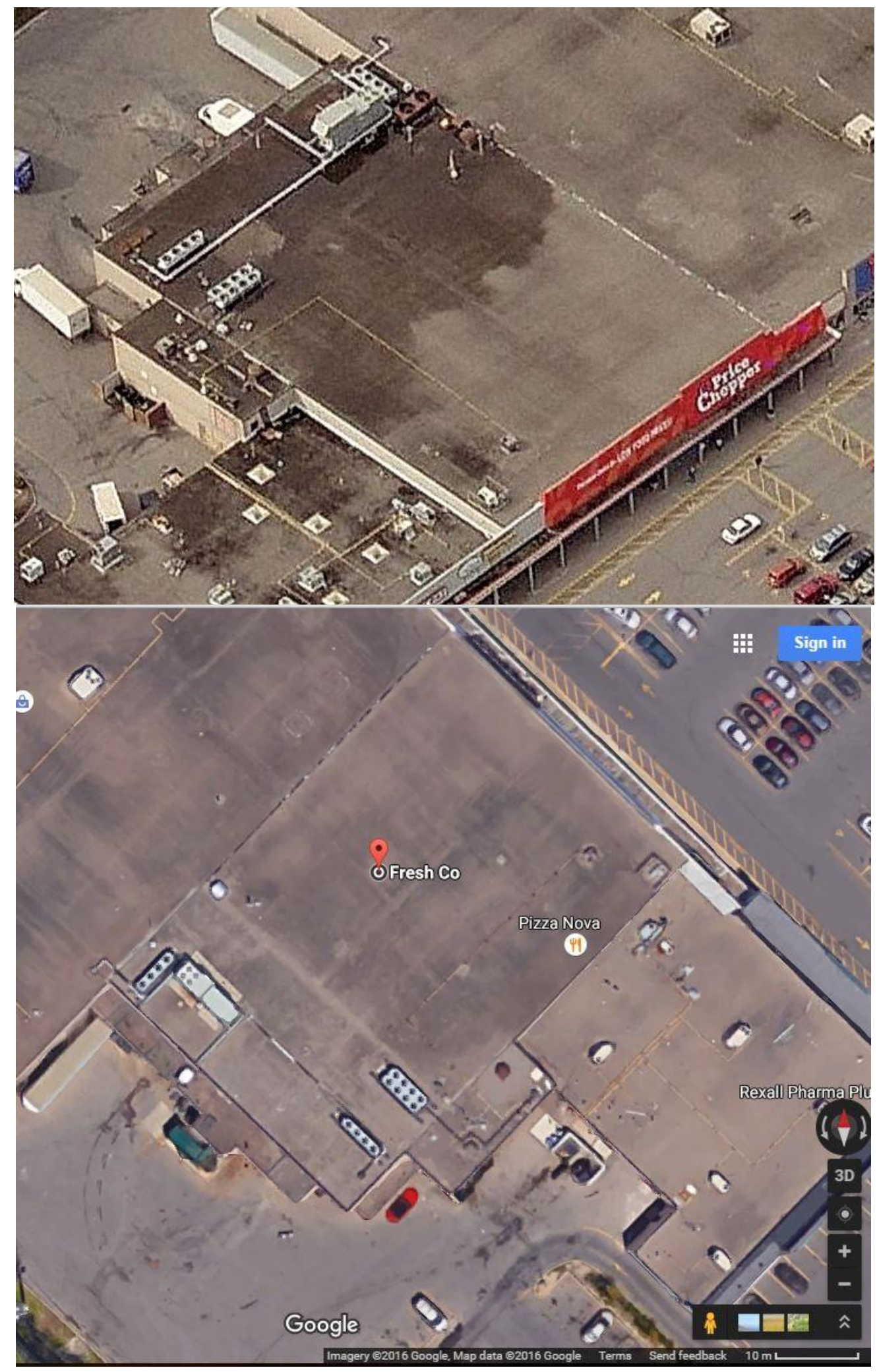

Figure 59 - FreshCo at 3100 Dixie Rd 


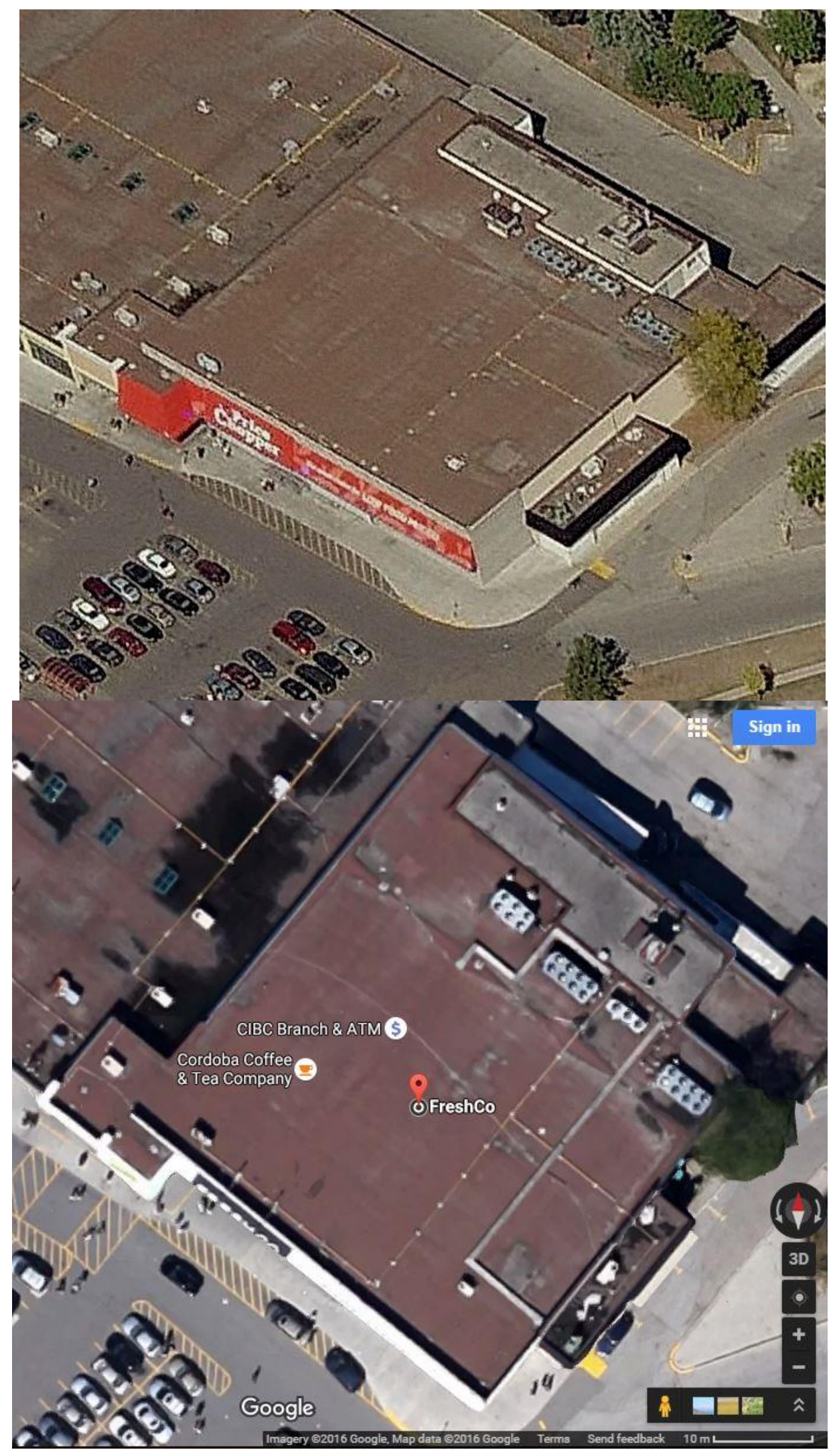

Figure 60 - FreshCo at 7205 Goreway Dr 


\section{2- Sobeys}

The only branch of Sobeys supermarket in Mississauga is located at 5602 Tenth Line West (Figure 61). The Google Maps and Bing Maps revealed that the roof is low-sloped and not overshadowed by surrounding buildings. The mechanical units also were isolated within its designated area.

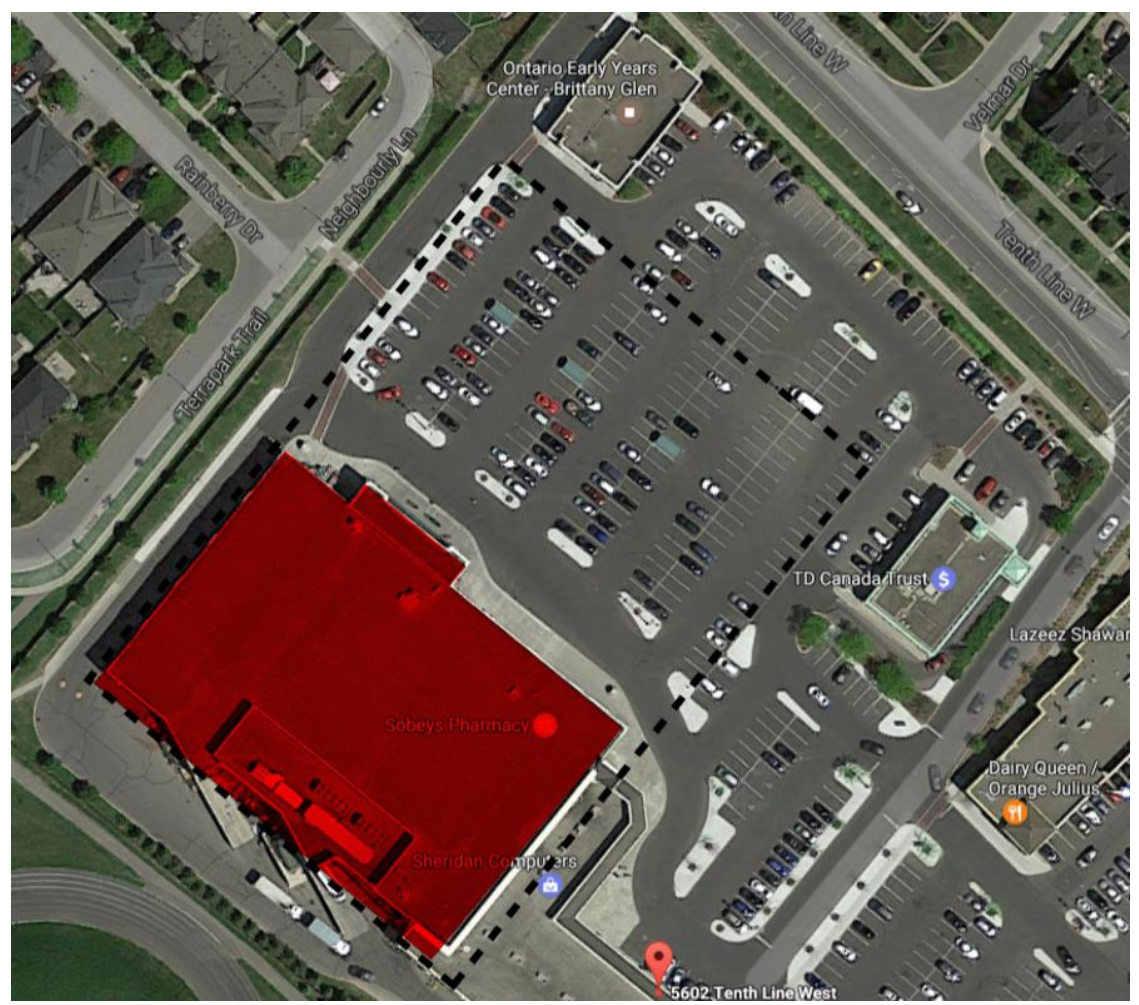

Figure 61 - Sobeys Branches in Mississauga

Figure 62, shows the roof morphology of this supermarket and Table 23 summarizes its information.

Table 23 - Data Summary of Sobeys Branches in Mississauga

\begin{tabular}{|c|c|c|c|c|c|c|c|c|}
\hline \multicolumn{2}{|c|}{ Sobeys Branch } & $\begin{array}{c}\text { Total } \\
\text { Groos } \\
\text { Area } \\
\left(\mathbf{m}^{2}\right)\end{array}$ & $\begin{array}{c}\text { Sloped } \\
\text { Portion \% }\end{array}$ & $\begin{array}{c}\text { Mechanical } \\
\text { Area }\left(\mathbf{m}^{2}\right)\end{array}$ & $\begin{array}{c}\text { Unoccupied } \\
\text { Area }\left(\mathbf{m}^{2}\right)\end{array}$ & Orientation & $\begin{array}{c}\text { Roof } \\
\text { Levels }\end{array}$ & $\begin{array}{c}\text { Approximate } \\
\text { Height }\end{array}$ \\
\hline $\mathbf{1}$ & $\mathbf{5 6 0 2}$ Tenth Line W & 4,535 & $0 \%$ & 110 & 3,395 & NW-SE & 1 & 8.2 \\
\hline
\end{tabular}




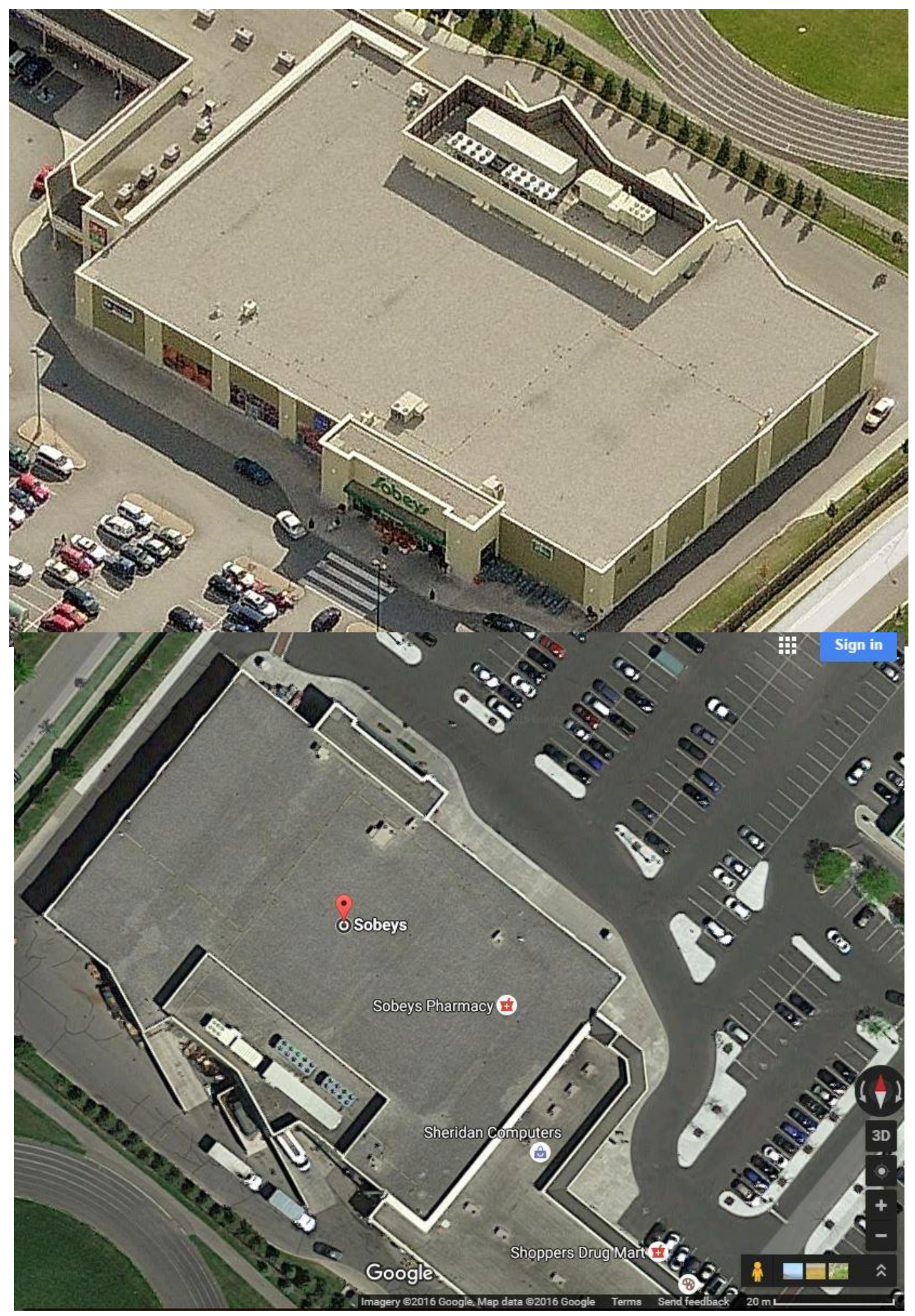

Figure 62 - Sobeys located at 5602 Tenth Line West 


\section{APPENDIX B: Snow Load Calculation}

In accordance to Division B Part 4 of the Ontario Building Code the load subject to snow or associated rain shall be calculated based on Article 4.1.6.2. or Article 4.1.6.4., whichever produces more critical effect ("Part 4 Structural Design," 2012).

The snow load for buildings in Ontario can be calculated from the following equation based on Article 4.1.6.2.:

$$
S=I_{S}\left[S_{s}\left(C_{b} C_{w} C_{s} C_{a}\right)+S_{r}\right]
$$

Factors,

$\mathrm{I}_{\mathrm{s}}$ (importance factor for snow load): 0.9

$\mathrm{S}_{\mathrm{s}}(1$-in-50-year ground snow load, in $\mathrm{kPa}): 1.1$

$\mathrm{C}_{\mathrm{b}}$ (basic roof snow load factor): 0.8

$\mathrm{C}_{\mathrm{w}}$ (wind exposure factor): 1.0

$\mathrm{C}_{\mathrm{s}}$ (slope factor): 1.0

$\mathrm{C}_{\mathrm{a}}$ (shape factor): 1.0

$S_{r}: 0.4$

\section{SLS:}

$S=0.9\left[1.1\left(0.8^{*} 1.0 * 1.0 * 1.0\right)+0.4\right]=1.15 \mathrm{kPa}$ or $S=\underline{1.15 \mathrm{kPa}}$

$(\mathrm{S}=\underline{24.1 \mathrm{psf})}$ 


\section{APPENDIX C: Tributary Area Load Calculation}

One storey supermarkets are usually long-span type of buildings with $10 \mathrm{~m} \times 10 \mathrm{~m}$ grid layout providing space for aisles and chillers either side ("Anatomy of a typical retail building," n.d.).

The spare snow load during summer time in tributary area of each column is equal to the extra exerted load from the vegetable assembly. The below equations was used to calculate the spare load in summer time for different layouts:

- Spare load for Middle Columns:

$$
\left(\frac{a b+b c}{2}\right)\left(\frac{x+y}{2}\right) S
$$

- Spare load for Side Columns:

$$
\left(\frac{b c+c d}{2}\right)\left(\frac{x}{2}\right) S
$$

- Spare load for Corner Columns:

$$
\left(\frac{a b}{2}\right)\left(\frac{x}{2}\right) S
$$

$\left({ }^{*} \mathrm{~S}\right.$ is Snow Load)

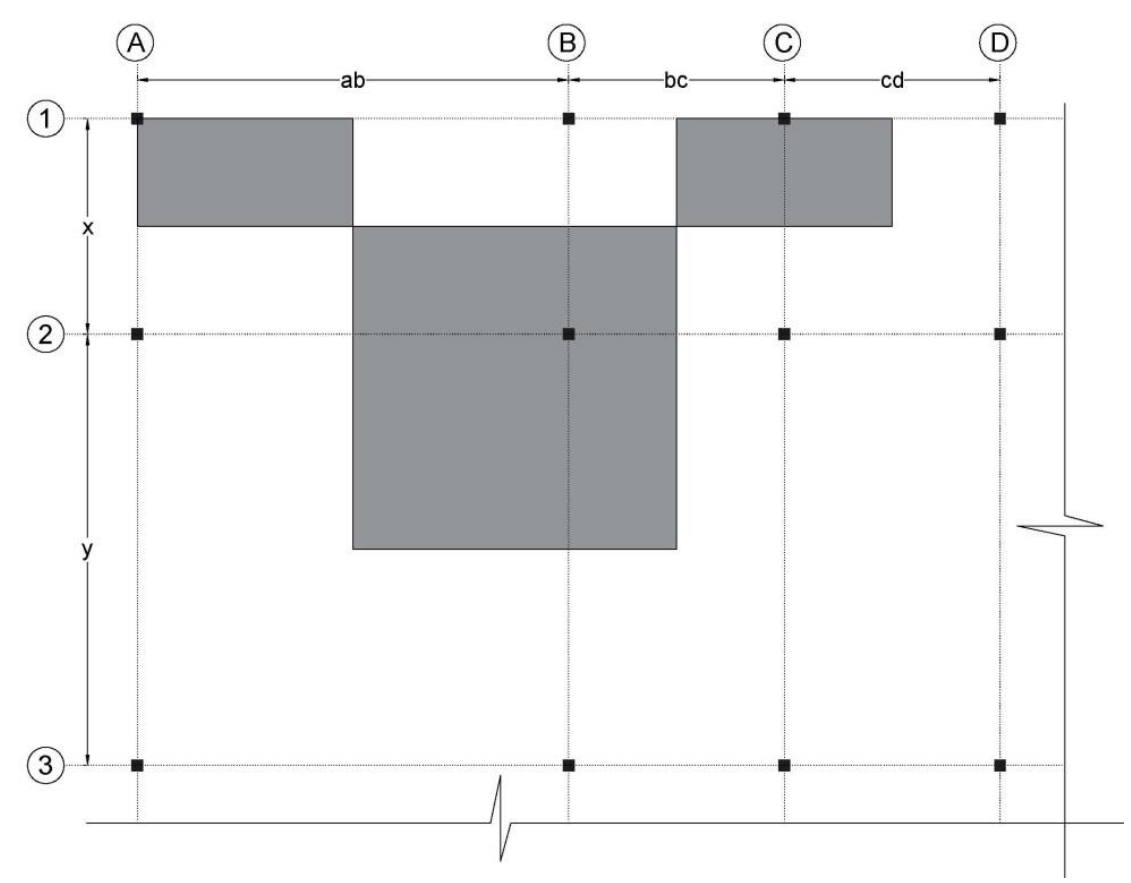

Figure 63 - Tributary Area of Columns 
Loblaws at 5010 Glen Erin Drive Mississauga, ON

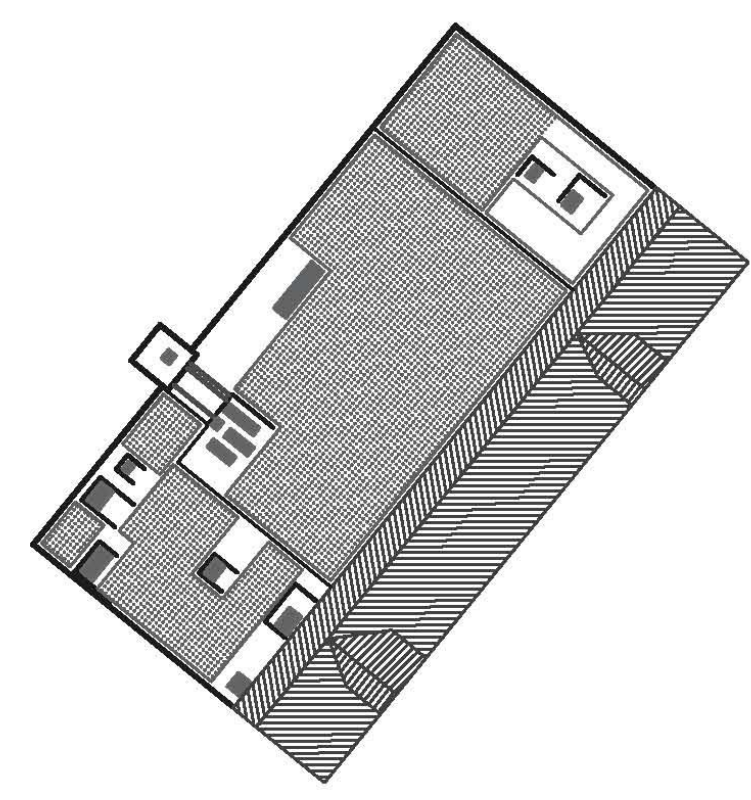

Potential Area for Extensive Assembly
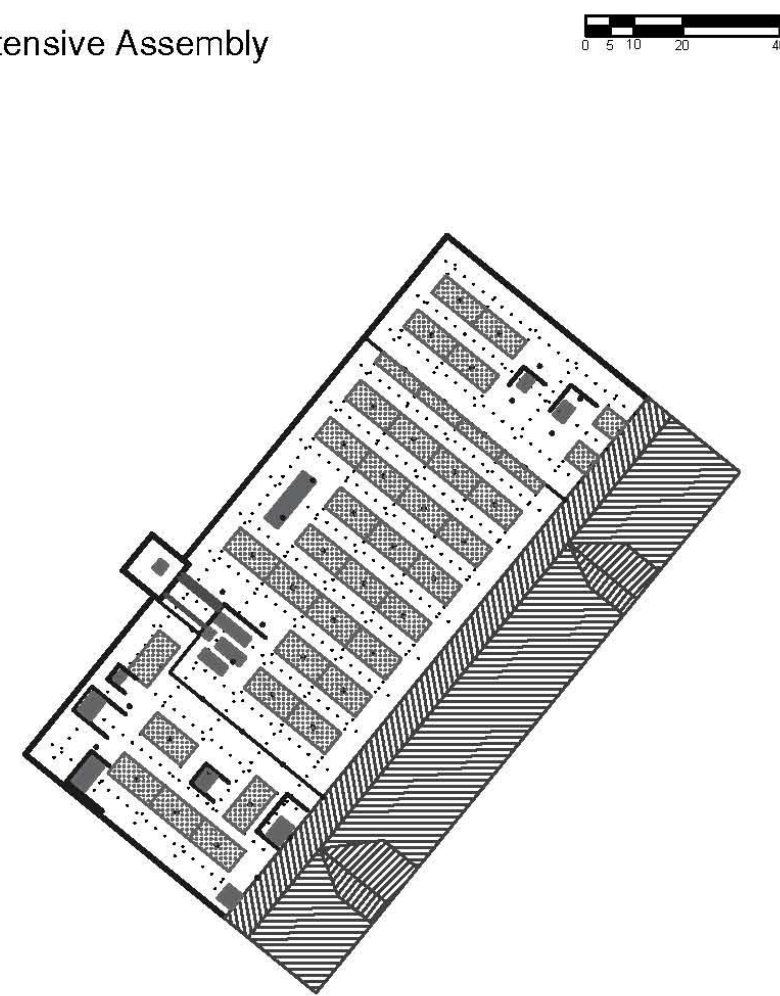

$\oplus$

\begin{tabular}{|l|c|}
\hline & $\begin{array}{c}\text { Area } \\
\text { (sq.m.) }\end{array}$ \\
\hline Rooftop Area & 10,840 \\
\hline Sloped Area & 3,395 \\
\hline Mechanical Area & 195 \\
\hline Potential Area (Extensive Assembly) & 4,934 \\
\hline Potential Area (20 cm Intensive Assembly) & 1,922 \\
\hline Potential Area (40 cm Intensive Assembly) & 961 \\
\hline
\end{tabular}

$\oplus$
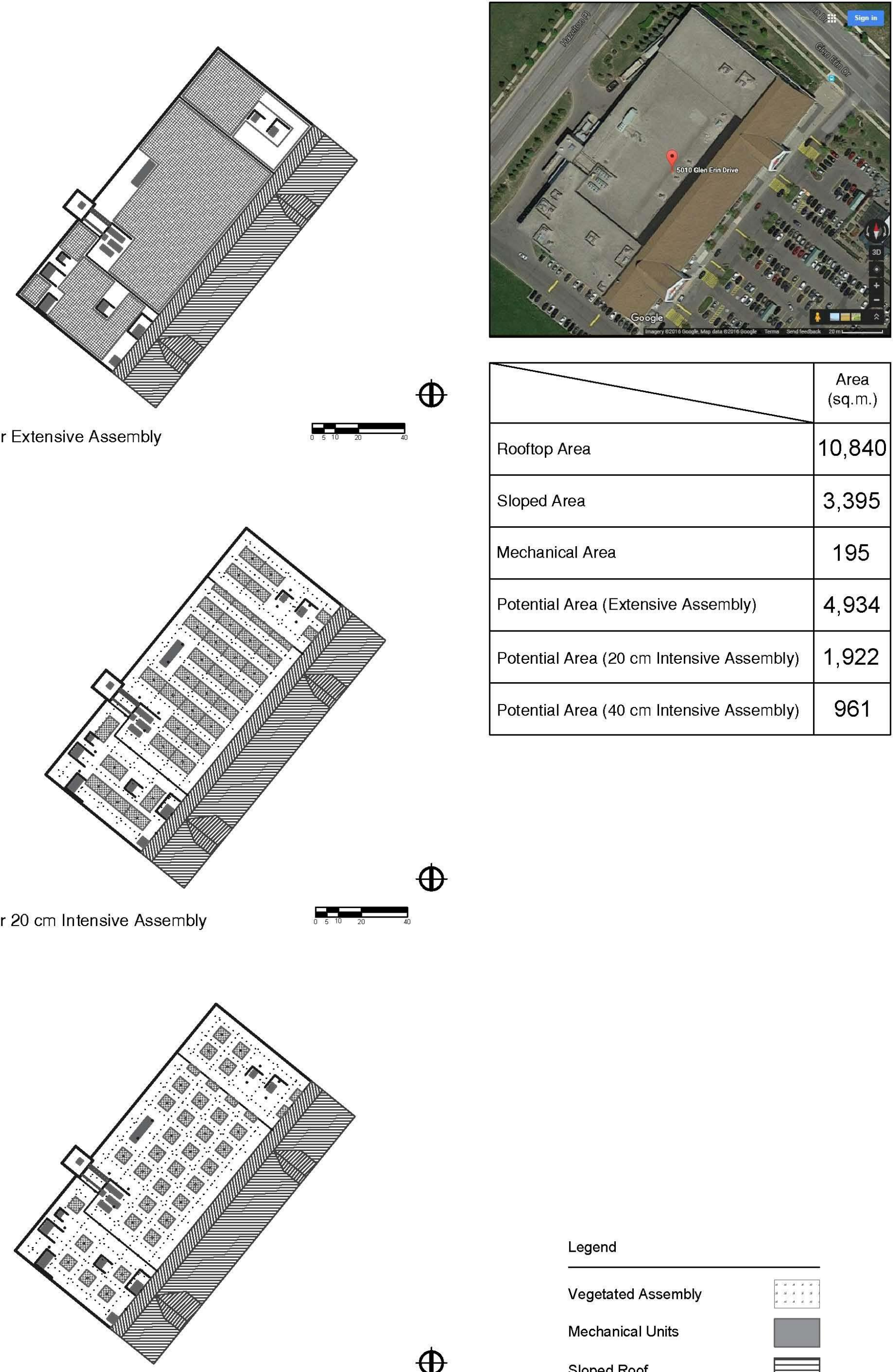

$\oplus$

\begin{tabular}{ll}
\hline Vegetated Assembly \\
Mechanical Units \\
Sloped Roof
\end{tabular}

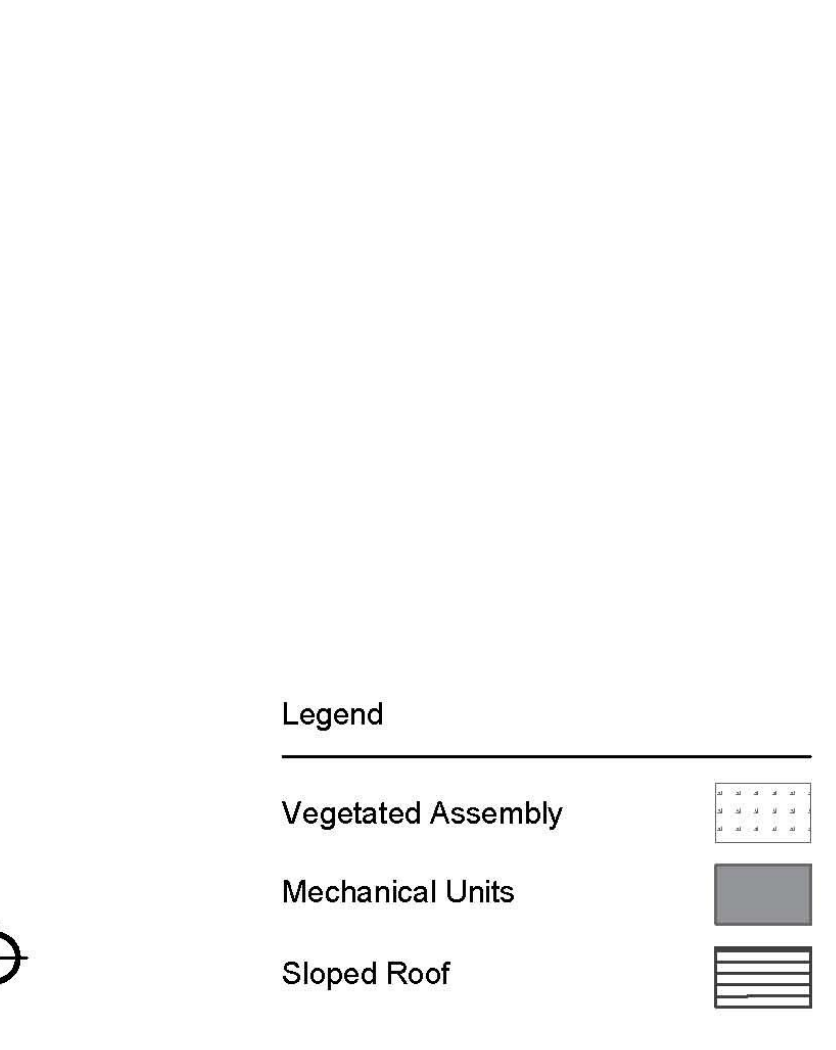

Potential Area for $40 \mathrm{~cm}$ Intensive Assembly

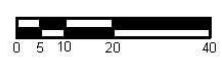




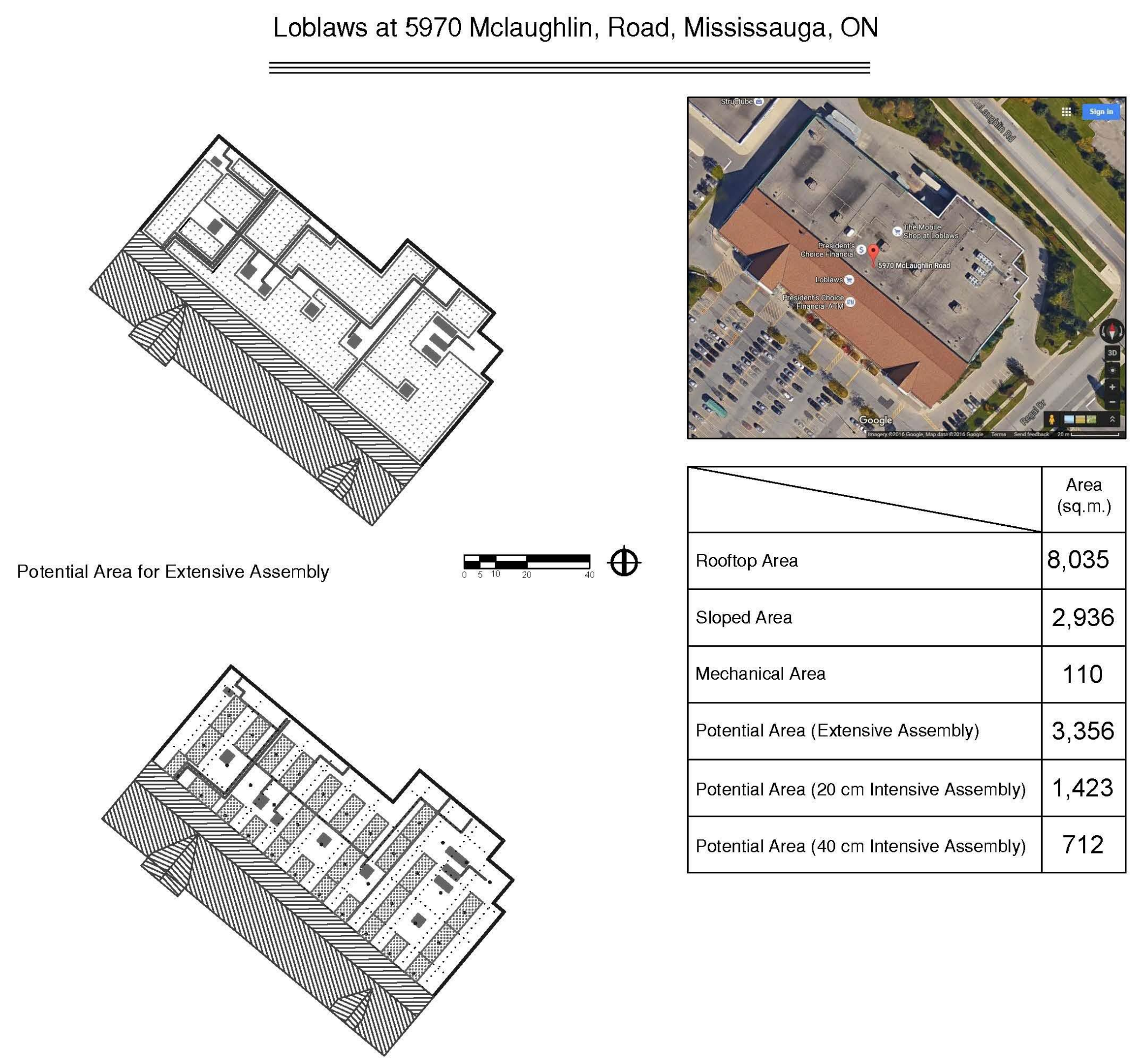

Potential Area for $20 \mathrm{~cm}$ Intensive Assembly

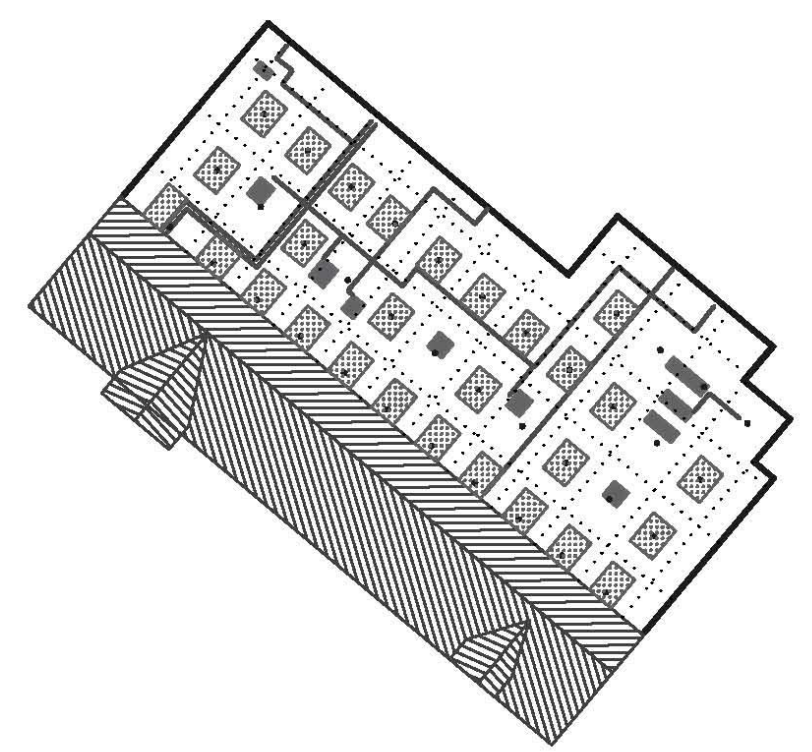

Legend

Vegetated Assembly

Mechanical Units

Sloped Roof 


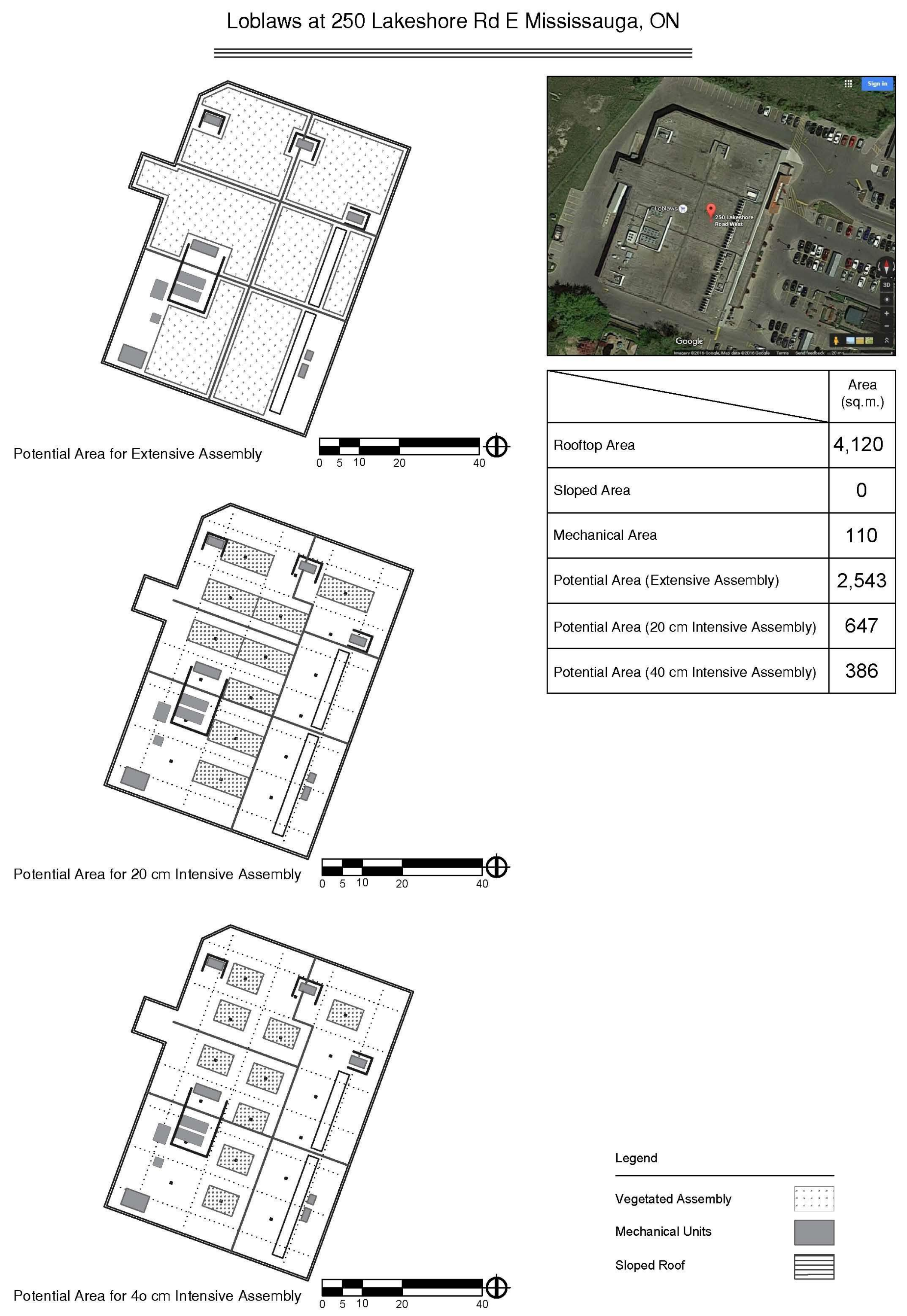


NoFrills at 2150 Burnhamthorpe Rd W Mississauga, ON
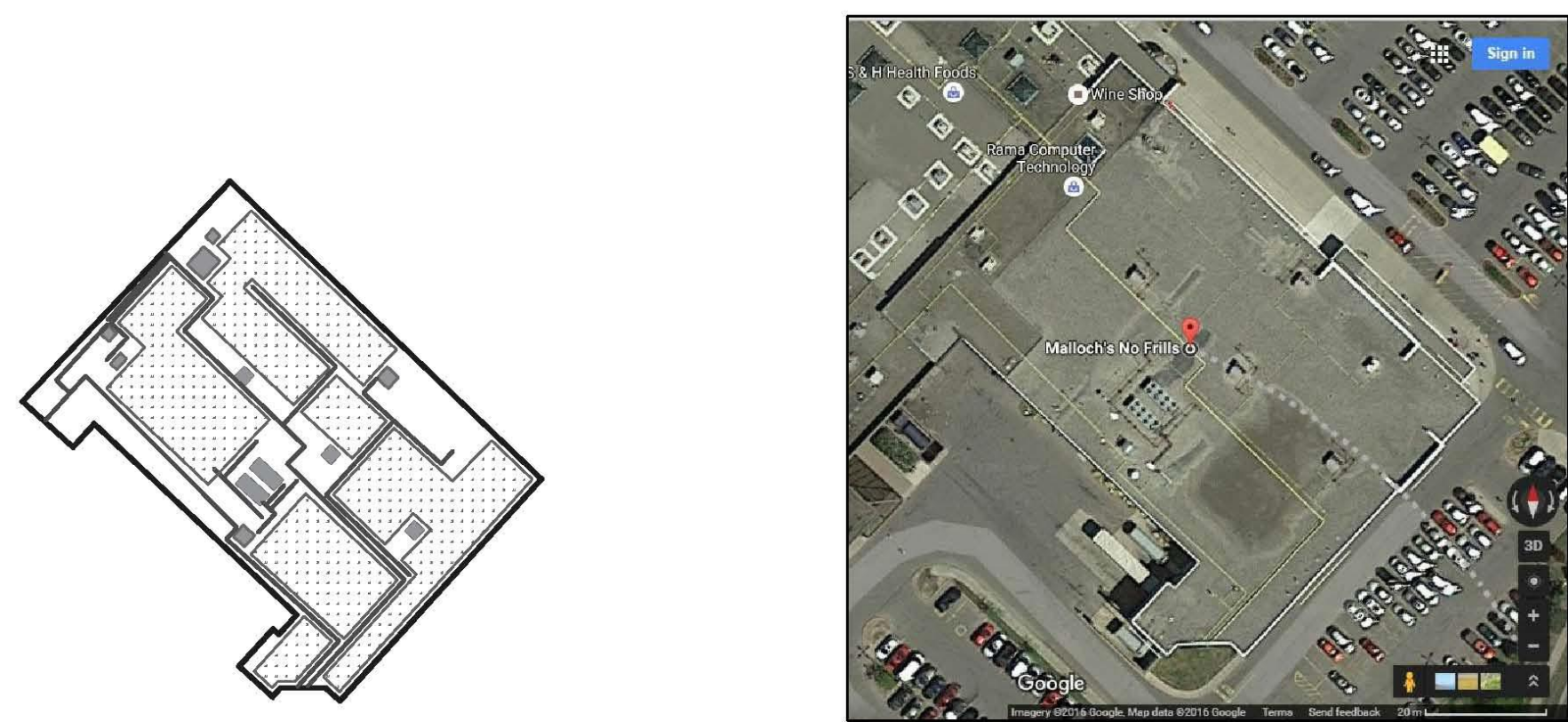

Potential Area for Extensive Assembly

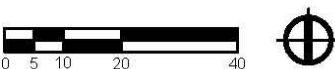

\begin{tabular}{|l|c|}
\hline & $\begin{array}{c}\text { Area } \\
\text { (sq.m.) }\end{array}$ \\
\hline Rooftop Area & 4,555 \\
\hline Sloped Area & 0 \\
\hline Mechanical Area & 100 \\
\hline Potential Area (Extensive Assembly) & 2,508 \\
\hline Potential Area (20 cm Intensive Assembly) & 824 \\
\hline Potential Area (40 cm Intensive Assembly) & 412 \\
\hline
\end{tabular}

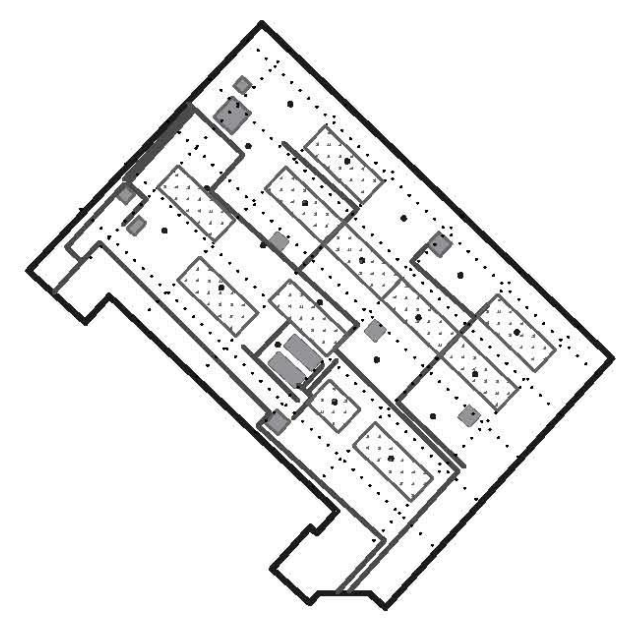

$\oplus$

Potential Area for $20 \mathrm{~cm}$ Intensive Assembly
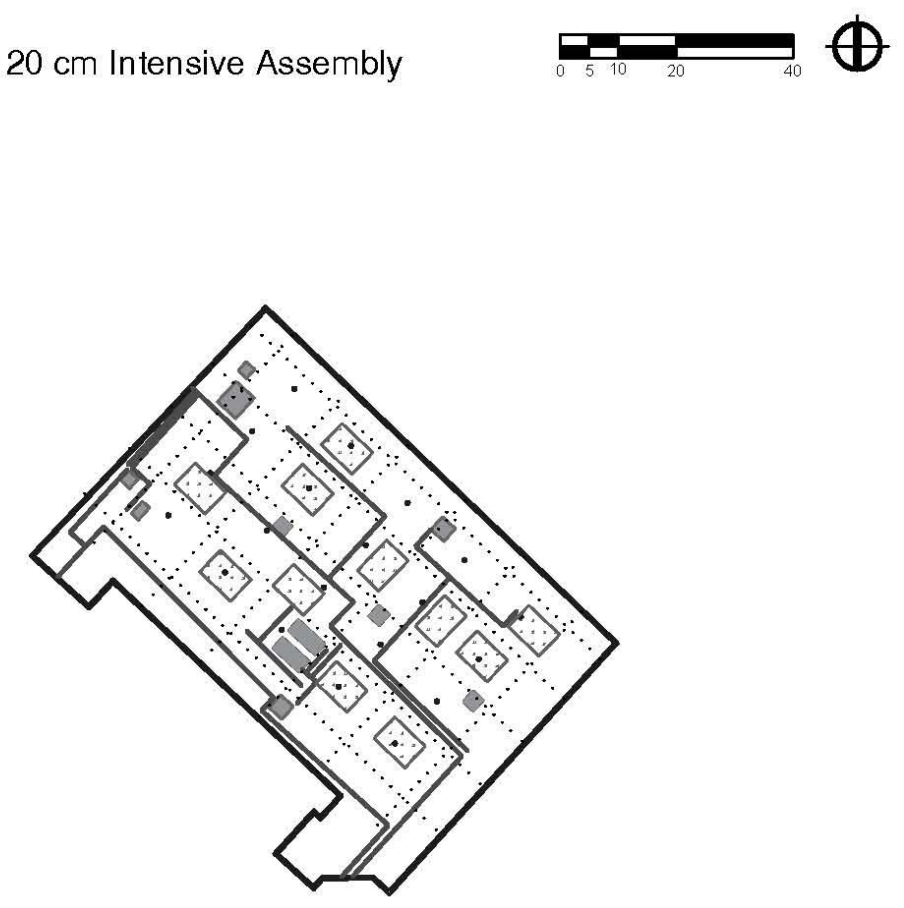

Legend
Vegetated Assembly
Mechanical Units
Sloped Roof

Potential Area for $40 \mathrm{~cm}$ Intensive Assembly

$\oplus$ 
NoFrills at 620 Eglinton Ave W, Mississauga, ON
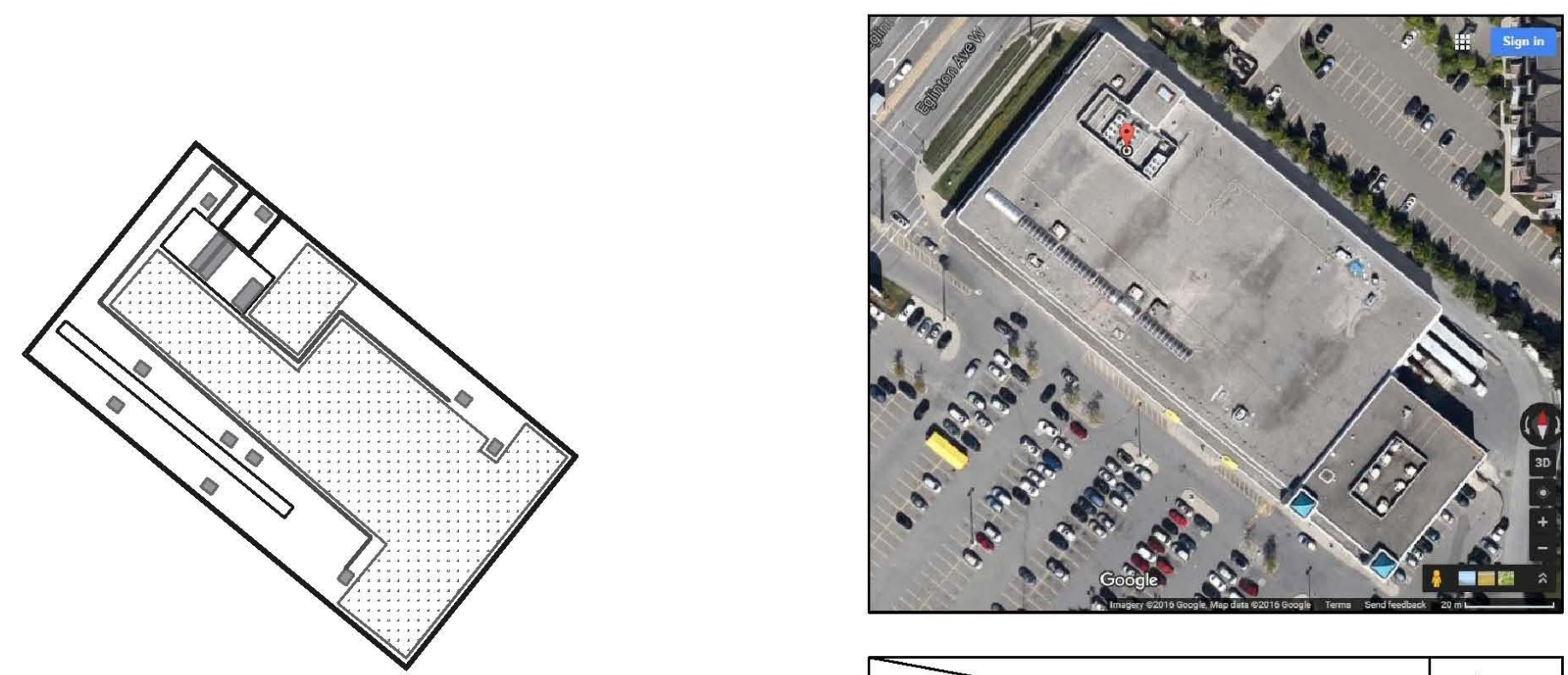

Potential Area for Extensive Assembly
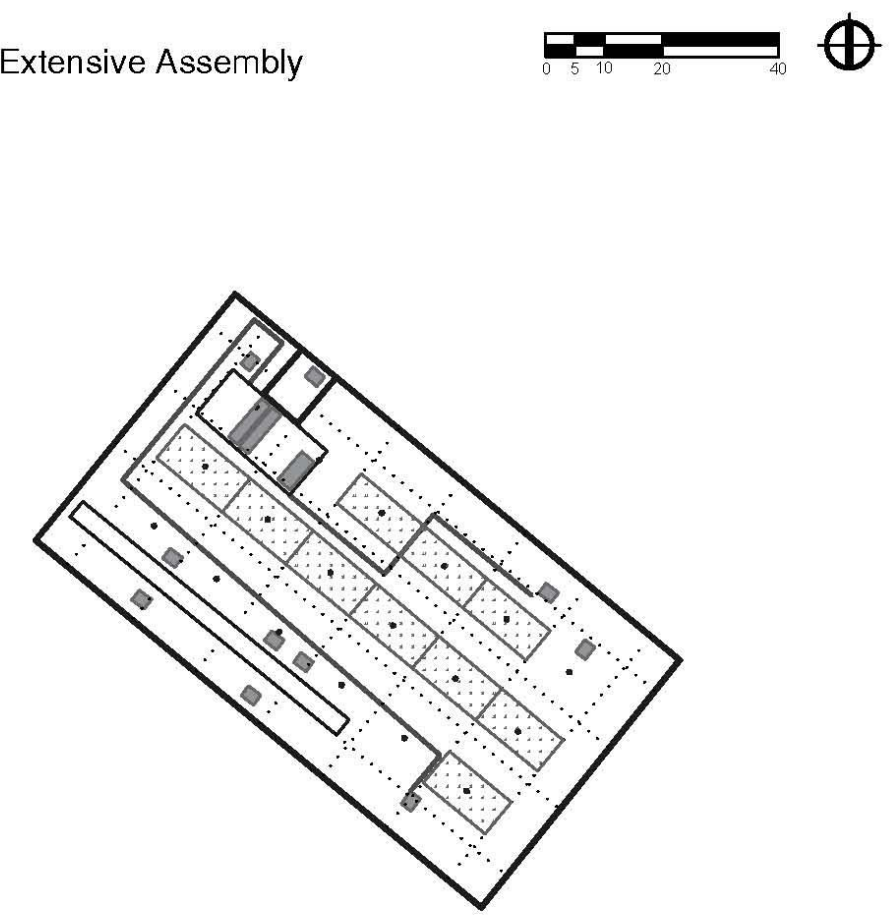

\begin{tabular}{|l|c|}
\hline & $\begin{array}{c}\text { Area } \\
\text { (sq.m.) }\end{array}$ \\
\hline Rooftop Area & 5,330 \\
\hline Sloped Area & 0 \\
\hline Mechanical Area & 110 \\
\hline Potential Area (Extensive Assembly) & 2,660 \\
\hline Potential Area (20 cm Intensive Assembly) & 991 \\
\hline Potential Area (40 cm Intensive Assembly) & 496 \\
\hline
\end{tabular}

Potential Area for $20 \mathrm{~cm}$ Intensive Assembly
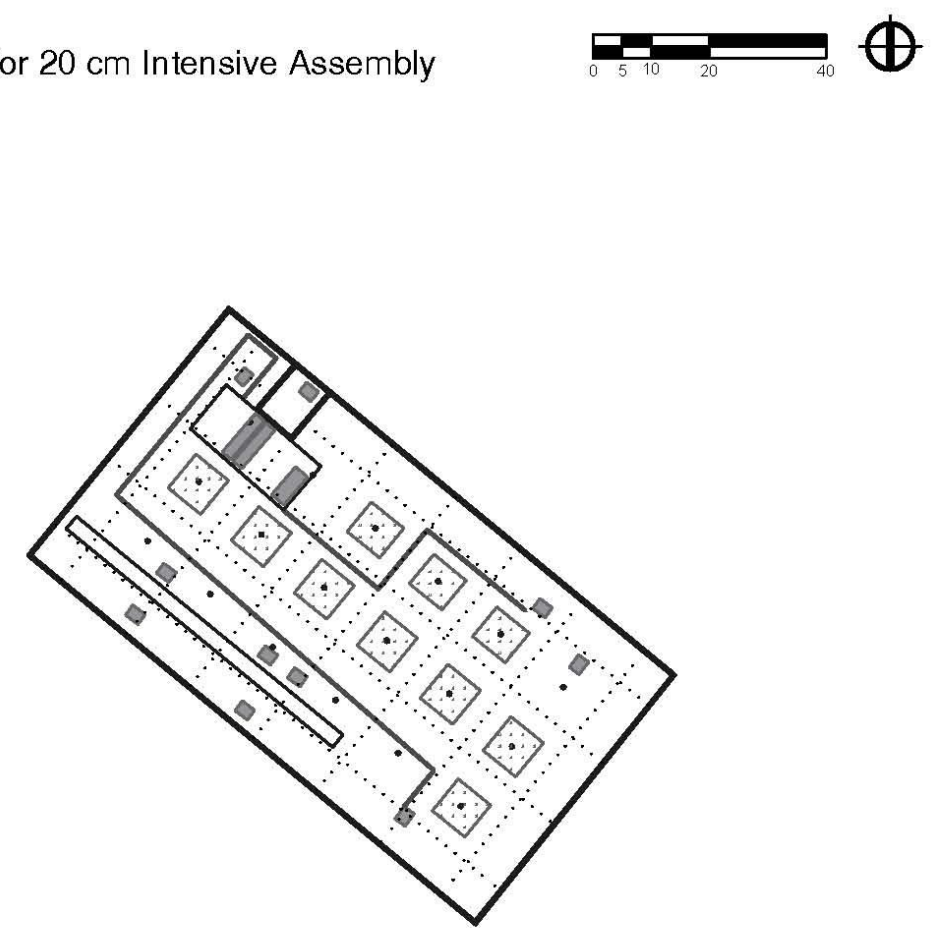

Legend

Vegetated Assembly

Mechanical Units

Sloped Roof 


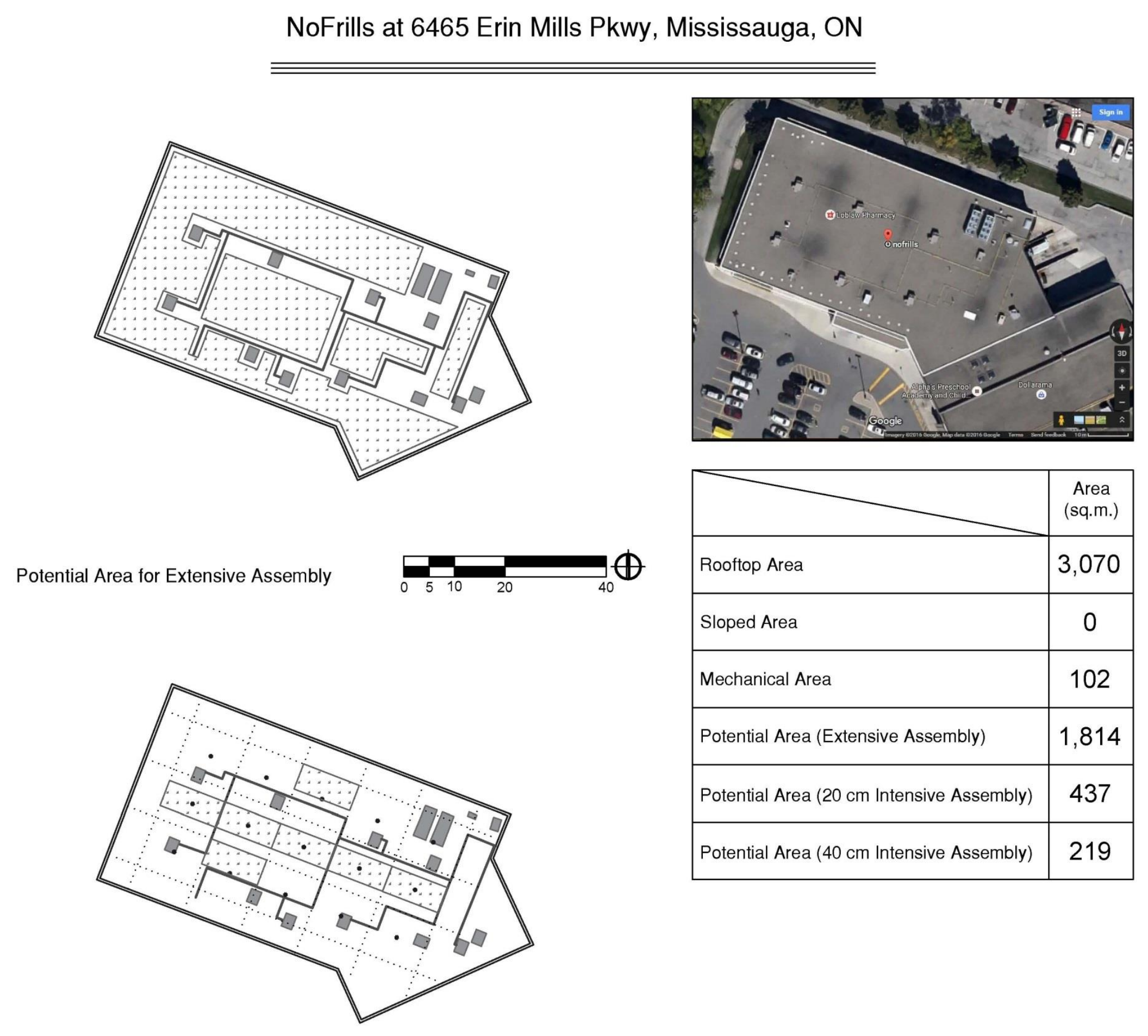

Potential Area for $20 \mathrm{~cm}$ Intensive Assembly
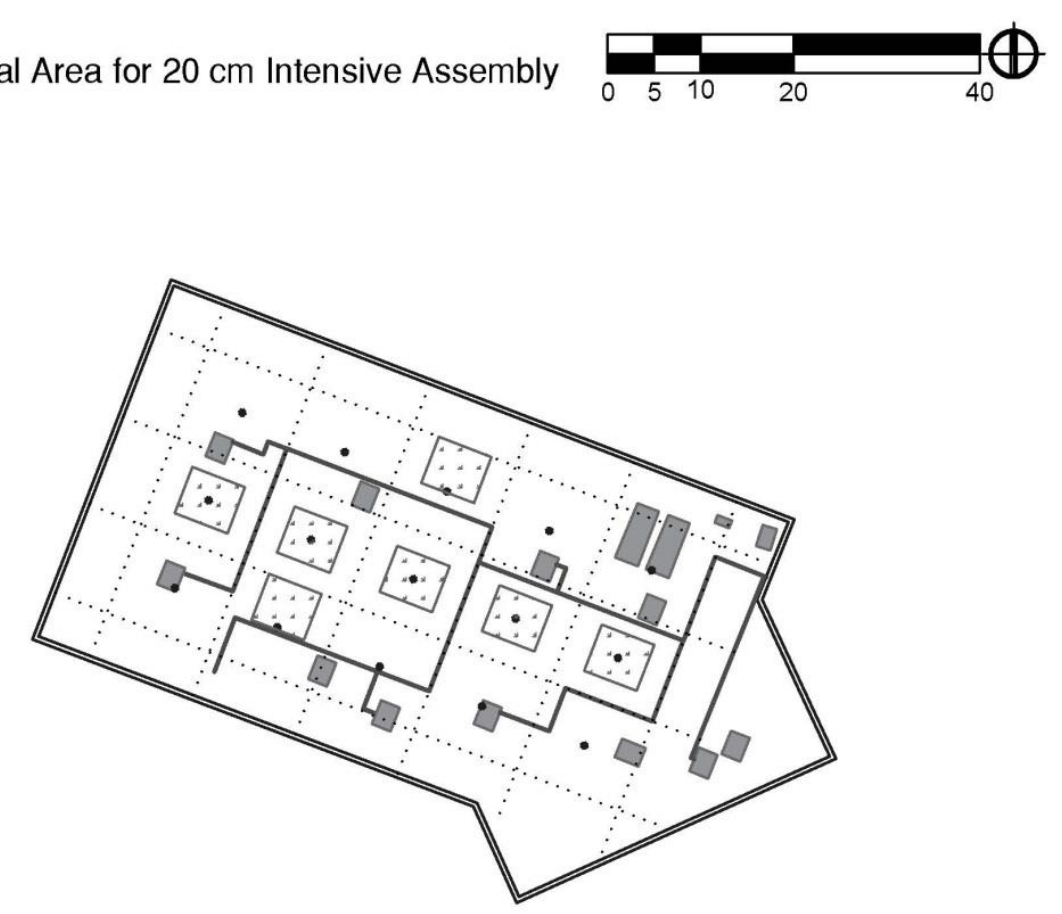

\begin{tabular}{l} 
Legend \\
\hline Vegetated Assembly \\
Mechanical Units \\
Sloped Roof
\end{tabular}

Potential Area for $40 \mathrm{~cm}$ Intensive Assembly

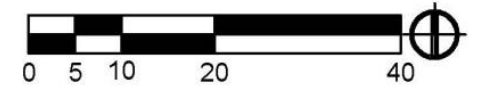

$$
\text { (1) }
$$


NoFrills at 4040 Creditview Rd, Mississauga, ON

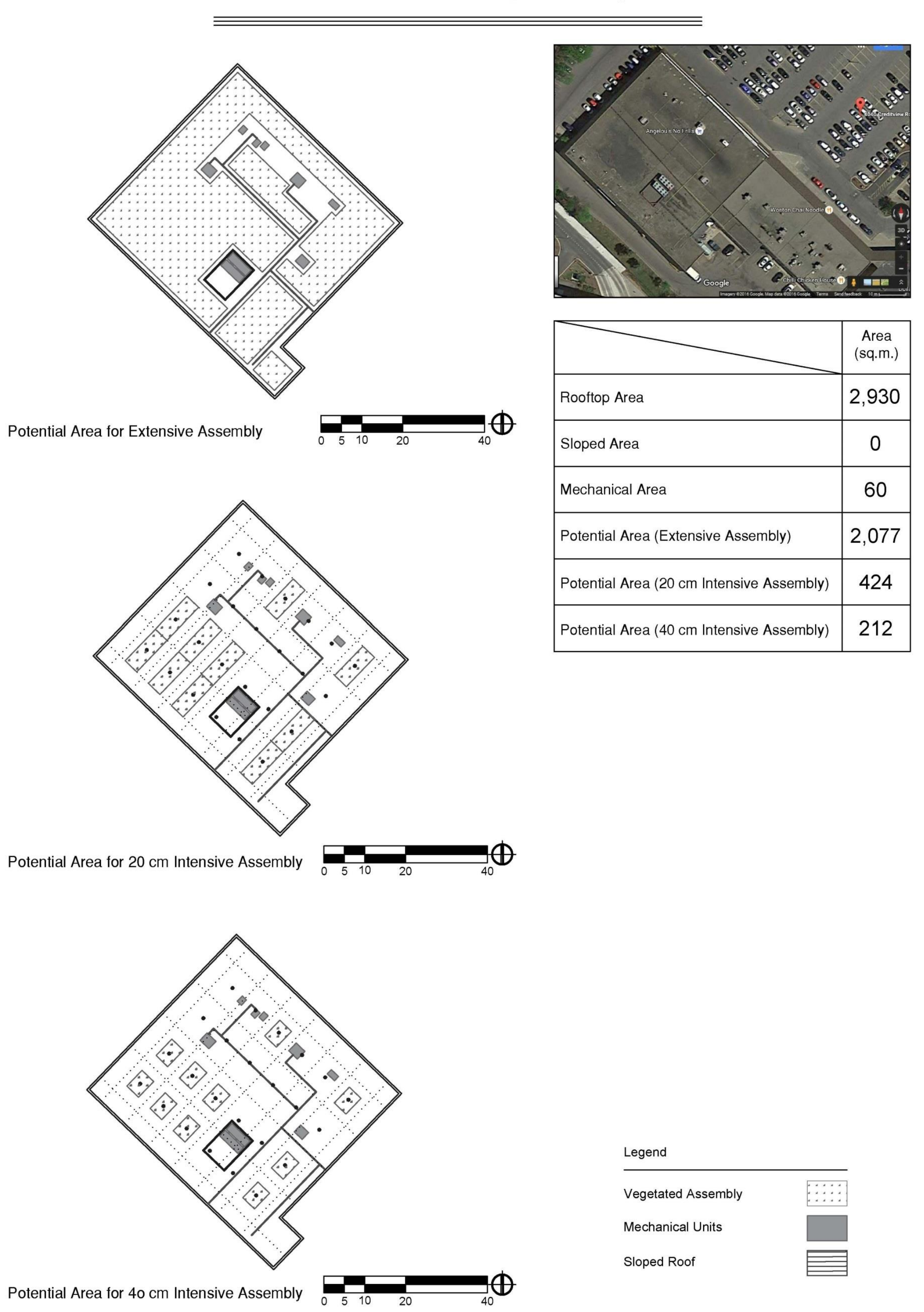




\section{NoFrills at 7070 McLaughlin Rd, Mississauga, ON}

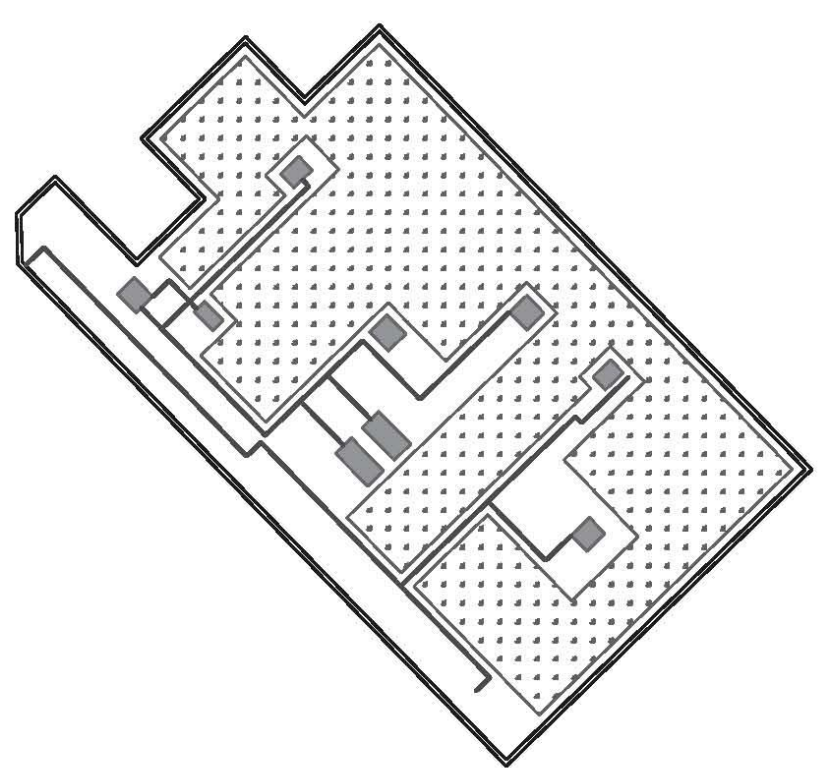

Potential Area for Extensive Assembly
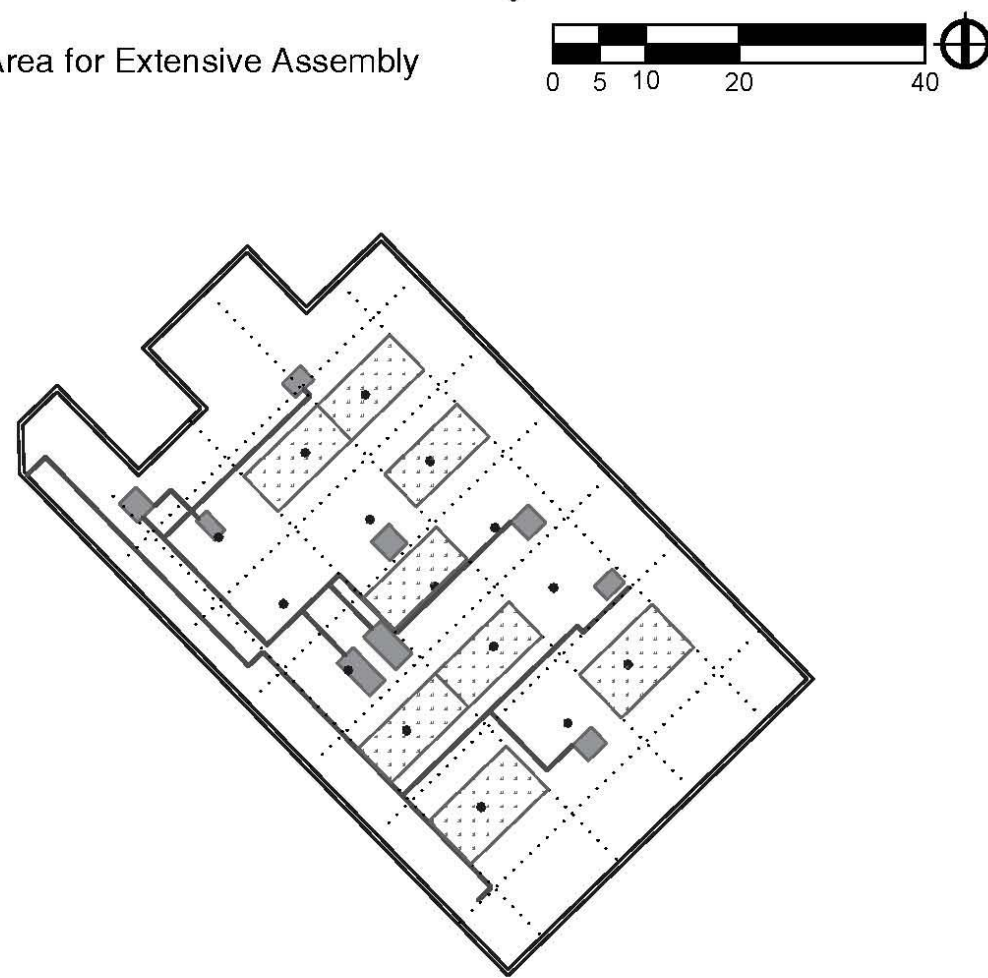

Potential Area for $20 \mathrm{~cm}$ Intensive Assembly

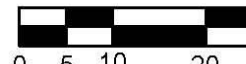

$\oplus$

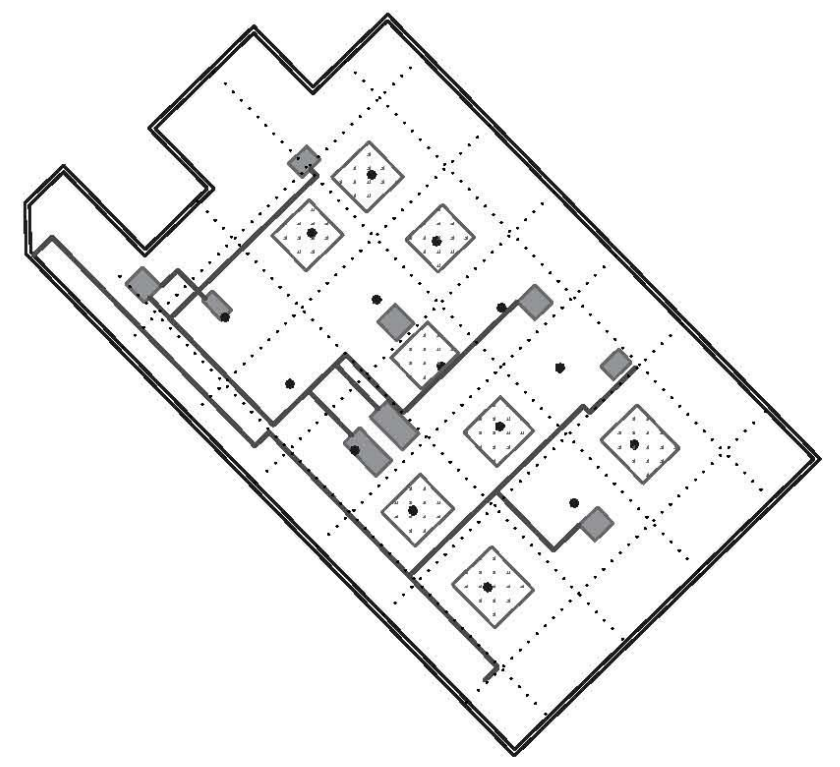

Potential Area for $40 \mathrm{~cm}$ Intensive Assembly

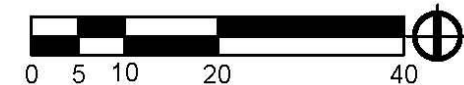

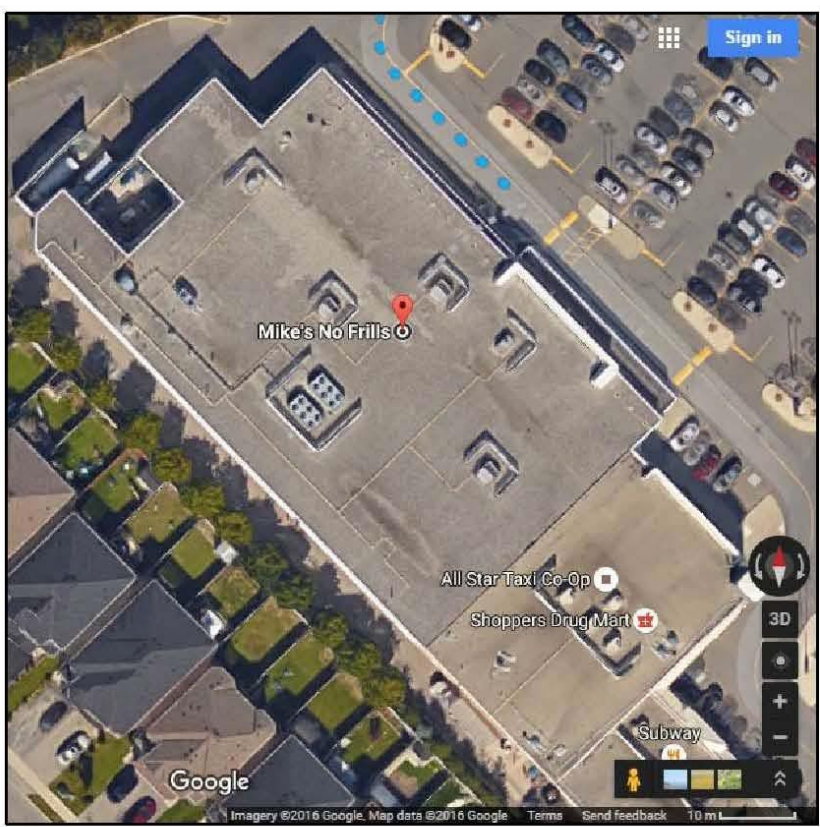

\begin{tabular}{|l|c|}
\hline & $\begin{array}{c}\text { Area } \\
\text { (sq.m.) }\end{array}$ \\
\hline Rooftop Area & 3,180 \\
\hline Sloped Area & 0 \\
\hline Mechanical Area & 80 \\
\hline Potential Area (Extensive Assembly) & 1,867 \\
\hline Potential Area (20 cm Intensive Assembly) & 482 \\
\hline Potential Area (40 cm Intensive Assembly) & 241 \\
\hline
\end{tabular}

Legend
Vegetated Assembly
Mechanical Units
Sloped Roof




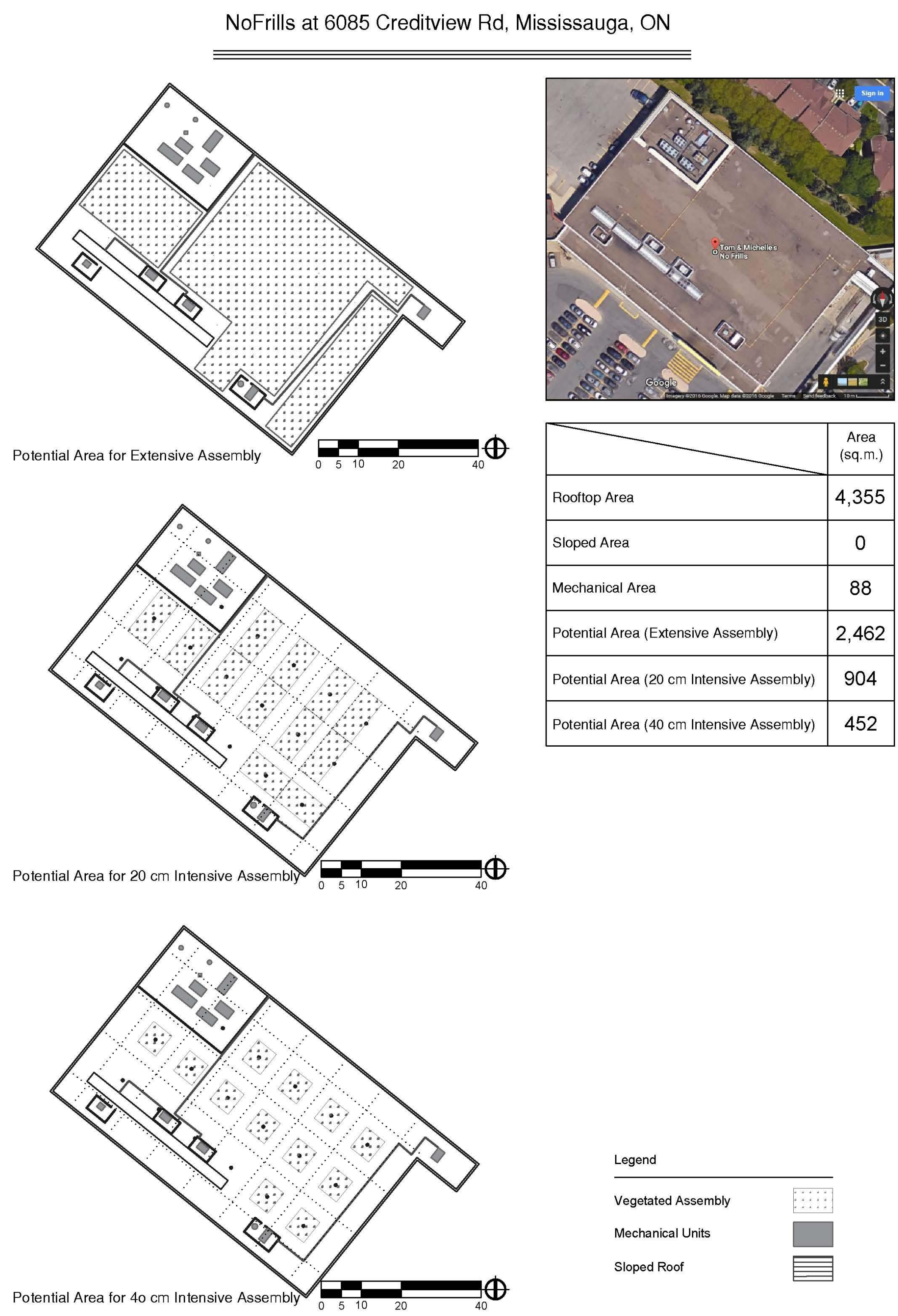




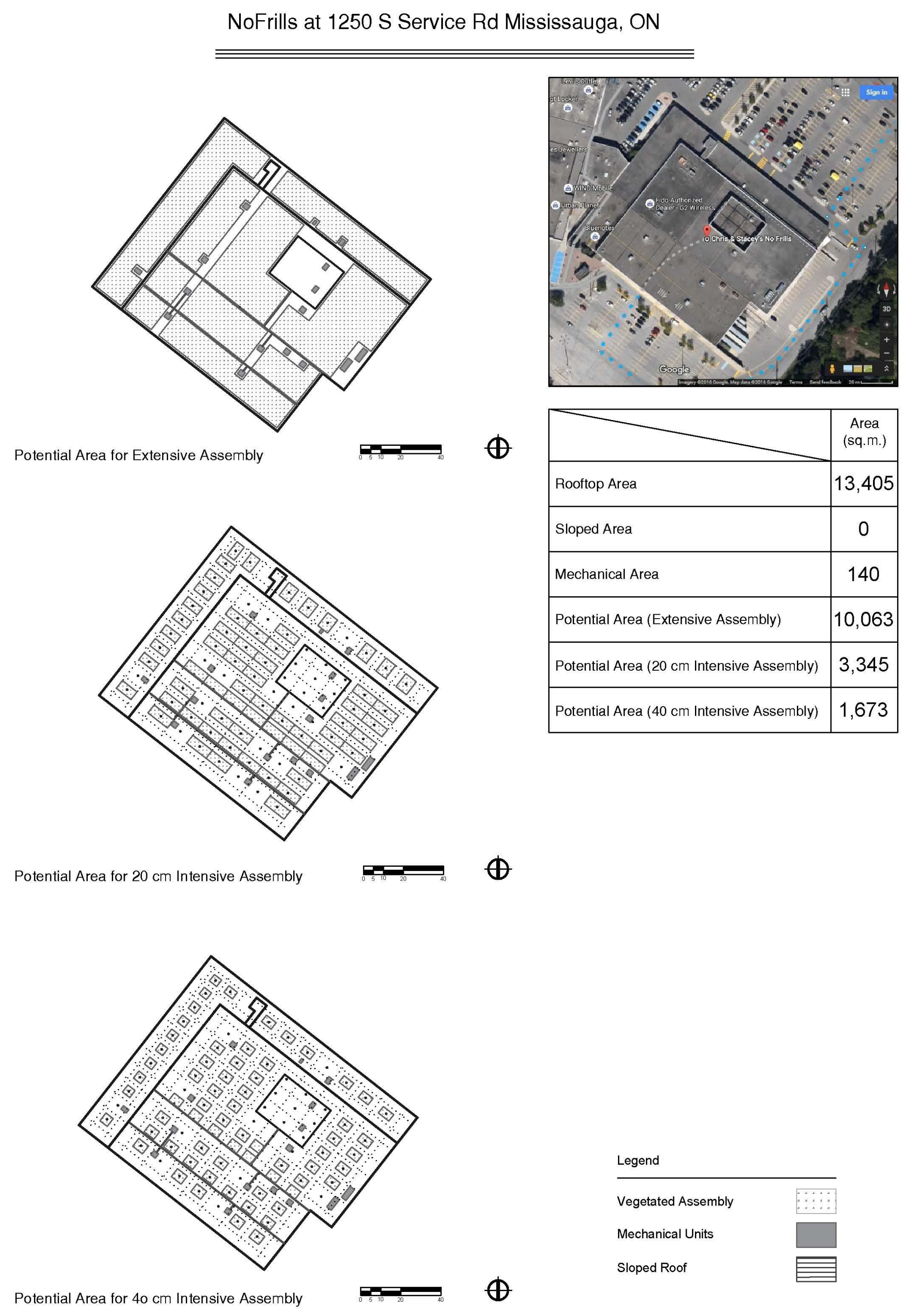


Food Basics at 3476 Glen Erin Dr, Mississauga, ON
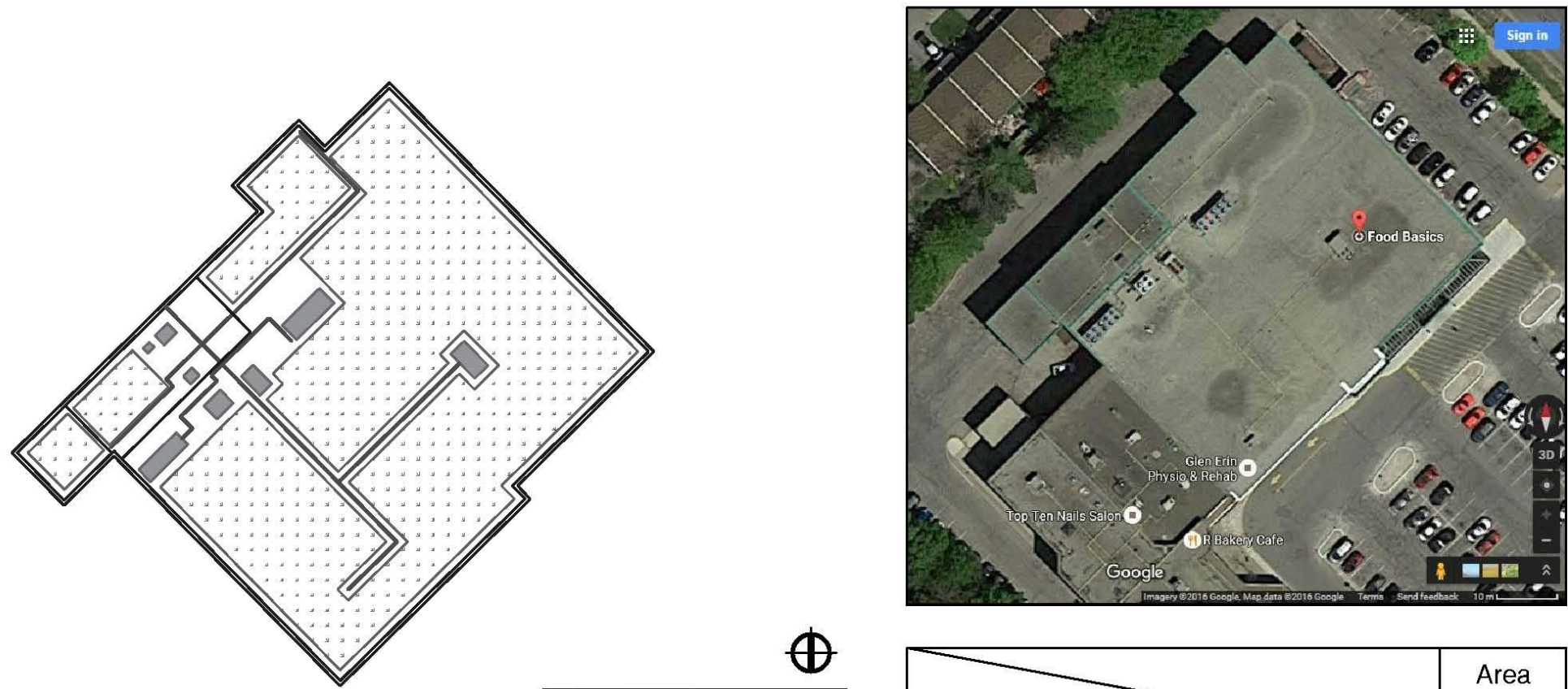

Potential Area for Extensive Assembly

(1)

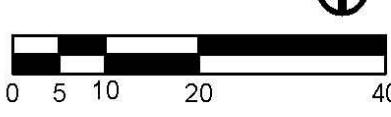

\begin{tabular}{|l|c|}
\hline & $\begin{array}{c}\text { Area } \\
\text { (sq.m.) }\end{array}$ \\
\hline Rooftop Area & 3,140 \\
\hline Sloped Area & 0 \\
\hline Mechanical Area & 95 \\
\hline Potential Area (Extensive Assembly) & 2,300 \\
\hline Potential Area (20 cm Intensive Assembly) & 504 \\
\hline Potential Area (40 cm Intensive Assembly) & 252 \\
\hline
\end{tabular}

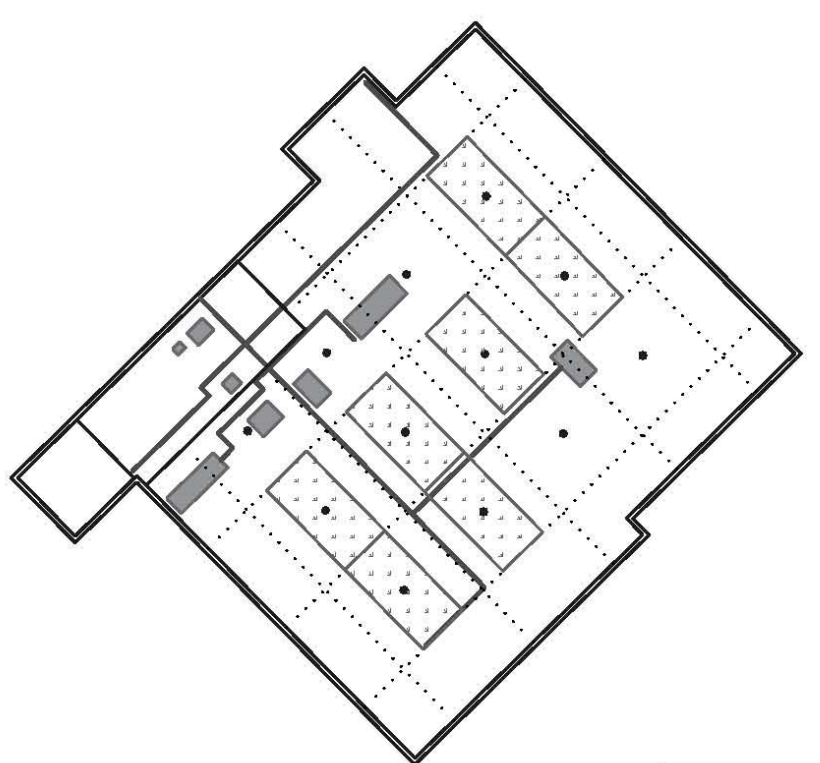

$\oplus$

Potential Area for $20 \mathrm{~cm}$ Intensive Assembly
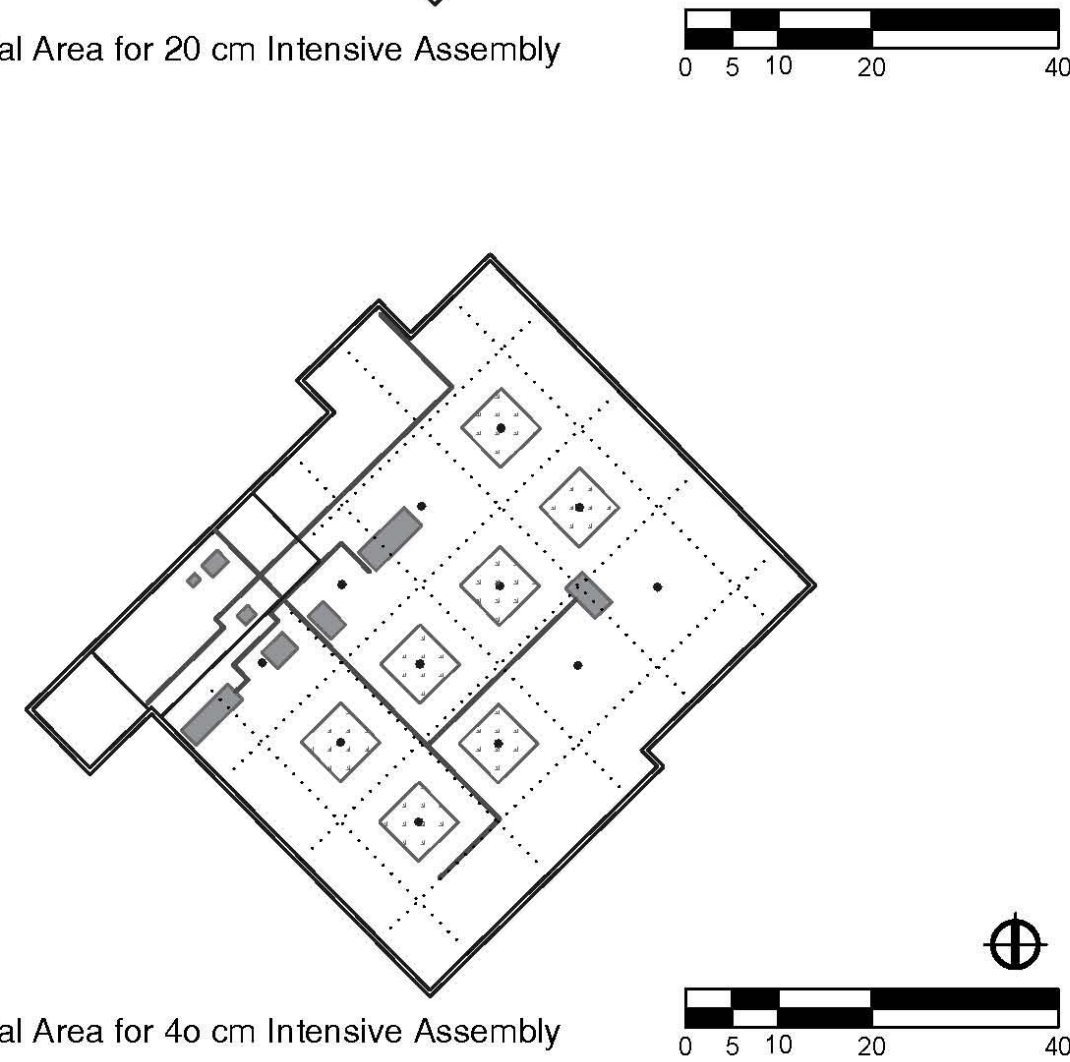

Legend
Vegetated Assembly
Mechanical Units
Sloped Roof

Potential Area for $40 \mathrm{~cm}$ Intensive Assembly

$\oplus$ 40 
377 Burnhamthorpe Rd E Mississauga, ON
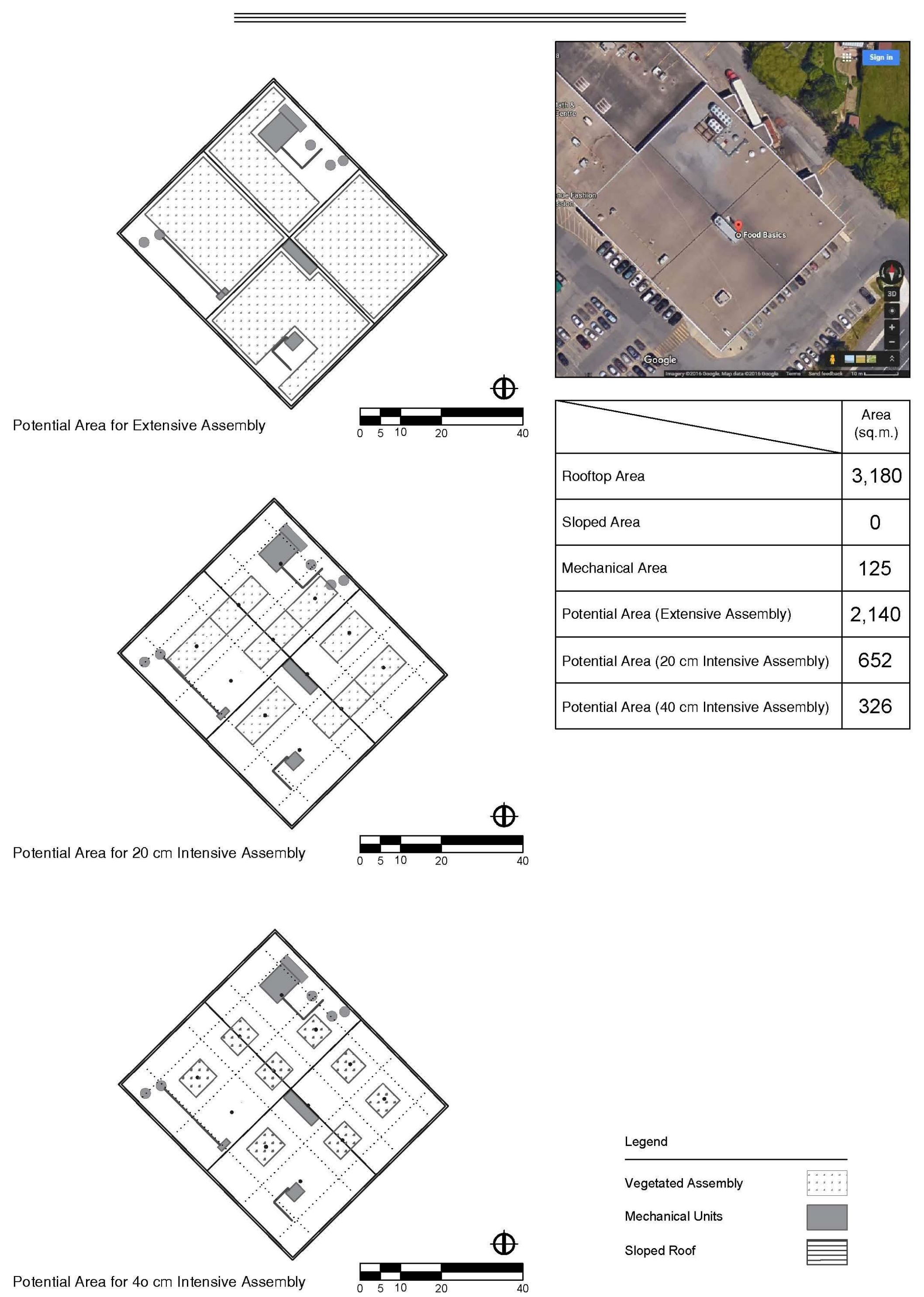
Food Basics at 2550 Hurontario St Mississauga, ON
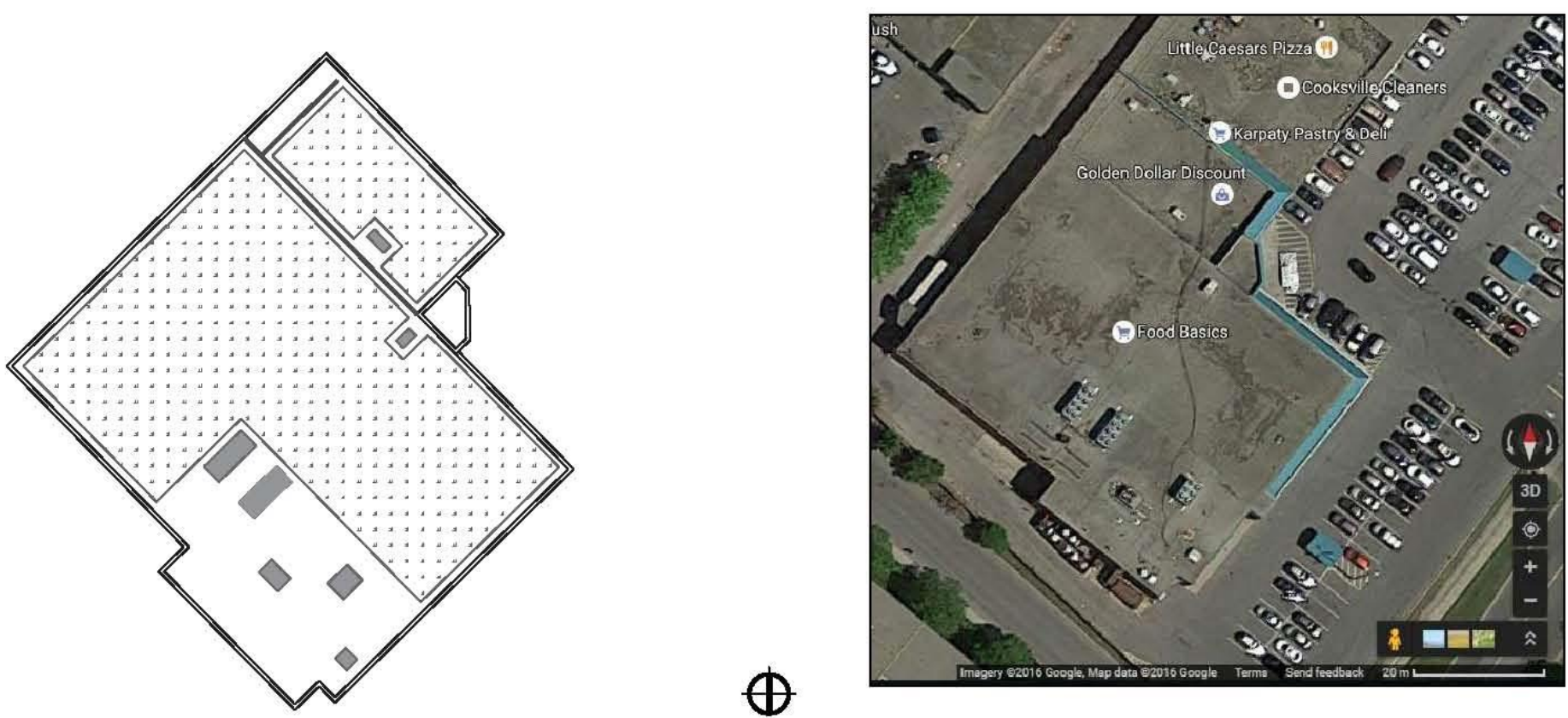

Potential Area for Extensive Assembly
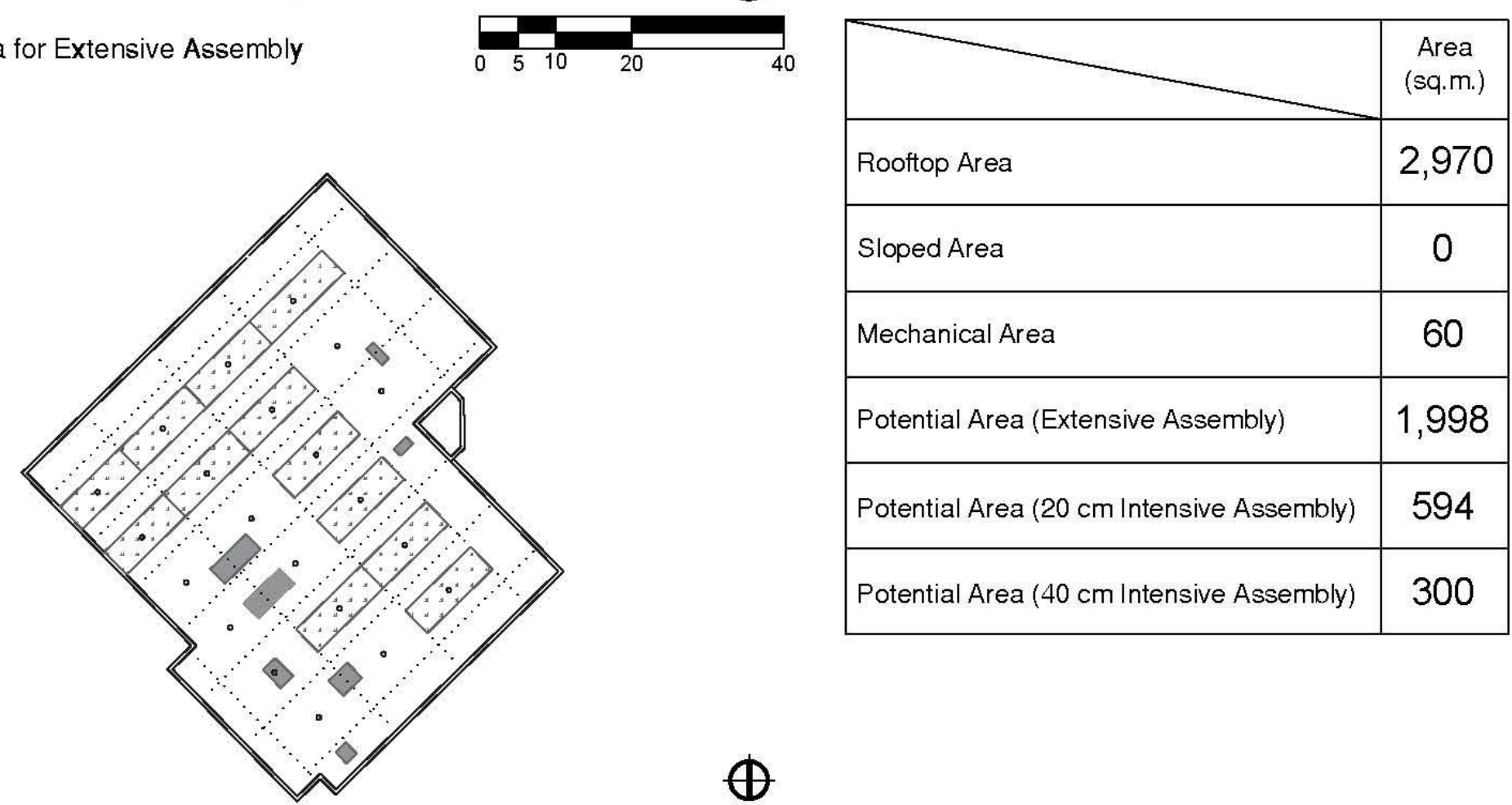

\begin{tabular}{|l|c|}
\hline Rooftop Area & 2,970 \\
\hline Sloped Area & 0 \\
\hline Mechanical Area & 60 \\
\hline Potential Area (Extensive Assembly) & 1,998 \\
\hline Potential Area (20 cm Intensive Assembly) & 594 \\
\hline Potential Area (40 cm Intensive Assembly) & 300 \\
\hline
\end{tabular}

$\oplus$

Potential Area for $20 \mathrm{~cm}$ Intensive Assembly
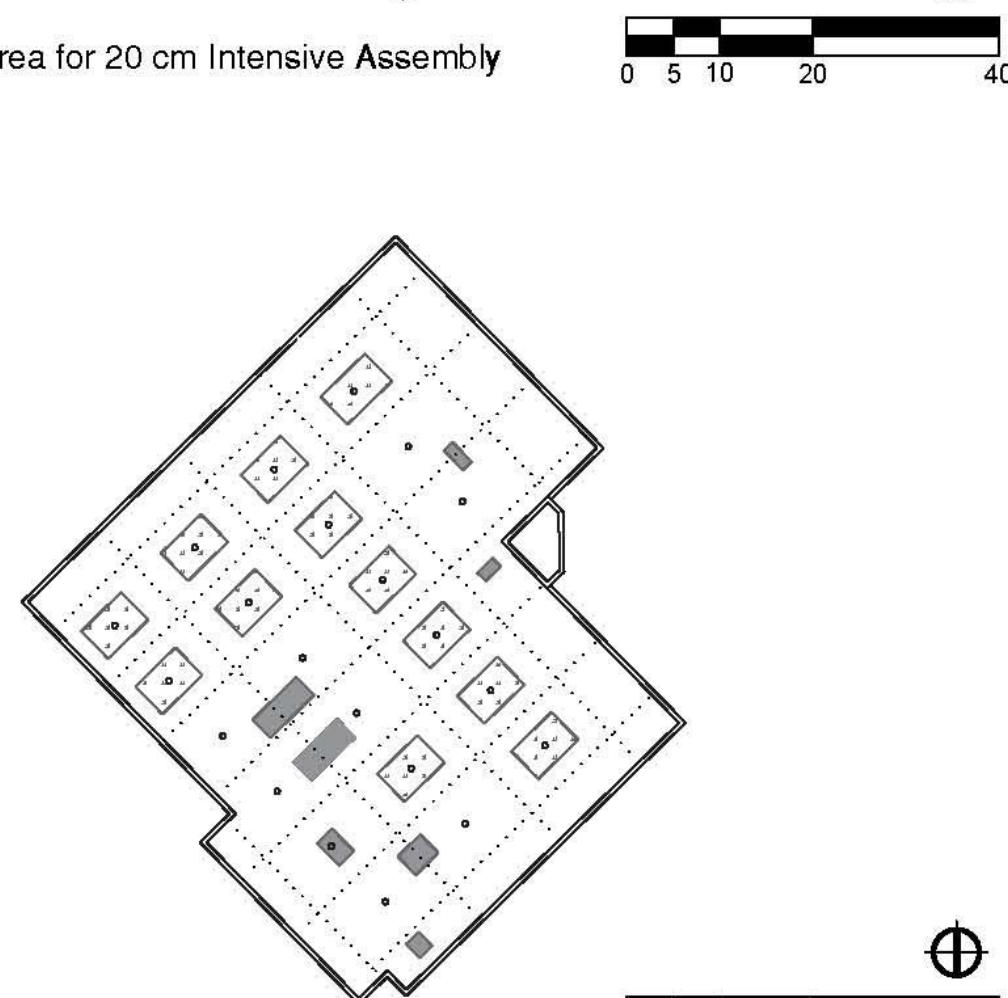

Legend
Vegetated Assembly
Mechanical Units
Sloped Roof

Potential Area for $40 \mathrm{~cm}$ Intensive Assembly

$\oplus$

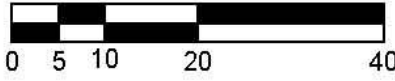




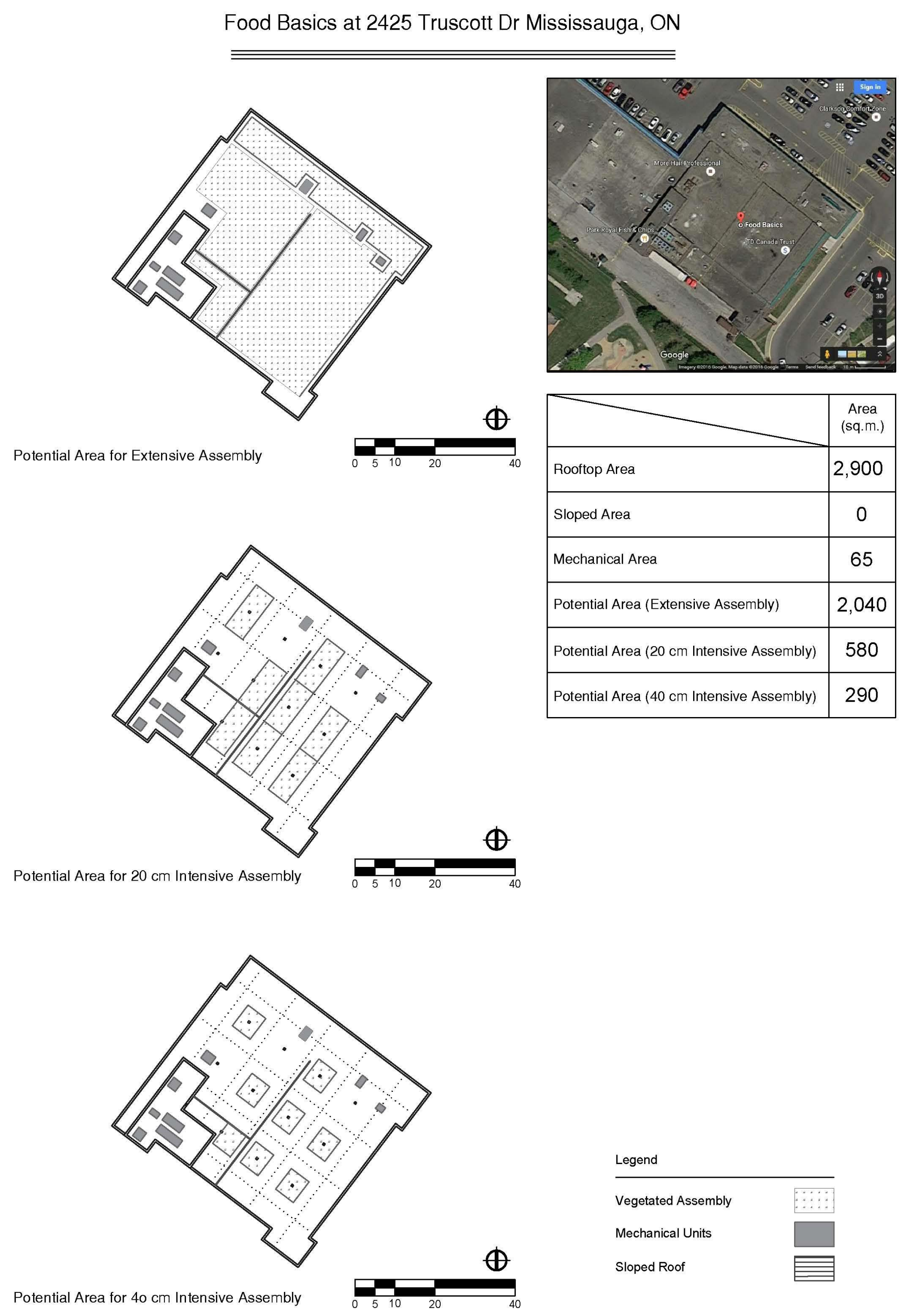




\section{Food Basics at 4141 Dixie Rd Mississauga, ON}

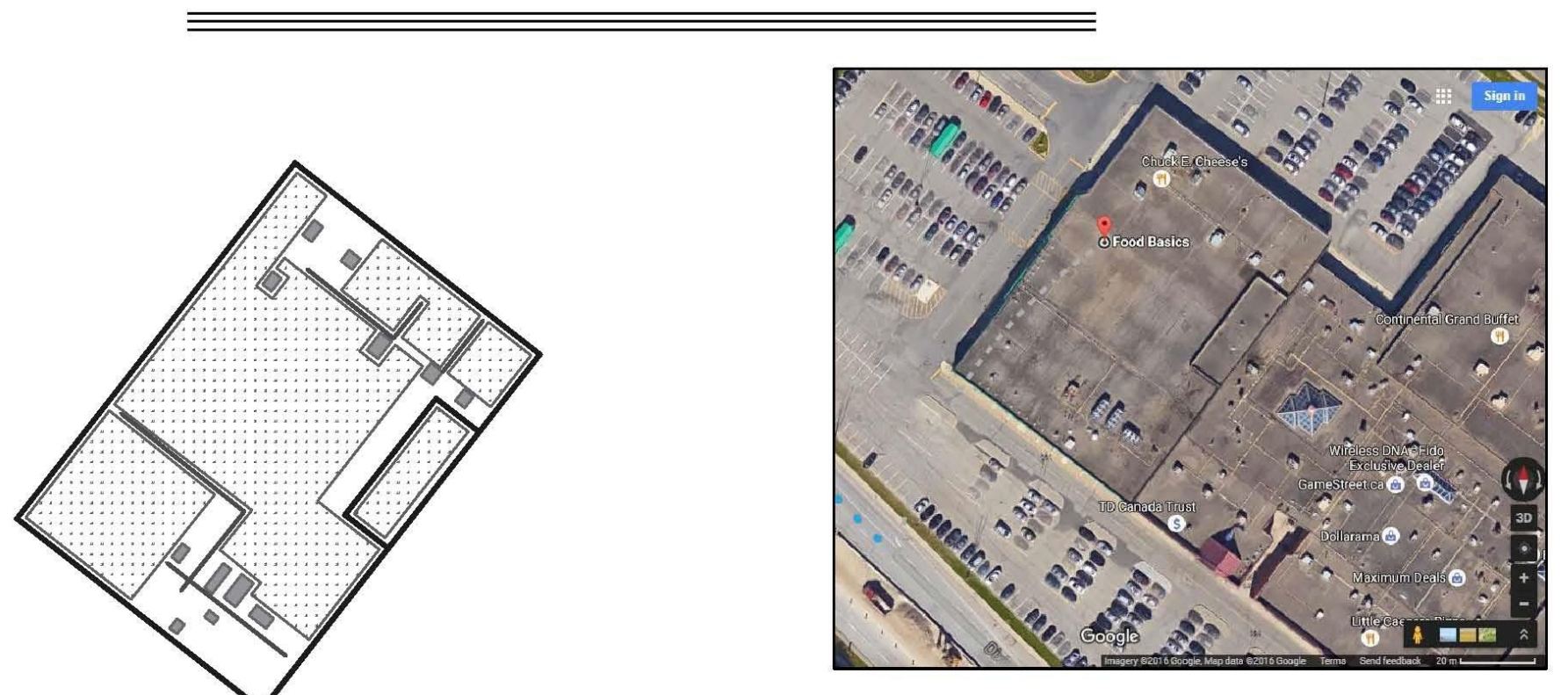

Potential Area for Extensive Assembly

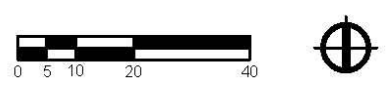

\begin{tabular}{|l|c|}
\hline & $\begin{array}{c}\text { Area } \\
\text { (sq.m.) }\end{array}$ \\
\hline Rooftop Area & 5,300 \\
\hline Sloped Area & 0 \\
\hline Mechanical Area & 105 \\
\hline Potential Area (Extensive Assembly) & 3,652 \\
\hline Potential Area (20 cm Intensive Assembly) & 926 \\
\hline Potential Area (40 cm Intensive Assembly) & 463 \\
\hline
\end{tabular}

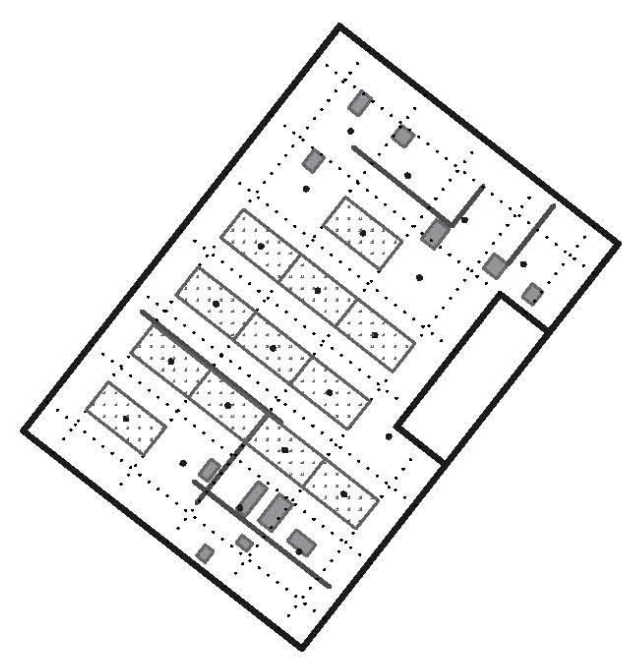

Potential Area for $20 \mathrm{~cm}$ Intensive Assembly
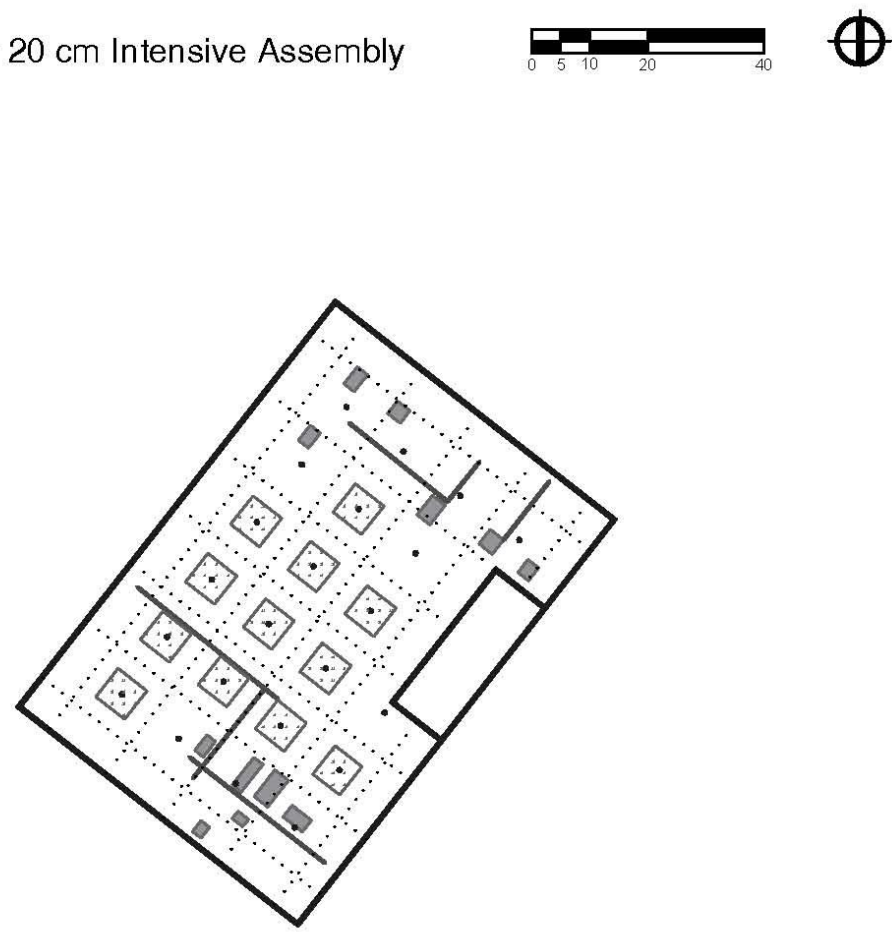

Legend
Vegetated Assembly
Mechanical Units
Sloped Roof

Potential Area for $40 \mathrm{~cm}$ Intensive Assembly

$\underset{0.510}{\square_{20}} \bigoplus$ 
Food Basics at 7070 St Barbara Blvd Mississauga, ON
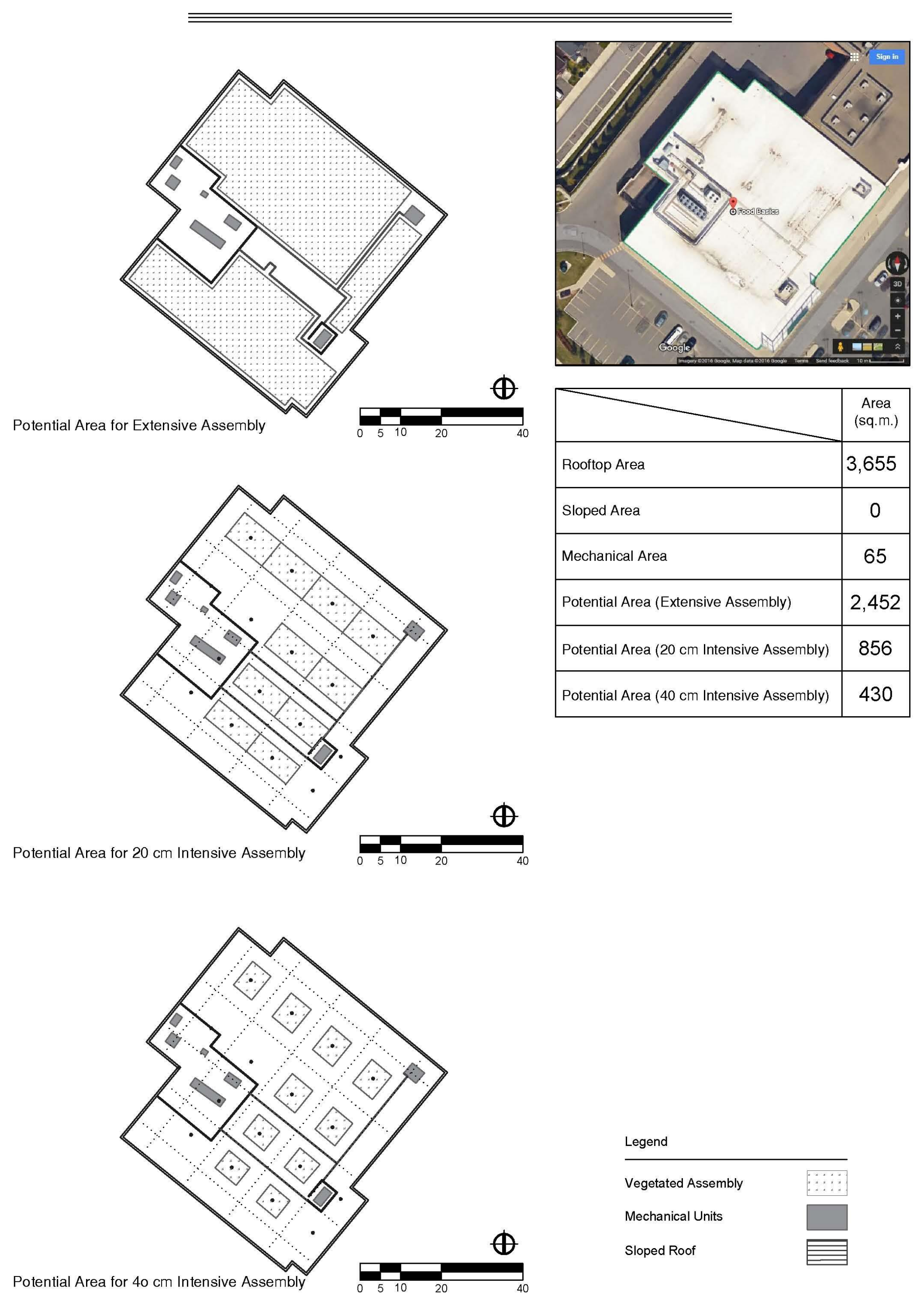

Legend
Vegetated Assembly
Mechanical Units
Sloped Roof




\section{Metro at 910 Southdown Rd Mississauga, ON}

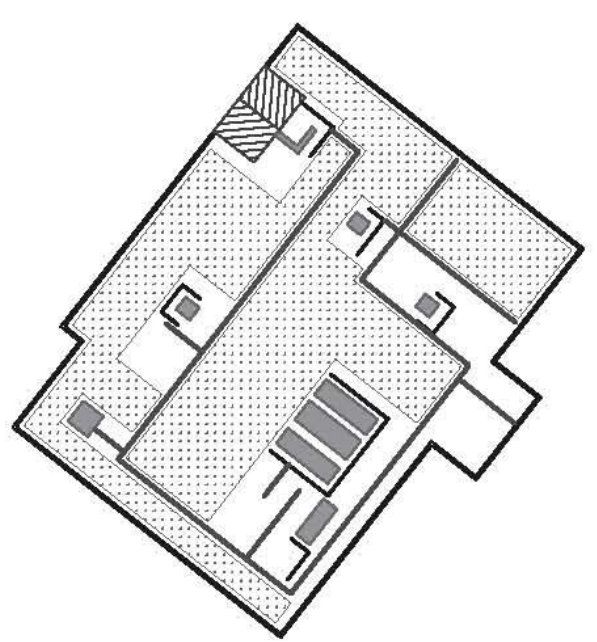

Potential Area for Extensive Assembly
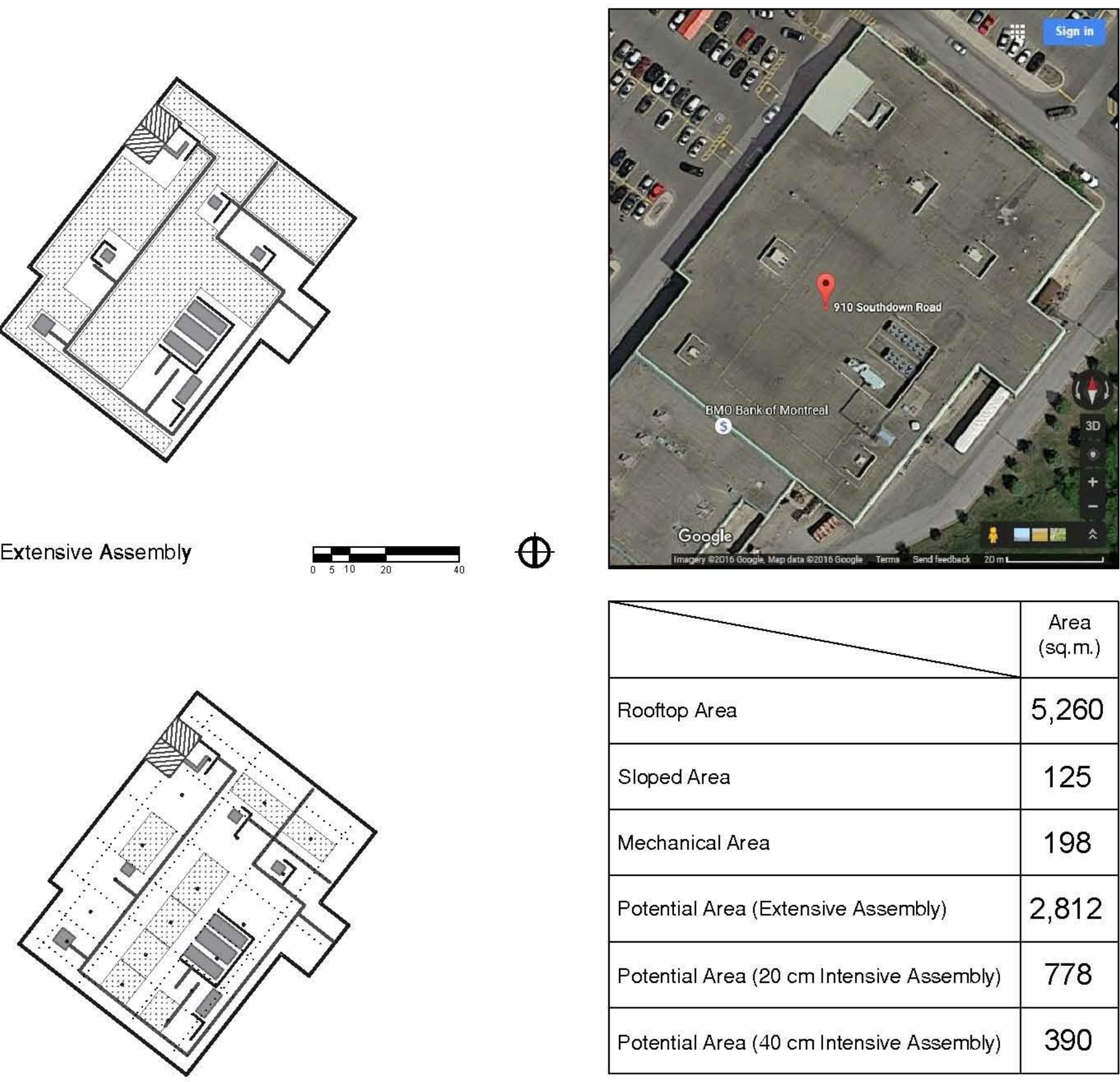

\begin{tabular}{|l|c|}
\hline & $\begin{array}{c}\text { Area } \\
\text { (sq.m.) }\end{array}$ \\
\hline Rooftop Area & 5,260 \\
\hline Sloped Area & 125 \\
\hline Mechanical Area & 198 \\
\hline Potential Area (Extensive Assembly) & 2,812 \\
\hline Potential Area (20 cm Intensive Assembly) & 778 \\
\hline Potential Area (40 cm Intensive Assembly) & 390 \\
\hline
\end{tabular}

Potential Area for $20 \mathrm{~cm}$ Intensive Assembly
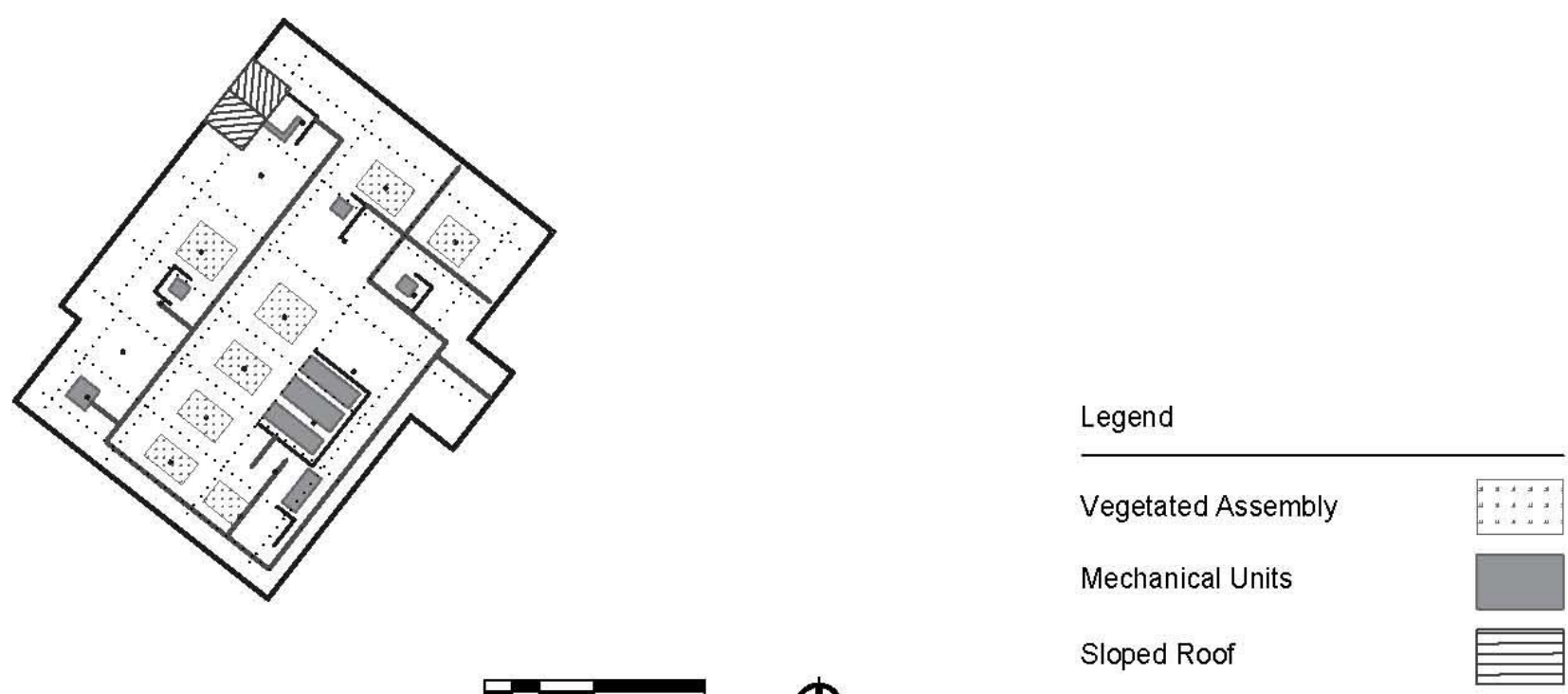

Potential Area for $40 \mathrm{~cm}$ Intensive Assembly 


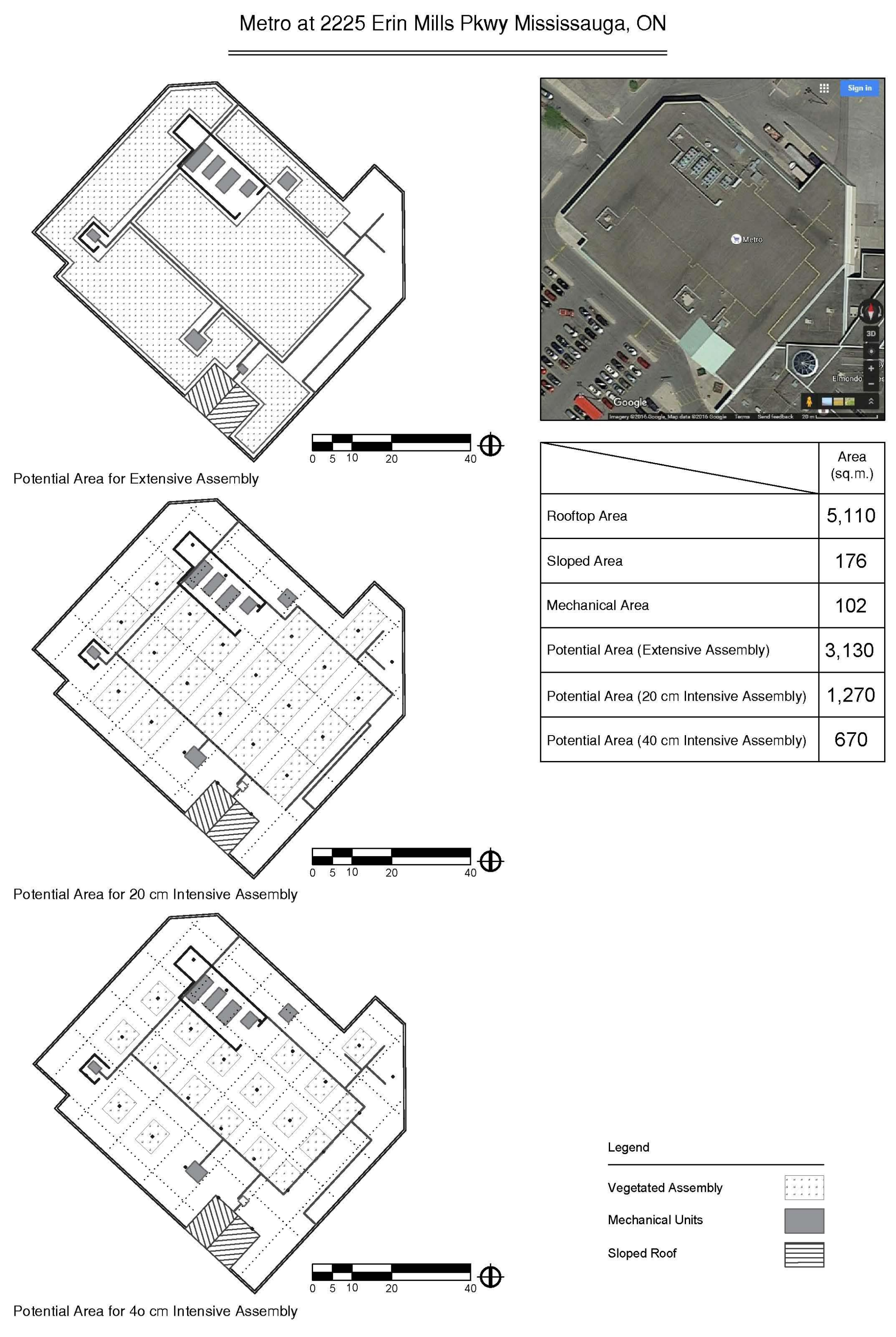


Metro at 1585 Mississauga Valley Blvd Mississauga, ON
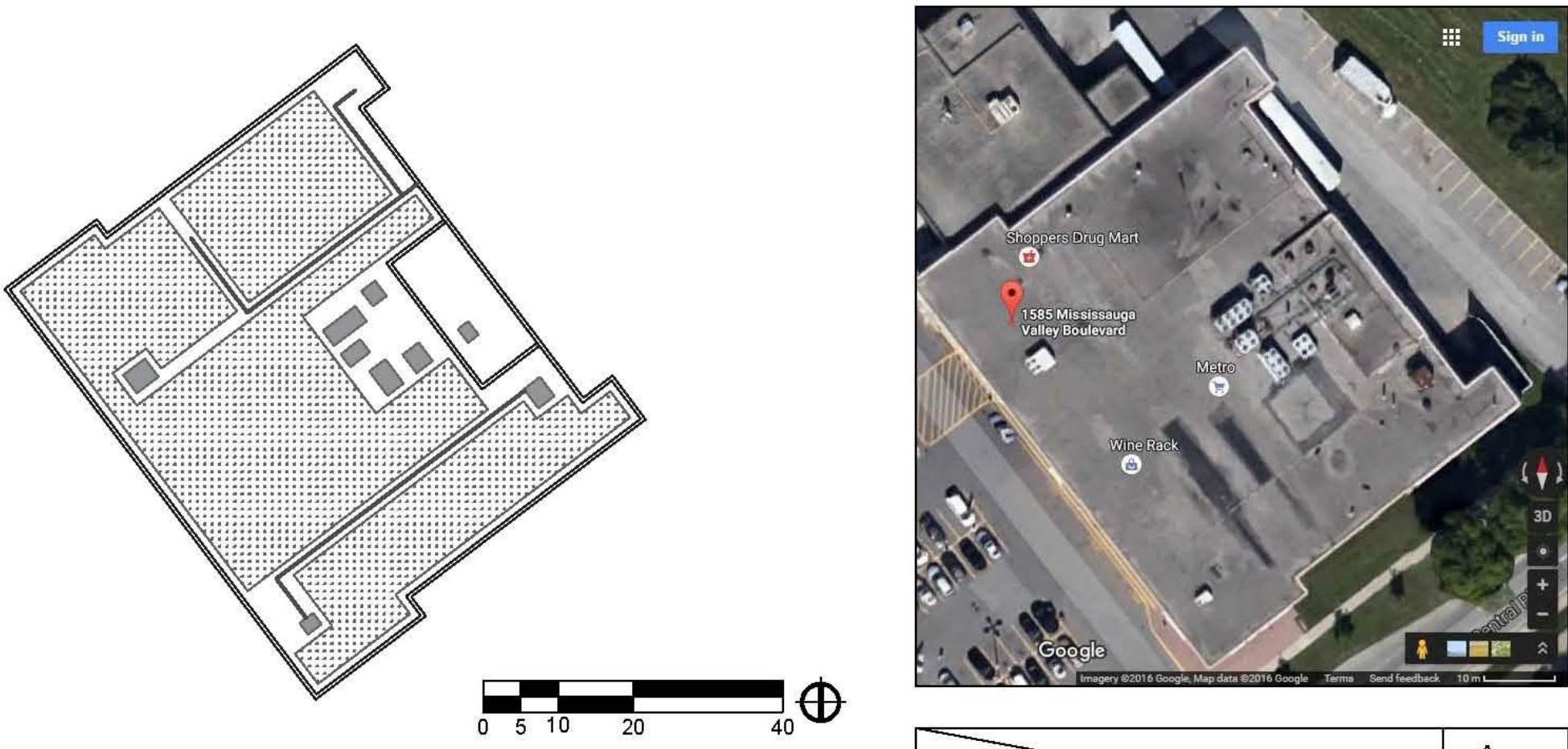

Potential Area for Extensive Assembly

\begin{tabular}{|l|c|}
\hline & $\begin{array}{c}\text { Area } \\
\text { (sq.m.) }\end{array}$ \\
\hline Rooftop Area & 3,380 \\
\hline Sloped Area & 0 \\
\hline Mechanical Area & 75 \\
\hline Potential Area (Extensive Assembly) & 2,315 \\
\hline Potential Area (20 cm Intensive Assembly) & 680 \\
\hline Potential Area (40 cm Intensive Assembly) & 340 \\
\hline
\end{tabular}

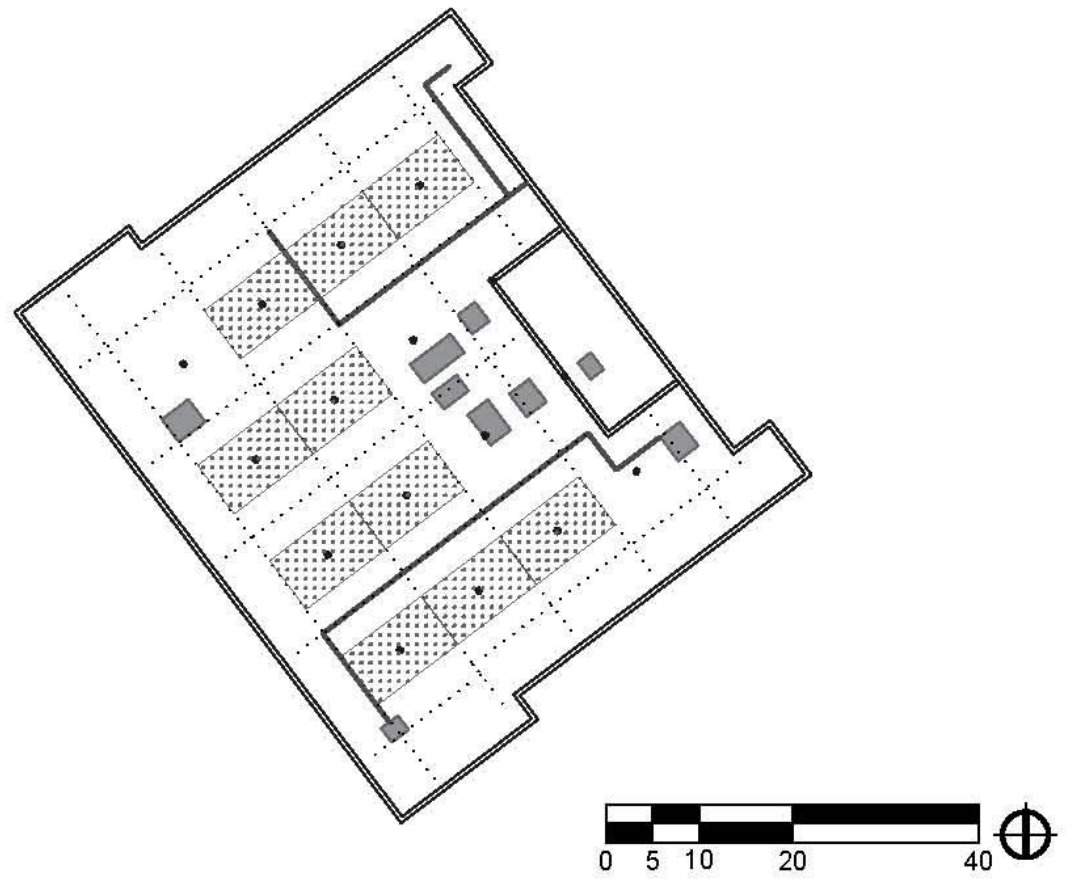

Potential Area for $20 \mathrm{~cm}$ Intensive Assembly

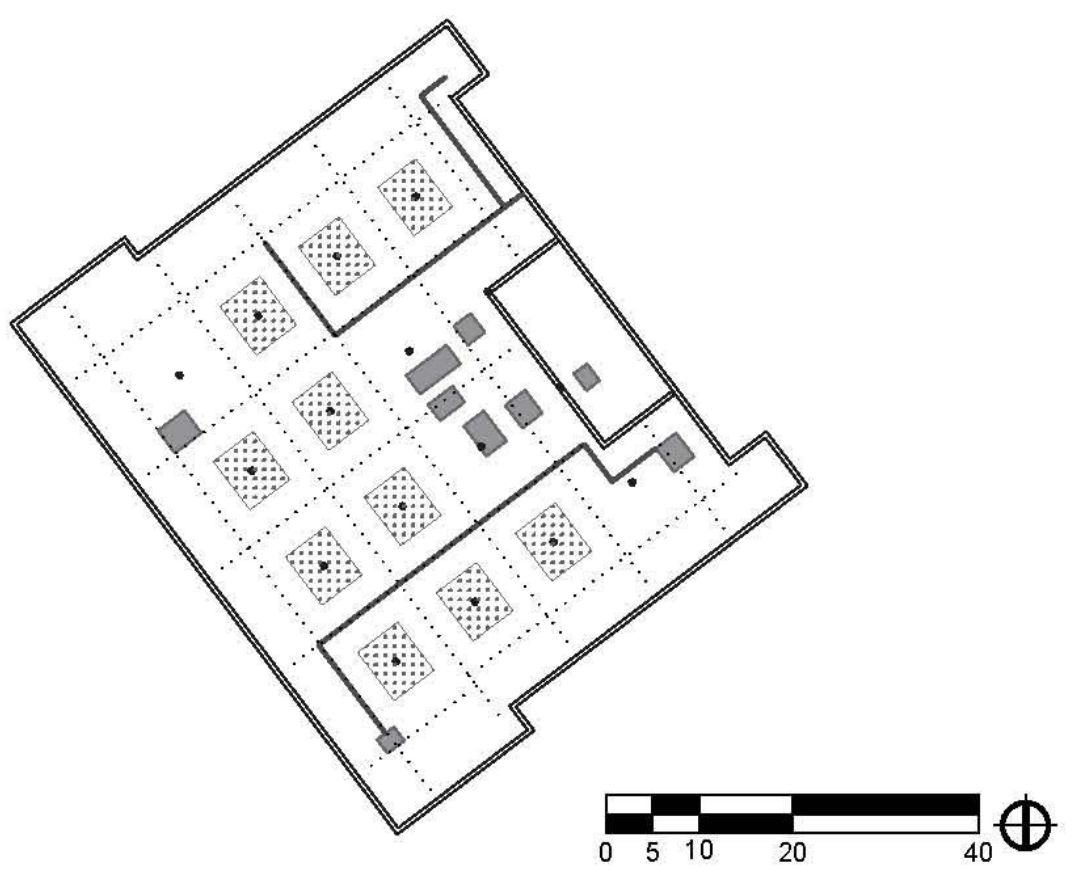

Legend
Vegetated Assembly
Mechanical Units
Sloped Roof

Potential Area for $40 \mathrm{~cm}$ Intensive Assembly 


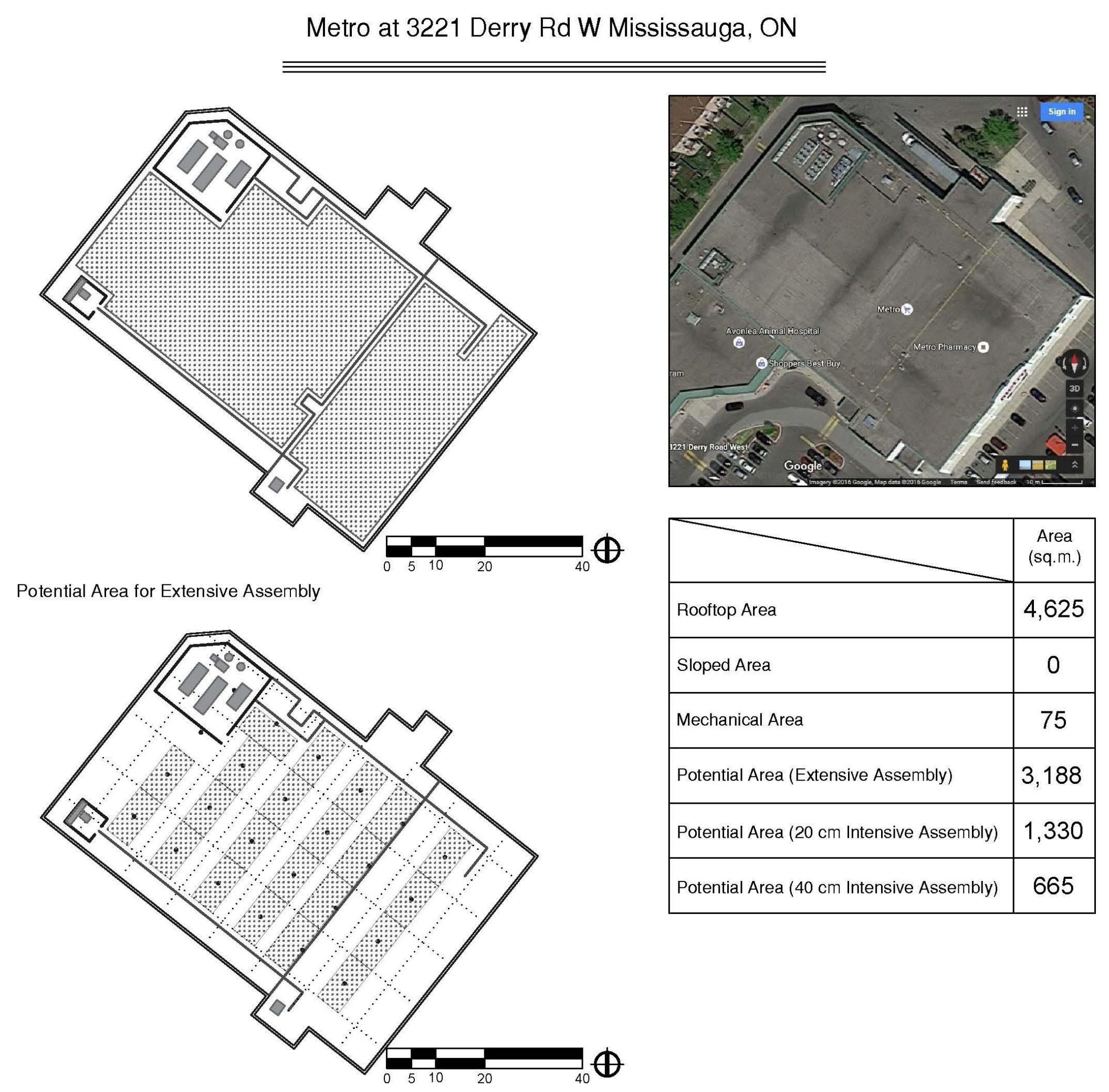

Potential Area for $20 \mathrm{~cm}$ Intensive Assembly

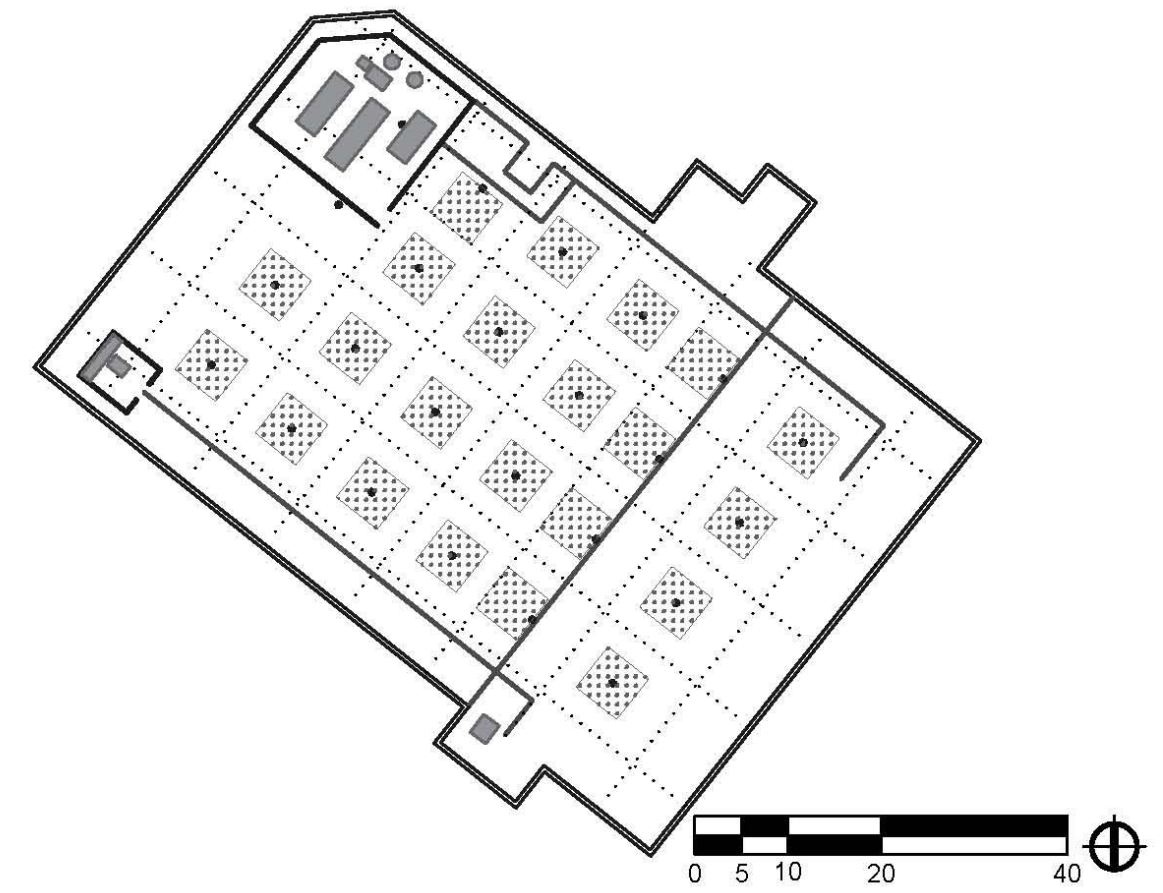

Legend
Vegetated Assembly
Mechanical Units
Sloped Roof

Potential Area for $40 \mathrm{~cm}$ Intensive Assembly 


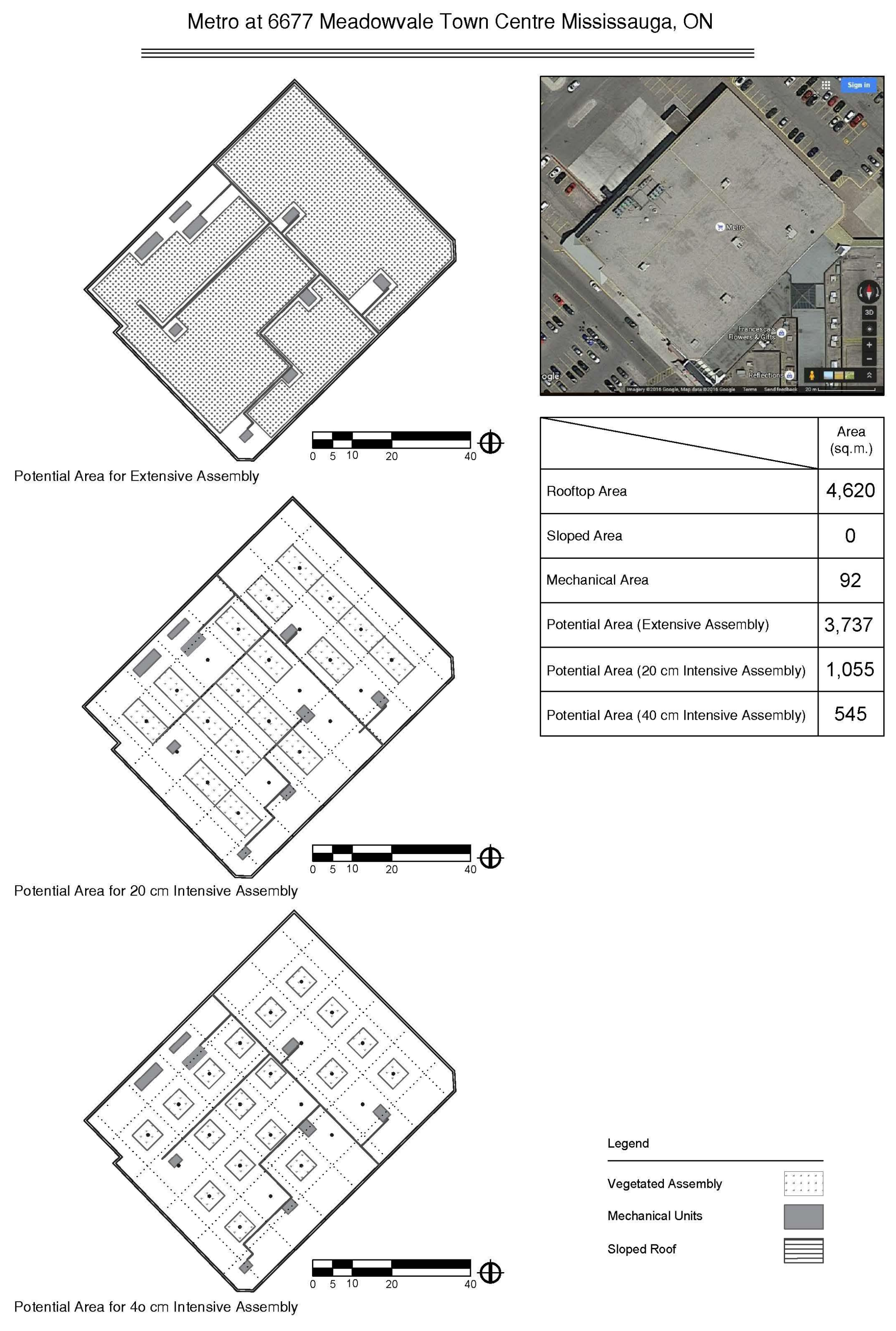




\section{Metro at 406 Lakeshore Rd E, Mississauga, ON}

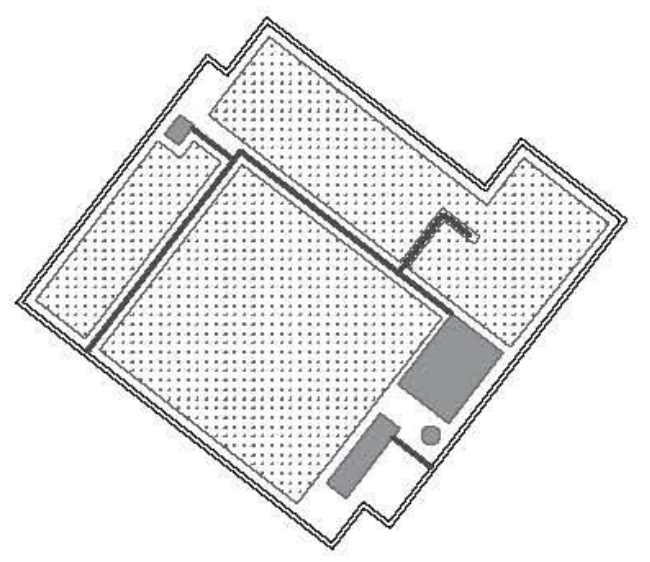

Potential Area for Extensive Assembly
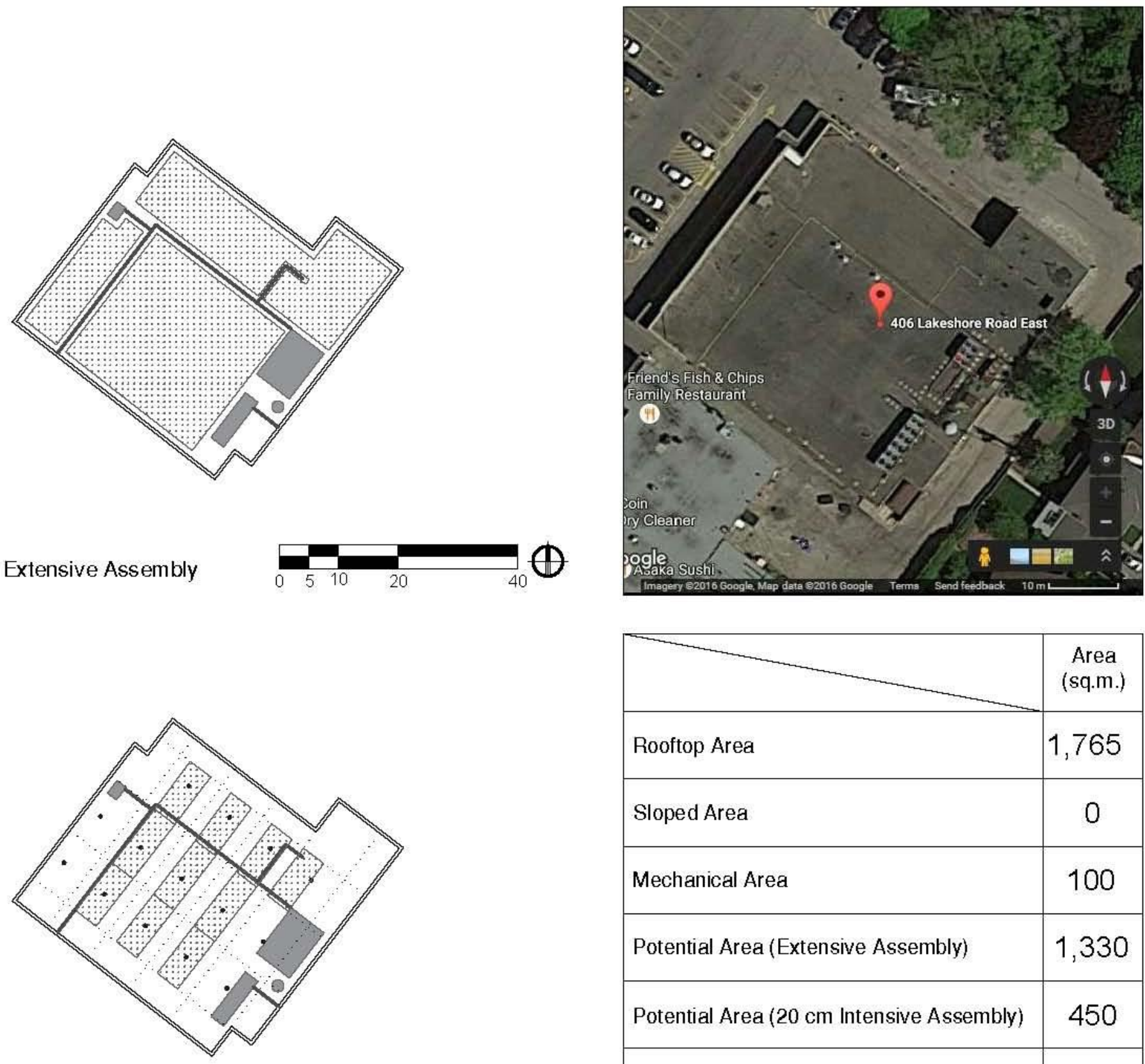

\begin{tabular}{|l|c|}
\hline Rooftop Area & $\begin{array}{c}\text { Area } \\
\text { (sq.m.) }\end{array}$ \\
\hline Sloped Area & 1,765 \\
\hline Mechanical Area & 0 \\
\hline Potential Area (Extensive Assembly) & 1,330 \\
\hline Potential Area (20 cm Intensive Assembly) & 450 \\
\hline Potential Area (40 cm Intensive Assembly) & 225 \\
\hline
\end{tabular}

Potential Area for $20 \mathrm{~cm}$ Intensive Assembly
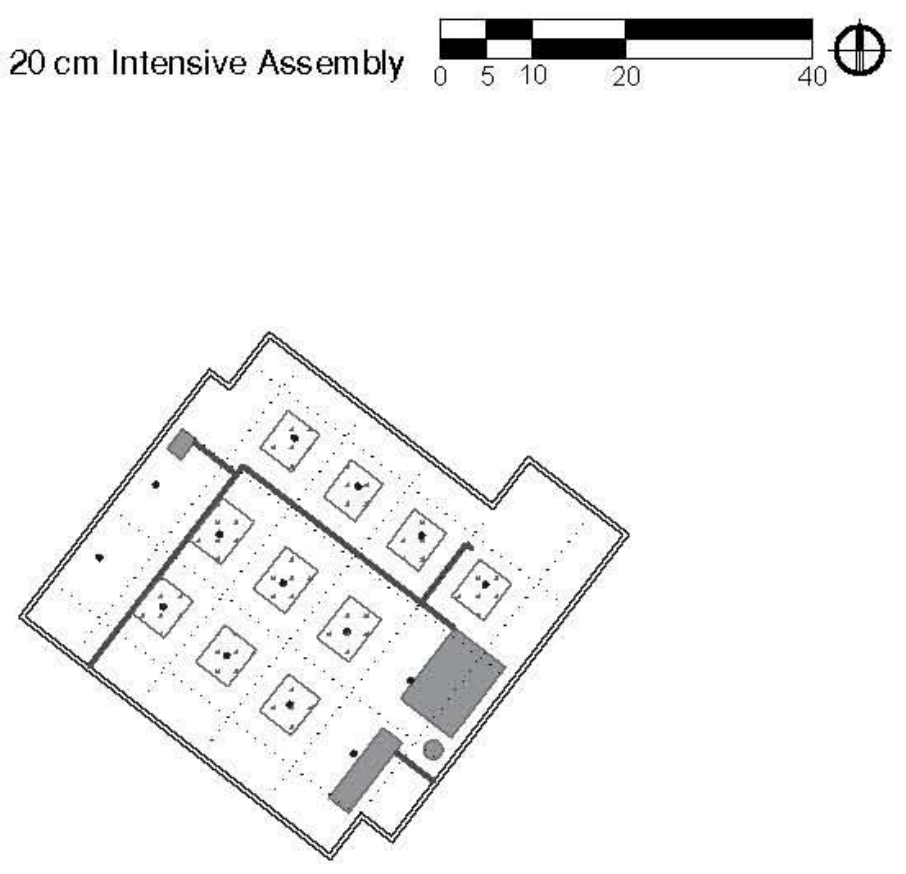

Legend
Vegetated Assembly
Mechanical Units
Sloped Roof

Potential Area for $40 \mathrm{~cm}$ Intensive Assembly

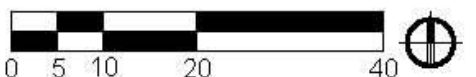


FreshCo at 2500 Hurontario St Mississauga, ON

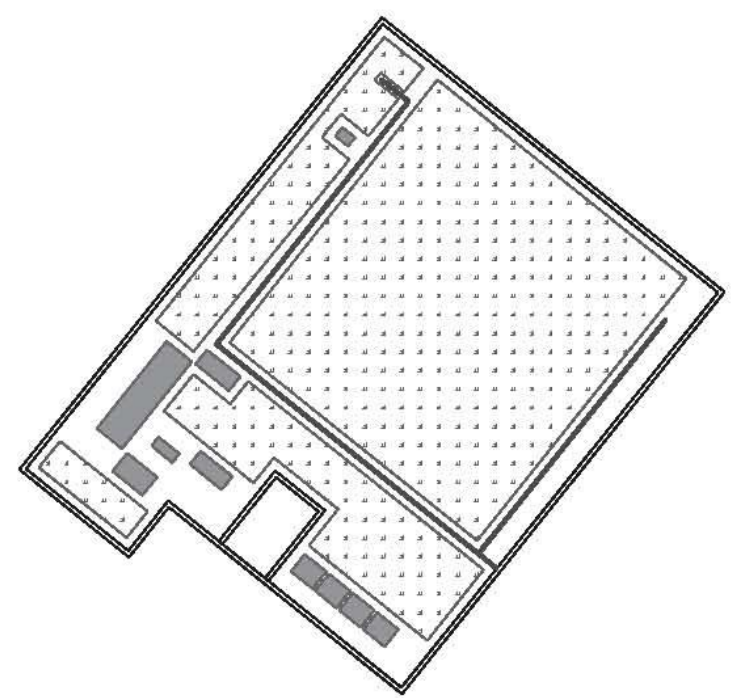

Potential Area for Extensive Assembly
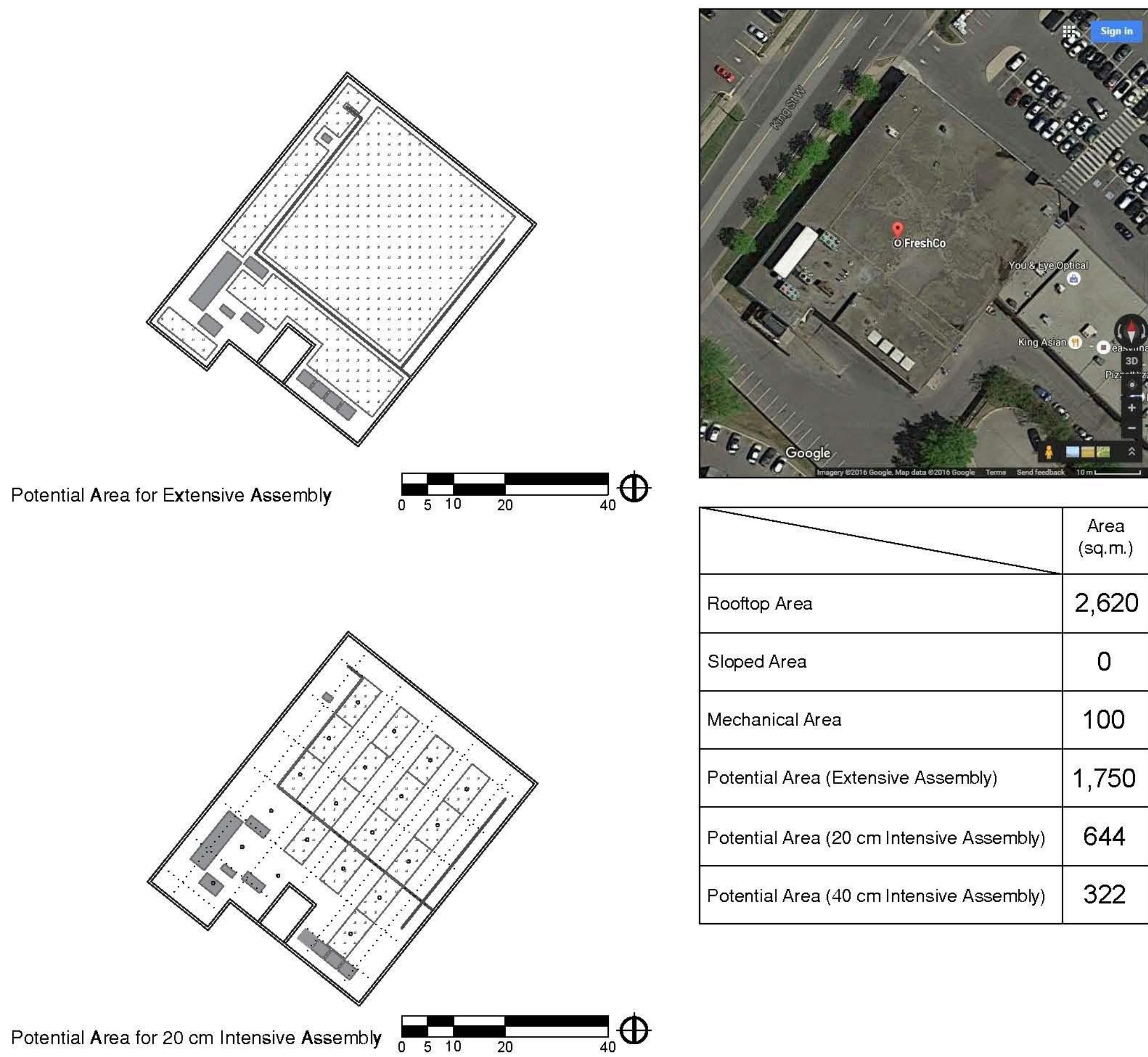

\begin{tabular}{|l|c|}
\hline & $\begin{array}{c}\text { Area } \\
\text { (sq.m.) }\end{array}$ \\
\hline Rooftop Area & 2,620 \\
\hline Sloped Area & 0 \\
\hline Mechanical Area & 100 \\
\hline Potential Area (Extensive Assembly) & 1,750 \\
\hline Potential Area (20 cm Intensive Assembly) & 644 \\
\hline Potential Area (40 cm Intensive Assembly) & 322 \\
\hline
\end{tabular}

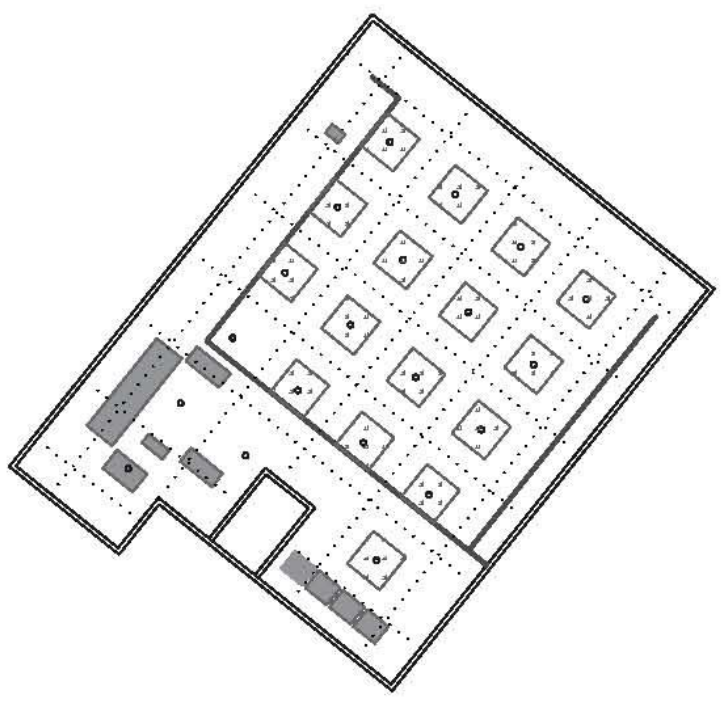

Legend
Vegetated Assembly
Mechanical Units
Sloped Roof

Potential Area for $40 \mathrm{~cm}$ Intensive Assembly

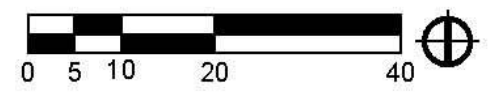

Sloped Roof 
FreshCo at 6040 Glen Erin Dr Mississauga, ON
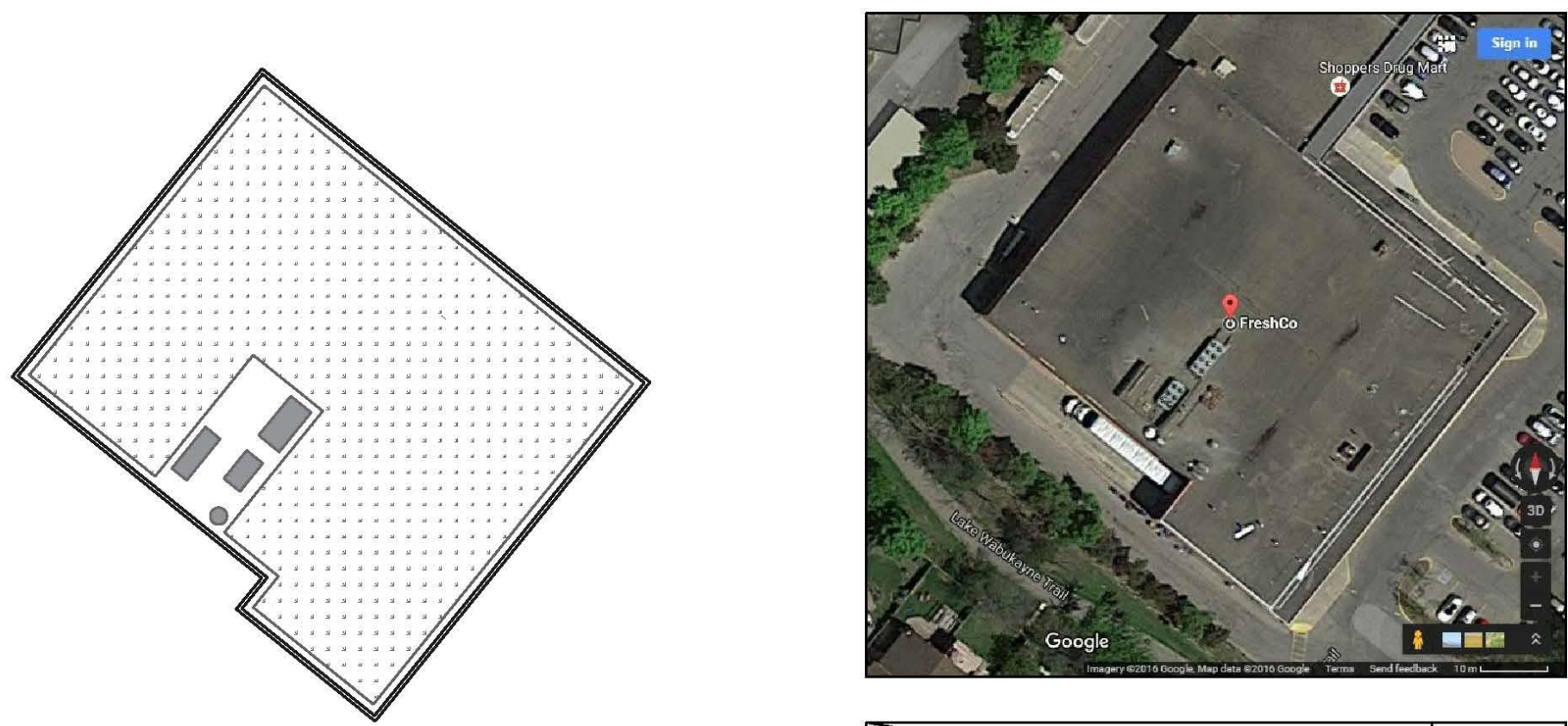

Potential Area for Extensive Assembly

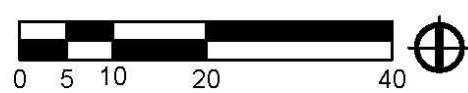

\begin{tabular}{|l|c|}
\hline & $\begin{array}{c}\text { Area } \\
\text { (sq.m.) }\end{array}$ \\
\hline Rooftop Area & 3,110 \\
\hline Sloped Area & 0 \\
\hline Mechanical Area & 50 \\
\hline Potential Area (Extensive Assembly) & 2,626 \\
\hline Potential Area (20 cm Intensive Assembly) & 776 \\
\hline Potential Area (40 cm Intensive Assembly) & 400 \\
\hline
\end{tabular}

Potential Area for $20 \mathrm{~cm}$ Intensive Assembly \begin{tabular}{llll}
\hline & & & \\
\hline
\end{tabular}
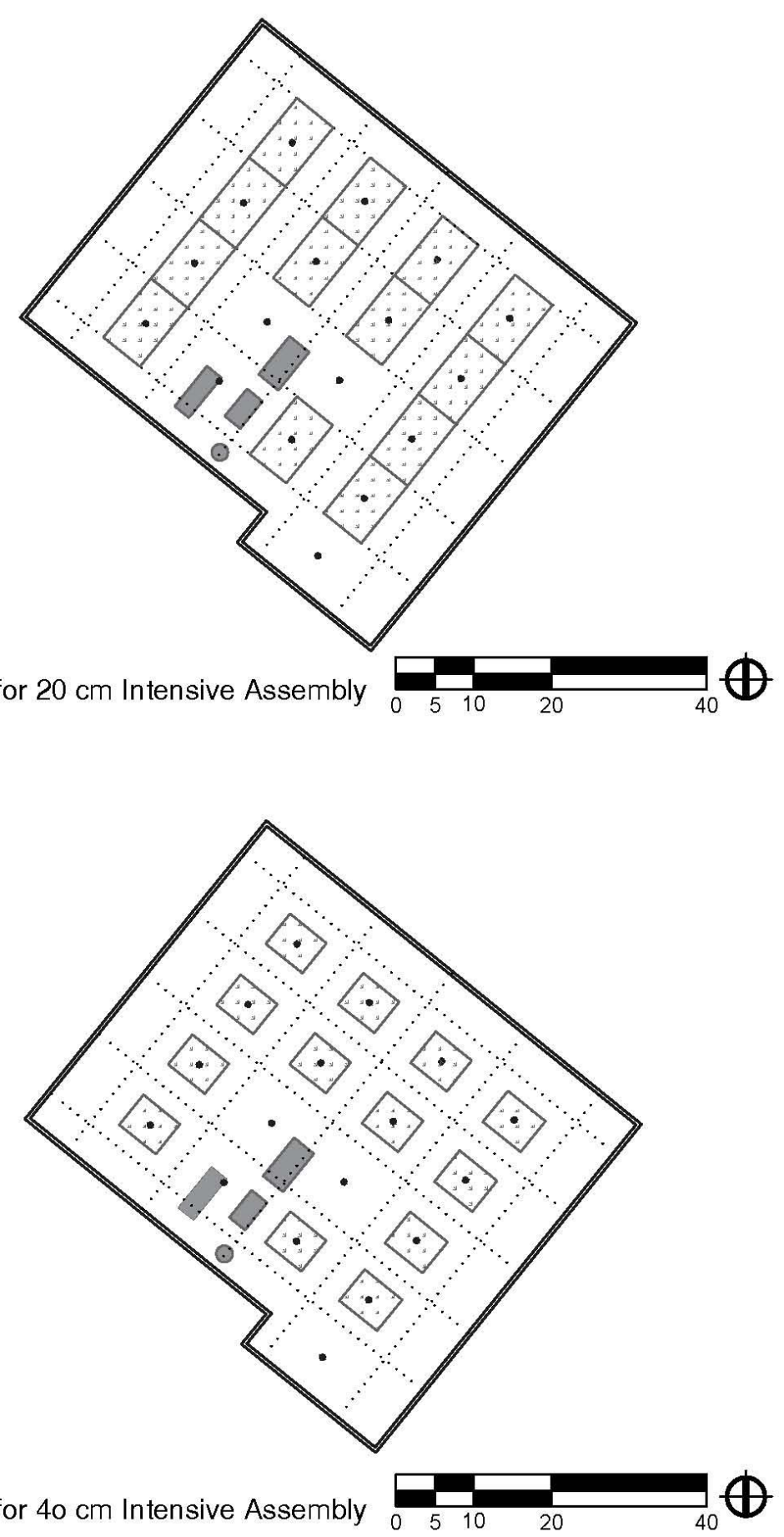

Legend
Vegetated Assembly
Mechanical Units
Sloped Roof

Potential Area for $40 \mathrm{~cm}$ Intensive Assembly $\oplus$ 
FreshCo at 1151 Dundas St W Mississauga, ON
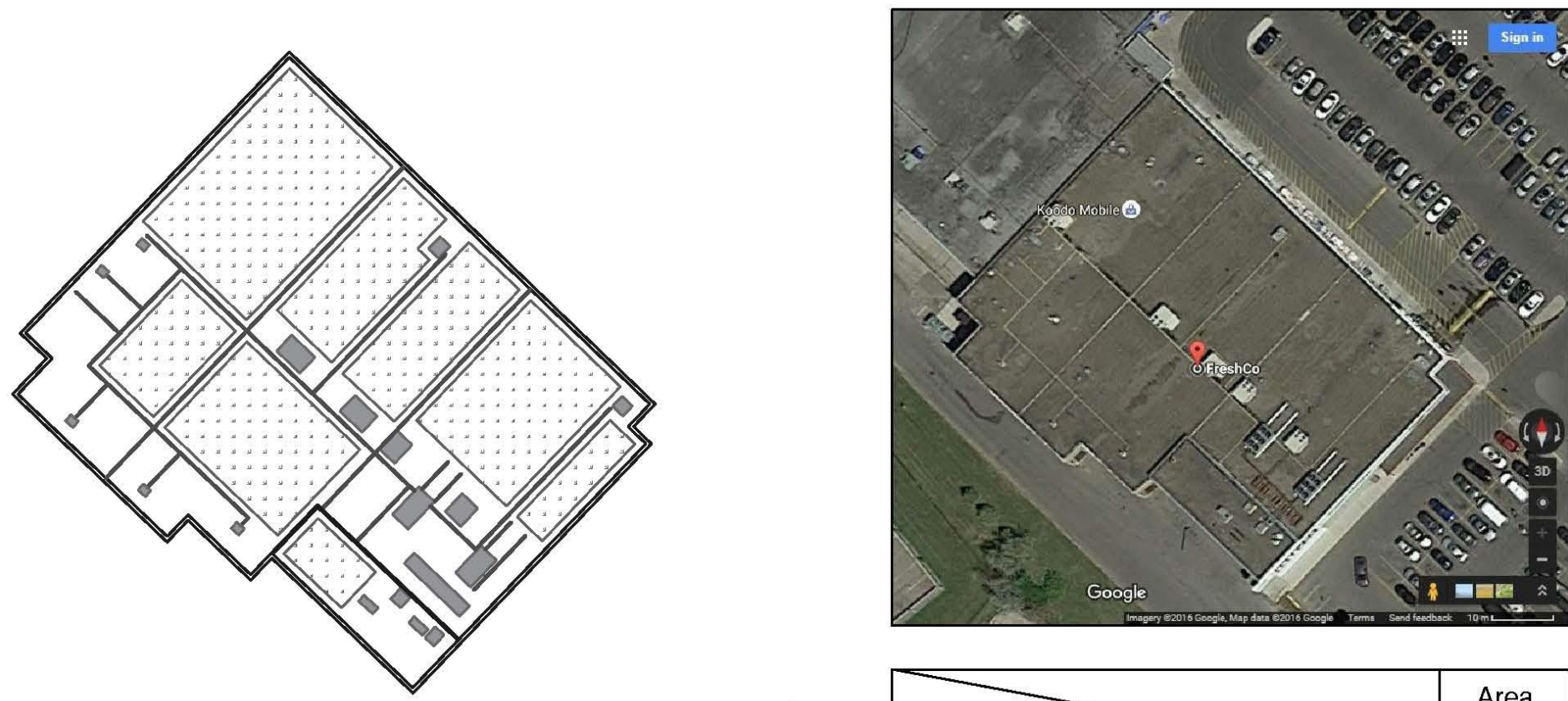

Potential Area for Extensive Assembly

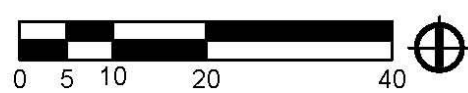

\begin{tabular}{|l|c|}
\hline & $\begin{array}{c}\text { Area } \\
\text { (sq.m.) }\end{array}$ \\
\hline Rooftop Area & 3,350 \\
\hline Sloped Area & 0 \\
\hline Mechanical Area & 110 \\
\hline Potential Area (Extensive Assembly) & 1,748 \\
\hline Potential Area (20 cm Intensive Assembly) & 820 \\
\hline Potential Area (40 cm Intensive Assembly) & 410 \\
\hline
\end{tabular}

Potential Area for $20 \mathrm{~cm}$ Intensive Assembly \begin{tabular}{lllll}
\hline & & & & \\
\hline
\end{tabular}

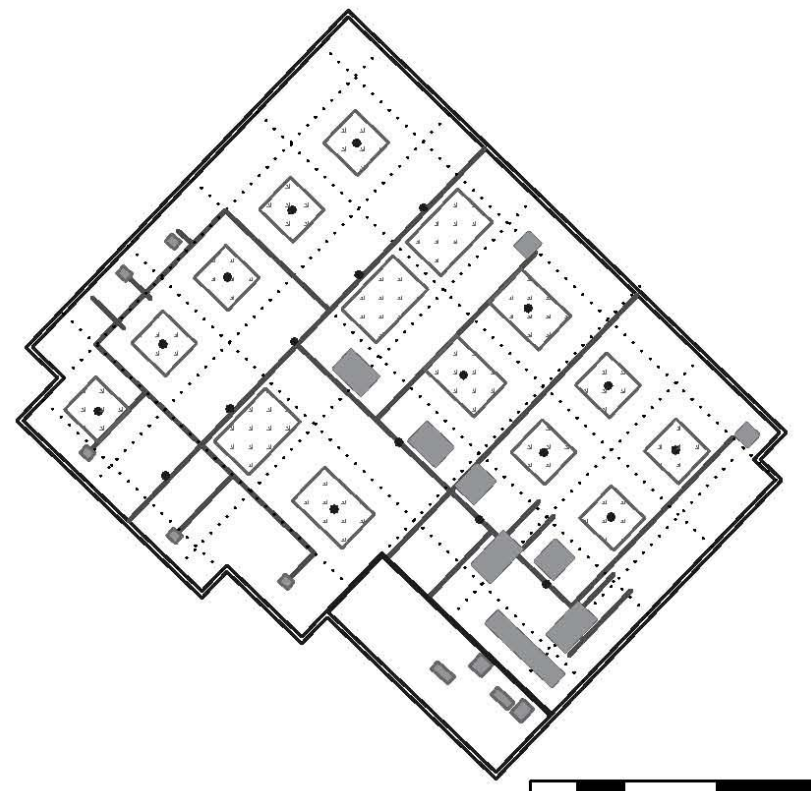

Potential Area for $40 \mathrm{~cm}$ Intensive Assembly

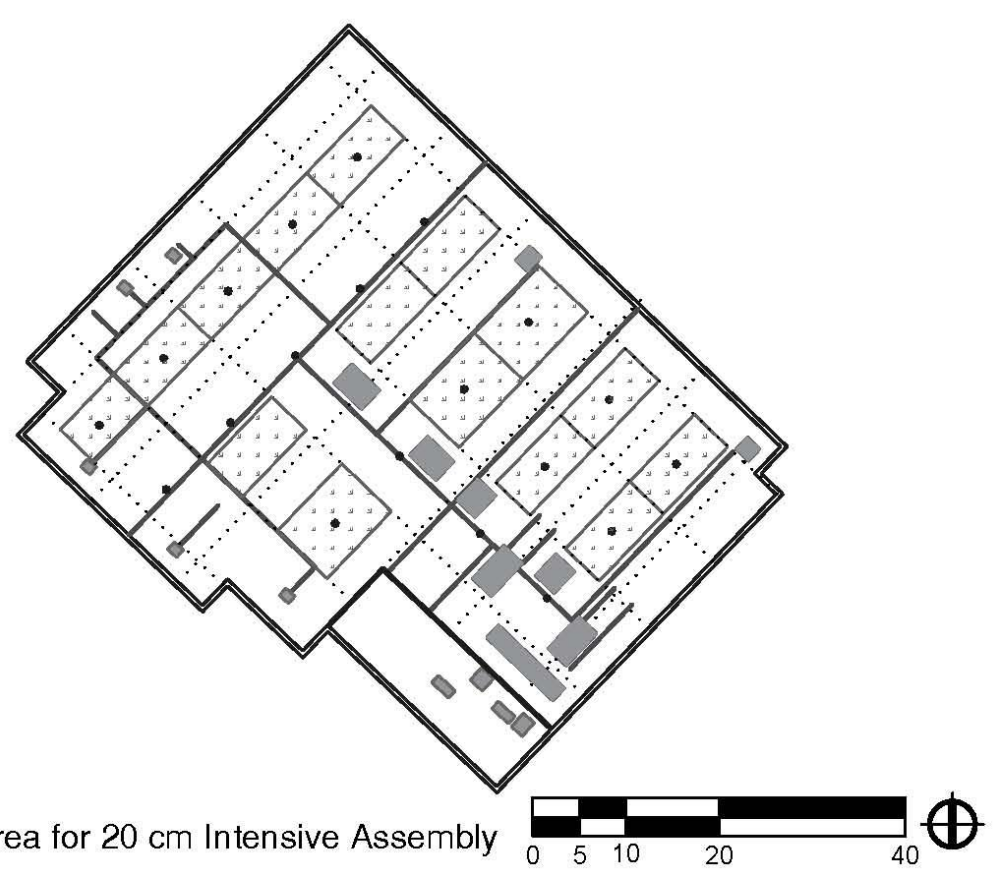

Legend
Vegetated Assembly
Mechanical Units
Sloped Roof




\section{FreshCo at 3100 Dixie Rd Mississauga, ON}

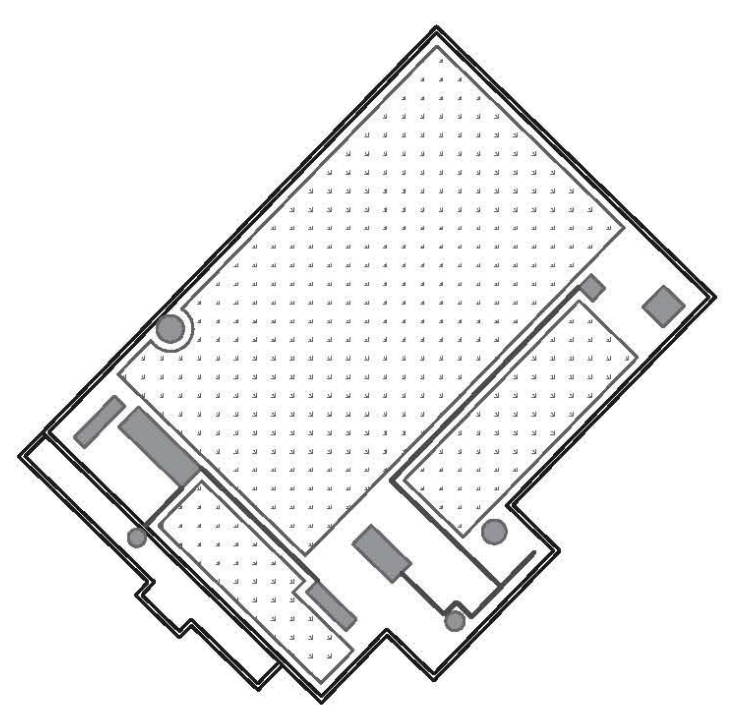

Potential Area for Extensive Assembly
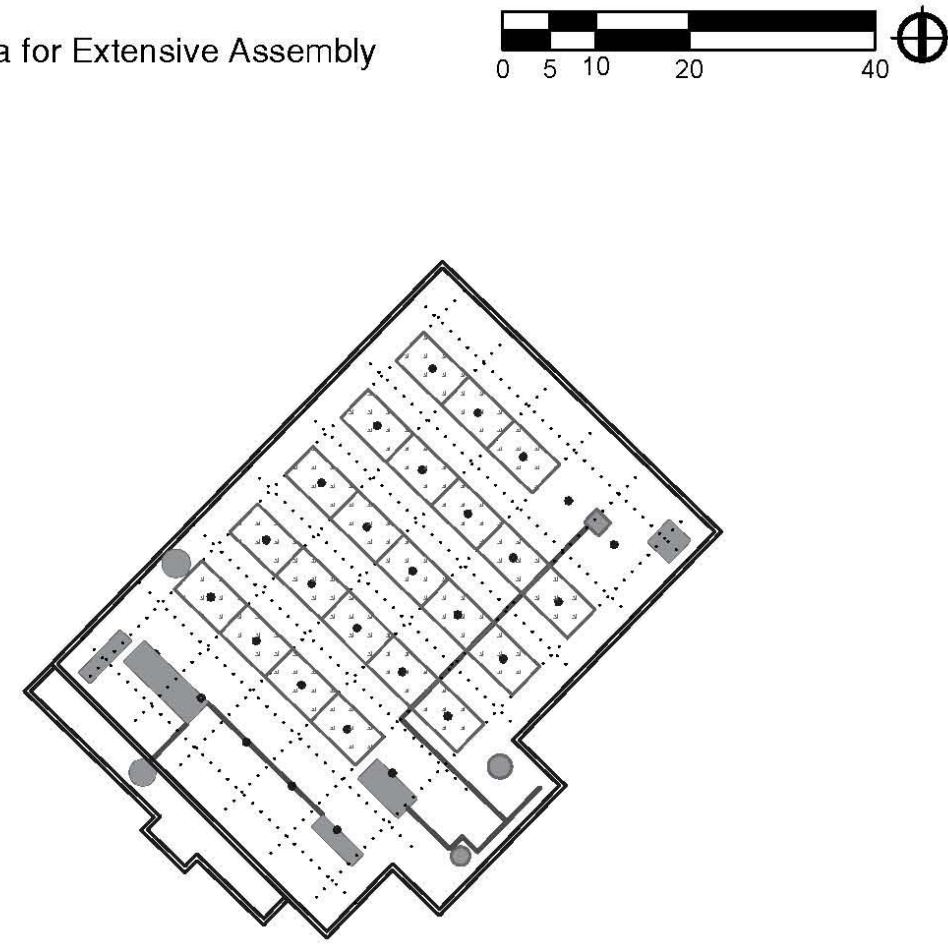

Potential Area for $20 \mathrm{~cm}$ Intensive Assembly

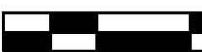

$\oplus$

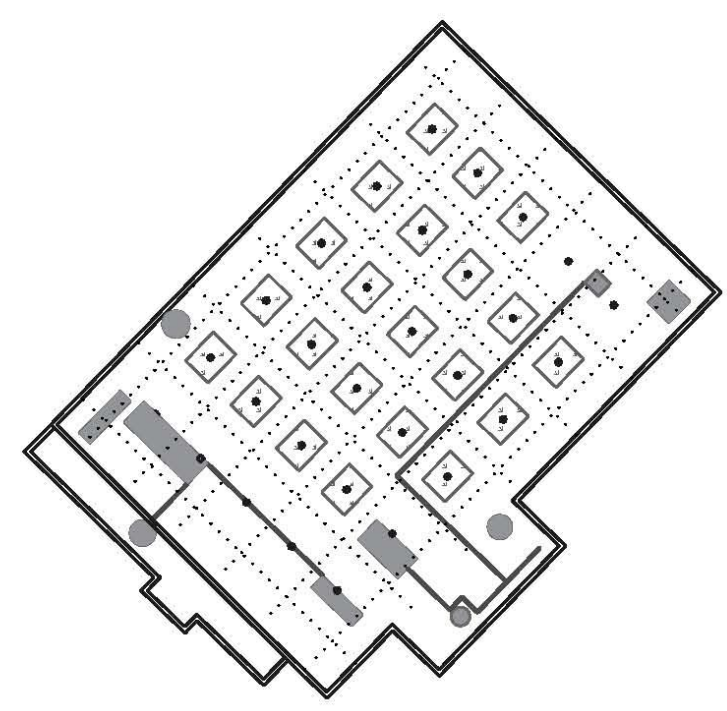

Potential Area for $40 \mathrm{~cm}$ Intensive Assembly

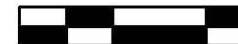

$\oplus$

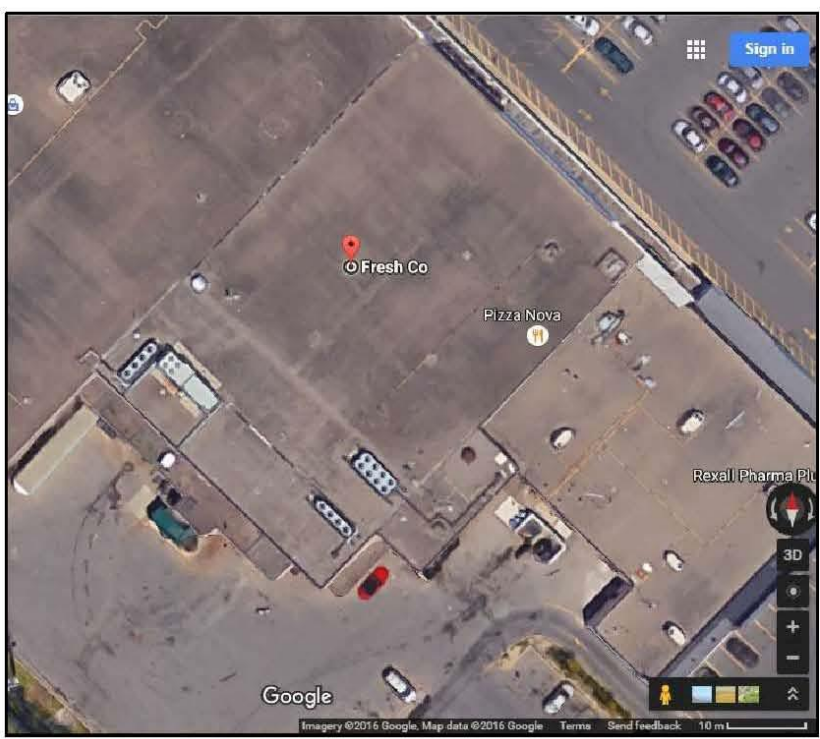

\begin{tabular}{|l|c|}
\hline & $\begin{array}{c}\text { Area } \\
\text { (sq.m.) }\end{array}$ \\
\hline Rooftop Area & 2,710 \\
\hline Sloped Area & 0 \\
\hline Mechanical Area & 100 \\
\hline Potential Area (Extensive Assembly) & 1,748 \\
\hline Potential Area (20 cm Intensive Assembly) & 638 \\
\hline Potential Area (40 cm Intensive Assembly) & 319 \\
\hline
\end{tabular}

Legend

Vegetated Assembly

Mechanical Units

Sloped Roof 
FreshCo at 7205 Goreway Dr Mississauga, ON
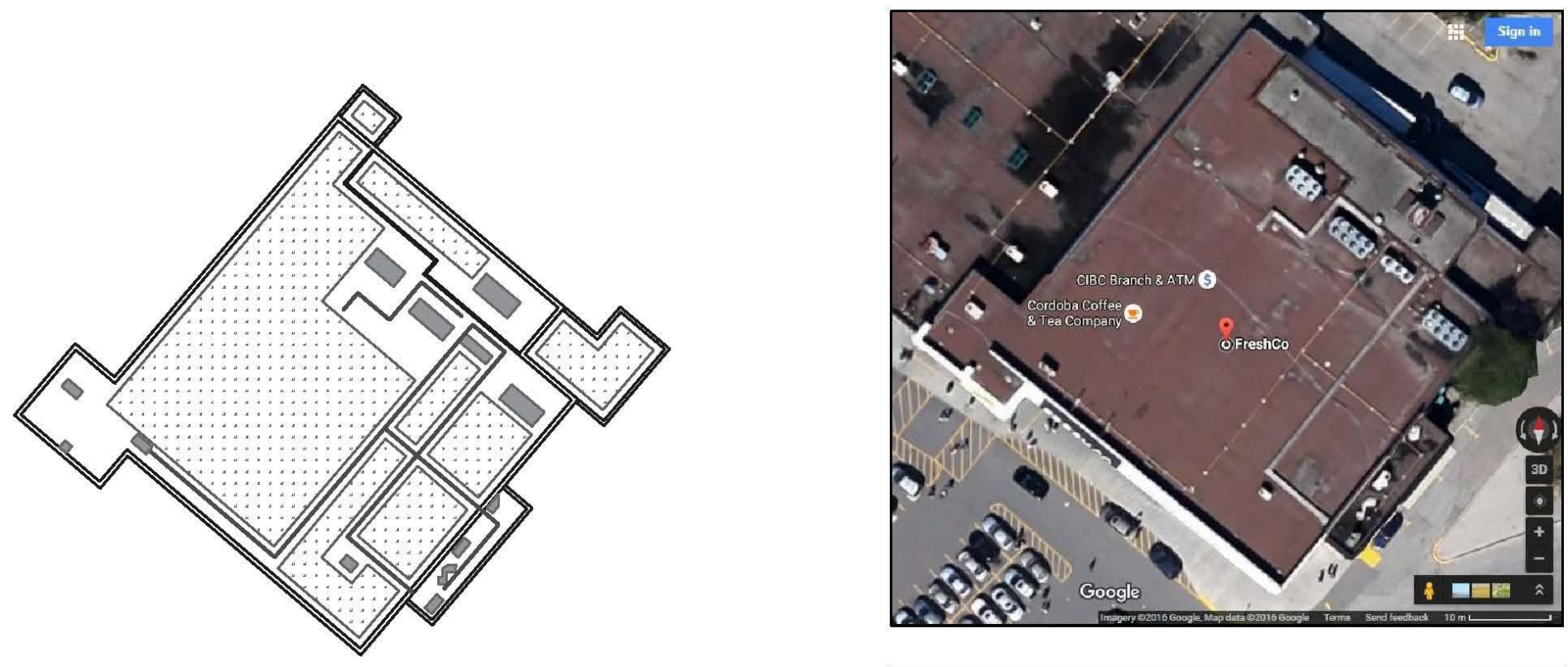

Potential Area for Extensive Assembly

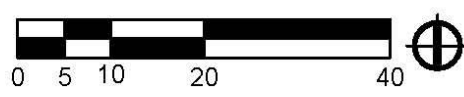

\begin{tabular}{|l|c|}
\hline & $\begin{array}{c}\text { Area } \\
\text { (sq.m.) }\end{array}$ \\
\hline Rooftop Area & 2,790 \\
\hline Sloped Area & 0 \\
\hline Mechanical Area & 85 \\
\hline Potential Area (Extensive Assembly) & 1,530 \\
\hline Potential Area (20 cm Intensive Assembly) & 594 \\
\hline Potential Area (40 cm Intensive Assembly) & 297 \\
\hline
\end{tabular}

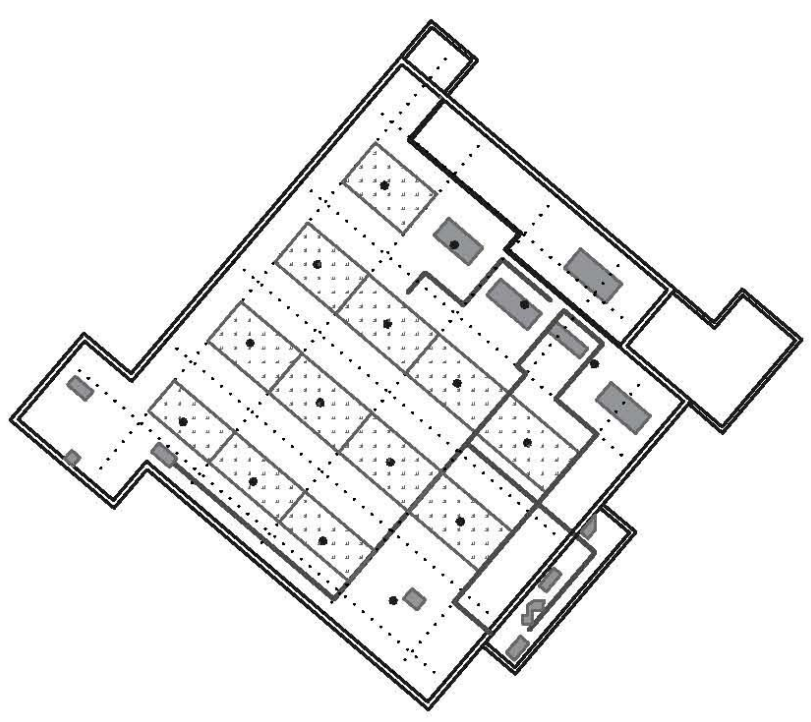

Potential Area for $20 \mathrm{~cm}$ Intensive Assembly
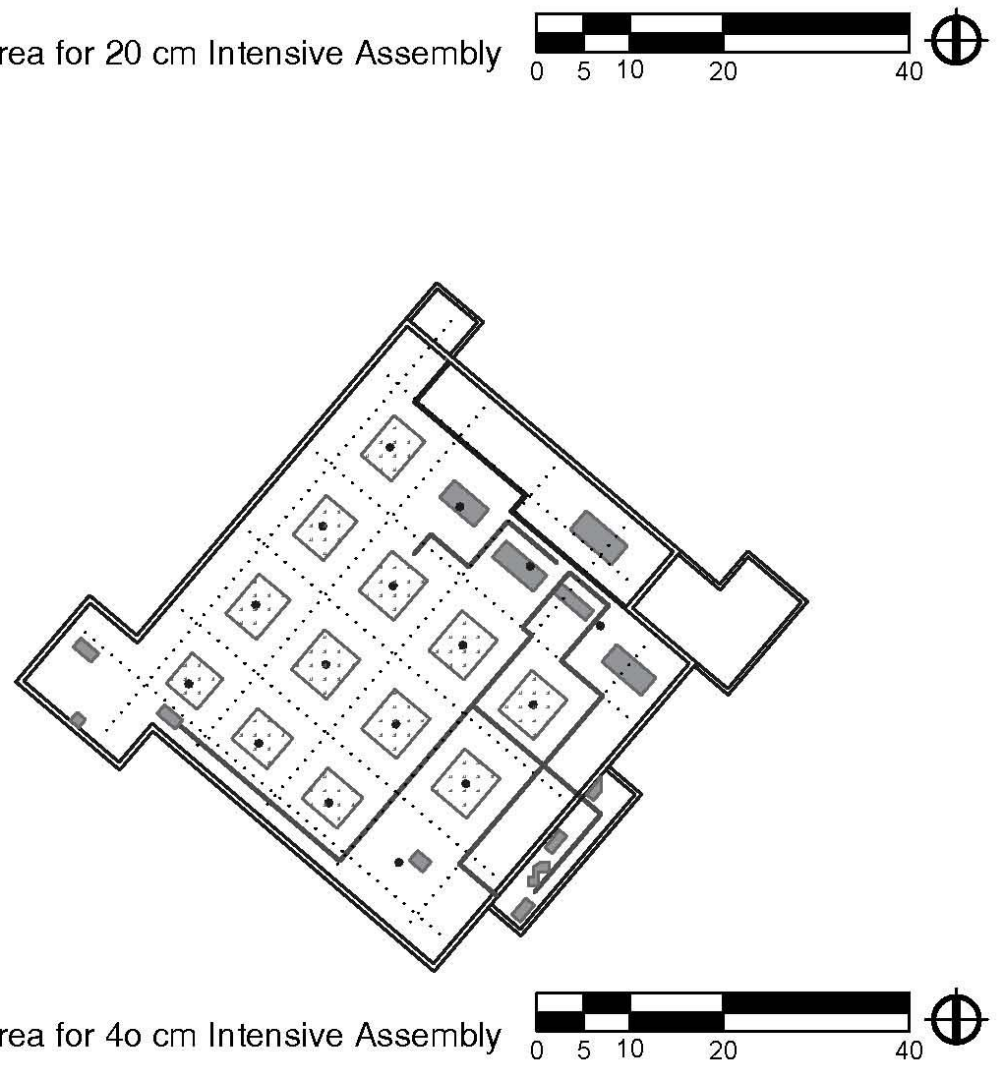

Legend
Vegetated Assembly
Mechanical Units
Sloped Roof

Potential Area for $40 \mathrm{~cm}$ Intensive Assembly 
Sobeys located at 5602 Tenth Line W, Mississauga, ON
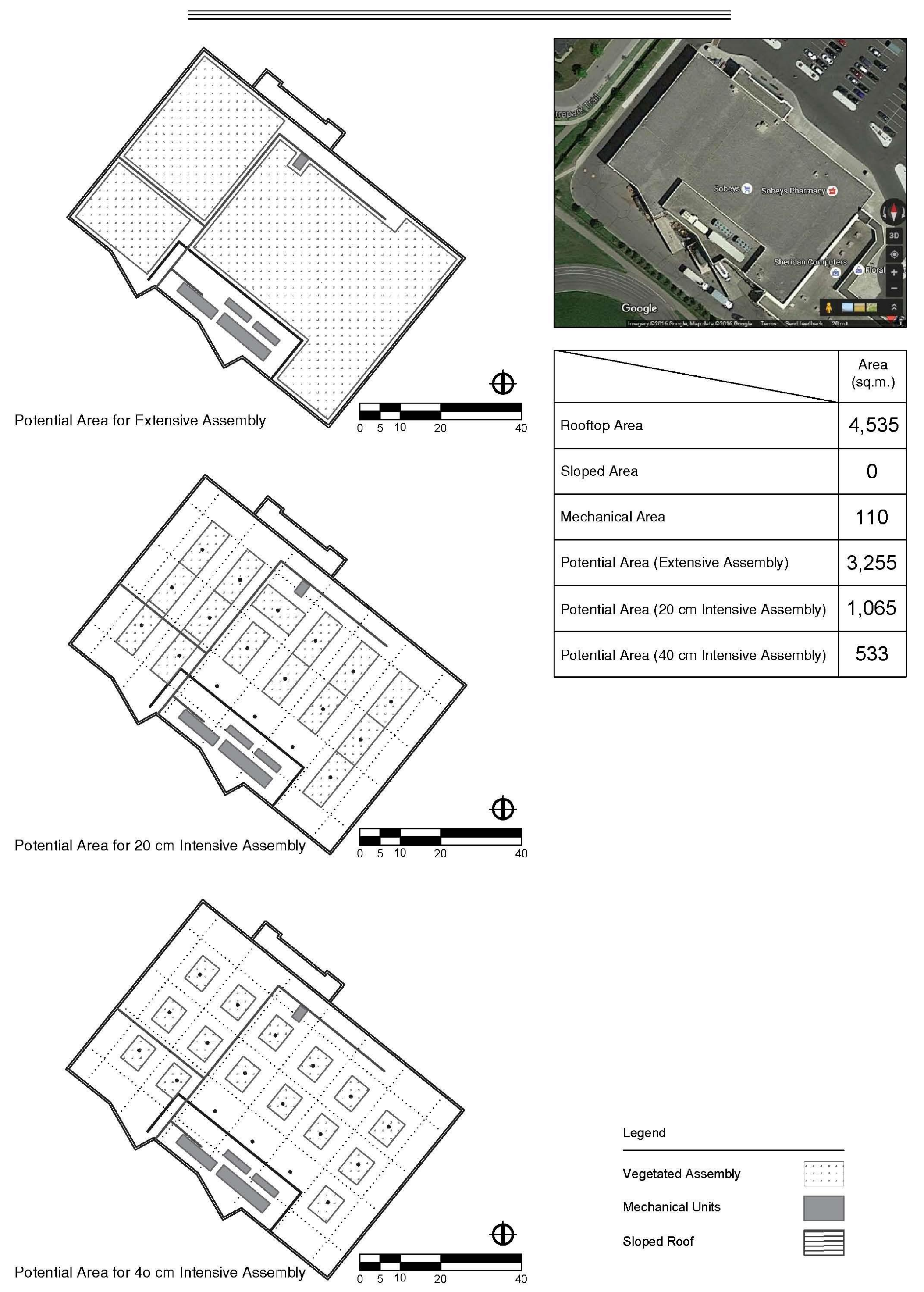

Legend
Vegetated Assembly
Mechanical Units
Sloped Roof




\section{REFERENCES}

About Brooklyn Grange. (n.d.). Retrieved from http://www.brooklyngrangefarm.com/

Anatomy of a typical retail building. (n.d.). Retrieved October 16, 2016, from http://www.steelconstruction.info/

Brooklyn Navy Yard, Building No. 3. (n.d.). Retrieved June 20, 2008, from http://www.greenroofs.com/projects

Castleton, H. F., Stovin, V., Beck, S. B. M., \& Davison, J. B. (2010). Green roofs; Building energy savings and the potential for retrofit. Energy and Buildings, 42(10), 1582-1591. http://doi.org/10.1016/j.enbuild.2010.05.004

City of Mississauga. (n.d.). About Mississauga. Retrieved from http://www.mississauga.ca/

Dunnett, N., \& Kingsbury, N. (2008). Constructing Green Roofs. In Planting Green Roofs and Green Walls (pp. 91-100). Timber Press.

EAGLE STREET ROOFTOP FARM. (n.d.). Retrieved from http://rooftopfarms.org

Eagle Street Rooftop Farm Fact Sheet. (2012). Retrieved from www.rooftopfarms.org

Gorgolewski, M., Nasr, J., \& Komisar, J. (2011). Carrot City: Creating Places for Urban Agriculture. New York: The Monacelli Press.

Gotham Greens. (n.d.). Retrieved October 6, 2016, from http://gothamgreens.com/our-farms/greenpoint Hallsal. (2007). GREEN “VEGETATIVE” ROOF BUILDING STANDARD FOR THE CITY OF TORONTO.

Homegrown Vegetables Without A Garden. (n.d.). Retrieved September 29, 2016, from http://earthbox.com/ 
Length of Growing Season in Ontario. (2016). Retrieved from http://www.agr.gc.ca/

Liu, K. (2012). Retrofiting existing buildings with green roofs. SabMagazin. Retrieved from http://www.sabmagazine.com/blog/2012/07/26/retrofittingexisting-buildings-with-green-roofs/

Orsini, F., Gasperi, D., Marchetti, L., Piovene, C., Draghetti, S., Ramazzotti, S., ... Gianquinto, G. (2014). Exploring the production capacity of rooftop gardens (RTGs) in urban agriculture: the potential impact on food and nutrition security, biodiversity and other ecosystem services in the city of Bologna. Food Security, 6(6), 781-792. http://doi.org/10.1007/s12571-0140389-6

Part 4 Structural Design. (2012). In Ontario Building Code.

Peck, S., \& Kuhn, M. (2003). Design guidelines for green roofs. Retrieved from http://aanb.org/wp-content/uploads/2016/08/Design-Guidelines-for-GreenRoofs-1.pdf

Pons, O., Nadal, A., Sanyé-mengual, E., Llorach-massana, P., \& Rosa, M. (2015). Roofs of the future : rooftop greenhouses to improve buildings metabolism. Procedia Engineering, 123, 441-448. http://doi.org/10.1016/j.proeng.2015.10.084

Raised Beds Soil Depth Requirement. (2014). Retrieved June 20, 2008, from http://eartheasy.com/raised-beds-soil-depth-requirements.html\#b

Specht, K., Siebert, R., Hartmann, I., Freisinger, U. B., Sawicka, M., Werner, A., ... Dierich, A. (2014). Urban agriculture of the future: An overview of sustainability aspects of food production in and on buildings. Agriculture and Human Values, 31(1), 33-51. http://doi.org/10.1007/s10460-013-9448-4

Stovin, V., Dunnett, N., \& Hallam, A. (2007). Green roofs - getting sustainable drainage off the ground.

Super Efficient All-In-One Garden. (n.d.). Retrieved September 28, 2016, from http://mycaja.ca/ 
Toronto, C. P. D. of. (2005). Making green roofs happen : a discussion paper presented to Toronto's Roundtable on the Environment. Toronto : City Planning.

Townshend, D. (2007). STUDY ON GREEN ROOF APPLICATION IN HONG KONG.

Urban agriculture: cultivating soils in the city. (2015). Retrieved from http://www.fao.org/

Werthman, C. (2007). Green roof : a case study (1st ed.). Princeton Architectural Press.

Wilkinson, S., \& Dixon, T. (2016). Green Roof Retrofit: Building Urban Resiliance. John Wiley \& Sons.

Wilkinson, S., \& Feitosa, R. (2016). Technical \& Engineering Issues in Green Roof Retrofit. In Green Roof Retrofit: Building Urban Resiliance (pp. 14-34). John Wiley \& Sons.

Wilkinson, S. J., Lamond, J., Proverbs, D., Sharman, L., Heller, A., \& Manion, J. (2015). Technical considerations in green roof retrofit for stormwater attenuation in the Central Business District. Structural Survey, 33(1), 36-51.

Zhang, X., Shen, L., Tam, V. W. Y., Wing, W., \& Lee, Y. (2012). Barriers to implement extensive green roof systems: A Hong Kong study. Renewable and Sustainable Energy Reviews, 16(1), 314-319. http://doi.org/10.1016/j.rser.2011.07.157 